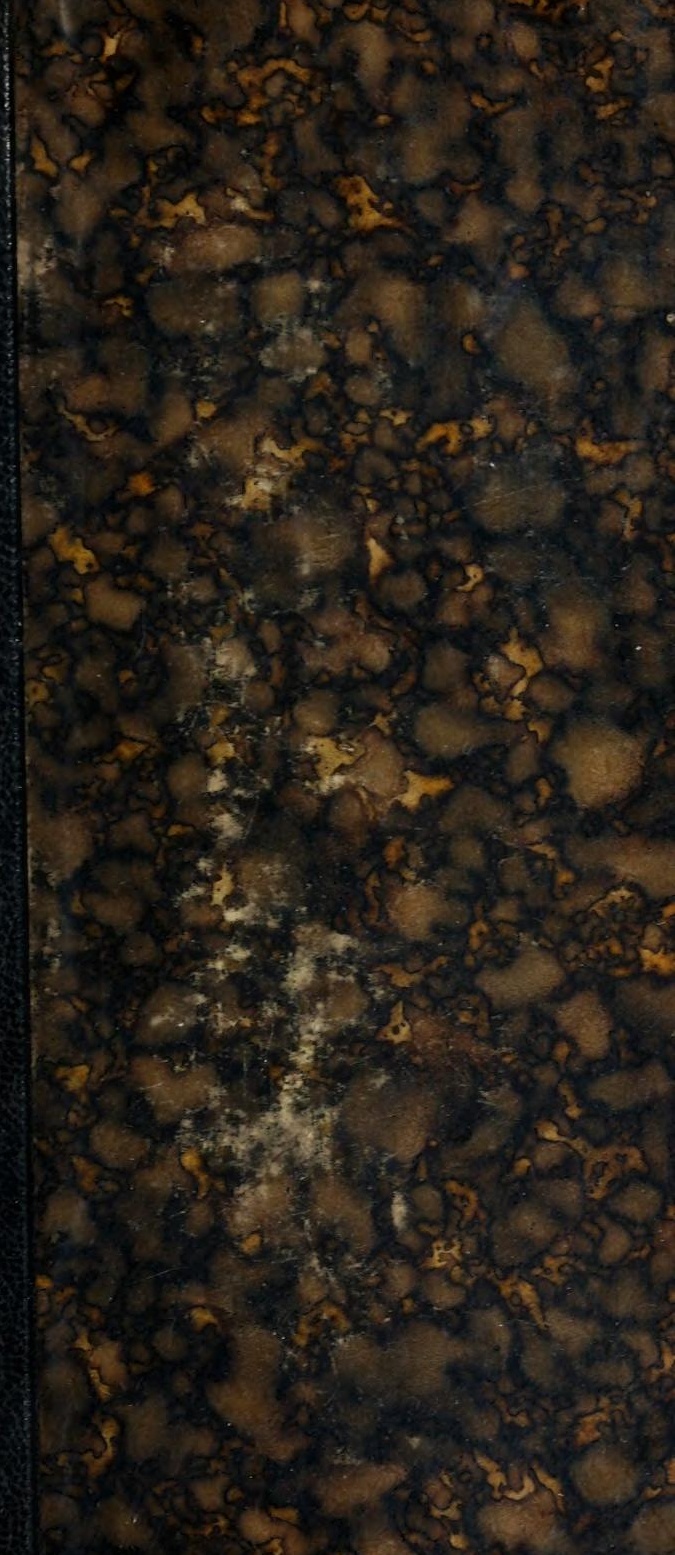




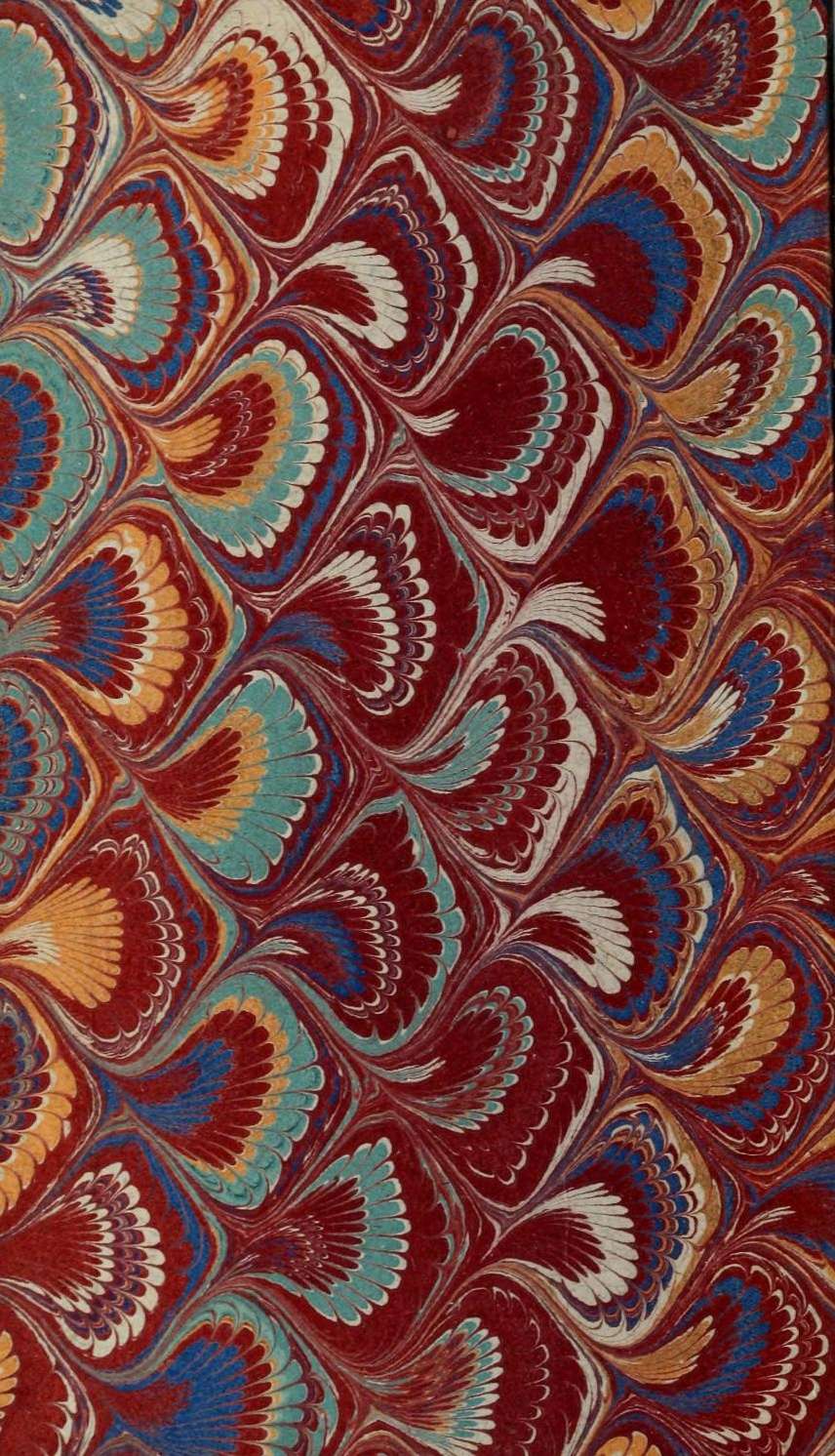




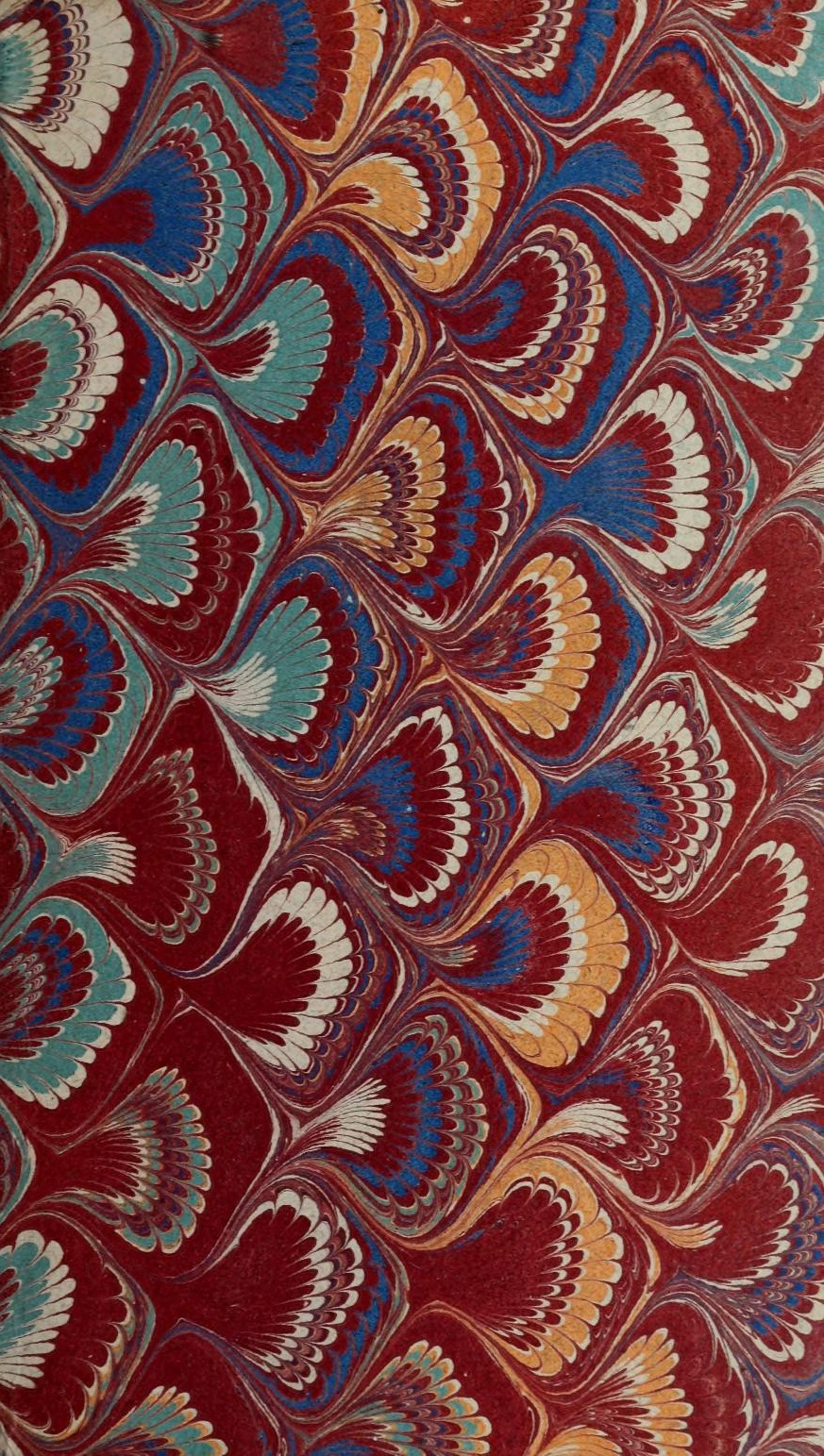



IYXHL TAITEIUN

632

$\checkmark$

. 
$i$

6 
⿷CONOMIE

$R U R A L E$.

TOME.PREMIER. 


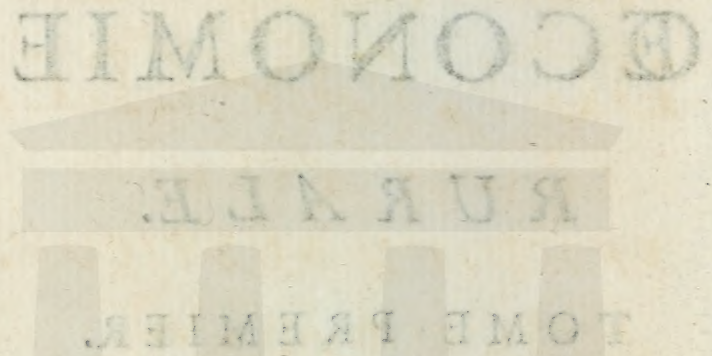

Digitized by the Internet Archive in 2010 with funding from University of Ottawa 


\section{(E) CONOMIE}

$R \cup R A L E$,

TRADUCTION DU POEME

DU P. VANIERE,

I N T I T U L E

PRADIUMRUSTICUM.

Par M. B ER L A N D.

TOME PREMIER.

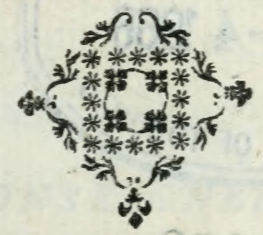

$A P A R I S$,

Chez les Freres Es T I EN E, rute Saint Jacques, à la Vertu.

M. D C C. L V I.

Avec Approbation \& Privilége du Roy. 


\section{FIN}

. I I I M N

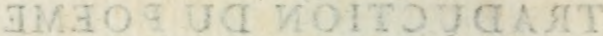

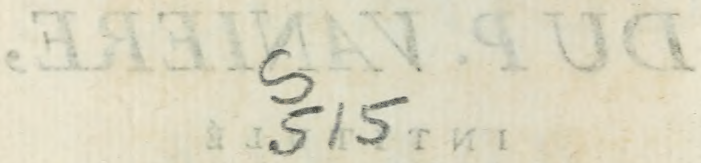

MugIt $V 354$ iana t.l

IBRAR
OCT - 1966

en 20

N/TERSITY OF TOROOU

1130139

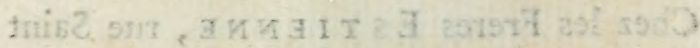

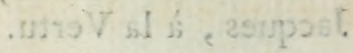

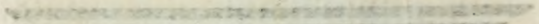

-

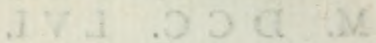

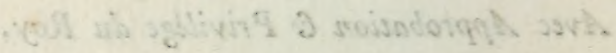




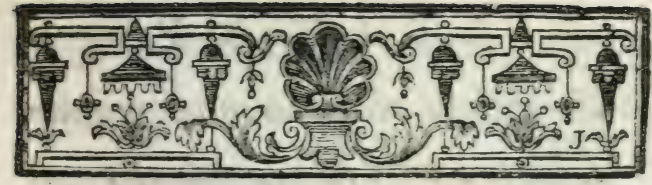

A MONSEIGNEUR

D'ALBERT D'ALLY,

DUC DE CHAULNES,

PAIR DE FRANCE,

BARON DE PEQUIGNY, \&C,

IIEUTENANT. GENERAI

DES ARMEES DUROY,

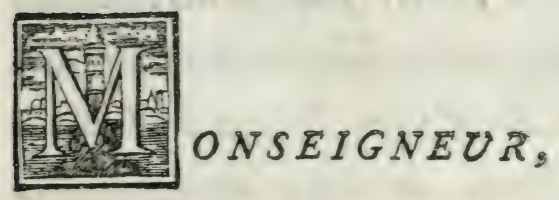

Votre attachement pour les Lettres, votre Nom, vos Digni. 


\section{E P I T R E。}

zés juftifieroient les plus grands Éloges : ce n'eft cependant point à ces titres, c'eft à votre Cour. à vos Vertus que je rends hommage. Si l'admiration faifoit naitre le talent, je peindrois ce. géle ardent qui vous anime pour le bien de la Patrie dans les di. vers Commandemens que vous confie Sa Majefé, ce dévouement, cette fidélité héréditaires dans votre Maifon à la Perfonne du Prince E aux intérêts de l'Etat. Je vous repréfenterois avec sette affabilité naturelle, cette vérité dans le caractére, E cette bonté officieufe qui vous 


\section{'E P I T R E.}

gagnent les coeurs. Enfin, que ne dirois-je point de l'étendue de vos connoiffances, $\mathcal{E} d u$ digne emploi que yous en faites? Ce n'eft point à des Arts frivoles que vous facrifiez vos loifrrs: l'utilité publique eft le feul objet de vos recherches, de vos libéralités, Es de vos travaux. L'Homme de Lettres n'a de droit Sur votre Eftime que lorfque Jes Écrits caractérifent l'honnêteHomme Es le Citoyen. Frappé de l'éclat d'un Mérite aufje rare, pouvois-je faire paroître cet $\mathrm{Ou}$ virage fous de plus heureux Auf. pices? Je me félicite chaque jour 


\section{É $P$ I $T$ E.}

de la permiffion que vous m'aver donnée de vous l'offrir, \& je the croirai autorifé à m'en ap. plaudir fi vous l'honorez de votre fuffrage.

Je. fuis, avec un profond refpect,

\section{MONSEIGNEUR,}

Votre très-humble \& trèsobéiffant ferviteur,

BERLAND。 


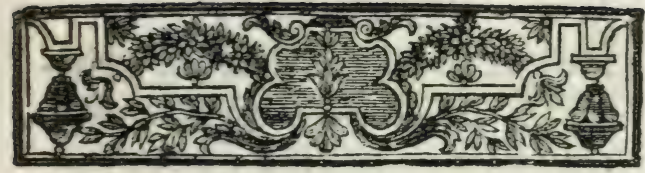

$P R E F A C E$.

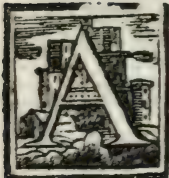

VANT que j'euffe fongé à traduire le Poëme du Pere Vanniere, il me paroiffoir furprenant que nousn'eneuffions point encore de verfion dans notre langue : je ne pouvois me perfuader que la difficulté de réuffir, fût une raifon fuffifante pour détourner des gens de Lettres de l'entreprendre. J'imaginois que la célébrité de l'Auteur, les éloges que lui ont donnés lcs Maîtres de l'Art, l'utilité de l'Ouvrage, \& le plaifir qu'il fait à la lecture, devoicnt balancer les difficultés, \& même les furmonter. Mais Tome I. 
lorfque je les ai vû naître à chaque page, \& fe multiplier fous ma plume à mefure que j'avançois dans cette traduction, $j$ 'ai loué la prudence de ceux qui n'avoient pas ofé entrer dans cette carriére, \& ma furprife a changé d'objet; c'eft ma hardicffe, ou plutôt ma préfomprion qui m’a étonné.

Tous les motifs qui peuvent déconcerter un Traducteur, fe font préfentés en foule pour me faire abandonner mon projet : difficulté de faire paffer d'une langue dans une autre les beautés, l'efprit, \& les images de rout Poëte en général; d’allier la fidélité dans la copie avec l'expreffion, les graces \& le coloris de l'original; de faifre en maître les teintes les plus légéres, les dégradations des couleurs, \& les ombres de tout ce 


\section{$P R E F A C E$.}

qui fait tableau : défaut de fecours en traduifant un Poëme qui n’avoit jamais été traduit, ni même commenté : raifon de découragement prife d'un injufte préjugé, mais néanmoins exiftant, qui range les Traducteurs dans la derniére claffe des gens de Lettres: difficulté de parler en François des travaux de la campagne fans choquer des oreilles Françoifes, d'annoblir par le choix des termes les détails champêtres, de rendre fupportable, quelquefois même agréable, la féchereffe des préceptes qu'entraîne néceffairement avec foi tout ouvrage didactique. En un mot, difficulté de faire gouter des leçons fur l'ECconomie Rurale à une $\mathrm{Na-}$ tion, dont une partie croyoit il n'y a pas encore long-tems, a ij 
que la terre devoit fervir nos befoins fans culture.

Nous ne fommes plus dans ces tems heureux où les Princes, les Généraux d'Armées, les Dictateurs même cultivoient la terre. L'agriculture étoit alors honorée comme le premier \& le plus utile de tous les Arts. Les Souverains \& les Grands ne fe contentoient pas d'encourager les Peuples par leur exemple, ils les éclairoient encore par leurs écrits. Salomon qui depuis le Cédre jufqu'à l'Hiffope connoiffoit tous les arbres \& toutes les plantes, fe faifoit un plaifir * de cultiver des jardins, d'y planter toute forte d'arbres, \& de mettre au jour fes obfervations. Différens Rois ont écrit

* Magnificavi opera mea, feci hortos \& pomaria, \& confevi ea cuncti generis arboribus. Eccl.6. 22. 


\section{$P R E F A C E$.}

fur l'Agriculture, \& Magon Général Carthaginois a laiffé fur cette matiére vingt-huit volumes, qui ont été traduits en Grec \& en Latin.

En Affyrie, en Perfe, en Egypte, on récompenfoit les gens dont les terres étoient bien cultivées, \& l'on puniffoit ceux qui négligeoient ce foin. Numa Pompilius \& Ancus Martius, tous deux Rois de Rome, avoient la même attention. Dans les premiers tems de la République Romaine on alloit fouvent chercher des laboureurs à la charrue, pour leur donner le commandement des Armées, \& leur confier le gouvernement des affaires : les Curius Dentatus, les Camilles, les Fabricius , les Catons faifoient leurs délices des travaux de la campagre, pafloient fucceffivement de la

a iij 


\section{vj $P R E F A C E$ 。}

Chaife Curule à la charrue, favoient manier également l'épée \& le hoyau, enfemencer les terres \& les conquérir, \& dépofant les faifceaux revenoient tout couverts de gloire \& de lauriers habiter leurs toits ruftiques.

Il n'eft point étonnant que dans ces tems reculés il y air eû tant d'A uteurs qui ayent écrit fur l'Agriculture, puifqu'elle étoit en crédit \&z en vénération; ils étoient fürs de trouver des lecteurs en traitant une matiére dont tous les honnêtes gens faifoient leur principalc affaire. Héfiode, Poẹte d'Afcra en Beotie, \& à peu près contemporain d'Homére à ce qu'on croit, eft le premier qui ait fait un Poëme fur la campagne ; il eft intitulé les ouvrages \& les jours. Varron Auteur latin, qui a écrit auffa 


\section{$P R E F A C E$.}

fur l'Agriculture, compte jufqu'à cinquante Auteurs parmi les Grecs fur le même fujet. Nicandre Poëte de Colophon, qui felon Suidas vivoit du tems d'Attale Roi de Pergame, \& duquel Quintilien dit que Virgile a emprunté beaucoup de chofes dans fes Géorgiques, a mis en vers les plaifirs \& les travaux de la campagne : Caton \& Palladius font venus enfuite; \& dans des tems poftérieurs, Pline \& Columelle font entrés dans de très-grands détails fur la culture des terres, la nourriture des beftiaux, les occupations des Fermiers, \& fur toute l' $\mathbb{E}$ conomie Rurale. Le plus beau génie de l'antiquité, Virgile luimême n'a pas dédaigné de faire des Géorgiques, \& c'eft de l'aveu des connoiffeurs, le plus beau \& le plus fini de fes ousvrages. 
$Q$ uoique l'Agriculture du tems des Empereurs fût tombée dans une forte de mépris, on confervoit encore de l'eftime \& de la vénération pour ces anciens perfonnages de la République, qui pouvant tenir les premiers rangs \& paffer une vie brillante au fein de la volupté, avoient préféré le féjour de la campagne à la pompe des Villes, des mours fimples, une table frugale, une vie retirée \& laborieufe, \& tous les attributs de la modeftie \& d'une fortune médiocre à l'éclat des richeffes \& aux douces flaterics des Courtifans.

On aimoit à fe fouvenir que ces grands hommes quand on venoit les chercher pour commander les armées, loin d'être enchantés de cette diftinc. tion ne quittoient leurs travaux domeftiques qu'avec regret; que 


\section{PREFACE. is}

c'étoir par foumiffion aux ordres de la République, \& non pour leur intérêt particulier, qu'ils recevoient la commiffion de Général, \& qu'il n'y avoit qu'un dévouement entier au bien de l'Etar \& de la Patrie, qui pût leur faire fupporter l'éloignement de leurs foyers ruftiques: auffi lifoit-on encore Columelle avec plaifir, quoiqu'il reprochât aux Romains le peu de cas que de fon tems ils faifoient de l'Agriculture.

"Je vois à Rome, dit cet Au" teur, des Ecoles de Philofo" phes, de Rhéteurs, deGéome" tres, de Muficiens, \& ce qui " eft bien plus étonnant de gens " occupés uniquement, les uns - à préparer des mets propres à " piquer le goût \& à irriter la "gourmandife, les autres à "orner la tête par des frifures 
"artificielles, \& je n'en vois waucune pour l'Agriculture : "s cependant on peut fe paffer " de tout le refte, \& la Répu"blique a été longtems floriffan"te fans tous ces Arts frivoles; "mais il n'eft pas polfible de fe " paffer du labour de la terre, øpuifque la vie en dépend.... "Oferoit-on comparer aux auw tres Arts la fage \& innocente " Agriculture que le feul déran"gement de nos mœurs a pî ren. "dre méprifable, \& par une "fuire néceffaire prefque ftérile "\& fans fruit?

Ne pourroit-on pas appliquer à notre fiécle ce que dit Columolle du fien ? \& notre goût pour les Arts frivoles, pour le luxe \& les plaifirs, n'a-t-il pas affez de rapport aux mœurs du. zems de Tibere, fous le régne duquel vivoit cet Auteur? Cetre 


\section{$P R E F A C E$.}

application a déja été faite dans un livre moderne $a$; l'Auteur étend les réflexions de Columelle, \& fe plaint qu'il n'y ait point en France d'Académie pour l'Agriculture \& le Commerce : "On n'a point, dit-il, " imaginé des prix pour multi"plier les Artiftes, les Manu. "facturiers, les Agriculteurs; "aucun fonds public ni parti" culier r'eft deftiné à encoura"ger les découvertes utiles à la "fociété. Un 6 Citoyen zélé "s'éleve \& rend publiques des "obfervationsfurl'Agriculture, "s fruit d'une expérience longue

a Il a pour titre Remarques fur les avancagres \& les défavantages de la France \& de la Grande Bretagne, \&c.

6 C'eft M. Duhamel du Monceau, de l'A. cadémie Royale des Seiences de Paris \& de la Société Royale de Londres, qui a donné un Traité fur la culture des terres, \& una. autre fur la confervation des bleds. 
" \& couteufe. Peu de gens feront "les mêmes effais, faute de "moyens, ou de crainte de per" dre s'ils ne réuffiffent pas: lui" même, faute de fecours, fera " forcé d'abandonner une étude " à laquelle le travail \& les facul» tés d'un feul Citoyen ne peu"s vent fuffire: enfin, c'eft pref"que un phénoméne entre les " fujets des prix des Académies " de France, que celtii de l'As) cadémie d'Amiens qui propofe "pour l'année 1753 , des quefsstions relatives at commerce; on "n'a prefque rien écrit fur l'A griv " culture, ni fur le commerce en "général, encore moins fur les " détails de ces objets, \& fur " ceux qui y ont rapport; on a " même négligé les fecours que " les Etrangers pourroient offrir " fur ees matiéres. On ne trouve s) dans aucune Bibliothéque pu- 


\section{$P R E F A C E$.}

" blique ni particuliere, de col"lection des ouvrages qui exif" tent fur le Commerce \& l'As" griculture: on a enrichi avec "foin la langue Françoife des "Poëfies \& des Romans de is toutes les Nations, on a tra"duit quelques-uns de nos Poë"stes \& de nos Romanciers " bons \& mauvais. Nos Auteurs " fur le Commerce \& fur l'A"griculture feront les derniers " connus.

L'Auteur a bien fenti que la caufe de notre répugnance pour l'Agriculture, provient des principes d'éducation qu'on reçoir en France, mais il n'a parlé que du peu de goût que nous avons pourles voyages, qui felon lui font la meilleure école, \& il n'a point contredit ces principes. Ce. pendant il auroit été important defaireconnoître en quoi péchoir 


\section{xiv PREFACE。}

cette éducation, puifqu'elle eft la fource de nos dégoûts \& de notre mépris pour tous les Arts utiles. En effet quand nous aurions autant de paffion que les Anglois pour les voyages, de quel avantage nous feroient-ils? que rapporterions-nous après avoir couru le monde? des ridiculcs, des vices de plus, \& fort peu de mémoires intéreffans pour la fociéré. Nous en voyons l'expérience tous les jours. Parmi le petit nombre de jeunes gens qui vont en Angleterre, il n'y en a aucun qui revienne meilleur ou plus inftruit; il n'eft mention dans leur Journal que des fingularités Angloifes, de quelques particularités fur les rpectacles \& les actrices, fur les promenades \& le jeu. On y parle auffi d'avantures galantes vraies ou fauffes: c'eft même le plus 


\section{PREFACE.}

gros chapitre du journal; mais il n'eft pas dit un mot du Gouvernement, de la Police, du Commerce \& de l'Agriculture. Pour voyager avec fruit, il faut fayoir autre chofe que chanter, monter à cheval, faire des armes \& aligner des vers. Il faut avoir au moins un commencement de fageffe, un defir ardent de fe perfectionner, dans la vûe de fe rendre utile à fa Patrie, une notiongénérale des Arts, un efprit docile \& le cour libre : il faut envifager le bien public comme l'objei principal d'un Citoyen; n'exiger l'eftime de perfonne, qu'après avoir fervi l'humanité; \& $\mathrm{fe}$ croire, quand on ne contribue pas au bonheur de la fociété, indigne de jouir des avantages qu'elle procure. Qu'avec ces préliminaires on va loin, \& que les progrès dans les Arts font 
XVj PREFACE.

rapides! On reconnoit alors que la.terre porte à regret un homme qui fe croit né uniquement pour lui-même, \&z qu'au contraire le particulier, fût-il artifan, qui par fon travail ou fes confeils, foulage, enrichit , éclaire $\mathrm{fa} \mathrm{Pa}^{-}$ trie, mérite autant d'honneur, \& de refpect qu'un Héros qui la défend.

Mais y a-t-il rien de plus oppofé à ces maximes que les principes de notre éducation? Nous fommes affaillis pendant notre jeuneffe par un tas de Maîtres. qui prefque tous ne nous enfeignent que des frivolités: on façonne le corps, on polit l'efprit fuperficiellement, \& on néglige le cœur, la partie effentielle de l'homme. On crieroit à l'extravagance, fi unP eintre s'avifoit de donner à fes figures des attitudes, des graces, \& une drape- 


\section{PREFACE. xvij}

rie avant d'avoir fait la tête, \& l'on n'a pas de honte de faire de nous des pagodes \& des $P$ antins avant que de nous rendre hommes: quand on nous a chargé la mémoire de Grec \& de Latin, \& qu'on nous a débité dans les Colléges, ou chez nos Parens, quelques vieilles hiftoires, qui n'ont point de trait à nos moeurs, on nous croit des modéles de perfection, \& on nous introduit dans le grand monde comme des Etres capables \& propres à tout, mais à tout ce qui n'eft point néceffaire. Les riches font élevés dans le mépris de tous les gens qui font obligés de travailler pour vivre; ils traitent l'artifan, le laboureur, le commerçant comme des efclaves, \& ne fouffrent ces efpeces dans Ia fociété que comme des ombres propres à faire fortir leur éclat. Tome 1 . 
Si par hazard le Gouverneur ou les Parens d'un enfant de qualité ont alfez de courage $\&$ de bon fens pour l'inftruire des devoirs de l'homme relativement à fes différens points de vûe, \& pour lui apprendre que la vertu, l'honneur \& les folides occupations compofentle vraicitoyen, que la nobleffe \& la fortune n'en. font tout au plus que le vernis, que les Arts de pur agrément ne font que l'acceffoire \& non l'effenticl de l'éducation, \& qu'on eft obligé d'être bon, bienfaifant, zélé pour l'intérêt public, plus indifpenfablement que d'être joli homme : ce jeune Seigneur eft tout étonné quand on le livre à fa propre conduite, \& qu'il fréquente les gens du bel air \& dubon ton, d'entendre prêcher la controverfe de tout ce qu'on lui a enfeigné, \& de voir que le plus 


\section{$P R E F A C E$.}

fêreé des cercles \& des affemblées, eft celui qui a le ton le plus avantageux, \& qui a le mieux perore fur les colifichets: s'il ouvre la bouche, "z qu'il s'avife de raifonner avec jufteffe fur des matiéres intéreffantes, on fe demande tout bas s'il eft François, \&z on ne lui répond que par une pirouette, ou un morceau d'Opéra. Les jeunes gens le perfiflent, \& il fe voit la: fable de tout le monde, parce qu'ilne reffemble pas au général; ;ainfr défolé de cé ridicule, le plus terrible fléau de l'amour propre, il maudit fes Parens \& fon Gouverneur, par qui il croie avoir été trompé, abjure leurs principes, s'en défait comme d'une craffe de Collége, devient fat, libertin, petit maître, \&r perd en un mois par le mauvais exemple, le fruit de l'éducation b ij 
la plus raifonnable \& la plus foignée.

Il n'eft donc pas avantageux de faire voyager un jeune homme, à moins qu'on n'ait verfé dans fon cœur les femences des qualités fociales \& patriotiques; ce n'eft pas même affez qu'il les air reçues, s'il eft l'unique ou du moins prefque le feul à les avoir, le mauvais exemple les étouffera bientôt \& les empêchera de fructifier. Il faudroit avant toutes chofes réformer la façon de penfer de la Nation : mais comment y parvenir? ce ne fera point par les préceptes, ils font inutiles; quand il s'agit de corriger toute une Nation, la voye la plus. courte eft l'exemple *. Er à qui appartient-il de montrer l'exem-

* Longum eft iter per præcepta, breve per empla. Sen. 


\section{PREFACE.}

ple, \& de faire cette réforme? C'eft aux Chefs de l'Etat, aux gens en place, aux principaux membres de laSociéré, c'eft à eux à donner le ton, en témoignant du goût pour le Commerce \& l'A griculture, à creufer ces deux fources inépuifables de richeffes $\&$ de bonheur, par leurs réflexions \& leurs travaux, à protéger, récompenfer \& honorer ceux qui cultivent ces Arts avec fuccès \& $z$ diftinction, \& à rejetter fur les occupations frivoles tour le mépris qu'on attache aux profeffions utiles: car tandisqu'il n'y aura qu'un petit nombre de particuliers à faire des obfervations, pour étendre le commerce ou le rectifier, ou pour multiplier les productions de la terre, le général de la Nation ne fé modélera point fur ces gens fans qualité, dont on ne fait aucun 


\section{xxij PREFACE.}

cas, \& les Auteurs patriotes \& bien intentionnés, auront beaw écrire contre la dépravation des. mœurs \& le vice de l'éducation. françoife, il n'en réfultera aucune réforme, \& on ne les regardera que comme des déclamateurs ou des Philofophes faftidieux.

Un feul homme a réformé nos idées fur la Philofophie, \& fon nom vivra toujours, parce qu'il a été le premier à nous donner des principes sûrs pour entrer dans les fentiers de la vérité ; un feul homme a changé la face du Commerce, \& quoique cette partie n'ait été qu'ébauchée par le grand Colbert, il s'eft immortalifé : un feul homme ne pourroit-il pas réforiner les abus de notre éducation, détruire nos préjugés honteux fur l'Agriculture, \& \&e feroit-il pas auffi glo- 


\section{PREFACE. xxiij}

rieux pour un Miniftre d'en être appellé, comme a Magon, le pere \& le reftaurateur, \& de fubjuguer l'efprit des François en le rournant au folide, que d'étendre les limites du Royaume par la guerre ex la dépopulation?

Horace, après avoir déploré dans une de fes plus belles Odes la corruption des moeurs de fon fiécle, \& prouvé que les pertes des Romains pendant la guerre provenoient de la molleffe de leur éducation, de leur goût pour les plaifirs \& la débauche, $\&$ du mépris qu'ils avoient pour l'utile, s'écrie avec éloquence : "Ce* ne font pas des Romains

Geruntamen Carthaginenfem Magonem. vel rufticationis parentem veneremur. Colum.

* Non bis juventus oria parentibus

Infecit aquor Sanguine Punico, 
xxiv PREFACE.

"femblables à ceux d'aujour-

"d'hui, qui ont teintla mer du

" fang des Carthaginois, \& qui s ont fait tomber fous leurs s coups le puiffant Antiochus, "Pyrrhus, \& Annibal notre plüs " fatal ennemi : c'étoit une race "d'hommes robuftes \& rufti"ques, exercés à manier la "houe, à rompre les guérets, \& "à couper du bois, dont ils por"toient des fardeaux felon l'or"dre qu'ilsen recevoient d'une "s mere rigide.

Les mêmes raifons fubfiftent

Pyrrbumque ón ingentem cecidit

Antiochum, Annibalemque dirum.

Sed rufticorum mafcula militur

Proles fabellis docta ligonibus

Verfare glebas ó fevere

Matris ad arbitrium recifos

Portare fuftes, doc.

1. 3. Od. 6 . 


\section{PREFACE.}

$x x y$

parmi nous. Notre penchant pour le luxe, pour l'oifiveté, la mollefle, \& les riens, nous détourne, \& nous détournera toujours, tandis qu'il durera, des occupations honnêtes \& avantageufes. Si je ne craignois de paffer les bornes de mon fujet, que j'ai peut-être déja franchies, il ne me feroit pas difficile de faire voir que la volupté gagne jufqu'aux troupes, que la plupart des foldats font énervés parla débauche, \& qu'en tems de guerre les Hốpitaux d'armée font prefque pleins de malades, avant même qu'on ait combattu. Le petit nombre des laboureurs fuffifant à peine pour les travaux de la campagne, on ne peut plus tirer de la charrue qu'une médiocre quantité de ces hommes robuftes pour en faire des foldats, à moins qu'on ne veuille laiffer les Tome $I$. 


\section{xxvj PREFACE.}

terres incultes; on eft donc obligé pour recruter les troupes de ramaffer dans les villes l'excrément du peuple, des fainéans, des cadavres vivans, qui s'engagent pour déferter, ou pour fe faire traiter de leurs maladies dans les Hôpitaux: d'où il arrive que le fond effectif d'une armée fe trouve réduit à la moitié quand il eftqueftion d'une bataille.

Il eft aifé d'après ces différentes obfervations de comprendre combien j'ai eu befoin d'encouragement dans la traduction d'un Poëme qui embraffe tous les travaux ruftiques, \& combien en même tems j'ai eu de difficultés à vaincre pour la mettre en état d'être lue par des François: car ils étendent le mépris quilis ont pour les détails champêtres jufqu'aux noms qui les expriment; il nous a plû d'at- 
PRE FACE. xxvij racher des idées baffes à une infinité de chofes que l'oreille ne peut entendre nommer dans un Ouvrage poëtiques, fans être révoltée. Les Grecs \& les Romains penfoient différcmment; nonfeulement ils avoient annobli tous les termes qui concernent les Arrs mécaniques, mais la fécondité de leur langue leur $c_{2}-$ froit dix expreffions pour une; la nôtre, au contraire, n'a fouvent qu'un mot pour fignifier une chofe, \& ce mot précifément eft une expreffion baffe, que le bel ufage a profcrite, \& releguée dans le ftile burlefque, ou comique:\&ztel eft, dit l'Abbé des Fontaines, le genre de notre langue, que fin nous voulons fubftituer aux mots vulgaires, un langage détourné, une périphrafe neuve pour exprimer de petites chofes, ces tours paroiffent finguliers, \&

cij 
xxviij $P R E F A C E$.

quelquefois même ridicules. Lc Pere Vanniere a bien fenti la pauvreté \& le caprice de notre langue à cet égard : auffi s'eft-il bien donné de garde de faire fon Poëme en François. Les Anglois qui veulent être libres en tout, fe font affranchis de cette délicateffe comme d'une fervitude: ilsfe fervent fans fcrupule des termes les plus communs, pourvû qu'ils défignent clairement leurs idées; \& dans la crainte de bleffer l'oreille, ils ne perdent point à choifir des mots, un tems qu'ils employent plus utilement à penfer \& à approfondir.

Malgré ces difficultés je me fuis foumis à l'ufage, \& j'ai refpecté la délicateffe de notre langue, parce que ce n'eft point à un fimple particulier à réformer un préjugé national; j’ai donc fait tous mes efforts, pour ban- 


\section{PREFACE. xxix}

nir de mon ftile les termes bas \& vulgaires, furtout dans les defcriptions, qui plus fufceptibles d'élégance \& d'agrémens, exigent un langage plus noble \& plus relevé. Mais comme tout Poëme didactique fuppofe des préceptes, \& que pour les donner il faut entrer dans des détails qui n'offrent que des images groffiéres \& communes, lorfque l'Auteur a pour objet des Arts mécaniques comme les travaux de la campagne, il ne m'a pas été poffible de rendre ces endroits avec élégance. Il feroit injufte dans ces morceaux d'exiger autre chofe d'un traducteur que de la clarté, de l'exactitude $\&$ de la précifion, \& il doit être difpenfé du coloris \& des graces, puifque notre langue n'en a point pour ces objets.

Il n'elt pas moins difficile de c iij 
xxx PREFACE.

faire paffer d'une langue dans une autre lesimages \& les beaurés d'un Poëme : car quoique la nôtre ait affez de fécondité, d'élégance \& d'harmonie, dans les fujets nobles \& fpirituels, on n'ignore pas que chaque langue a fon génie particulier, \& que les images qui plaifent dans une feroient infoutenables dans une autre, fi on les copioit littéralement. Les beautés d'une langue étrangére reffemblent, pourla plupart, aux plantes rares qu'on nous apporte d'une région éloignée pour enrichir nos jardins: l'art le plus induftrieux, les arrofemens les plus fages, les foins les plus vigilans, ont bien de la peine à les fauver: tout cela ne rachette point la température de l'air, la qualité de la terre \& le dégré de chaleur; elles. perdent de leur agrément à être 


\section{PREFACE.}

ainfi tranfplantées, meurent fouvent, \& dégénérent toujours pour les propriétés. Un Traducteur a les mêmes inconvéniens à craindre : ce n'eft qu'à force de méditations fur fon original, de corrections \& d'avis, qu'on rend fupportable la traduction d'un Poème, \& que l'on en conferve une partie des beautés. On eft même obligé quelquefois de rejetter les images, ou bien de les remplacer par quelque chofe d'équivalent, parce que notre langue, délicate \& fcrupuleufe, n'admet point les figures fortes, les métaphores hardies, les conftructions neuves. La moin. dre licence contre la Grammaire nous bleffe : dès qu'on veut prendre l'effor par des routes inconnues, la critique furveillante eft aux barriéres, \& nous arrête. Ainfi pour être lû \& goûté par les

$$
\text { c iiij }
$$


xxxij PREFACE.

connoiffeurs, il faut fe renfermer dans le cercle des tours \& des expreffions adoptés par l'ufage, de façon cependant que l'on paroiffe * riche \& varié, même dans fa médiocrité, \& que fi les mêmes termes reviennent, ce foit de loin à loin, \& fous des jours différens. Pour cela le grand point eft de bien connoître le fond de fa langue, de faire valoir, \& d'étaler artiftement ce qu'elle a de riche, à l'imitation de l'Optique, dont l'ingénieufe magie multiplie, quand elle veut, les mêmes objets.

* Voulez-vous du Public mériter les amours,

Sans cefle en écrivant variez vos difcours;

Un ftile tropégal \& toujours uniforme

En vain plaît à nos yeux, il faut qu'il nous en* dorme.

Boil.art Pöet. 


\section{$P R E F A C E . \quad x x x i i j$}

Mais s'il eft mal aifé de traduire, même en profe, un Poëme qui a pour objet un Art mécanique, il l'eft encore davantage, pour ne pas dire impoffble, de le faire en vers; parce que notre langue encore plus rigide pour la Poëfie, ne pardonne rien, \&z que d'ailleurs la rime \& le mécanifme de notre verfification ne peuvent s'accorder avec la fidélité qui oft le principal mérite d'une traduction: " on omet, ou l'on ajoûss te néceffairement, \& dès-lors " on ceffe d'être Traducteur, "proprement dit; on n'eft qu'un "s imitateur ou un paraphrafte. C'eft le fentiment de l'Abbé des Fontaines; il l'a foutenu dans lafeuille 477. des Obfervations fur les écrits modernes, contre l'opinion de M. le Préfident Bouhier; \& l'a encore fortifié 
xxxiv PREFACE.

par de nouvelles raifons dans fon Difcours fur la Traduction des Poëtes. Le Pere Sanadon dans la Préface qui eft à la tête de $f_{a}$ traduction des Oeuvres d'Homére, avoit penfé de la même façon avant l'Abbé des Fontaines. Pour ne pas m'étendre davantage fur cette matiére, je renvoye le Lecteur aux Ouvrages que je viens de citer; je releverai feulement la contradiction où l'A bbé des Fontaines eft tombé, en parlant de notre verfification. Voici comme il s'exprime dans fon Difcours fur la traduction des Poëtes :" Pource "qui eft de la rime qui caracté"rife particulierement nos vers, " on tme permettra de compter "pour rien ce prétendu agré" ment qui n'eft point raturcl, "\& qui eft incapable de faire par slui-même d'autre impreflion. 


\section{PREFACE}

"fur notre ame, que celle du " dégoût, \& de l'ennui, ، Il foutient la même chofe dans fon Difcours fur les Géorgiques : "Que ne pourroit-on pas dire "ici ( ce font fes termes) des " inconvéniens de notre verfi"s fication, \& du vice radical de "nos vers, furtout de nos vers "Alexandrins, dont l'hémifti" che périodique, en les cou"pant avec une infipide égalité, "produir néceffairement une " uniformité ennuyeufe dans des souvrages de longue haleine, " \& endort le lecteur, fur qui "s la rime feule fuffiroit d'ailleurs ss pour produire cet effet.

Selon ces deux citationsl'Ab. bé des Fontaines penfe qu'il eft impoffible de faire en vers François quelque chofe de fupportable, fi l'ouvrage eft de longue haleine. Cependane il affure 
xxxvj PREFACE.

dans fon même Difcours fur les Georgiques: "Que Defpréaux, "dans fon Art Poëtique, a en" fanté un Ouvrage fí accompli, "que ceux qui fe donnent les "airs de le méprifer en fentent " eux-mêmes la perfection : que "M. l'Abbé Durefnel a réuffi " dans fa traduction en vers des " deux Poëmes de Pope, fur la "Critique \& furl'Homme *, \& "qu'enfin nous pourrions pro"duire d'excellens Poëmes fur "la Mufique, fur la Pcinture, " fur la Navigation, fur l'Art de " la guerre.

Comment tout cela fe peut. il, fi la rime \& le mécanifme de nos vers produifent nécelfairement une uniformité ennuyeufe ; \& $\mathrm{fi}$, felon l'Abbé desFontaines,

* Autre contradiction, puifque felon lui eoute traduetion en vers eft infidéle. 


\section{PREFACE. xxxvij}

"s on peut foutenir fans air de pa"radoxe, qu'il n'y a plus dans le - monde que de la profe, \& que " tousles vers en langue vulgaire "chez toutes les Nations moder"nes, ne font que des phrafes " coupées, dont les mots font " comprés avec une marque au " bour de chaque ligne, inventée " pour la diftinguer de la fuivan" te, \& appellée rime?

Je ne crois pas que le judicieux Auteur qui nous a donné l'e prit du Pere Maffllon, \& qui nous fait efpérer celui de l'Abbé des Fontaines, mette cette contradiction dans la collection qu'il fait de fes traits d'efprit \& de jufteffe.

L'A bbé des Fontaines a outré fa propofition : il devoit fe borner à dire qu'on ne peut pas faire en vers une traduction fidéle d'un Poëme de longue ha- 
Xxxviij $P R E F A C E$.

leine. M. l'Abbé Durefnel n'a point réuffi comme Traducteur, c'eft comme imitateur, \& quelquefois même comme créateur. Les François qui ont lû lePoëme de Pope en Anglois foutiennent que M. l'Abbé Durefnel différe de fon original, prefqu'autant pour les images \& les penfées, que pour la langue \& la verfification. On affure que le célébre Auteur de la Tragédie de Didon a achevé la traduction en vers des Géorgiques; fi cela eft, on peut prédire, fans faire tort à $M$. le Franc, que ce fera une imitation heureufe, un portrait bien deffiné, dont l'expreffion fera léchée autant que le fujet le permet, qui aura quelques traits de Virgile, \& auquel il ne manquera pour être parfait que plus de reffemblance avec l'original. 


\section{PREFACE. $x x x i x$}

Si je n'avois confulté que mon inclination, j'aurois traduit en vers le Pere Vanniere; mais quelques charmes qu'ait pour moi la Poëfie, les barriéres infurmontables qu'oppofent conftamment la rime \& la mefure aux efforts d'un Traducteur, pzrtifan de la fidélité, m’ont fait donner la préférence à la profe. C'eft bien affez d'être affujetti à prendre le caractére \& le génie defon Auteur, à faifir les tours qui lui font propres, à s'élever \& à defcendre avec lui, à le fuivre dans fes écarts même, comme une ombre attachée à fes traces; en un mot à le rendre trait pour trait, felon le génie de la langue qui l'interprête, fans s'affervir aux régles d'une verfification tyrannique, qui difpute fans ceffe le pas à l'exactitude, \& fouvent au bon 
xl PREFACE.

fens. Un Traducteur n'a donc pas trop, même en profe, de toute fon attention, \& de tout fon art, fur tout fi l'original n'a point encore été traduit nicom. menté. Or le Poëme du Pere Vanniére eft dans ce cas; perfonne avant moi n'a entrepris cet ouvrage, aucun guide ne m'a montré le chemin, aucun commentaire pour l'éclairciffement du texte, ne m'a applani les difficultés : j’ai quelquefois traduit le même endroit de dix façons différentes, avant de trouver lc vrai fens; il m'a fallu me remplir des expreffions \& des tours propres à mon Auteur, afin de pouvoir par la comparaifon des paffages intelligibles, tirer des lumiéres pour ceux qui ne l'étoient pas, \& démêler leur faux jour. Ceux qui traduifent lés Poëtes anciens ont vingt guides 


\section{$P R E F A C E$.}

au lieu d'un; prefque toutcs les difficultés font levées; les fecoursdes commentateurs, qu'on appelle communément variorum, autrement des différens Scholiaftes, vous mettent en état de choifir le fens le plus raifonnable, \&qui eft le mieux appuyé: vous n'avez point la crainte de donner à gauche dans les endroits fufceptibles de plufieurs interprétations différentes, parce que l'obfcurité de ces paffages, \& l'éloignement des tems ne permettant pas de connoître clairement la penfée de l'Auteur, on peut rarement vous contredire avec certitude : mais quand on a traduit un Poëme moderne, quelques gens de Lettres contemporains de l'Auteur, dont l'âge n'eft pas reculé, peuvent vous montrer évidemment vos erreurs, \& vous combattre avec Tome $I_{\text {. }}$ 


\section{xlij PREFACE.}

des armes sûres, s'il leur a tranfmis des éclairciffemens fur les endroits difficiles. Il faut done des recherches pénibles, des corrections fans nombre, \& une attention plus fcrupuleufe pour réuffir dans la premiére traducction d'un Poëme moderne, qu'il n'en faut dans la verfion des Poëmes anciens. On peut à la vérité confulter quelques gens de goût; mais ce qu'un Traducteur n'entend point après une forte application, eft ordinairement plus obfcur encore pour celui que l'on confulte, à moins que la difficulté ne roule fur quelque régle d'Art, \& que celui à qui vous vous adrefrez ne foit un Artifte intelligent.

Quelque conftance, quelque peine qu'exige une traduction d'un long Poëme; il n'eft point peut-être de travail plus ingrat , 


\section{PREFACE.}

$\&$ auffipeu flateur pour l'amour propre. Les Lecteurs, pour la plípart ignorans, confondent la verfion d'un Poëme avec celle d'un ouvrage fec \& purement dogmatique, où il n'eft queftion ni de goût, ni d'efprit, ni de penfées fublimes ou délicates, ni de comparaifons brillantes, ni de graces, ni d'harmonie; ils netiennent point compte de cctte perpétuelle contenfion d'efprit ou il faut être, pour ne pas perdre de vûe fon modéle, \& ne pas fe livrer à fa propre imagination, de votre pénétration à faifir les rapports des deux langues, à appercevoir toutes les beautés, \& à les placer dans leur jour avec la même entente, le même deffein, \& fans autre différence quecelle du langage; ils ne font point cas du difcernement qu'on doit avoir, pous: 


\section{xliv $P R E F A C E$.'}

apprécier les figures \& leur fubftituer des ornemens équivalens, quand le génie de la langue le demande. On ne remarque point les différens ftiles qu'un Traducteur eft obligé de prendre, felon les fujets que traite fon Auteur, parce que bien des gens ne fe doutent pas que la profe foit fufceptible de différens nombres. Comment donc vous loueroit-on du foin que vous avez pris de rendre votre ftyle tantốt coulant \& léger, comme un ruiffeau qui ferpente; tantôt plein \& majeftueux comme un fleuve qui roule fes eaux avec dignité ; tantôt vif, précis, faillant \& ferré comme un jet d'eau qui s'élance dans les airs à perte de vîe ; tantôt harmonieux \& mefuré comme une cafcade qui charme à la fois les oreilles \& les yeux? Tout cela eft moins que 


\section{PREFACE.}

rien, vous dit-on, dès qu'on fait deux langues; rien n'eft fi aifé: on vous ravale même au point de vous comparer à un Graveur, qui tire l'eftampe d'un tableau. Comme l'Abbé des Fontaines a fait voir le peu de jufteffe de cette comparaifon humiliante, je vais rapporter fes termes: "L'eftampe, dit-il, ne repré"fente que le fimple deffein; " mais une traduction fidéle \&z " élégante, n'exprime-t'elle que " le fond de la penfée du Poëre? "n'en a-t-elle pas tout le colo"ris, c'eft-à-dire les images, "les agrémens, la vivacité, l'har" monie? Tout au plus fon co" loris eft moins vif par le défaut " du métre: une traduction en "profe n'eft donc point à un ori"ginalen vers, ce que le burineft " au pinceau. Si on vouloit com" parer une bonne traduction à 
*lvj $P R E F A C E$.

" une bonne copie de tableau, la " comparaifon dans un fens " pourroit fembler plus jufte; " cependant elle eft encore im"parfaite, en ce que le Peintre " copifte ne fait aucun ufage de " fon génie, \& n'a d'autre em"ploi que de choifir fes couleurs " fur fa palette, \& de les appli"quer fuivant fon modéle : le "Traducteur au contraire doir " pour ainfi dire, créer lui-mê"me fes couleurs; il faut que " Fon génie les cherche, les trou"ve, les affortiffe, \& les appli" que avec goût, \&c.

Malgré ces raifons, le commun des lecteurs ne donne qu'aे regret le nom d'Auteur à quelqu'un qui traduit un Poëte, \& s'il réuffit, on ne lui accorde. d'autre talent que celui de favoir bien deux langues; if n'y a que des Traducteurs mê- 


\section{$P R E F A C E . \quad x i v i j$}

mes, ou des gens confommés dans la belle Littérature, qui puiffent eftimer la valeur d'une bonne traduction de Poëme, \& quand on peut obtenir leurs fuffrages, on eft peu touché de n'être pas goûté des autres Lecteurs. Les bons Traducteurs font plus rares que les bons Hiftoriens, que les bons Orateurs, \& que les bons Poëtes. C'eft une preuve qui gît en fait : retranchez deux ou trois Traducteurs François, le refte eft miférable: les Poëtes Grecs \& Latins font pour ainfi dire deshonorés dans les verfions qu'on en a faites; nous avons eu au contraire dans tous les genres plufieurs écrivains créateurs qui ont réufli. Ia meilleure traduction que nous ayons de Virgile eft fans contredit celle de l'Abbé des Fontaines; cependant quoiqu'il 
ait eu le fecours des autres Tra. ducteurs \& des Scholiaftes, combien de fautes n'y pourroit-on pas reprendre? Dira-t-on que cet Auteur ignoroit le latin, ne favoit pas écrire, \& ne connoiffoit pas les régles? non fans doute ; il ne manquoit ni d'efprit, ni de connoiflances, ni d'art, c'étoit le précepteur du bon goît, \& il avoit plus d'une fois fait fes preuves de Littérateur éclairé, \& de bon Ecrivain. Ses fautes viennent donc du grand nombre de difficultés qui 1e préfentent dans une longue traduction, \& de ce que le cerveau le mieux conftitué n'eft que rarement capable d'une attention affez forte \& affez conftante, pour arriver à la perfection dans un parcil ouvrage.

Quelle raifon, malgré tant d'écueils, a donc pû m’engager 


\section{PREFACE. xlix}

à traduire le Pere Vanniere? c'eft le cas que les connoifleurs fone de fon Poëme; c'eft l'agrément des defcriptions, la nouveauté de plufieurs fujets qui n'avoiene point été traités, comme les légumes, les oifeaux de la baffecour, les pigeons \& les parcs; c'eft l'honneur que j'efpérois me faire, fi je furmentois les obftacles; c'eft enfin l'envie d'affoiblir le dégoût qu'on a pour l'agriculture \& la vie champêtre, en mettant à la portée d'un plus grand nombre de perfonnes les préceptes \& les beautés du Prcedium rufticum.

Quand un Orateur Evangélique a le bonheur de ramener au bercail une brebis égarée, il ne regrette plus fes travaux apoftoliques, fon zéle eft payé par le falut d'une feule ame. Je n'ambitionnerois également, pour

Tome $I$. 
fruit de ma traduction, que de rendre agriculteur un feul François; mais je voudrois que ce fût un homme en place que je puffe convertir, afin que par fon exemple \& fon autorité, il fit des profélites qui travaillaffent à leur tour à la propagation de l'agriculture. Quelle fatisfaction pour moi fi je voyois un jour la Nation auffi curieufe des travaux \& des plaifirs champêtres, qu'elle eft aujourd'hui paffionnée pour des amufemens frivoles!

Il eft tems de paffer aux défauts que la critique a repris dans le Poëme du Pere Vanniere. Quelque partifan que je fois de cet Auteur, fon mérite ne me fait point illufion, \& je ne veux point fuivre la folle manie de la plupart des traducteurs, qui relevent comme des beautés les 


\section{PREFACE。}

taches mêmes de leur original, au lieu de fe borner à les couvrir: c'eft une petiteffe de a jurer par un Auteur \& d'en être idolâtre au point d'encenfer fes erreurs. Ami du vrai en tour, je ne puis diffimuler que le Pere Vanniere n’a pas toujours éré guidé par un goût für; il a indifcrétement embraffé tout ce qui concerne la maifon ruftique, comme fi un Poëme étoir un Traité; il eft entré dans des détails petits ou inutiles; il s'eft appefanti fur des fujets qu'il ne falloit qu'eflleurer, \& ne s'eft pas trop foucié de foulager l'attention du Lecteur par des fictions agréables; il eft d'autant moins excufable de s'être livré à fon penchant pour les minuties, que lui-même

a N'ullius aidictus jurare in verba magiftri. Hor.

e ij 
Se reproche ce défaut dans for XIIe livre, où il dit à l'article des poulets:

Dum moror és nimio per Jing ula verfor amore.

Il auroit dû fe fouvenir du précepre d'Horace qui veut a qu'on fupprime tous lés détails qui ne font pasfufceptiblesd'agrément, $\&$ imiter le Prince des Poëtes, qui au jugement de Pline n'a pris que la fleur de fon fujet. D'ailleurs le Poëme du Pere $\checkmark$ anniere, quoique d'une grande étendue, puifqu'il contient environ I 2000 vers, n'a que bien peu de morceaux fublimes, \& les digreffions qui terminent la plupart des livres de ce Poëme plaifent moins par le fond que

2

Et que

Desperat tractata nitescere poffe relinquit. Art.p. 


\section{$P R E F A C E_{\text {。 }}$}

parl'élégance du ftile, \& par l'harmonie. Virgile au contraire fait voir dans les Epifodes des Géorgiques toute la beauté de fon génie; il s'éleve avec ces aîles de feu qui raviffent une ame aus célefte féjour. ( Rouffeau.)

J'ai dit que te Pere Vanniere n'avoit pas mis affez de fictions dans fon Poëme ; car à l'exception de trois ou quatre livreśqu'il a femés de fables \& de métamorphofes, it' r'y en a point dans les autres pour délaffer le lecteur : cependant tout Poëme doit être nourri de fictions, la Fable eft même l'ame de la Poëfie ; \& un ouvrage didactique en exige plus qu'tun autre, à caufe de la féchereffe des préceptes, à moins qu'on n'ait l'art de les mettre en defcriptions, \& de les relever par des comparaifons ingénieufes, \& des images fré-

$$
\text { e iij }
$$




\section{liv

quentes, comme a fait Horace dans fon Art Poëtique. Les plus grands Maîtres ont jugé la fable néceffaire dans un Poëme, pour peu qu'il foir long; \& la raifon en eft prife dans la nature. Tout Poëme en général doit avoir pour objet ou de corriger nos mours, ou de multiplier nos connoiffances en nous amufant; mais comme les régles d'art exigent une grande contention d'efprit, \& que lếs principes de morale mortifient nos fens, on y trouve toujours quelque chofe d'auftére, de fec \& de rebutant. Le bon Poëte a donc l'adreffe de coudre fa morale \& fes préceptes à * une fiction agréable, afin de les faire goûter : il fait qu'il

* Une morale nue apporte de l'ennui;

Le conte fait paffer le précepte avec lui.

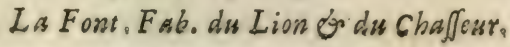




\section{PREFACE. Iv}

faut traiter le commun des hommes comme des enfans, \& $\mathrm{cm}$. mieller les bords de la coupe qui contient le reméde propreà leur guérifon ; il joint à laction principale des épifodes intéreffans, dans lefquels font fondues pour ainfi dire, les vérités morales dont il veut imbiber notre ame; il nous montre nos vices dans ceux desautres, \& nous en infpire de l'horreur par les couleurs dont il les peint: les préceptes tout nuds échappent, ou révoltent; mais quand ils tiennent à une action elle leur donne de la confiftance \& de l'agrément; ils font alors fur l'efprit la même impreffion qu'un beau tableau fur les yeux, le précepte s'empreint avec la fable dans la mémoire. Inftruifez en action, dit Rouffeau dans une de fes Epîtres : pourquoi cela? fi ce n'eft 


\section{lvj $P R E F A C E$.}

pour attacher le lecteur, \& faire paffer l'inftruction à la faveur d'un récit féduifant; en un mot on ne lit des vers que par délaffement, \& parce qu'on efpere y trouver des chofes amufantes, qui demandent peu d'application pour être entendues. Un Poëte ne doit donc qu'entamer les régles d'un art, moins pour l'enfeigner que pour faire nầtre l'envie de l'apprendre par l'heureux choix qu'il fait d'un. petit nombre de préceptes encadrés dans des fables, ou de belles. defcriptions : l'utile doit être enveloppé, on ne veut voir paroître que le plaifir \& les graces, autrement un Poëme manque fon effer, qui doit être de nous difpofer par le charme de la fiction \& de l'harmonie, à une étude plus férieure, de ce qu'on n'a fair qu'ébaucher. 


\section{PREFACE. lvij}

Comment donc le Pere Vanniere dans une remarque, pag. 273. a-t-il pû traiter la fable de fottifes ix de contes de vieilles? Saint Grégoire de Nazianze a adopté dans fes Poëfies quelques fables reçîes, \&z en a inventé d'autres. Synéfius, Evêque de Ptolémaide, jugeoir la fablé néceffaire dans un Poëme. Le Pere Rapin, \& tous les bons Poëres doivent en partie leur célébrité aux fables qu'ils ont eû le génie d'inventer \& l'adreffe d'inférer à propos dans leurs Poëmes.

Quoi quilen foit, le PereVanniere a fes épifodes, mais dans un autre genre que ceux de Virgile, \& du Pere Rapin : ce font des écarts Poëriques qui lui font propres; d'ailleurs fa fécondité dans l'expreffion, l'harmonie \& la douceur de fes vers, la multitude \& l'aménité de fes defcriptions femblent 


\section{lviij PREFACE.}

dédommager des agrémens de la fable. On trouve par-tout des payfages charmans; fes tableaux des mours \& des plaifirs champêtres ont un fi beau coloris, qu'on eft tenté de renoncer au réjour des villes. Quelques gallicifmes déparent un peu fon ftile; il n'eft pas auffi pur que celui du Pere Rapin, mais il eft auffi élégant \& plus varié; fon vers n'elt pas Virgilien, c'eft un mode qui affecte pourtant l'oreille avec plaifir: il eft même d'une harmonie trop foutenue. L'Auteur a marqué trop d'éloignement pour les élifions, fes vers en deviennent trop fonores. Il eft de certaines duretés qui préparene utilement l'oreille a fentir tout le mérite des beaux fons qui fuivent. C'eft ainfi que les diffonances en mufique, quand elles fonthabilement fauvées, produi- 


\section{PREFACE. lix}

fent une harmonie qui flate davantage. Virgile a excellé dans cette partie, comme dans les autres, c'eft partout un grand Mầtre. Cependant on peut dire que $f_{1}$ le Poëme de Vannicre eft auldeffous des Géorgiques pour les épifodes \& leftile, il eft au-deffus pour la variété des fujets \& pour le choix des détails dans les endroits où il ne s'eft pas arrêté à des minuties.

Comme il n'y a point de vers François fans rime, \&x conféquemment qu'un vers n'en eft un qu'autane qu'il rime avec un autre quile fuit, je ne me fuis point affujetti à cette régle qui défend de mettre douze fyllabes mefurées dans un ouvrage de profe. J'ai évité les rimes autant que je l'ai pû ; mais quand douze fyllabes fe font préfentées par hazard dans la forme d'un vers 
2x PREFACE.

Alexandrin ou diffylabe, jen'a point cru devoir rompre cette mefure. M. de la Motte \& l'Abbé des Fontaines ont méprifé avee raifon certe fauffe délicateffe, puifqu'il n'y a point d'unité dans nos vers, \& qu'ils doivent marcher pour ainfí dire accouplés.

A l'égard des épithétes j'en ai rerranché quelques-uns qui auroient paru oiffs's, \& j'en ai fubftitué d'autres à certains qui autroient été puériles ou approchansdu pléonafme: la langue latine en admer beaucoup qui n'auroient point de grace en François, c'eft au Traducteur à les bannir quand il a du goit. Je me fuis permis en récompenfe quelques légéres ad ditions pour l'éclairciffement de certains paffages, ou pour rendre la phrafe 


\section{$P R E F A C E$.}

$l x j$

plus coulante; mais ce n'a été que dans des cas indifpenfables, \& rarement ai-jeajouté plus d'un ou de deux mots.

Pour ce gui eft des remarques au lieu de les hériffer de difcuffions grammaticales dont on eft revenu aujourd'hui, \& qui pour l'ordinaire font peu fatisfaifantes, $j$ 'ai cité plufieurs morceaux pris de différens $\mathrm{Au}-$ teurs tant anciens que modernes, qui avoiene q'zelque rapport au fujet, \&z aux penfées du Pere Vanniere: perfuadé qu'il y avoit plus à gagner pour la jeuneffe dans la comparaifon qu'elle feroit à portée de faire de ces morceaux avec ceux qui leur reffemblent dans le Pradium rufticum, que dans des minuties de Grammairé. J’ai penfé d'ailleurs qu'elle 


\section{ixij PREFACE.}

sorneroit volontiers la mémoire de ces imitations, en voyant l'utilité qu'en retirent les bons Auteurs, quand ils favent fe les approprier, comme le Pere Vanniere, par des applications heureufes.

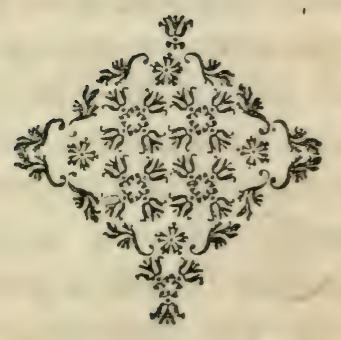



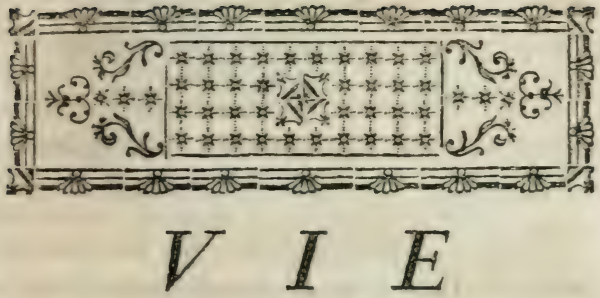

DU PERE VANNIERE T I R E' $E$

DU SUPPLEMENT

\section{AU DIC'TIONNAIRE}

\section{$D E M O R E R I$.}

Tacones Vanniere, Jefuite, Poëte Latin, $\checkmark$ \&l'un des meilleurs entre les modernes, étoit né le 9. Mars 1664 , à Caulfes, Bourg du Diocéfe de Bćziers,en Languedoc,comme il le dit lui-méme a la fin du cinquiéme livre de fon Pradium rufticum. On voit par le mê-me endroit que fon Pere aimoit beaucoup les oscupations de la campagne, \& que ce fut fous lui qu'il commença a s'inftruire de ces occupations qu'il a fi bien décrites dans l'ouvrage que l'on vient de nommer.

Le jeune Vanniere fit fes études à Béziers au collége des Jéluites, \& après fa Rhétori- 


\section{UXV YIEDU PERE YANNIERE.}

que, il entra dans la Société, en I 680, à l'âge de feize ans \& demi. Lorfqu'il eut fini fes deux années de noviciat, il alla faire fa Philofophie au collége de Tours, où fon talent rare \& fingulier pour la Poéfie latine ne tarda pas à fe dćclarer; car dès la premiére année de fa régence, il s’annonça par le Poëme intitulé, Stagna. L'annće fuivante, appellé a Touloufe pour y continuer fa régence, il donna dans cette ville fon Poëme des Colombes, qui fit dire au célébre Santeuil, parlant de l'Auteur, que ce nouveausenu avoit dérangé tous les Poères Latins modernes fur le Parnafle. Le Pere Vanniere donna encore le Poëme fur la Vigne; \& celui qui a pour titre Olus, parut peu après à Montpellier, où l'Auteur étoit Profelfeur de Philofophie. La connoillance qu'il eut l'avan tage de faire de M. de Lamoignon de Bafville, Intendant ce Languedoc, \& de M. Flechier, Evéque dedVinies, lui fut d'une grande utilité pour perfectionner fon goût \& les talens: il en reçut des avis uriles, \& il fe fit un devoir de les fuivre. Rappellé à 'Touloufe par fes Supérieurs, il fut mis à la tête de la Maifon des Penfionuaires, \& après avoir rempli ce pofte durant fix années, on lui accorda la place d'Ecrivain dans le collége de Touloufe, ce qui lui convenoir d'autant plus, qu'ii pouvoit vaquer a la compofition avec plus de liłerté. Quoiqu'il parût tout occupé de fon Pre- 


\section{VIE DU PERE VANNIERE. ISY}

diam rufficum, il ne lailfa pas de s'effayer fur plus d'un genre de Poèfie : il commença entraures un Poèime fur faint François Xavier; mais en ayant communiqué le plan au Pere de la Rue, celui-ci le détourna de l'exécution. Danŝ la fuite il fux Recteur du Collége d'Auch oǹ il ne refta que trois ans. Revenu à Touloufe, il fut envoyé à Paris en 1730 . pour $y$ pourluivre un procès intenté au fujet du legs que M. de la Berchere, Archevêque de Narbonne, avoit fait de fa Bibliothéque aux Jéfuites de Touloufe. Le Pere Vanniere fut accueilli à Paris comme il le méritoit; tous les gens de lettres voulurent le voir \& le connoître. L'événement du procès qui l'avoit fait venir à Paris, n'ayant pas été tel qu'il le fouhaitoit, it-retourna a Touloufe, où il eft morr le 22. Août 1739 dans la foixante-feiziéme année de fon âge.

Les dix premiers Poëmes ou chants de for. Predium rufticum, avoient paru réunis en. un feul volume in-12. l'an 1710 . à Paris, Depuis l'Auteur revit cet ouyrage, \& l'augmenta de fix autres chants. Ainfi il y en a feize dans l'édition faite à Touloufe en ${ }^{7} 730$. in-r 2. \& dans celle qui a paru en 17.46 in2 2. à Paris, chez Bordelet, \& que l'on affure être augmentée \& revue avec un nouveau foin. Cette derniere édition eft ornée de plusfieurs vignettes gravées par Brunet, \& toutes aforties aux différens fujets qui font décrits-

\section{Tome $I_{0}$}




\section{Lxvj VIE DU PEREVANNIERE.}

dans l'ouvrage. Ces feize livres comprennent fous le titre de Pradium rufticum, tout ce qui a rapport aux travaur \& à la vie de la campagne, comme le dit l'Auteur lui-même dans fa préface, ou épitre dédicatoire en profe à M. de Lamoignon de Bafville. C'eft peut-être l'ouvrage qui approche le plus de Virgile, \& de la perfection en ce genre. L'auteur fi judicieux duSpectacle de la Nature en fait un grand ćloge dans le tome deuxiéme de fon ouvrage, au commencement du cinquiéme entretien, \& tous les connoifleurs en ont toujours parlé auffi avantageufement. $)$ Les perfonnes de goût qui poffédent la lansg gue latine, dit M. Titon du Tillet, admi» rent non-feulement la beauté \& la férons dité du génie du Pere Vanniere, la juiteffe os \& le naturel avec lefquels il peint tous les э) fujets qu'il traite, mais encore l'élégance „\& la pureté de fon ftyle, dignes du régne s d'Augurte; en quoi il l'emporte prefque fur »s tous nos Poëtes Latins, au jugement des s) meilleurs connoiffeurs. Depuis l'édition des. Touloufe on a réimprimé cet ouvrage en Hollande \& encore depuis à Touloufe; cette derniere édition, eft, dit-on, très-belle. On n'eft point furpris de cet empreffement pour un livre qui fera lu \& eftimé tant qu'il reftera du geût parmi les hommes, \& quelque foin de cultiver les belles lettres. On n'eftime pas moins, \& avec raifon, les autres 


\section{VIE DU PERE VANNIERE. Lxvij}

œuvres poetiques du Pere Vanniere, imprimées in-12. à Paris, chez Simon en 1730 fous ce titre: Jacobi Vanierii è Societate Je ${ }_{\text {ub }}$ opufcula. Ourre neuf éclogues fur l'amitié, fon ellence, fes caractéres, fes devoirs, fes effets; on trouve dans ce recueil, des lettres, quelques odes, des épigrammes, des hymnes, des épitaphes. M. Titon du Tillet a fait aulfi imprimer a la fin de fon Parnafe françois, in-folio, une piéce qui eft dans ce recueil, \& qui eft a la louange du Parnaffe, que $M$. Titon lui-mêne a fait exécuter en bronze. Elle eft adreflée à M. He Caullet, Préfident à Mortier au Parlement de Touloufe, qui eft mort depuis, \& M. Titon y a joint la traduction ou imitation en profe \& en yers, que le Pere Biumoy en a faite. Le Pere Vanniere, homme fort laborieux, \& qui pendant plus de go ans a travaillé, dit - on, ${ }_{13} \&$ I 4 heures chaque jour, ne s'eft pas borné à exercer fes talens fur la Poéfie. Tout le monde connoît fon Dictionnaire poétique imprimé à Lynn chez Briaffon en 1710 in40. C'eft affurément le meilleur ouvrage en ce genre, \& il étoit prefque impoffible qu'ur Auteur qui connoilfoit fí bien les poètes, \& qui étoit lui-même un poète excellent, ne fit pas en ce genre quelque chofe de fortbon. Il y a un abregé de ce Dictionnaire pour la commodité des ieunes étudians; mais le grand ouvrage dú Pere Yannieve eft un Dic- 


\section{'Zxiij VIE DU PERE YANNIERE,}

tionnaire françois-latin, auquel il travailloit depuis 20 ans, plus étendu, plus complet, \& fans doute plus parfait que tout ce que nous. avons en ce genre. Le Pere Théodore Lombard eft chargé de le continuer, \& c'eft dans. ce deffein qu'on a accordé à cet habile Jefuite la penfion que Sa Majelté donnoit à fon illuftre confrere. M. Titon du Tillet profitane du voyage que le Pere Vanniere fit à Paris en 1730 , \& dont celui-ci rend compte dans une de fes lettres a la fin de fes opufcules, fit exécuter en fon honneur un beau médaillon, où font repréfentés fur le revers plufieurs fujets des travaux \& des plaifirs de la campagne, avec ces mors pour legende: Delicia ó ruris. opes. Certe marque d'ertime étoir dûe à un. homme qui dans fes poéfies s'eft fair un devoir de témoigner la fienne à tous ceux qui. s'étoient diftingués dans les lettres, \& avec qui il avoit eu quelque liaifon, ou à qui il croyoit devoir de la reconnoiffance. Le Pere Vanniere étant entré un jour dans la cour du. Collége de Louis le Grand, le Pere Porée fe zrouva à la porte de la Claffe de Rhétorique: qu'il régentoit, il fut au-devant de lui, le complimenta, \& l'ayant conduit jufqu'à la. porte de fa Claffe, éleva fa voix en difant; Bhétoriciens, fortez, ér venez voir le plus grand Pä̈te de nos jours.; il fut promptement obéi par les écoliers qui ne font pas fâcchés de prendre l'air, \& qui entourérent ẹn même 


\section{VIE DU PERE YANNIERE, EXIX}

sems une perfonne dont leur Régent faifoit tanc de cas. M. des Forges Maillard, connux par les Poéfies françoiles, a honoré la mémoire de cet habile Jefurte par une Ode françoife, adreflée à M. Titon du Tillet, \& imprimée dans le Mercure de France, deuxiéme volume du mois de Décembre 1739 , \& dans le Supplement de la de eription du Parnafe françois. Il y a dans la vingt-feptiéme Atrophe de certe Ode une penfée finguliére, qui fait honneur au Pere Vanniere, mais qưi paroit outrée. Le Poëte dit que le Pere Rapin. confola Euterpe de la mort de Virgile, \& que le Pere Vanniere l'avoit confolé de la mort du Pere Rapin. Cette fecondie partie eft jufte: mais la premiére l'êt-elle : Depuis Virgile jufqu'auP.Rapin n'avons-nous donc eus aucun Poère Latin digne d'eftime, \& capable de confoler Euterpe? Cette mufe a-t-elle été dans les larnes durant ce nombre de fiécles qui fe funt écoulés depuis la nort de Virgile jufqu'au Pere Rapin? M. des Forges Maillard a un peu, ce femble, abufé de la liberté que les Poëtes ont de feindre. Sans faire icil'énumération de tous les Poetes qui. ontexcellé dans le même genre qui a acquis tantde gloire aux PP. Rapin \& Vanniere, nous. renvoyons M. Maillard aux Mémaires de Travoux, où il trouvera cette énumération faite avec équité dans les mémoires de Juin $1_{70} 3^{\circ}$ 2rticle 104 pages 104.2 \& fuivantes. En 


\section{IXX VIE DU PERE VANNIERE.}

$I 743$, le fieur Perit, graveur, a fait le portrait du Pere Vanniere, au bas duquel on lit ces vers latins de Mr. Vanniere, neveu du célébre Jefuite.

A pice quem Gallis alium natura Maronem, Ingeniumque dabant, nec non labor omnia vincens. Dum pietas, mores, vulsus zirtutis amorem Spirabant, flemus qui flebilis occidit orbi, Abftulit hunc oculis, animis non invida tollet Sors, vivet dum vivet amor, dum rura manebun .

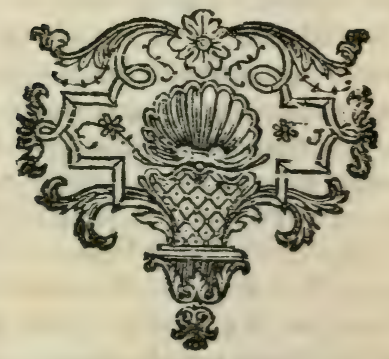




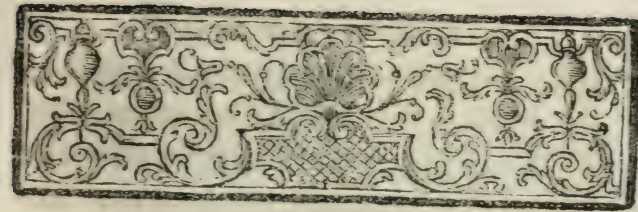

(E) C NOMIE R U R A L E.

\section{LIVRE PREMIER。}

Quelles précautions l'on doit pren. dre dans l'achat d'une Terre, E pour fon amélioration.

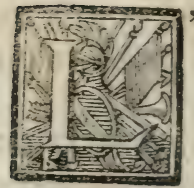

'A MOUR de la Gloire me tranfporte, je veux entrer auffi dans les fen. tiers gliffans du Parnaffe. Je ne puis réfifter à l'ardeur qui m'anime, le nom de Poëte ni fes veilles ne me rebutent point. Nom fi refpecté jadis, je veux vous mériter; (I) quoiqu'aujourd'hui l'on montre malignement au doigt ceux qui vous portent, \& que mon ombre ne puiffe pas jouir de la réputa. Tome I. 
' RE A U U TIONS POUR mOrt.

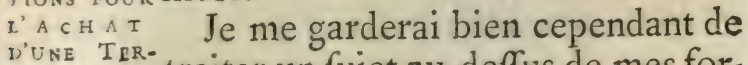
R'UNE TRR- traiter un fujet au-deffus de mes forces, \& peul convenable à mon caractére. L o U Is, vainqueur de l'U. nivers, offre à l'efprit un beau champ pour fe fignaler : mais qui n'a pas couru cette carriére? Et d'ailleurs les Poëtes ne pourroient jamais rendre dans leurs fictions (quoiqu'elles (2) ne leur coutent rien) tout ce que ce grand Prince a fait de mémorable. Les exploits de nos jours furpaffent ceux des tems fabuleux. Eblouie de tant de hauts faits, la Renommée n'a plus de voix ; \& les grandes actions font fi familiéres à notre fiécle, qu'on les voit fans les admirer.

Mon goût n'eft pas non plus de chauffer le Brodequin ou le Cothurne, pour exciter les ris ou pour arracher des larmes; je ne veux pas aufi prendre le ton de la plaintive Elégie, \& me livrer fans fujet à la douleur. Encore moins tremperaije ma plume dans le fiel, pour le diftiler, comme un Cinique, fur tout le genre humain. 


\section{R U R A I E. Liv. I.}

Epris d'une paffion fecrette pour les charmes de la vie champêtre, je PrÉRA POU me fuis amufé à peinćre les objets qui m'ont agréablement flaté. (3) Le D'EXE TER travail ne coute point quand le fujet plait ; (4) \& le plaifir \& la nature me rendront Poëte, $f_{1}$ je n'en ai pas le génie.

D I V IN I T É S chimériques, Cé- Invocation. rès, \& vous Bacchus, ce n'eft point vous que j'invoque. Le Dieu des Chrétiens, feul véritable, eft le feul qui féconde nos champs par le foufle de fa puifiance. Pere \& confervateur de la race humaine, vous créâtes autrefois l'homme fous de meilleurs aufpices, pour qu'il vécût exempt de maladies \& des terreurs de la mort : il auroit paffé des jours heureux, fans crime, au milieu des richeffes de la campagne, jufqu'à ce qu'ennuyé de la vie, il eût rompu le fil de fes jours, \& quitté la terre pour habiter vos céleftes lambris. Mais le crime d'un feul nous a tous fait déchoir de notre premiére grandeur : la Pomme fatale, mangée 


\section{4 \\ (E) C O N M I E}

malgré votre défenfe, a privé tous Tins rour les arbres de leurs ornemens; lor 2'A A A A I des épis, \& la pourpre des raifins x.. ne parent plus nos campagnes, fi elles ne font cultivées; la terre ne produit plus d'elle-même que de ftériles chardons, \& des herbes inutiles : il femble qu'elle fe plaife à venger les outrages faits à votre puiffance. Nous cédons au deftin, \&z nous fubiffons volontiers la peine du crime de notre premier pere : nous ne demandons point, Grand Dieu! que la terre nous faffe gratuitement des largeffes, ni que vous renouvelliez votre antique Alliance avec nous. Mais nous vous prions de bénir le travail que vous nous impofez; afin qu'il puiffe nous rendre ce qu'autrefois la nature produifoit fans peine dans des tems plus heureux.

Sommai:e Dieu pUISSANT ! je vais fous vos de tout l'ou- aufpices examiner la nature des dif-
vrage. férens terreins. Je donnerai des Laboureurs expérimentés pour cultiver le fond qu'on aura acheté ; j'enfeignerai à foigner les troupeaux, à for 


\section{R U R A L E. Liv. I.}

mer le bouf aux travaux ruftiques qu'il partage avec le Laboureur, \& PREACEaे couvrir une campagne d'arbres fauvages \& cultivés. Enfuite, après $\mathcal{L}_{\mathbb{R}} \mathrm{E}$. avoir traité des moiffons, des prairies, \& des différens travaux de l'Agriculture que raméne chaque année, les légumes, la vigne \& fon aimable jus fuccéderont naturellement. Quand les champs auront reçu les hommages que je leur dois, je préfenterai fur la fcéne les oifeaux domeftiques \& les tendres colombes. Les abeilles, leurs cellules \& leur gouvernement trouveront auffi place dans mes vers ; après quoi je parlerai des étangs \& des hôtes qu'ils renferment; fans oublier les parcs qui fervent de retraite au chevreuil $\&$ au cerf timide.

\section{(5) O vous! l'honneur \& l'ap- Dédicace.} pui de votre Maifon, IL L USTRE LA M O I GNON, Magiftrat éclairé chargé des affaires publiques; c'eft vous qui, pour ne rien laiffer à défirer à ceux qui cultivent la terre, m'ordonnez de mettre la main à cet

$$
\text { A iij }
$$




\section{6 \\ ⿷匚 C O N O M I E}

$\overline{P R \dot{E} C A U}$. Ouvrage en leur faveur. Ils vous dor. тrons pour vent déja tous les autres avantages D' ACH A T dont ils jouiffent; leurs moiffons ne RE. craignent point la main avide du foldat ; ils ont gouté les douceurs de la paix, même dans la plus grande chaleur de la guerre; au lieu du hoyau, on n'a point armé leurs mains d'un fer meurtrier. Jamais un Laboureur, forcé de partir, n'a renvoyé fes bœufs libres du joug, ni laiffé des ouvrages imparfaits aे fa femme \& $े$ fes enfans éplorés. (6) Quoique l'Héréfie, fe rappellant fes antiques fureurs, excitât des monts voifins des bras ennemis à prendre les armes; quoique nos murs ne retentîffent que du bruyant fracas de la guerre, la paix a toujours pris foin de nos guérêts ; \& jamais nos Laboureurs n'ont eu d'autre inquiétude que celle de célébrer dignement nos triomphes.

Cette fage précaution met en état la province de fournir abondamment au Roi de nouveaux fubfides. Eh ! comment pourroit-elle fe refufer à vos demandes? Si l'obéiffance ou le 


\section{R U R A L E. Liv. I.}

zéle ne nous remuent pas affez puiffamment, votre éloquence, ILLUS- TrOsS DOCR TRE LAMOIGNON, nous rend géné- ${ }^{2}$ A C H A I I reux. A votre voix, les coffres du g.

Prince fe rempliffent de toutes les fommes qu'exigent les frais de la guerre; \& nos villes, pour le falut du Prince $\&$ de la Patrie, facrifient leurs richeffes \& leurs habitans. Paroiffez donc, Laboureurs, examinons enfemble la culture que la terre exige de vous; afin que dans ces tems de calamité, elle réponde mieux à vos foins.

(7) L A I S S o ns à l'opulence fes ce quili faut vaftes domaines : que cent charrues confidurer puiffent à peine fuffire au labourage acherte une de fes terres, on y confent. Mais que celui qui veut joindre l'utile à l'agréable dans une maifon de campagne, en achette une oì fes occupations bornées lui permettent d'en jouir, fans l'abforber tout entier. Qu'il ne fe contente pas d'en confidérer la fituation \& l'afpect, qu'il en connoiffe \& l'air, \& les eaux ; qu'il obferve, non pas la quantité de jets

A iiij 


\section{E C O NOMIE}

PRECATT- d'eaux qui s'y trouvent, mais s'il y a trons pour quelque ruiffeau affez commode $\&$ $I^{3}$ A $C$ A $A$ T
ONE TERE. din, \& porter enfuite au loin dans les campagnes la fécondité avec la fraîcheur.

1 air.

Que le ciel y foit pur, \&z que les tiédes zéphirs y régnent plutôt que les fougueux aquilons; que le niveau du terrein ait une pente infenfible i.a fiuzation versles vents pluvieux du midi : enfin que votre maifon ne foit pas enfevelie dans une vallée profonde, nifituce fur des rochers nuds \& ftériles, ni empeftée parles exhalaifons d'un ma: rais.

Une montagne qui eft en face du nord, eft le féjour des tempêtes; les moiffons dans les plaines font fujettes à des inondations fréquentes. D'un autre côté, une maifon fituée dans le fond d'une vallée, voit à peine le ciel; elle eft fubmergée parles eaux qui y féjournent, \& leurs exhalaifons condenfées fe convertiffent en brouillards, \& nuifent aux bleds en épis, \& à la vigne en fleur.

La fertilité. N'achetez point avec empreffe- 


\section{R U R A L E. Liv. I.}

ment une terre qui vous aura plû au premier afpect; fouvent la fuper- PRO: ÉSAUficie du fol nous féduit \& nous trom- ${ }^{2}$, А с н А pe $(\bar{\gamma})$ Il faut connoître de longu D'Une TERpe. ( 8 ) Il faut connoitre de longue $\mathrm{R} \mathrm{E}$. main les champs \& les amis qu'on veut avoir : ce qui eft bon en foi, \& par fa valeur intrinféque, doit toujours plaire par préférence. Quand vous verrez peu de fruits, des arbres mal nourris, \& petits dans leur eipéce, c'eft une preuve que la terre a quelque mauvaife qualité. Mais vous La falubité. faurez infailliblement qu'un pays eft mal fain, fi vous n'y voyez que peu de vieillards, files habitans ont un teint pâle \& livide, s’ils font décharnés, sils ont la vîe mauvaife, la refpiration difficile, \&r l'éprit aufí petant que le corps foible. L'eau doit ĉtre faine \& légére, \& auffi eftimée que l'air pour fa bonté. La meilleure eft celle qui fe précipite du haut d'un rocher. L'eau de fontaine qu'on peut puifer aifément, eft du fecond ordre ; vient enfuite celle de citerne. La plus mauvaire eft celle qui, dans les champs, coule lentement, \& fans murmure. Mais pour l'eau des marais, ou croiffent les trif 
$\overline{\overline{P R E C A U}-}$ tes rofeaux, je ne confeille d'en boire Tross pour qu'à ceux qui, ennuyés de vivre,

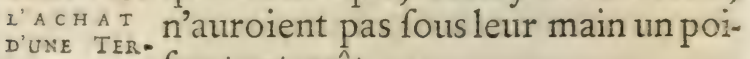

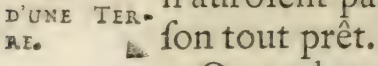

On ne demande à l'air \& à l'eau ni odeur, ni faveur. Si les anguilles foifonnent en une riviére, \& que fon eau ne décolore ni le teint, ni les lévres de ceux qui en boivent; fi on ne voit point au fond \& autour des vafes qui la contiennent une efpéce de croute fale \& mal propre; fi elle bout promptement quand on l'expofe au feu, \& que les légumes $s^{\prime} y$ cuifent facilement; fi elle reprend peu de tems après fa fraîcheur natırelle, ainfi que les eaux qui coulent du haut des montagnes, \& qui doivent leur légéreté à la précipitation de leur cours : une eau de cette qualité rend aul corps fa force, donne à l'efprit de la vivacité, la vie aux terreins les plus arides, \& porte la fertilité dans tous les champs qu'elle arrofe.

$\mathrm{Ne}$ faites aucun cas de ces Terres fomptueufes où les eaux ne viennent que de fort loin, elles font d'un entretien ruineux : aimez les beautés 
de la nature, \& non la parure de l'art. Faites choix d'une Maifon de troxs pour campagne qui ne doive fes ornemens ${ }^{\mathrm{I}^{\prime} \mathrm{A}} \mathrm{c}$ н $\mathrm{A}$ I qu'à fa fituation avantageufe, à feS ${ }_{R E}$.

bois champêtres, à fes agréables fontaines, à fes vaftes prairies toujours verdoyantes; \& ne préférez pas une terre qui ne donne d'agrémens qu'à grands frais, \& dont les revenus foient abforbés par le luxe \& la dépenfe; de peur que ce fond, loin de vous rapporter aucun profit, ne confomme encore pour fon entretien vos autres biens.

Que tout acquéreur d'une maifon de campagne en fache les revenus; qu'il confidére combien il y a de paille, combien de tonneaux de vin, combien de preffoirs, combien de barils d'huile. Qu'il n'eftime pas fon terrein par fon étendue, mais par la bonté de la terre; qu'il compte les mefures de bled \& les muids de vin, \& on pas les arpens. Il doit connoître, outre les revenus, les charges \& les redevances de la terre, \& fon profit annuel, toutes les dépenfes prélevées; s'informer du détail de 
PRÉ chu chaque chofe, \& prendre des lumié. tions rouzres de fes Laboureurs mêmes. Qu'il I'A CHA I examine fi fes beftiaux reviennent. D'HNE TER = rafíafiés des pâturages; fi la forêt peut fournir de bois la maifon, tant pour les réparations, que pour le chauffage; fi l'eau néceffaire pour l'arrofement des jardins, vient d'une fource toujours pure, ou s'il faut la puifer dans des puits avec des feaux ou des pompes; fi le chemin eft commode pour le tranfport des denrées ; fi, fans être beau, du moins il eft pratiquable; \& $x$ fi le maître n’eft pas dégoûté d'aller à fa campagne, par les profondes orniéres, \& la difficulté des paffages.

Ne vous embarraflez pas de favoir fi ce fera le matin en allant à votre maifon, ou le foir à votre retuur, que vous aurez le foleil en face, \& que vous ferez obligé de tourner la tête pour éviter fes rayons. Ne vous mettez point en peine fi la maifon eft fimple en fon architecture, pourvî qu'elle vous garantiffe du froid \& des chaleurs : ou fi, bâtie dans le goût de ces immenfes Châteaux, refpec. 


\section{R U R A I E. Liv. $I$.}

tables par leur antiquité, elle n'eft pas trop vafte, \&x ne reffemble pas à PróncAU-

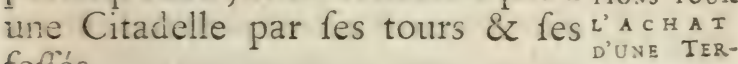
foflés.

Au cas que le bâtiment foit trop XE.

grand, relativement au terrein, vous jouirez de la folie de votre prédécefleur, pourvî que vous ne faffiez pas trop de dépenfe pourl'entretien : car étant plus en état de voir vos amis à votre maifon de campagne, vous y retournerez plus fouvent.

Peu doit vous importer encore que votre prédéceffeur ait laifié la terre en friche, la vigne fans culture, \& qu'un ruiffeau proméne infructueufement fes eaux dans un jardin qui n'eft point foigné ; le travail d'une année peut aifément réparer tous ces petits defordres. Faites l'acquifition d'un signescerfond qui puiffe, à peu de frais, s'a- taias d'une méliorer ; où tout croiffe à plaifir ; où la terre libérale ne produife que de grands arbres, dont les feuilles, fortement attachées à leurs rameaux, en faffent l'ornement, même pendant l'hiver, malgré la neige \& les frimats; où, apres un peu de repos, 


\section{I4 E C O N O M I E}

elle recommence fes largeffes avec PRÉAT - la même profufion; toujours féconE'A с मि A de, \& parée de verdure; toujours D'UNE TER-facile à Ouvrir, fans retenir l'eau, $\&$ fans fe crévaffer dans les chaleurs.

Mais, de peur que la premiére couche de la terre ne vous trompe, faites en tirer à quelques pieds de profondeur. Car, ainfi qu'une nourrice mal faine communique aux enfans qu'elle allaite fa maladie avec fon lait; les moiffons \& les fruits fe reffentent du terroir quand il eft vicieux.

Biens fitués Je ne voudrois pas qu'on eût plupays. mat, \& expofés aux mêmes coups de vent. S'ileit beau d'avoir plufieurs domaines dépendans d'une feule terre, d'un autre côté n'eft-il pas imprudent d'expofer toute fa fortu. ne aux cas fortuits d'un feul canton ? D’ailleurs, la variété plaît quelquefois; on aime à voir un autre ciel, de nouvelles routes, \& différens côteaux.

Laproximité Faites en forte que votre maifon d'une ville, de campagne foit fituée à la proxi- 
mité d'une grande ville, d'un gros bourg, ou du moins d'une riviére ProNE POUR navigable : la facilité des tranfports ${ }^{2}$, $\mathrm{C}$ Н $\mathrm{A} \mathrm{T}$ fait la richeffe d'une Terre. Avec cet ${ }_{\mathrm{R} E \text {. }}$

avantage, on a toujours de quoi s'occuper à la campagne; les ouvriers ne manquent point pour tous les travaux ruftiques, \& votre table peut être promptement couverte de toute forte de mets. Quand vous êtes attaqué d'une maladie fubite, vous pouvez jouir du Médecin ; s'il ne vous foulage pas, il adoucira du moins vos maux par des paroles confolantes. Faites pourtant choix d'une maifon de campagne à une certaine diftance de la ville, afin de n'être pas importuné par des vifites trop fréquentes.

Vous vous écarterez fur tout du Du grand grand chemin, par où paffent ordi-chemin.

nairement les troupes qui changent de garnifon. La foudre \& la grêle que vomit un nuage épais, infpirent moins de crainte aux Laboureurs, que la pouffére qui vole fur le paffa. ge d'un bataillon d'infanterie, ou d'un efcadron de cavalerie. Une fermiére 


\section{I6 E C O NOM IE}

PREA trons po:r pour les pouffins qu'elle éléve; le I'A C H A T berger croit fon troupeau plus en fus. E. reié à l'afpect d'un loup, \&z lui-même eft moins effrayé, que lorfqu'au loin il entend hennir les chevaux d'un régiment de cavalerie, \& que fes yeux, jufqu'où ils peuvent atteindre, font frappés de l'éclat des armes qui brillent le long du chemin. Car le foldat, accoutumé aux rapines, prend des routes détournées pour sapproprier par adreffe ou à force ouverte tout ce qui fe préfente. On arrache le Laboureur de fa charrue, on lui commande durement de fervir de guide, \& d'atteler fes boufs à des chariots pour trainer le bagage, \& foulager la troupe fatiguée. Ses entans \& fa trifte moitié le pleurent à fon départ, comme fi on l'entraînoit à la guerre; ils croyent voir en fa main des armes au lieu d'un aiguillon, \& s'imaginent qu'il ne verra jamais fes champs ni fes dieux domeftiques.

Du bon \& Il convient auff que vous faffiez du mały ais une étude du caraktére $\&$ des mcurs roifin. de 


\section{RU R A LE. Liv. I. I7}

de votre voifin : car il y auroit de $\overline{P_{R E} \bar{E} \subset U}$. la folie à être à foi-même l'arti- rioxs nour fan de fon infortune, \& à laiffer aे $\mathrm{L}^{\prime} A \subset A$ A des enfans pour héritage des procès $\mathrm{R}$ r. éternels avec un voifin de mauvaife foi ; tantôt il détournera le ruiffeau qui arrofe vos prairies, tantôt il fera une digue pour inonder vos champs; une autre fois, il pratiquera un nouveau fentier pour piller vos fruits, il rognera une portion de votre terre, arrachera la borne qui fert de limite, ou bien ce feront fes beftiaux qui viendront impunément gâter le foin de vos prairies; (9) \& fi quelque bête de votre troupeau a touché au moindre brin d'herbe dont la propriété foit incertaine, ou fi vous faites abattre un arbre planté fur un folfé mitoyen : aufifitôt procès dont le Juge faura faire fon profit; car il mangera en frais vos troupeaux, avant de prononcer que le terrein contefté vous appartienne; (10) \& la victoire vous coute fi cher, que vous auriez mieux fait de laiffer fur pied cet arbre, quelque pernicieux que xilt fon ombrage pour vos moifforis. Tome $I$. 


\section{I8 EE C ONOMIE}

$\widetilde{P R E ́ C A U}$ Je ne vous parle point du raifin, TIOAS POUR des noix, des pommes, des agneaux I'A C H A I \& des brebis qui vous feront enlevés D'UNE TER- furtivement, Si quelque bœuf vous manque, jettez vos foupçons fur votre voifin; car le bœuf n'eft pas un animal vagabond qui aille au loin, $\&$ qui s'égare.

Que de jours défagréables vous pafferez au milieu de ces débats! (I I) L'amitié par tout a des douceurs ; mais en campagne principalement, un bon ami eft d'une reffource infinie; il diffipe vos ennuis par les charmes de fa converfation; on mange l'un chez l'autre alternativement, \& l'on fe donne réciproquement des avis \& des fecours. Si cet agrément vous manque, \& que votre efprit pour délaffement n'ait d'autre fatisfaction que le chant des oifeaux, le filence des bois, ou la fociété de quelques domeftiques ftupides, vous abandonnerez bientôt vos foyers ruftiques pour ceux de la ville. Cependant une campagne n'aime rien tant que l'œil du Maitre, pourvî que l'Agriculture lui plaife, 
$\&$ qu'une indolente volupté ne lui faffe pas toujours rechercher l'ombrage des bois, ou la fraîcheur des fontaines.

C'eft pourquoi ne faites conftruire Trons pour L'ACHAT D'UNE TER:RE。 de bâtimens qu'à proportion de vos facultés, \& de l'importance de la terre. Vos premiers foins pourtant doivent être de planter des arbres; vous penferez enfuite à votre logement $\&$ aux étables.

Commencez par faire valoir toutes les parties de votre fond, négligées par votre prédéceffeur : ( 12 ) car la terre, cette nourrice des hommes, eft toujours dans la fleur d'une jeuneffe brillante; le tems ne prend rien fur elle, \& ne diminue point fa fertilité ; un peu de culture la pare, \& la maintient en vigueur. Pour nous, au contraire, dès que la vieilleffe (maladie incurable) nous affaiffe par fon poids, nous n'allons qu'en empirant, \& nos beaux ans n'ont point de retour.

Il faut épierrer vos champs, \& en Epierrer tes arracher les mauvaifes herbes, la fougére \& le jonc. Vous ferez mourix

$\mathrm{B}$ ij 
PRÉ la fougére en femant des féves; vous Jions rour vous déferez des joncs \& des mauI A EHAT vaifes herbes en y faifant paffer la. DUNE TER- charrue; pour les pierres, $c^{\prime}$ eft avec la main qu'il faut s'en délivrer. On en fait enfuite un tas au milieu des champs, ou on les enfouit en terre. Cependant il arrive fouvent qu'un champ dégarni de pierres trompe l'efpérance du Laboureur; foit que la terre, venant à fe durcir après l'enlévement de ces pierres, diftribue fon fuc aux plantes avec moins d'abondance; foit que ces cailloux qui fe rencontrent près des racines, les garantiffent, par leur oppofition, de la chaleur immodérée du foleil.

$\mathrm{Si}$ vos prairies, à caufe de leur vieilleffe, ou de la quantité de mouffe qui les couvre, ne vous rapportent que de mauvais foin, chargez-les de cendre ou de fumier. L'effet de cette premiére opération eft-il trop lent ? labourez vos prairies, femez-y du froment; \&, de peur qu'une fermentation trop forte ne nuife aux premiéres moiffons, vous diminuerez se grand feu en femant des grains 
mélangés qui produifent beaucoup d'herbes, ou des féves qui pouffent en peu de tems, ou des navets qui prennent beaucoup de fubftance.

Votre terre eft-elle trop chargée de bois? faites-en abattre une certaine quantité ; \& qu'au lieu de gland l'on voye des épis dans vos champs: ear le terrein d'une forêt exploitée, eft très - propre à donner du bled. Mais fi le bois manque fur votre terre, vous y planterez des chênes, du plâne \&r des ormeaux, que pourront voir plufieurs générations; vous remplacerez les oliviers, qu'un vent de midi aura renverfés, \& vous ne fouffrirez pas que des arbres fans rapport, ou qui ont dégénéré, \& qui ne donnent que de méchant fruit, occupent un pouce de votre terrein; il faut y mettre la hache fans miféricorde, ou bien après les avoir élagués, il faut les greffer, \& les contraindre à vous donner de meilleur fruit.

Au cas que votre terre ne s'imbibe pas de toutes les eaux qu'elle reçoit, $\&$ que ces eaux croupiffantes dans IIONS TOUR LACH A T: DUNE TER = RE. 
PRECAUrons rour fons, faute d'une pente qui les faf-
I. A H A I fe écouler vers la riviére la plus vos champs faffent mourir vos moifD'UNE TER -

RE. prochaine: voici le reméde; ouvrez de larges foffés qui traverfent cette plaine marécageufe; quand vous rencontrerez un fond fabloneux, conftruifez ( I 3) une raye couverte, \& à chaque extrémité de cette raye élevez avec des pierres une efpéce de petit pont, afin qu'aucun obftacle n'arrête l'écoulement de l'eau des deux côtés.

Ah! fi vous aviez un marais à deffécher pour en faire fortir un champ, qui n'eût point encore vî le jour, avec quelle ufure cette terre nourrie d'un limon gras, \& repofée depuis un tems immémorial, ne vous dédommageroit-elle pas de vos travaux \& de vos femences? Il eft une plaine aux environs de Beziers, où le Laboureur proméne aujourd'hui la charrue, \& qui n'étoit autrefois fillonnée que par les vaiffeaux. Les ( 14$)$ Romains, maittres alors d'une grande partie du monde, eurent la conftance d'ouvrir un chemin à tra- 
vers une longue montagne, pour $\overline{\overline{P R E ́ C A U-}}$ l'écoulement des eaux du marais, rioss pour afin de ne rien perdre de ce terrein $\mathrm{C}^{\prime} A \subset$ С $A \mathrm{~T}$ qu'ils croyoient le meilleur de tout $\mathrm{D}^{\mathrm{R} \mathrm{E}_{0}}$. TIR-

l'univers. Ouvrage fans doute digne de leur grandeur, \& dont profitérent les fiécles fuivans.

Le paffage qu'on avoit pratiqué pour l'écoulement des eaux de ce marais, n'étoit plus connu de nos jours ; mais on retrouva la route qu'elles avoient tenu, (i 5 ) lorfqu'on perça la même montagne à l'occafion du fameux canal, qui fait aujourd'hui la jonction des deux mers. (16) Alors cet ancien monument de la grandeur Romaine, parut en oppofition avec l'entreprife des François. Rome fembloit réclamer la fupériorité fur nous, du moins à l'égard de cet ouvrage ; mais fi elle triompha des difficultés à force de bras \& de conftance, elle ne fut conduire à la mer par ce chemin, que les grenouilles du marais avec fes eaux : la France, au contraire, entretient fur les deux mers un com. merce confidérable depuis qu'elle a 


\section{4 \\ CEO N O MIE}

I KECAU- fu ouvrir fous la terre même un rions pour ample paffage à fes vaiffeaux : tanI'ACHA A tôt ils craignent le fort d'Icare, \& RE. croyent voguer au milieu desairs, tant le lit du canal eft élevé, \& tantôt ils defcendent $f i$ bas qu'ils croyent cingler fur l'Acheron dans l'Empire des morts; mais un inftant après qu'ils ont traverfé cette mer fouterraine, à force de rames, \& qu'ils découvrent les hautes tours de Beziers, \& Ies agréables campagnes d'alentour, lieux fortunés qu'éclaire le foleil de fes rayons les plus éclatans, ils fe croyent tranfportés au milieu des Champs Elifées.

Mais malgré la beauté du ciel ¿ $z$ les dehors enchantés de Beziers, on êt plutôt faifi de crainte qu'affecté d'un fentiment de plaifir; car les eaux qui fe précipitent de la montagne font un fi horrible fracas, qu'on croit entendre ces torrens fougueux des Alpes, qui grofis parles pluies, roulent impétueufement leurs flots parmi des rochers déferts. Les vaiffeaux fe voyent au bord d'un précipice, \& font frappés 
d'une horreur fubite au bruit formidable que font les eaux par leur chîte. Cependant, au moyen des ouvrages immenfes \& des éclufes qui D'UNe TERretiennent les eaux, \& les met qui R.E.

1 \& $L C A U=$ retiennent les eaux, \& les mettent fuccefivement au niveat, les vaiffeaux chargés defcendent avec une merveilieufe facilité de ces lieux fouvent efcarpés, que les chévres même ne franchiffoient ci-devant qu'avec peine.

( I 7 ) Ce monument eft votre outvrage, fameux Riquet ; c'eft à vous que Beziers, où vous prites naiffance, eft redevable de fa fortune \& de fa réputation : c'eft à vous que la France doit la merveille quil'honore le plus \& l'enrichit davantage. Alcide, en applaniffant des montagnes, en détourflant le cours des fleuves, s'eft acquis l'immortalité. Vos travaux ont furpaffé ceux d'Hercule, en nous procurant la communication des deux mers, par un canal diune immenfe étendue, \& le chef-d'œuvre d'un génie fupérieur. Ah! fi le ipectacle des chores d'ici bas vous touche encore, daignez du haut des

$$
\text { Toine } 1 .
$$


26 (E) C N O M I E

cieux confidérer votre ouvrage : à

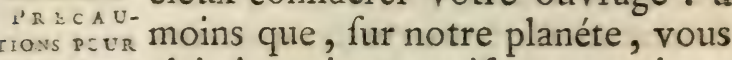
I' А С А D'UNE TER- ble enfant, iffu du fang des Lamoignons par fa mere. Que de rares exemples de vertu il trouvera dans fa famille ! foit qu'il fuive les nobles traces de fon pere ou de fon oncle, foit que le cafque de Mars ou le mortier de Thémis couvre un jour fon illuftre tête.

Les caux. Si vos champs arides manquent de fontaines \& d'eaux, \& que vous apperceviez les indices ordinaires qui dénotent les fources, creufez la terre, \& donnez la liberté à ces eaux renfermées qui ne demandent qu'à voir le jour. Mais dans la crainte que ces indices, quelquefois douteux, ne vous trompent, étendezvous à terre, \&z regardez l'orient au lever du foleil. Si vous voyez fe lever au-deffus d'un champ un petit nuage, ou quelques légéres vapeurs, fouillez cet endroit, vous y trouverez de l'eau. De plus, fi vous y voyez de la mouffe \& de la fariette fauvage, plantes qui fe plaifent 
R U R A LE. Liv. I.

toutes les deux dans les terreins humides, \& que vous apperceviez PIOES POUR des effains de moucherons voltiger $\mathrm{I}^{\prime} A \subset$ H $A$ I au-defflis en forme de tourbillon : D'UNE TERles joncs, les faules, le pouliot fáuvage, \& tous les arbrifieaux qui croiffent aux environs des fontaines \& des riviéres, $y$ abondent, ce font autant de fignes évidens qu'il y a des fources cachées en cet enciroit.

C'eft par ces indices, (18) \& non par l'intelligence de la baguette divinatoire, que découvrent des fources ces gens qui, après avoir jugé à l'œil qu'il y avoit de l'eau en quelqu'endroit, vont publier qu'ils doivent cette découverte à une baguette miraculeufe. Comme fi les eaux, qui coulent dans des lieux fouterreins, avoient la vertu de faire incliner une branche de coudrier, tandis qu'un fleuve profond \& rapide n'a pas le même pouvoir.

C'eft ainfi que les Augures à Rome, feignant de mefurer le ciel ( 19 ) avec des baguettes courbes, \& confidérant le vol des oifeaux, leur attribuoient les prédictions qu'ils fai-

$C$ ij 
foient, quoiqu'ils ne les duffent qu'à I' RE $A U$ - leurs lumiéres; parce que le peuple
TIONS POUR I'A CHA T croyoit plus au vol des oifeaux D'UNE TER- qu'aUX confeils d'un efprit éclairé.

Un jour un de ces impoiteurs qui cherchent les fources \& les tréfors, vantant fon art devant moi, \& $\&$ méme étant fur le point de duper une troupe d'idiots auxquels l'efpérance d'une fortune rapide donnoit de la foi ; je feignis d'admirer comme eux fon talent, \& je cachai fous un buiffon devant l'affemblée la même piéce de monnoie qu'il difoit y avoir trouvée. Mais comme je voulois prouver que cette baguette s'inclinoit à la volonté de celui qui la tenoit, \& non par elle-même, je profitai d'un moment où ce fourbe avoit les yeux tournés d'un autre côté, \& je repris fans être apperçu la piéce de monnoie. Un moment après cet homme prend la baguette, \& la fait mouvoir entre fes doigts qui paroiffent immobiles; d'où il conclut que fa baguetie ne s'incline que par la feule vertu de l'or caché qui attire tout à lui. Mais, m’écriai-je, il n’y 


\section{R U R A I E. Liv. I.}

a point là d'or caché. On reconnut la fourberie de l'impofteur, \& l'on TIONS DOUR en rit beaucoup. Il fe trahit lui-mê- ${ }^{2} A$ A H A $\mathrm{A}$. me par fa fuite \& fa honte : cepen- $\mathrm{RE}$. dant il continue encore l'exercice de fa baguette, qui lui fait effectivement trouver de l'or chez les dupes.

Si quelqu'un de ceux qui ont befoin d'eau, n'ajoute pas foi aux différens indices que j'ai donnés, qu'il ouvre la terre, \& qu'après avoir creufé une efpéce de puits, il mette au fond des lampes allumées, des floccons de laine, des briques qui n'ayent pas encore été cuites, des vafes renverfés, \& qu'il ferme cette petite foffe avec plufieurs ais de bois. Trouve-t-il après la nuit les lampes éteintes, les vafes mouillés \& dégoutans, la laine humectée, les briques détrempées \& fendues par l'humidité ? Qu'il cherche de l'eau dans cet endroit ; \& s'il lui refte encore quelque doute, qu'il y apporte des charbons allumés: alors sil voit que la terre exhale une épaiffe vapeur, c'eft une preuve qu'ily a des fources en ce terrein; à moins que les eaux Tome $I$. 
qui y féjournent ne proviennent des $P_{R} E C A U$
TIONS POUR pluies de l'hiver.

I'ACHAT D'UNE TER.

Que l'on confidére enfuite la quaRE. lité de la terre. Celle qui eft chargée de craye fournit peu d'eau, \& encore eft-elle défagréable ; une terre noire donne de meilleure eau, mais en petite quantité ; la terre remplie de gravier n'a qu'un filet d'eau, mais fupérieure aux autres par fa douceur. Il ne faut pas compter fur celle qui coule parmi des cailloux rougeâtres, eile s'échappe par des conduits

- inconnus, \& trompe nos efpérances. L'eau qui paffe fur un fond de fable argente qui la purifie, eft plus faine \& plus abondante que les autres. Les meilleures ont leur fource au pied d'une colline, \& celles qui font pefantes fe trouvent dans les terres graffes : mais les plus abondantes, ainfi que les fleuves les plus rapides, yiennent des montagnes les plus élevées. (20) Soit que les eaux de pluie \& celles de neige fondue, foient forcées d'aller fe réunir dans de vaftes fouterreins, d'où , comme d'un réfervoir général, dériyentles fources 


\section{R U R A I E, Liv. $I$.}

$8 x$ les fleuves; foit que les eaux de l'Océan, qui, comme une ceinture, entourent notre globe, aillent fe dé- ${ }^{\prime}$ А с н A $\mathrm{A}$. charger par des conduits cachés fous RE. la terre, \& même fous le fond de la mer, que l'eau preffe l'eau, que chaque flot en pouffe un autre, \& que par des routes inconnues l'eau s'éléve jufqu'au fommet des plus hautes montagnes, de la même façon que monte la liqueur le long d'un linge ou d'un morceau d'étoffe, ou comme des eaux renfermées à leur chute dans des canaux de plomb, s'élancent du baffin par un jet auffi haut que la colline d'où elles partent a d'élévation, \& frappent les airs avec impétuofité.

Ou, comme l'efprit de vin, des fleurs $\&$ des plantes, exalté par la chaleur du feu, fe condenfe, s'attache au chapiteau de la cucurbite, \& diftille goute à goute, de même le feu qui échauffe les entrailles de la terre, fait fermenter les eaux qu'elle contient comme fielle étoit une vafte montagne creufée en forme de vafe d'airain, \& les fait s'élever en va- 
$\overline{P R E C A U}$ peurs humides : aufititôt qu'elles ont IONS POUR atteint les froides concavités d'une z'A ch A t montagne, elíes fe condenfent, \& r. $\quad$ forment une légére rofée. Les pierres \& 2 toutes les autres matićres d'alentour, font imbibées de ces particules d'eau, d'où peu à peu naît un ruiffeau, qui, pénétrant infenfiblement à travers les montagnes \& $\mathrm{x}$ les veines de la terre, fuit la route la plus inclinée, \& fe répand dans les champs qui font au-deffous.

La chaleur de la terre, qui garantit les plantes des rigueurs du froid quand elles font couvertes de neige, \& les tourbillons de feu qui, par une éruption fubite, s'échappent du mont Etna, embrafent l'air au loin, \& fément la défolation \& l'effroi dans les plaines de la Sicile, prouvent que les entrailles de la terre font autant de fourneaux ardens. Jojgnez à ces preuves les fontaines minérales, les différens bains d'eau chaude, dont la terre eft le foyer; ajoutez que c'eft par fa chaleur que fe forment l'or \& les autres métaux, ouvrages que jamais les hommes ne 
pourront imiter. Le fein de la terre renferme tant de chaleur, que ceux PRECAUqui travaillent aux mines s'maginent habiter déja l'empire de Pluton; l'a- $\mathrm{D}$ ' $\mathrm{RE}$. D'UNE TER. ctivité des feux qu'elle contient eft fi puifante, qu'ils l’ébranlent jufques dans fes fondemens, \& renverfent les montagnes.

C'eft à l'imitation des volcans que nous avons imaginé nos foudres militaires : leur flamme terrible eft un funefte préfent de la terre, \& non pas le larcin de quelque impie Prométhée.

Le feu qu'enferme la terre fe décéle par l'effervefcence même des eaux de l'Océan ; \& depuis peu dans les Indes il eft forti de la mer une ifle qui s'étoit détachée du fein de la terre. L'apparition en fut fignalée par un bruit épouvantable, \& par une grêle de pierres énormes lancées du fond des eaux. Les ondes bouillonnantes de la mer en jettérent au loin d'épaiffes fumées; \& les curieux qui, pour comprendre ce phénoméne, voulurent aller voir cette partie de la mer devenue tout à coup folide, 
PKECAU IIONS POUK $x^{3} A C H A T$ D'UNE TERRE. ne fentirent, hélas! que trop les effets de ces feux fouterreins : eux \& leurs vaiffeaux en furent auffitôt confumés.

L'immenfe quantité d'eau renfermée dans le creux des montagnes, eft depuis la naiffance du monde dans une continuelle fermentation qu'excitent les feux concentrés de la terre. Des vapeurs légéres montent jurqu'au fommet des montagnes, d'où retombant par goutes, elles forment un ruiffeau qui, prenant fon cours par les champs les plus en penie, va rendre à la mer les eaux qu'il tenoit d'elle. C'eft par cette railon que l'eau qui a fa fource au hauid'une montagne, eft plus légére \&̃ plus faine, parce que fes particules ne font compofées que de vapeurs déliées, \& que paffant à travers le fable, qui pour elle eft une forte de tamis, elle y dépofe toutes les immondices dont font chargées les eaux de pluye. Car quoique celles-ci s'exhalent aufi en vapeurs par la force du foleil quiles pompe, elles confervent toujours le gout défagréable qu'elles ont con- 


\section{RUR A L E. Liv. I.}

tracté dans la terre, en s'imprégnant des différens fels des plantes; \& PrecAUborfqu'on a préféré pour la provifion ${ }^{\prime}$ ' $\mathrm{ACH}$ A $\mathrm{I}$ d'un vaiffeau l'eau de citerne à celle ${ }^{\text {D'UNE TER- }}$ de fource, elle eft fi corrompue en pleine mer, que les nautonniers, quelque ardente que foit leur foif, ne fauroient en boire.

Réfléchiffez long-tems oì vous jetterez les fondemens de votre maifon, afin qu'elle foit commode, faine, \&z placée dans une fituation agréable. Que l'art \& la dépenfe n'en faffent pas tout l'ornement: qu'elle plaife auffi par le délicieux ombrage de fes bois, \& par le doux murmure d'un ruiffeau qui, ferpentant au milieu des prairies, conferve à peu de fräis les agrémens de votre campagne.

Fuyez le voifinage des torrens \& des grands chemins, de peur que vos champs trop expofés ne foient ravagés par une inondation, ou pillés par des voleurs. Il eft à propos de vous éloigner auffi des triftes marais, dont les exhalaifons peftiférées enfantent les maladies, gâtent les grains \& les fruits qu'on veut garder pour 


\section{C C ONOMIE}

PRECAU l'hiver, \& rouillent même les uften. rions pour ciles de campagne après un certain D', Аснат tems. Ces marais produifent des D'UNE TER- brouillards qui font mourir les moiffons; leur vafe croupiffante donne l'être à des légions d'infectes qui vous déchirent le vifage avec leurs trompes: enfin le limon des marais engendre des milliers de grenouilles, nation ennemie du repos \& du fommeil, \& qui (2I) femble par fes coaffemens répéter les anciennes injures des payfans de Lycie.

Que votre maifon ne foit pas enterrée dans des vallées fombres. J'ajmerois mieux, fuivant la coutume de nos ancêtres, \& felon l'ufage des aigles, loger mes pénates fur la cime d'une montagne, quand ils clevroient être le jouet de tous les vents, que de me voirpendant l'hiver environné de brouillards au pied d'une colline, $\&$ étouffé dans l'été par les fouffles brulans de la canicule, fans refpirer l'haleine d'aucun zéphir.

Vous ne choifirez donc point un lieu bas expofé à être noyé par les pluyes de l'hiver, ni trop élevé, \& 
RURALE. Liv.I. 37 en butte aux fureurs des vents du midi, ni eicarpé de maniére à reffentir Tincommodité des ravines. Mais au cas que vous preniez un terrein dans $\overline{1} \mathrm{RECA \textrm {U } ^ { - }}$ TIONS POIIR I'A C H A = () $U N E T E R$ un vallon, choififfez-le de façon qu'il y ait de l'air. Si vous vous placez fur le haut d'une montagne, qu'il y $\mathrm{en}$ ait une plus haute qui vous ferve d'abri contre les vents. Enfin fi vous vous logez dans la plaine, qu'elle ait une pente qui puiffe donner l'écoulement aux eaux de pluye.

Lorfqu'un fond de terre eft gras, qu'ili eft un pencélevé, avec une pente infenfible vers le midi, \& qu'un agréable ruiffeau coule aux environs; c'eft une excellente fituation pour une maifon de campagne : conftruifez-y votre demeure, vos celliers, dos étables, \& tracez-y le plan de tous ros bâtimens. Mais, de peur que par trop de précipitation vous ne fafiez en bâtiffant quelque faute effentielle, laiffez ce plan d'ouvrage foumis, pendant toute une année, à l'examen d'un cenfeur rigide, qui. puiffe avec vous en juger fainement. Il ne convient pas d'avoir une 


\section{8 (E) C ONOMIE}

PRECAU- petite maifon quand les terres font tions pour confidérables, ni un grand château $x^{\prime} \wedge$ C HA $\triangle$ T quand le fond de terre eft de peu de valeur : que l'édifice réponde à l'étendue de vos domaines. Il eft moins flateur de faire des entreprifes hardies, qu'il n'eft glorieux de les finir : plus on a mis de fafte en commençant un édifice, plus il eft honteux de le laiffer imparfait. Pour être logé au large à votre maifon de campagne, $\&$ faire avancer l'ouvrage, fans jetter l'or à pleines mains, faites ufage des matériaux qui font fur votre fond. La terre vous fournit les pierres pour la conftruction des murs; la charpente fe fera des arbres de votre bois, ainfi que les ouvrages de menuiferie; vous y trouverez auffi tous les fagots \& $x$ tous le bois taillis dont vous aurez befoin pour cuire la brique \& la chaux. Tirez le fable de votre terre, ou faites-le amener dans des charrettes, après l'avoir pris à la riviére la plus proche. Mais vous tiendrez tout cela prêt avant que vos murs fortent de terre.

Que vos bœufs pendant la faifon 
R U R A L E. Liv. I.

morte de l'hiver, vous aménent les pierres: que la hache jette à bas TIOAS POUR plufieurs planes de votre bois, des ${ }^{\prime}$ A $A$ C A A $A$ T chênes énormes par leur groffeur, $\mathrm{RE}$. des fapins qui durent long-tems dans un lieu fec, des frênes fauvages remarquables par leur hauteur, \& (22) des hêtres que laffemblage le plus fort n'empêche pas de travailler. Mais vous ne ferez abattre le peuplier qu'au commencement du décours de la lune; \&, lorfque cet arbre fera entamé jufqu'au cœur, laiffez-le quelque tems menacer de fa chûte, afin que fa féve âcre \& corrofive ayant eu le tems de couler, le bois puiffe durer plus longtems.

Si le pays trop gras ne fournit pas de pierres propres à la conftruction, faites cuire des briques d'argile détrempée dans une grande quantité d'eau. Quand elles ont été façonnées dans des moules de bois de chêne, on les fait fécher fur une aire bien unie. Qu'on ne travaille à cet ouvrage qu'après l'été jufqu'à la fin de l'automne, ou qu'après l'hiver, lorf- 


\section{0

PRECAU-que le printems \& les zéphirs renrions raur dent la faifon plus douce. Le foleil $Z^{\prime} A C H A T$
$D^{\prime} C N E$ TER$2 \mathrm{~s}$. fécher la brique, elle ne conferveroit pas fa premiére forme fans s'étendre ; \& pendant les grandes chaleurs elle fe fend au foleil.

Faites chauffer votre four à chaux pendant trois ou quatre jours fans interruption, jufqu'à ce que la pierre fe fende aux extrêmités, \& qu'on ne voye plus dans l'obfcurité s'élever de longs traits de flamme \& de fumée.

On fait cuire au four différentes pierres de chaux, felon les différens ufages auxquels on veut les employer. Il faut qu'elles foient molles pour des enduits de muraille, \& dures pour les autres ouvrages de maconnerie. Le meilleur fable eft celui qui fait du bruit fous les doigts en le maniant, \& qui ne laifie ni tache, ni craffe fur un linge blanc, quand on l'a fecoué.

Dès que vous aurez raffemblé les matériaux néceffaires, vous jetterez les fondemens de votre maifon, pour- 
vî que ce ne foit pas fur des ruines de vieux bâtimens. Mais $\mathrm{fl}$, après troxs pour avoir creufé bien avant, le terrein $\mathrm{L}^{\prime}$ A C $\mathrm{AH}$ A T n'eft pas encore folide, contentez- $\mathrm{R}$.

vous d'une profondeur égale à l'élévation de la quatriéme partie du mur que vous voulez conftruire. Alors vous pourrez enfoncer des pilotis, fur lefquels vous poíerez vos premiéres pierres de fondation.

Que votre maifon regarde directement le midi, afin que le foleil plus élevé pendant l'été, \& n'entrant que très-peu par les fenêtres, n'échauffe pas trop votre appartement, \& que plus abbaiffé vers la terre pendant l'hiver, lorfqu'il retourne au tropique du capricorne, il puiffe pénétrer chez vous, \& vous réjouir par la douceur de fes regards.

On eft aujourd'hui dans l'ufage de donner tant de jour aux maifons de ville \& 2 de campagne, de faire des fenêtres fi larges, fi élevées, \& en fi grande quantité, qu'on diroit que ce ne font que des colonnes, \& non des murs, qui foutiennent les toits. On jureroit que les hommes à Tome I. 


\section{CE C O O M I E}

PRECAU préfent, fe croyant fuffifamment aे TIONS pour l'abri des injures de l'air entre des D'U A C A T m murs de verre, ne font plus fenfibles RE. à la rigueur du froid, aux vents pernicieux du midi, ni aux ardeurs de la canicule : car la chaleur pénétre bien plus aifément par de larges croifées ; \& lorqu'en hiver les aquilons font déchaînés, de foibles rideaux de toile, mis au-devant des fenêtres, ne fuffifent pas pour garantir d'un froid piquant. Mais pour augmenter le plaifir de la vûe, \& faire paroitre une maifon plus riante audehors, on aime mieux fouffrir audedans, $\&$ acheter même à grand prix fon incommodité. C'eft ainfi que le François efclave de l'ufage, lui facrifie la raifon; $\&$, fi la mode le vouloit, (23) il échangeroit l'or \& l'argent avec de vil papier, \&z donneroit pour de méprifables effets une monnoye qui a une valeur intrinféque.

Qu'on fuive la mode à la bonne heure dans les bâtimens qu'on éléve à la ville, parce que le vent n'y fourfle pas comme en plein champ; mais 
â la campagne, tenez-vous en à l'ancienne pratique de vos ayeux, \& ne donnez entrée à l'air par vos fe- ${ }^{\prime} \mathrm{A} \mathrm{A} \mathrm{H} \mathrm{A} \mathrm{I}$ nêtres que le moins que vous pour $-\mathrm{R} \mathrm{E}$, rez. N'ayez point pour objet, lorfque vous bâtiffez, d'étaler tous vos meubles par une longue enfilade d'appartemens; mais que les iffues en foient aifées, \& diftribuées de façon que vous n'ayez point d'inquiétude de vos hôtes, \& que vous puiffiez dormir en füreté.

Dès que la maifon deftinée à vous loger fera achevée, faites conftruire féparément les bâtimens néceflaires pour conferver les grains \& les autres fruits de la terre, dans la crainte de choquer les yeux des femmes, qui aiment en tout la décence, \& qui feroient dégoutées de voir fans ceffe les uftenciles de campagne, les chiens, \& même les riches produc. tions de la campagne. Vous choifrez pour vos celliers les endroits les plus frais; pour ferrer votre huile, le lieu le plus expofé au foleil ; \& ne mettrez que dans un endroit bien $\mathrm{fec}, \&$ fur des planches garnies de paille, les 


\section{CE C O N M I E}

$P_{R E C A U}$ fruits mûrs réfervés pour l'hiver, tels zross pouk que les pommes \& les poires. Pour

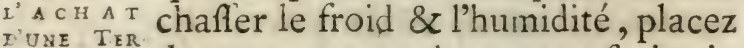
$x:$. de tems en tems dans votre fruiterie des charbons allumés; car les vents du nord rident les fruits, \& ceux du midi les gâtent. Vifitez fouvent votre fruit, \& ne manquez pas d'enlever celui qui fe reffentira de l'humidité, dans la crainte qu'elle ne fe communique de l'un à l'autre, \&que la contagion ne devienne générale fur les planches.

Que les vents du nord donnent de lair à vos greniers ; mais préfervezles de ceux du midi dont les aîles humides endommagent les grains. (24) Les Languedociens bâtiffent leurs greniers au milieu du chemin devant la porte de leur maifon; ils font ainfi à l'abri de la pluye, qui pénétre tout, \& de l'action de l'air qui fait impreffion fur tous les corps.

Quand les charenfons font entrés dans un tas de bled, ils n'en occupent d'abord que la partie fupérieure ; mais tout le tas bientôt fera infulté de ces infectes, fi vous vannez dans votre grenier ce grain qui eft déja en partie rongé. 


\section{R U R A L E. Liv. I.}

Donnez au fermier une maifon vafte, au berger une petite cabane, TIOXS DOUR

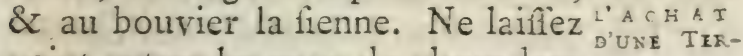
point entrer les eaux de pluye dans $\mathrm{rz}$.

l'étable; elles détruifent les murs, amolliffent \& corrompent la corne du pied des animaux, \& leur occafionnent toutes fortes de maladies. Qu'on n'ait point à craindre le feu d'aucune lampe fufpendue en l'air, ou attachée aux murs de l'étable. Le four oì la fermiére fait cuire fon pain, doit en être éloigné, de peur que les foliveaux de l'étable, échauffés par le feu du four, ne s'enfląmment à la moindre étincelle, \& ne caufent un incendie général.

Le Laboureur aime fur-tout une Ia cuifne, cuifine fpacieufe, où tous fes gens raffemblés puiffent fe chauffer auprès d'un bon feu, fe délaffer des fatigues du jour, fans que le travail ordinaire des foirées en foit interrompu : car le fermier ne permet pas pendant l'hiver qu'on travaille le jour à des ouvrages qu'on peut faire la nuit.

Après le repas, viennent s'affeoir' autour du foyer le laboureur remar. 


\section{CE C ONOMIE}

PRECAU quable par fa grande taille, le conTIONS POCR ducteur des chévres hideux par fes

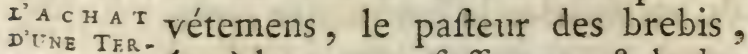
$R E$,

(25) le nerveux foffoyeur, \& le dur bouvier. S'il eft refté quelques olives plus tenaces que les autres aux branches d'olivier qu'ils ont rompues, ils s'occupent àles chercher \& à les cueillir, à nétoyer les toifons des brebis, à fendre l'ofier, qu'ils rendent fouple dans de l'eau chaude, à préparer les échalas pour la vigne, ou à conftruire des corbeilles avec de l'ofier. Et jamais les jeunes villageoifes n'ont tant de plaifir à manier leurs fufeaux que dans ces agréables momens : car, tandis que le fermier fait fa ronde avec une lumiére, \& qu'il va compter les brebis au bercail, les enfans n'étant plus retenus alors par la préfence diu pere, une des filles agace, par fes propofitions tendres, l'idiot Ménalque, qu'elle feint d'aimer. Elle flate ce pauvre garçon par des déclarations malignes \& fimulées, afin qu'à fon tour il s'explique, \& que fon gofier ranque exprime fon amour par une shanfon. 
R U R A L E. Liv. I.

Bientôt il s'applaudit de fon chant, tient à grand honneur les éclats de rire de l'affemblée ; \& dans le ravif- ${ }^{\prime}$ A c fement où il eft des railleries qu'il ex- $\mathrm{Rz}$. cite, il ne s'apperçoit pas que (26) la rufée Theftilis fe moque de lui, \& lui noircit le vifage. C'eft ainfi qu'à la campagne comme à la ville, l'on trouve des originaux faits pour l'amufement d'autrui. On peut impunément les piquer comme on feroit des boufs avec l'aiguillon; loin de s'en fâcher, ils témoignent eux-mê. mes leur fatisfaction par leur gayeté.

Qu'au hangard fous lequel le laboureur, pendant les pluyes d'hiver, met à couvert fes voitures, $\&$ r répare fa charrue $\&$ fes charrettes, il n'y ait que des poteaux pour le foutenir, au lieu de porte.

Si le chemin qui conduit à votre campagne eft bien fréquenté, il convient que fur la route on établiffe une hôtellerie pour les voyageurs. Mais faites-vous un devoir de donner le couvert aux pauvres dans vo. tre maifon. C'eft du nom d'hofpice qu'autrefois les Anciens compofé- 


\section{8 (E) C N O M I E}

$\widehat{P_{R E C A U}}$ rent celui de Jupiter hofpitalier, peTIUNS FOUR re des dieux \& des hommes. Ils ne

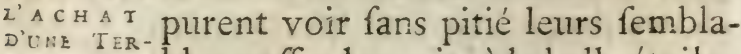
R.E.

bles paffer les nuits à la belle étoile, tandis que les plus vils animaux avoient un gite pour s'y repofer, \& ils exercérent réguliérement l'hofpitalité. Cependant ils ne favoient point, dans ces tems infortunés, que Dieu fe cache fouvent fous les vêtemens du pauvre, \& que toutes les pieufes libéralités font écrites au ciel.

Que l'aire ne foit pas trop éloignée, afin que fi quelque nuage trompeur vient tout à coup à fe réfoudre en pluye, la proximité de la maifon vous donne la facilité de fauver plus promptement vos gerbes mal battues. Choifffez pour votre aire un lieu un peu plus élevé, \& dégarni d'arbres, afin qu'elle foit plus expofée à l'air \& $x$ au vent qui la nettoyent. Il faut l'applanir avec un grand cylindre, ou bien ( 27 ) la paver; c'eft un ouvrage dont on ne voit pas la fin : au lieu qu'une aire fans pavé o béit à la longue aux coups du fléau,

retient 
fetient les grains dans fes gerfures, ou les falit en fe pulvérifant.

Ayez deux petits réfervoirs d'eau, un qui ne ferve qu'à rouir le chan-re. vre, \& l'autre dont l'eau pure \& claire invite les troupeaux à s'y défaltérer. Que toutes les immondices de la maifon \& de l'étable; que les feuilles dont les vents ont dépouillé les forêts, \& qui couvrent la terre en hiver; que le limon, fi la riviére en a laiffé dans quelque débordement, foient portés dans une foffe à couvert, \& loin de la mailon. Par ce moyen le fuc du fumier fe conferve, \& ne s'évapore point; cette eau fale fait mourir toutes les graines mauvaifes, \& vos moiffons ne font point mélangées d'herbes inutiles.

Que vos vergers \& votre parterre foient à la proximité de la maifon, ainfi que tout ce qui plait à la vûe, ou qui pourroit provoquer au larcin. Ayez du côté du nord un bois qui vous pare du vent \& du froid; que fon ombrage en été vous rende toute la fraîcheur dont il vous garan-

Tome $I$. 


\section{0 \\ (E) CONOMIE}

$\overline{\overline{P R E C A U}}$ tiffoit l'hiver, \& qu'utile dans ces PRECAU
Trons pour deux faifons il tempére, \& le grand

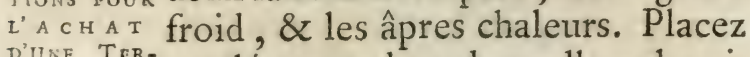

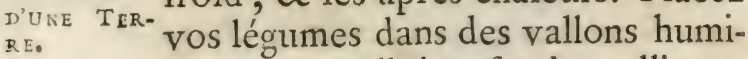
des, \& vos oliviers fur des collines; que dans la plaine on voye flotter vos épis ondoyans, ou l'herbe de quelques vaftes prairies; que vos vignes aul-delà parent un agréable côteau, \& qu’autant que la vî́e peut s'étendre, elles fixent les yeux de toute part. Comptez les arpens que vous avez en prairies, en terres labourées, en olivets \& en vignobles, par l'ouvrage \& le revenu. Comparez le profit avec la peine, \& faites moins d'état du nombre des denrées que du produit de la vente.

La terre que vous avez deftinée au labourage, comme la plus digne des foins de Cérès, demande le retour perpétuel des mêmes travaux : elle réclame, après la récolte, une partie de fes largeffes pour les femences; mais elle manque fouvent à fes engagemens, foit que l'année trop féche ou trop pluvieufe ait été nuifible aux moiffons, foit que le 
champ ftérile par lui-même n'ait pas fourni la fubftance néceffaire aUX PIONS ROUR épis, foit qu'ils ayent été renverfés par la grêle, ou qu'ils ne portent que RE.

peu de grains.

La dépenfe qu'on eft obligé de faire pour l'entretien d'une vigne, en confomme quelquefois les revenus; la récolte des olives eft auffi bien cafuelle, \& quoiqu'elles fe confervent en bon état avec peu de culture, les fortes gelées \& les grandes chaleurs les empêchent de venir à maturité; les premiéres pluyes du printems en font mourir la fleur, \& en jonchent la terre.

Les prairies ne vous donnent point ces inquiétudes; elles ne courent prefque aucun rifque, \& toutes les pluyes leur font propres, foit que les vents du nord ou du midi les aménent. Le froid ni la chaleur ne leur caufent point de dommage, pourvî que quelques ruiffeaux viennent les rafraîchir pour éteindre leur ardeur : d'ailleurs elles n'attendent prefque rien de votre travail, \& dès qu'une fois l'herbe a pouffé, .elles

$$
\text { E ij }
$$




\section{2 \\ E $C O N O M \cdot I E$}

vous donnent leurs richeffes, fans vous caufer d'embarras. L'infatiable I'ACH A I Fermier en retire différens fervices: D'UNE TER- elles maintiennent les beftiaux on fanté, leur donnent du foin pour l'hiver, \& des pâturages pour le refte de l'année. Quelque riante que foit une campagne, une prairie en augmente l'agrément, foit que l'on voye les pleurs de l'aurore briller comme des diamans fur des brins d'herbe entremélés de fleurs rouges, foit que l'herbe panchée prefque à terre femble demander à être foulée, \& paroiffe vous offrir un lit de repos, foit que l'on regarde un ruifieau qui conduit pardifférens canaux vient la défaltérer, foit qu'elle reverdiffe fans ceffe pour donner de nouvelles récoltes, qui re coutent point de nouvelles femences.

C'eft pourquoi, fi le niveau de votre prairie n'eft pas trop en pente, \& ne laiffe pas les eaux s'écouler trop précipitamment; fi elle ne boit pas auffi trop promptement l'eau qu'elle reçoit, à l'imitation du fable qui eft fans confiftance; enfin fi les 
R U R A L E. Liv. I.

pluyes n'y féjournent pas comme en un lac, femez-y, quelque vafte TrO:S POUR qu'elle foit, de la luzerne, \& toutes les autres plantes qu'aiment le plus ${ }^{2} \mathrm{R}$. L'A C H A T les beftiaux; pratiquez-y plufieurs rigoles pour donner paffage aux ruiffeaux, à moins que !a terre, par fon humidité naturelle, ne produife un tendre gazon, fans avoir befoin d'être arrofée.

Mais, dira-t-on, quelle forte de biens faut-il préférer? les oliviers, les prairies ou les vignes. Suivez l'ancien ufage des Laboureurs du lieu ; car toute efpéce de terre n'eft pas propre à toute forte de productions. (28) La Garonne qui baigne à fa fource un pays dont les habitans creufent le fein des montagnes, \& manient avec des tenailles de groffes maffes de fer, voit à quelque diftance les pâturages les plus gुras, \& les Fermiers s'occupent à faire d'excellens fromages, ou à planter des arbres fruitiers. Peu après les champs qu'elle arrofe préfentent à fon admiration les plus belles moiffons, \& fes bords charmans font enfuite ta- 


\section{4

PRECAU . piffés de pampres \& de vignes. TIONS POUIT

I'ACH A I

D'UNE TER.

z. $\mathbf{x}$,

Dans quelque fituation que vous vous trouviez, \& quel que foit l'héritage que vous ont laiffé vos peres, que la hache cruelle ne touche qu'en partie à vos anciens bois. (29) Voyez combien les Anglois ont à fouffrir du froid, avec leur charbon de terre qu'ils brulent au lieu de bois, \& combien ils pâtiffent en refpirant la fumée de ce charbon; puifqu'ils fone obligés de venir à Montpellier pour changer d'air, \& y rétablir leurs poumons defféchés.

Ville célébre, conftruifez de nouveaux murs qui vous donnent une plus vafte étendue; ornez vos fauxbourgs des plus beaux édifices, \& renfermez dans votre enceinte des jardins fpacieux qu'on pourroit admirer même à Verfailles; afin que toute la France, qui bientôt manquant de bois, n'aura que du charbon de terre à mettre en fes foyers, vienne un jour participer à la bonté de votre air, pour rétablir fa fanté: car bientôt elle reffentira les mêmes maux que les Anglois, pour avoir 
trop refpiré la fumée pernicieufe de ce charbon; à moins que les Maîtres Trons pour des Eaux \& Forêts ne préviennent ce malheur. I'A C H A T D'UNE TER-

Prenez dans vos bois celui qui vous eft néceffaire pour la réparation de votre maifon, pour votre chauffage, pour la charrue, \& la conftruction de vos vaiffeaux; mais confervez à votre poftérité les forêts que vous tenez de vos ancêtres.

(30) Nous vous pleurons encore, Regrets fur bois charmant, chênes refpectables l'exploitation par vos années, dont l'ombrage épais les bois que calmoit nos peines, nous délaffoit la maifon de de nos travaux, \& faifoit près de cámpácesne de Touloufe l'ornement de notre mai- Touloufe.

fon de plaifance. Ce n'eft qu'avec douleur que nous montrons aujourd'hui aux étrangers qui nous viennent voir, ces lieux fortunés contigus à la maifon que vous décoriez autrefois, \& qui maintenant font hériffés d'épines $\&$ de buiffons.

Que ceux qui liront mes vers, permettent ces regrets, hélas! trop. légitimes à un Poète amateur de la campagne, \& qu'on nous laiffe au

E iiij 


\section{CEONOMIE}

$\mathrm{P}_{R} \bar{E} \mathrm{CA}$ moins la confolation de nous rappelToNs rove ler la mémoire de ces bois, puifque X'ACHAT les deftins jaloux n'ont pas voulu T2: qu'ils fiffent plus long-tems nos plaifirs. Je me les repréfente toujours, \& je crois voir encore mes chers contreres prendre le frais fous leur verd feuillage. J'y vois les uns dans les retraites les plus fombres, méditer profondément fur la loi du Créateur, \& fur fes divines largeffes; d'autres récitent les faintes priéres auxquelles leur facré miniftére les oblige chaque jour : ceux-là couchés fous un arbre touffit, goutent le plaifir du repos; ceux-ci répondent au ramage des oifeaux par les airs qu'ils chantent, ou qu’ils répétent fur un tendre chalumeau; d'autres enfin, pour compenfer les veilles qu'ils ont données à l'étude, fe livrent aux douceurs du fommeil.

Defcription Là plufieurs s'amufent à jouer au du jeu de mail. On choifit pour ce jeu un endroit dégarni d'arbres, autour duquel il y en ait feulement pour donnerde l'ombre.

L'aire bien fablée, \& fermée tout 


\section{R U R A E. Liv. I.}

à l'entour par des planches de bois, préfente quatre allées. Il y a un an- rioss pour neau de fer au milieu du jeu, à tra- $A \subset A T$ A vers lequel, fi on a l'adreffe de fai-n.

re paffer fans fupercherie un petit globe de buis, ou de le lancer audelà du but, après lui avoir fait parcourir les quatre allées, on eft proclamé vainqueur par les fpeciateurs qui font affis fur des fiéges élevés.

Ceux qui ont envie d'entrer en lice pour difputer le prix, fe prélentent armés de bâtons ferrés, ¿̋ font réfonner les bois des coups vigoureux cont ils frappent le petit globe. C'eft ainfi que, fatiguant leur corps à ce rude exercice, ils donnent du relâche à leur efprit.

Là j'en vois d'autres occupés à la Mention des lecture. Quoique les bois femblent cunferes de deftinés à la récréation, Apollon n'infire en aucun endroit avec autant de chaleur : c'eft dans le filence des bois, \& fous leur ombrage, que ceux qui ont le cion de la parole apprennent à dévoiler au peuple les vérités les plus fublimes, \& à frapper de la foudre évangélique les cœurs les plus endurcis. 


\section{CE C ONOM IE}

C'eft-là , cher Cleric, que je vouts PRÉEAU-
TIONS POUR ai vil tout couvert des lauriers, que

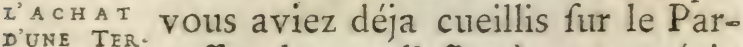
DUUNE TER naffe, donner l'effor à votre génie Le perecle fertile, \& mettre au jour des vers sic.

que Touloufe admirant toujours ne peut récompenfer aujourd'hui que par fes louanges. (3 I) Vous avez été couronné tant de fois, que fes largeffes font épuifées; aufí vous a-t-elle affocié aux Membres de fon Académie pour y juger ceux qui étoient autrefois vos concurrens.

Avec quelle avidité je prêtois l'oreille aux beaux vers que vous récitiez, foit qu'il vous plût de chauffer le cothurne de Sophocle, foit que laifrant le ton de Melpoméne, vous rendiffiez en notre langue toute la fineffe des plaifanteries de Térence, foit que les flots de votre éloquence plus rapides qu'un torrent, coulaffent de votre bouche toutes les fois que vous me répétiez les difcours que vous deviez prononcer vers le milieu de l'automne. Tous les citoyens alors quittoient la campagne pour repeupler la ville, comme fi le 


\section{R U R A L E. Liv, I.}

talent de la parole, qu'ils vous avoient tant de fois reconnu, pri- PRONS DOU

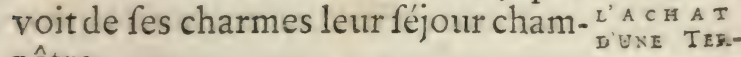
pêtre.

Vous vous plaifiez, je m'en fouviens, à vous enfoncer dans le bois, ou à vous affeoir avec moi fous un vieux châtaignier. Là fe trouvoit une fontaine, dont l'eau pure \& fidéle comme une glace repréfentoit $\mathrm{fi}$ bien les fruits de cet arbre, fes feuilles agitées par les zéphirs, \&z les oifeaux lègers qui voltigeoient de branche en branche, qu'on doutoit fitous ces objets n'étoient pas effectivement au fond de cette fontaine, ou fi l'on voyoit paroître leur image fur $f a$ furface.

C'eft là qu'après vous avoir lî les premiers effais de ma Mufe, vous aviez la bonté de m'encourager \&z de m'aider de vos confeils, en me défignant les vers qu'il faloit refondre ou polir. Quoique votre nom n'ait befoin que de vos vers, pour étendre au loin fa réputation, je ferois donc un ingrat $f i j$ 'oubliois de parler de vous dans cet Ouvrage, 


\section{E C O NOM I E}

PRECA. que vous avez daigné corriger, \& Iloxs roukje n'entendrois guéres l'intérêt de I' A C H A T mon amour-propre fi je ne me gloriRE. fiois d'avoir été votre ami dès mes plus tendres années.

Ie perecam- C'eft auffi dans ces lieux, cher piltron.

Campiftron, autre partie de moimême, que vous travailliez à mériter les éloges du public, \& cette réputation d'homme de génie, qui rend Touloufe fi glorieufe de vous avoir pour citoyen; réputation qui entraine le Sénat \& le Peuple pour vous entendre, (32) foit que, digne émule de votre frere, vous vous difinguiez comme lui par des Trayédies, foit que vous tiriez des fons de la lyre ou du chalumeau,ou qu'également verfé dans la langue Latine \& la nôtre, vos difcours fe reffentent de la majefté Romaine, ou de l'aménité Françoife.

Be- C'eft dans ces bois, \& pendant vos premiéres années que je vous eus pour dificiple, cher Belot, vous quaujourd'hui je voudrois avoir pour maître. Dis le tems de vos études vous vous étiez fait un nom, \& 


\section{RU R A L E. Liv. I.}

vous paroiffiez avoir tant d'aptitude pour tous les arts, qu'on ne pouvoit

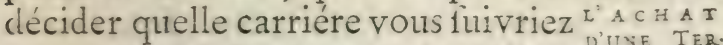
pour acquérir la plus grande célébri- $R$ E.

té : car, foit que les temples retentîffent de vos difcours évangéliques, foit que vous vouluffiez eifacer notre gloire en vous tournant du côté des Mufes, la ville ne vous applaudiffoit pas moins, \& paroiffoit auff empreffée de vous entendre que lorfque dans la chaire théologique, vos lumiéres diffipent les ténébres de la foi, \& que vous enfeignez cinq cens difciples, qui prennent de vous des leçons de piété, moins encore dans vos difcours que dans vas mœurs.

Agréables retraites, arbres toujours verds, fous lefquels fe font formés de fi grands hommes, hélas! qu'êtes-vous devenus? De quels triftes murmures ne retentit pas le Parnaffe lor fqu'approcha l'heured'abbattre ce bois chéri! Mais que purent les tendres Elégies contre les coups de la hache inflexible ? Envain le célébre Mourgue en témoigna fes re- La P. Mour grets (33) par des vers aufifi touchans gue. 


\section{2 \\ E C O N O M I E}

que les accens d'Orphée : le tems

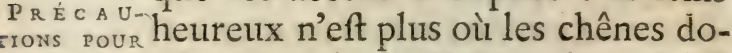
z'A C H A T ciles à la voix des Poëtes, leur obéifD'UNe TER- foient. Toute la fenfibilité de ceuxci fe réduifit à pouffer quelques gémiffemens à chaque coup de coignée, comme pour implorer les fecours des perfonnes qui, le plus fouvent, avoient joui des charmes de leur ombrage. Nous accourons : \& de même que fur un champ de bataille, où giffent impitoyablement les plus braves Capitaines, dont les illuftres noms vont périr avec eux, on eft fecrettement faifi de trifteffe $\&$ d'horreur en confidérant leur difformité, \&z leurs playes encore dégoutantes, qui offrent la plus affreufe image; ainfi fommes-nous tout enfemble frappés d'horreur \& touchés de pitié en voyant ces arbres, autrefois majeftueux, cruellement tranchés par le fer, triftement étendus fur la terre, \& leur feuillage, $\&$ leurs rameaux honteufement féparés de leurs troncs, fécher par tas en différens endruits, en attendant qu'ils ferviffent de proye aux flammes dévorantes. 
RURAIE. Livi I. $\quad 63$

Hélas! que la coupe de ce bois a savi d'agrémens à notre maifon de campagne, \& $q$ 'elle eft aujourd' irons pour campagne, \& qu'elle eft aujourd hui ${ }^{2}$ 'AC A A différente d'elle-même! L'urgente $\mathrm{R}_{\mathrm{RE}}^{\mathrm{D} \cdot}$. néceffité, qui, dans des tems malheureux, nous a confeillé de l'abbattre, \& d'employer à l'ufage de Bellone les délices de notre campagne, nous oblige encore aujourd'hui, par le même efprit d'œeconomie, ennemi de toute forte de luxe, de mettre à profit tous nos champs : la charrue vient, pour ainfi dire, jufqu'au pied de notre maifon antique, pour en fapper les tours \& les murs, \& l'on moiffonne à préfent où l'on voyoit autrefois de belles avenues d'ormeaux réguliérement plantés. Nous payons bien cher maintenant le peu d'ombrage que nous avons pendant les chaleurs de l'été, par l'éloignement des lieux où il faut l'aller chercher.

La longue allée qui fépare nos vignes, \& qui étoit autrefois garnie d'ormeaux plantés à égale diftance, n'a plus qu'un gazon pour ornement, $\&$ pas un feul arbre pour abri. $S^{2}$ 


\section{4 \\ (E) C ON O MIE}

$\widehat{P R E C A U}$ quelque tronc, ou quelque mince arrions pour bufte furvivant à la deftinée, cou-

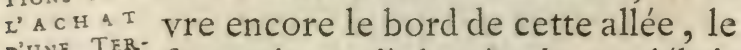
D'UNE TER- fouvenir, qu'à la vûe de ces débris on fe rappelle du charmant ombrage qu'on avoit autrefois, rouvre notre ancienne playe. On n'élague plus chaque année le buis ni le poirier, on permet à leurs rameaux vagabonds de s'étendre à leur gré, \& l'on a arraché les fleurs \& les légumes de notre jardin, qui ne produit plus que de l'orge pour la nourriture des chevaux.

L'eau qui, autrefois refferrée dans des canaux, s'élançoit avec force dans les airs, \& donnoit un fpectacle de différens jets d'eau, rampe à fon gré, \& s'étend avec liberté dans la campagne. Jadis, mife à la torture, pour ainfi dire, cle différentes façons, elle jaillifioit de la gueule d'un lion ou d'un monftre marin ; maintenant, tout à fait ruftique, elle ne fert qu'à arrofer de vils haricots, ou de miférables choux : les lions \& les veaux mârins font remplis de toiles d'araignée, oubien 


\section{R U R A LE. Liv. I.}

les oifeaux vont y bâtir intérieurement leurs nids.

Il y avoit autrefois un grand bafIIONS FOUR fin qui fervoit de réfervoir aux eaux $\mathbb{R} \boldsymbol{L}$. de notre maifon de campagne : une gondole nous portoit autour de nos prés fleuris, \& nous nous amufions à préienter un apas aux avides poirfons, ou à nous repofer fous quelque arbre touffu, pour goufer la fraicheur de l'eau, \& nous derrober aux ardeurs du foleil. Hélas! puisje le croire? cette gondole vendue avec le bois de chauffage, a eu le même fort, \& a garni les foyers pour fervir au feu d'aliment. La truite, ce charmant poiffon qui nageoit vers la rive où nous venions ordinairement nous affeoir, \& qui par le mouvement de fes yeux \& de fa queue, fembloit mendier les petits morceaux de fruit $\&$ de pain dont nous faifions provifion pour elle, a cédé le féjour de ces eaux, aujourd'hui dormantes \& limoneufes, aux importunes grenouilles. L'habitation des paons eft maintenant infectée par la mauvaife odeur des pouTome $I$. 


\section{E CONOMIE}

$\overline{P R E C A}$ les qui y couchent; les pigeons, amaTIONS POUR teurs des maifons de campagne pro-

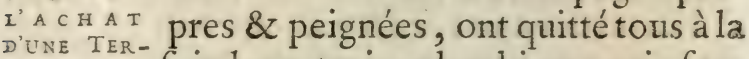
RE. fois leurs trois colombiers, qui, foutenus par des colonnes de marbre, fervent à préfent de retraite aux rats $\&$ au finiftre hibou.

Nous aurions nous-mêmes changé de maifon, fi la nôtre, quelque avilie qu'elle foit, n'étoit encore plus agréable que les autres maifons voifines : car, malgré les ravages qu'on y a faits, \& fa rufticité actuelle, elle conferve toujours, en dépit de fes maîtres, une grande partie de fon éclat, \& plaira toujours par le foin que prend la nature de la dédommager de fon ancienne décoration.

Ce font de ces maifons négligées pour l'ornement, qu'il convient d'acheter, illuftre Lamoignon, quand une heureufe fituation eft leur principal agrément, \& quand des fources intariffables, jointes à la fertilité de la terre, en font la richeffe.

Defcription Si quelqu'un eft curieux de conducharcau de noître tous les embelliffemens que
Baville. 


\section{R U R A L E. Liv. I.}

l'art peut donner à des maifons, à des eaux, \& à des jardins avanta- PRECAUgeufement fitués, qu'il aille voir le $\mathrm{C}^{\prime}$ A château que vous avez fait confrui- $D^{\prime} U$. re fur la Terre de Courfon : qu'il examine la richeffe du fond, la variété des fleurs, la fertilité des vergers, l'agrément des bois, les belles avenues, \& la fuperbe architecture des bâtimens : \& qu'il foit émerveillé de l'efprit d'ordre, d'invention \& de détail qui a préfidé à ces ouvrages, foit qu'au loin il admire l'enfemble de ce château, \& que fes yeux fe repaiffent par avant-goût des charmes d'un beau lieu, foit qu'étant parvenu à la premiére entrée, \& qu'indécis entre l'art \& la nature, il arrête fes regards fatisfaits tantôt fur le château même, tantôt fur les plaines qui font à l'entour.

On fe plaît fur tout à regarder la ftatue de marbre qui repréfente, dirai-je votre augufte pere, ou celui du peuple : on ne peut s'empécher de contempler (34) fes traits avec une fecrette vénération; ces mêmes traits que Thémis, la plus 


\section{8}

$\overline{P R E C A U}$ TIONS TOUP I'A C H A T TUNE TER. RE.

furre protectrice des hommes, emprunta autrefois pour dicter des loix à ce Royaume.

(35) Comme votre éloquence avoit foutenu les prétentions de la Sculpture \& de la Peinture, lorfque ces delix Arts fameux qui enfeignent à rencire fidélement des figures fur le marbre, ou à les animer fur une toile avec un pinceau \& des couleurs, demandérent à être maintenus dans les priviléges d'Arts libéraux; ils veulent aujourd'hui, par reconnoiffance, tranfmettre votre image à la poitérité. Mais vous, digne fils, quoique votre pere n'ait befoin, pour perpétuer fon nom, que de fa propre renommée, plus durable que le marbre, vous défirez que cette marque de diftinction foit plutôt accordée à ce grand Homme ; afin que l'air majeftueux du pere, \& la piété filiale, foient à jamais confervés dans le même monument.

Que dirai-je des autres merveilles qui le préfentent de toute part dans ce féjour enchanté ? Soit qu'on aille fur les lieux les admirer, foit qu'on 


\section{RU R A LE. Liv. I.}

s'arrête \& qu'on les parcoure des yeux, la nature, pour ne point fati- io guer la vîe en n'offrant qu'une per- ' $^{\prime}$ с с н $\mathrm{A}$ 工 fpective vague \& indéterminée, la D’U I I Rfixe agréablement par de charmans côteaux qui régnent de toute part, $\&$ où l'on voit dans tout leur éclat les richeffes de Bacchus \& les tréfors de Cérès. Il femble que la terre ait raffemblé, dans l'étendue du terrein que les yeux peuvent parcourir, toutes les productions qu'elle ne diftribue au refte de l'univers qu'avec la plus grande oconomie.

On ne voit point ailleurs dans les autres bâtimens autant de dignité fans fafte, ni tant d'agrémens \& d'élégance, avec fi peu d'ornemens recherchés; aucun bois ne fournit ailleurs un auffi frais ombrage, ni d'auffi délicieufes retraites; les arbres n'ont nulle part autant de grace $\&$ de fertilité, \& ne font auffi bien taillés; jamais figues \& poires en efpalier n'ont tant fait de plaifir : on ne voit point la même fymétrie dans les autres parterres, ni d'aufif beaux légumes dans aucun jardin; 


\section{CE O NOMIE, \&C.}

PREAU- quoique pourtant, dans votre $a b-$ trons rour fence, les fleurs \& les arbres fe né-

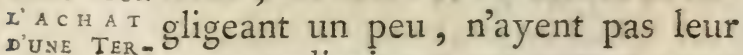
RE. grace ordinaire : car autant vous regrettez ces lieux, autant ils défirent votre retour. Qu'ils ayent du moins la confolation de pofféder votre aimable fils de Courfon, de le délaffer de fes travaux, de raffafier leurs défirs en contemplant l'image du pere dans ce fils chéri, qui, prefque votre égal, \& votre concurrent en mérite, fait votre fatisfaction en marchant dignement fur vos traces.

Pour vous, quelque agréable que foit le château de Baville, fitué aux environs de Paris, perdez l'envie que vous avez de le revoir, \& gardez-vous de dérober au Prince \& au Peuple votre utile períonne, dont les Dieux, pour gage de leur protection, leur ont fait préfent. C'eft un crime à tout homme chargé des intérêts publics, de bannir les foins, $\&$ de ne vivre que pour lui.

Fin du Livre premier. 


\section{REMARQUES}

\section{Sur le premier Livre.}

T. Pere Vanniere rend compte des motifs L qui ont déterminé fa Mufe à choifir les Travaux champêtres, par préférence à d'autres fujets. Il invoque enfuite le vrai Dieu an lieu des divinités de la Fable, \& fait l'expofio tion des matiéres qui doivent remplir les feize Chants de fon Poème. Il dédie fon Ouvrage à M. de Lamoignon, alors Intendant du Languedoc, \& paffe aux précautions que l'on dnir prendre dans l'achat d'un fond de Terre. II parle de la fituation des lieux, de la qualités de l'air \& des eaux, des orremens, des revenus, des batimens, des indices d'une bonne terre, de l'inconvénient qu'il y a d'avoir un manvais voifin, \& des réparations de la maifon. L'Aureur détaille les premiers foins qu'on doit donner à la terre. Il faut épierrer les champs, zenouveller l'engrais des prairies, planter des arbres, deffécher des marais. De-là il prend occafion de rappeller l'ourrage qu'entreprirent autrefois les Romains, pour faciliter l'écoulement des eaux d'un marais à travers une montagne ; ce qui améne l'éloge du Canal de Languedoc, pour lequel le fameux Riquet fit percer la même montagne. Viennent enfuite les moyens de décourrir les four- 
ces, la réfutation de la baguette divinatoire; l'origine des fontaines, les feux fouterreins. Les différentes fituations pour une maifon de campagne font difcuićes, \& l'Auteur dit un mot de tous les matériaux néceffaires à la conftruction, \& de tontes les efpéces de bâtimens qui concernent une maifon ruftique. Il fait enfuite la diftribution du fond en prairies, en vignobles, en terres labourables, \& en bois; ce qui lui donne lieu de parler de la maifon de plaifance des Jéfuites de Touloufe, de regretter fes bois de décoration qu'un intérêt domeftique a fait abbattre, \& de faire le portrait \& l'cloge de quelques Jéfuites qui fe promenoient dans les allées de ce bois.

\section{(1) [Qusiqu'aujourd'bui l'on montre ma-} liznement au doigt ceux qui vous porient. ] Le nom de Poëte eft aujourd'hui une dénomiriation injurieufe, on rougit de le porter : on ne dit de quelqu'un qu'il eft Poëte, qu'avec l'air, le ton, \& tous les accompagnemens de mépris qui dégradent le talent \& la perfonne. On montre un Poete comme un fou, on lui parle comme à une marote, \& on ne le voit chez foi qu'à huis clos. Voici comme Madame Deshoulieres décrit le défagrément de cet état dans une de fes Epitres. Je n'en citerai qu'une partic.

A rêver dans un coin, on fe trouve réduit ;

Ce n'eft point un conte pour rite.

Dès que la renommée aura femé le bruit 


\section{Sur le premier Livte.}

Que vous favez toucher la Lire,

Hommes, femmes, tout vous craindra,

Hommes, femmes, tout vous fuira ;

Farce qu'ils ne fauront en mille ans que vous dire.

Ils ont là-deflus des travers

Qui ne peuvent fouffrir d'excufes :

Ils penfent, quand on a commerce avec les Mufes,

Qu'on ne fait faire que des vers.

Et plus bas :

Plus d'un exemple vous répona Des malheurs dont ici je vous ai menacée. Ie favoir nuit à tout, la mode en eft paffée ; On croit qu'un bel efprit ne fauroit être bon.

(2) [Quoiqu'elles ne leur content rien.] II y a dans le texte : aufint cuncta licet. Cet enrdroit eft imité d'Horace.

\section{Pictoribus atque Poetis}

2) nidlibet audendi Semper fuit agua poteftas. Art. Poet.

(3) [Le travail ne coute point quand le fujet plait. ] Horace dit aufli, en parlant des joueurs de paume :

Molliter aufferum fudiofalleme laborem. I. II. Sat, II.

(4) [Le plaifir é la nature me rendrone Poëte, Ji je n’en ai pas le génie. ]

Sina:ura negat, fasit indignatio verfum. Juvenal.

(s) [O vous! l'honneur ól'appuide votre Maifon, Illuftre Lamoignon. ] Nicolas de la Tome $I$.

G 
Moignon, Seigneur Comte de Launai Courfon, \& aufi Seigneur Marquis de la Mothe en Poitou, par érection du mois d'Octobre I700, mais plus connu fous le nom de Bafville, qui lui avoit été donné dans fa jeuneffe, étoit fils de Guillaume de Lamoignon, Premier Préfident au Parlement de Paris. Il fut pendant trente-trois ans Intendant en Languedoc, \& mourut Confeiller d'Etat ordinaire le I7 Mai I724, ayant eu pour fils UrbainGuillaume connu fous le nom de Courfon, fucceffivement Intendant de Rouen \& de Bordeaux , aufli mort Confeiller d'Etat ordinaire, \& au Confeil des Finances, le I 2 Mars 1742 . Celui-ci a été pere de Guillaume de Lamoignon de Montrevault, aujourd'hui l'un des Préfidens au Parlement de Paris.

(6) [Quoique l'Hérésse.] Il eft ici queftion des Proteftans des Cevennes, qui s'étoient révoltés. Il y a eu aufti dans les Cevennes des Fanatiques pendant la guerre de 1689 , qui avoient été fottement abufés par de prétendues prophéties du Miniftre Jurieu.

(7) [ Laiffoins à l'opulence fes vaftes domaines. ] Virgile, Géorg. Liv. II. a dit auff:

\section{Laudate ingentia rura}

Exigsum coltto.

- (8) [Il faut connoître.]

Chacun fe dit ami ; mais fou qui s'y repofe :

Rien n'eft plus commun que ce nom,

Rien n'eft plus rase que la chófe. LA Fontaine, Fable 77 . 


\section{Sur le premier Livre.}

Plût-ì-Dieu qu'on obfervat toujours la maxime de Vanniere! on ne feroit pas fi fouvent victime de la méchanceté des faux amis, de leur indifcrétion, ou du moins de leur imprudence. Eh ! qu'importe, dit quelque part M.de Fontenelle, qu'on foit bleflé par un furieux ou pa: un étourdi ? on n'en eft pas moins blefie. La Fontaine, dans fa Fable de l'Ours $\&$ de l'Amateur des jardins, dit auffi bien lenfément :

Rien n'eft fi dangereux qu'un ignorant ami, Mieux vaudroit un fage ennemi.

(9) [Et fi quelque béte de votre troupesn.] C'eft ainfi que dans la Fable des animaux malades de la pefte, l'Afne eft condamné pour une légére peccadille.

L'Afne vint à fon tour, \& dit j'ai fouvenance

Qu'en un pré de Moines paffant, Ia faim, l'occafion, l'herbe tendre, $\&$ je penfe Quelque diable aufi me pouffant, Je tondis de ce pré la largeur de ma langue; Je n'en avois nul droit, puifqu'il faut parler net. A ces mors on cria haro fur le baudet: Un Loup quelque peu clerc, prouva par fa hatangue, Qu'il falloit dévouer ce maudit animal, Ce pelé, ce galeux, d'où venoir tout le mal: Sa peccadille fut jugée un cas pendable. Manger l'herbe d'autrui! quel crime abominable :

(10) [ Et la victoire wous coute fo cher.]

$G$ ij 
Tout le monde fait la Fable de l'Huitre $\&$ des Plaideurs : en voici feulement la morale.

Mettez ce qu'il en coure à plaider aujourd'hui, Comprez ce qu'il en refte à beaucoup de familles : Vous verrez que Perrin tire l'argent à lui, Et ne lailfe aux Plaideurs que ie fac $\&$ les quilles.

(II) [ L'amitié par tout a des donceurs.] Rien n'eft fi doux qu'un ami, quand il a de la candeur \& de la difcrétion : mais que ces qualités font rares !

Qu'un ami véritable eft une douce chofe!

I! cherche vos hefoins au fond de votre cœur,

11 vous épargne la pudeur

De les lui découv rir vous même.

Un fonge, un rien, tout lui fait peur,

Quand il s'agit de ce qu'il aime.

L. Foutaine, Fable des deux Amis.

Il n'eft point de plaifir égal à celui d'ouvrir fon cœur à un ami fûr, de dépofer dans fon fein fes plus cheres penfées, \& de lui être attaché par le lien de l'honneur, de la vérité, du goût, \& du plaifir. C'eft ainfí que le cœur de David, felon l'expreffion d'un Auteur, s'étoit interné avec celui de Jonathas : conglutinata erat anima David anime Jonathe. Il y a dans la Henriade un morceau fur l'amitié qui a bien de l'élévation.

Henti de l'amitié fentit les nobles flammes. Amitié, don du ciel, plaifir des grandes ąmcs, 
Anuitié, que les Rois, ces illultres ingrats, Sont affez malheureux pour ne connoître pas.

Horace s'exprime avec tranfport, quand il décrit la rencontre qu'il fit à Sinueffe de trois de fes amis. Dieux! quels amis c'étoit ! les trois plus grands génies, \& les trois plus belles ames de Rome : Virgile, Plotius, Varius.

Poffera lux oritur mulio gratifina : namque Plotius, \& Varius Sinueffe, Virgiliufque Occurrunt, anima quales neque candidiores Terra tulit, neque queis me fit devinetior alter: O qui complexus \& gasdia quanta fuerunt! Nil ego contulerim jucundo fanus amico.

(I.2) [ Car la terre, cettenourrice des homsnes. ] Cet endroit eft imité de Columelle : - La terre, dit-il, a reçu de l'Auteur de la nan) ture une jeuneffe éternelle; elle a toujours * enfanté \& enfantera toujours, \& il n'eft pas ") à craindre qu'elle tombe dans la vieilleffe ") \& la caducité comme l'homme. “ Lucrece n'eft pas de cet avis dans fon fecond Livre : il penfe que la nature s'elt ufée à force de produire; que les animaux font beaucoup plus petits que dans le premier âge du monde, \& que tout dépérit fenfiblement. Cette opinion eft fauffe : la nature eft la mềme; \& les animaux feroient auffi robuftes \& auffi grands qu'autrefois, s'ils vivoient à leur gré dans les bois. Yoici les vers de Lucrece :

$\mathrm{G}$ iij 
Jamque adeo fracte eft aras effaraque tellus, Vix cnimalia parva creat gra cuncla creavit Sasla, deditgise ferarum ingentia corpora partw.

(I3) [ Confruifez une raye couverte. ] Cela s'appelle aufi dans quelques endroits une pierrée. Voici comme les Autcurs qui ont écrit fur le ménage de la campagne \& la culture des terres, s'expliquent à cet égard. »On creufe en terre une rigole profonde de » trois pieds, on en remplic la moitié de pe" tits cailloux, \& l'autre moitié avec une ") partie dée la terre qu'on a tirée de la rigole * mème, \& on l'égale au niveau du champ. "Quand on n'a ni pierres propres, ni gros * graviers pour garnir le fond de la rigole, $\gg$ on y met des javelles de farment bien liées, „\& affez groffes pour la garnir à moirié, \& ») l'on jetre des feuillages par deffus. Aux » deux bours de chaque raye on fait avec áe » grandes pierres deux efpéces de petit pont ») pour foutenir les terres, \& entretenir le: 2) paftage \& l'écoulement des eaux. Par ce » moyen les terres humides fe defféchent, \& w deviennent très-bonnes \& très-fertiles en „ bled.

(I4) [ Les Romains, maîtres alors d'une grande partic du monde.] "Ils defféchérent 2s autrefois un marais aux environs de Be-* "ziers, près d'un village qu'on appelle Mon»tedi ; \& pour l'écoulement des eaux, per" cérent la même montagne que le célébre » Riquet, Auteur du Canal de Languedoc, 


\section{Sur le premier Livre.}

$\rightarrow$ \& dont le nom fera immortel, fit auffi crett") fer pour y pratiquer un paffage aux bat") teaux a Ceci eft tiré d'une note latine du Pere Vanniere.

(Is) [Lorqu'on perça la montagne à l'occafion du fameux canal. ] Voyez le Dictionnaire de Moreri. Il a depuis fon embouchure dans le port de Cette jufqu’à Touloufe, plus de foixante-dix lieues de longueur. Il a fallu fouvent le couder \& le courber pour gagner le niveau autour des montagnes, l'affermir fur des pilotis dans des terreins mouvans, l'appuyer fur des ponts ou des arches de pierre dans les vallées, efcarper ou abbattre certaines montagnes, en percer d'autres \& les voûter pour le recevoir; on a excavé plus de deux millions de toifes cubes de terre, \& plus de cinq mille de rochers; on a conftruit cent quatre éclufes pour élever ou defcendre les barques, feize énormes chauffées pour repouffer les eaux incommodes, vingt-quatre épanchoirs pour lacher les eaux du canai, quand on craint qu'il ne s'empliffe de fable ou de limon. On compie dans cet ouvrage plus de I 40000 toifes cubes de maçonnerie en pierres, à quoi il faut ajouter les jettées de 200 toifes, \& le mole de 500 , qui couvrent à préfent le port de Cette.

( I6) [ Alors cet ancien monument de los grandeur Romaine. ] Il y a dans le texte:

\section{Prifcofque labores}

Oppofuit noftris Romana potentia captis.

G iiij 
Ce vers eft bien majeftueux, \& donne une belle image de la grandeur Romaine : il femble qu'on voye le génie de Rome \& celui de la France, rivaux l'un de l'autre, \& furpris de leur rencontre, fe difputer la fupériorité fous la voûte de la montagne. Cette penfée feroit honneur même à Homere \& à Virgile.

( I 7 ) [ Ce monument eft votre ouvrage, fameux Riquet.] La jonction des deux mers avoir toujours paru impoffible; parce qu'entre la Méditerranée \& l’endroit où la Garon ne commence à être navigable, il n'y avoit que quelques filets d'eau, \& un intervalle de plus de quarante lieues. Cependant, quoique ce terrein fût immenfe, inégal, \& fort élevé vers le milieu, au-deffus du niveau de la mer, M. Riquet, de la ville de Beziers, eut affez de pénétration pour concevoir nettement le projet d'un canal où les barques franchirosent cette hauteur, \& pafferoient en montant \& defcendant de Touloufc à la Méditerranée, \& de la Méditerranée à Touloufe. Il y a long-tems qu'on a propolé de faire en Bretagne deux canaux également uti. les, l'un qui joindroit la riviére de Rennes à celle de Dinan, \& l'autre qui formeroit une communication entre la Vilaine \& la riviére de Laval. Il réfulteroit de ces deux jonotions un commerce confidérable qui enrichiroit plufieurs villes, \& fur tout Rennes où le commerce eft mort, \& où l'habitant n'eft pas dans l'aifance. Je crois \& l'on doit penfer que des motifs plaufibles ont empêché l'exécution 
de cette entreprife : mais le zéle de $M$. le Duc d'Aiguillon, ainft que des principaux chefs des Etats, pour les vrais intérêts de la Province, \& le choix éclairé qu'on a fait de M. de la Bourdonnaye, pour remplir la place de Procureur Général Syndic, font efpéyer que ces canaux feront commencés \& même achevés en peu de tems.

( I8) [ Et non far l'intelligence de la baguette. ] On a découvert la fauffeté des merveilles qu'on attribuoit à cette baguetre ; on a démontré l'impoffibilité de fa prétendue action fur les tréfors \& fur les fources, \& l'on en fait à préfent auffi peu de cas que du petit bâton d'un joueur de gobelets.

( I9) [Avec des baguettes courbes.] C'étoit un petit bâton recourbé par le haut en forme de croffe, dont fe fervoient les Augures dans leurs fonctions, pour défigner dans le ciel les quatre points principaux qui deroient fervir à déterminer les bons ou les mauvais augures.

(20) [Soit que les eaux de pluye.] Le Pere Vanniere décrit ici différentes opinions fur l'origine des fontaines, \& paroit fuivre celle de Defcartes, qui croyoit que l'eau de la mer fe répandolt fous terre de tout cûté, \& que trouvant au pied des montagnes des ou. vertures fpacieufes, \& un dégré de chaleur capable de la faire monter en vapeurs, fans élever avec elle les fels que leur poids fair demeurer au fond, le haut des cavernes arrêtoit \&. épaiftifoit cetre vapeur, \& en formoir dey 
ruiffeaux , comme le couvercle d'un alambis réfout en eau la vapeur qui s'y attache.

Le Pere Rapin, qui a aufí parlé de l'origine des fontaines, après avoir expofé différens fentimens, en adopte un contraire à celui du Pere Vanniere. Il croit que l'eau de la mer vient en droiture juíqu'aux fontaines, qu'elle dépofe fon fel \& fes immondices en fe filtrant à travers les terres, \&r qu'elle s'épure ainfi à force de paffer au milieu des rochers \& des fables qu'elle rencontre.

Interior nam cum raro fit corpore zellss, Inque Specus altos imperfofo oque meatus Interdism defcendat, of in loca concava fidat $U_{n d a}$ maris, rara per curva foramina terro Perque finus ipsos furtivo lubrica lap su Paulation infinuat fefe, cacumgue per imos Aut quarit calles ster, aut molitur eundo. Arque ubicunque magis rupta de vifocra terre Diducunt crebroque patent odapersa mestu Tum largus magis atque magis fe fundit agua fors Idcirco latices manant ex aquore falfo Non falf : nam cum multium tellure fub imâ Musliplices Se per Salebras of acerba locorum Perque car os flexus \& inaquales per arenas Torfit agens maris anda, falis qua craffa marimo Materies berebat aqua purgatur : \& omne Ces per cola means vitium derergitur unda.

M. Pluche eft d'un fentiment contraire à toutesces opinions, \& foutient que les vapeurs de la mer font beaucoup plus que fuffifantes 
pour fournir d'eau la furface de la terre $\&$ le lit des riviéres; que les pointes des montagnes font deftinees à arrêter les vapeurs de la mer qui flottent dans l'air; que les efpaces qui féparent ces pointes font les bafins prepares pour recevoir les brouillards epaifis, \& les nuées précipitées en pluye; que leurs entrailles font nos chàteaux d'eaux ou nos réfervoirs communs; qu'enfin les ouvertures latérales par lefquelles les eaux coulent, font placées à l'égard des plaines de façon que l'eau y puifle tomber, s'y répandre, \& les fertilifer plutón que de prendre fa route par deffous terre, \& de regagner ainfi la mer, apres avoir fait ure circulation inutile. Le fentiment de M. Pluche eft folidement prouvé $S$ appuyé des obfervations de M. Mariote, qui a calcule combien il peut tomber de pouces d'eau fur la terre en un an.

(2I) [ Semblo par fes coajemens répéser los anciennes injures despoyjans de Lucit.] Les habitans de cette contree furent changés en grenouilles, pour avoir accablé d'injures Latone, mere de Diane \& d'Apollon qu'elle portoit encore dans fon fein, \&: pour lavoir empéchée de fe défaltérer au bord du marais ou ils éroient à couper des joncs. Ovide L. 6 . Métamorphofe 4. termine ainfi certe Fable:

\section{Sed nune quogue turpss}

Litibus exercent linguas, pulfoque pusiore

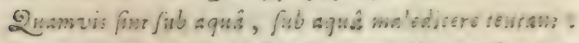

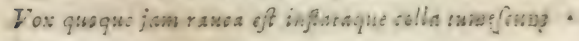

Ip sague dilatant parulos convitian rionsso. 
(22) [Et des bétres. ] Le Pere Vanniere a railon de parler ainfí du hêtre, parce que ce bois travaille tant qu'il ditre, \& tourmente continuellement les affemblages.

(23) [Il échangeroit l'or és l'argent avec de vil papier. ] Il paroît que l'Auteur a ici en vûe les Billets de banque, qui ont fait tant de bien \& tant de mal daus la France. L'inimitable Auteur des Lettres Perfanes a plaifamment allégorifé cette révolution dans les Finances. "D Dans une ine près des Orcades, il ") naquit un enfant qui avoit pour pere Eole, $n$ Dieu des Vents, \& pour mere une Nimple ") de Calidonie. ... Il apprit dans fes voya" ges que dans la Bétique l’or reluifoit de ss route part : cela fit qu'il y précipita fes pas. " Il y fut fort mal reçu de Saturne qui régnoit "pour lors. Mais ce Dieu ayant quitté la n terre, il s'avifa d'aller dans tous les carre") fours, où il crioit fans ceffe d'une voix "rauque : Feuples de Bétique, vous croyer ๖) être riches parce que vous avez de l'or \& " de l'argent; votre erreur me fait pitié. n Croyez-moi, quittez le pays des vils mé") taux, venez dans l'Empire de l'Imagina* tion, \& je vous promets des richeffes qui " vous étonneront vous-mêmes. Auffitôt il " ouvrit une grande partie des outres qu'il " avoit apportées, \& il diftribua de fa mar"s chandife à qui en voulur. Le lendemain il v revint, \& s'écria : Peupies de Bétique, ¿ voulez-vous être riches? Imaginez-vous - que je le fuis, \& que yous l'êtes beaucoung 


\section{Sur le premier Livre.}

vaphifi. Mettez-vous tous les matins dans l'ef-

" prit que vorre fortune a doublé pendant la

" nuit. Levez-yous enfuite ; \&, fi vous avez

1) des créanciers, allez les payer de ce que

1) vous aurez imaginé, \& dires leur d'imagi-

") ner à leur tour. A quelques jours de lầ il » revint encore, \& dit : Peuples de Bétique, 2) je vous avois confeillé d'imaginer, \& je v) vois que vous ne le faites pas. Hé bien! à "préfent je vous l'ordonne. J'apprens que 1) quelques-uns de vous font affez déteftables ") pour conferver leur or \& leur argent : s encore paffe pour l'argent. Mais pour de » l'or!.... Mais pour de l'or $! .$. Oh!

" cela me met dans une ind:gnation! . . . .

n) Je jure par mes outres facrées, que s'ils ne D) viennent me l'apporter, je les punirai févé1) rement, \&cc. "

(24) [Les Languedociens.] Ces peuples s'appelloient anciennement Tectofares. C'étoient du tems cies Gaulois les peuples qui habitoient une partie de la Gaule Celtique, entre lles Pirenées \& les Cevennes, \& qui étoient fi puiffans \& fi nombreux, qu'il s'en détacha une colonie pour traverfer la Gréce, alors triomphante. Ils furent s'établir au-delà de la Phrygie $\&$ de la Cappadoce, fans qu'aucun des peuples voifins ofat les attaquer ni les inquiéter. Pline \& Florus les appellens Tholiftobogi.

(25) [Le nervenx foffoyeur. ] Ce mot a. deux fignifications; il fert à défigner les gens qui ouvrent les foffes pour enterrer les morts, 
ainfi que les ouvriers qui font des foffés dans les campagnes pour l'écoulement des eaux. J'héfitois d'employer ce mot, dans la crainte que le Lecteur ne confondît ces deux forzes d'ouvriers : mais on m'a dit que, pour exprimer ce dernier fens, il n'y avoit point d'autre terme généralement connu en France. En Bretagne on appelle ces gens Conroyeurs ou Lambalais, parce qu'ils font prefque tous des environs de Lamballe, \& la terre glaife dont ils fe fervent pour les foffés fe nomme $d u$ conroi. Mais ces termes font locaux, ufités feulement dans cette province, \& re s'entendroient point ailleurs.

(26) [La rujée Theftilis. ] Sous ce nom on comprend généralement toutes les villageoifes. C'eft aufli dans un fens générique que Virgile l'a employé. Ecl. 2 .

Theftilis or rapido fefls meforibus aftu Allia ferpillum queberbas contundit olentes.

Théocrite, Idylle 2. dome ce nom à une $\mathrm{em}=$ poifonneufe.

(27) [La paver.] Virgile ne confeille pas de paver l'aire, mais de la pétrir en quelque forte, \& de l'affermir avec de la terre vifqueufe.

Area cum primis ingenti aquanda cylindro Et vertenda manu ê cretâ folıdanda tenaci.

(28) [La Garonne.] Cette riviére a $\int_{2}$ 


\section{fur le premier Livre.}

ource dans les Pirenées près de la Catalogne, traverfe le haut Languedoc \& toute 13 Guyenne; \&, ayant reçu la Dordogne, elle prend le nom de Gironde fous lequel elle fe décharge dans la mer de Gafcogne, près de la Tour de Cordouan. Il ya dans les Pirenées quantité de mines de fer ; c'eft pour cela que le Pere Vanniere dit que les habitans manient avec des tenailles de groffes maffes de fer, parce que la plupart font forgerons. Il y a dans le texte mafjas Cinalybis. Le mot Chalybs dont on fe fert pour exprimer l'acier ou le fer, dérive des Chalybes, peuples qui forgeoient beaucoup de fer, \& qui felon Pline habitoient les bords du fleuve Thermodoon dans la Cappadoce; mais qui, felon Juftin \& plufieurs aurres Auteurs, font les mémes que Ies habitans des Pirenées. Virg. Georg. L. I.

India mittit ebur, molles fua thura fabai.

At Chalybes nudi ferrum.

E.t dans un autre endroit il employe le mor Chalybs pour l'acier.

Vulnifcusque Chalybs vaita fornace liquescit.

Le Poëte Flaccus L. 4. Argonaut. parle auth des Chalybes.

Non ità fit metrenda tibi savifflme quanquam

Gens Chalybum duris patiens cui cultus in arvis

It tonat affliciâ femper domus ignea margâ. 
Rouffeau, dans fa Cantate des Forges de Lemnos :

C'eft ainfi que Vulcain, par l'Amour excité, Armoir coatre lui-même une époufe volage, Quand le Dieu Mars encor tout fumant de carnage, Arrive l'œil en feu, le bras enfanglanté. Que faites-vous, dir.il, de ces armes fragiles, Fils de Junon, \& vous Chalybes affemblés? Eft-ce pour amufer des enfans inutiles, Que cet antre gémit de vos coups redoublés ?

(29) [ Voyez combien les Anglois ont a Souffrir.] Il en meurt beaucoup de la maladie de confomption, que leur caufe, dit-on, la fumée du charbon de terre. Quand ils font attaqués de cette maladie, ils font dans l'ufage de venir ì Montpellier pour refpirer un air plus pur. Le Pere Vanniere fait fentir avec efprit que les François feront bientôt dans le même cas; à moins que les Grands-Maîtres des Eaux \& Forêts ne prennent des précautions pour faire planter de nouveaux bois, ou pour empêcher la trop grande confommation qui s'en fait. Il y a des gens qui foutienment qu'ayant foixante ans nous ne pourrons plus nous chauffer qu'avec du charbon de terre. Voici ce que difent les Auteurs du Dictionnaire Enciclopédique au mot Bois : » Le bois de chauf2) fage ne peut devenir extrêmement rare \& "d'un grand prix, fans chaffer de la capitale s) un grand nombre de fes habitans. Or il eft w conftant que la capitale d'un royaume ne $\Rightarrow$ peur être attaquée de cette maniére, fans 


\section{fur le premier Livre:}

n que le refte du royaume s'en reffente. Je

b he prérois qu'un reméde à cet inconvé-

") nient ; \& ce reméde eft même de nature à

" prérenir le mal, fi on l'employoit dès à

" préfent. Quand les forêts dẹs environs de

》) la ville furent épuifées, il fe trouva un hom-

2) me qui entreprit d'y amener à peu de frais

") les bois des forèts éloignées, \& il y réuffit.

"Lorfque la négligence, dans laquelle on per-

s: fifte, aura achevé de détruire les forêts

ग) éloignées, il eft certain qu’on aura recours

s) au charbon de terre; \& il eft heureufement

w) démontré qu'on en trouve prefque par

D) tout. Mais pourquoi n'en pas chercher, \&

n ourrir des carriéres dès aujourd hui ? Pour-

" quoi ne pas interdire l'urage du bois à tous

v les états \& à toures les profeflions dans lef-

* quels on peut aifément s'en paffer ? Car il

》) en faudra venir là tôt ou tard; \& f fil l'on s'y

" prenoit plutôt, on donneroit le tems à nos

w) forêts de fe rétablir : \& en prenant pour

„) l'avenir d'autres précautions que celles

3) qu'on a prifes pour le paffé, nos forêts, mi-

») fes une :ois fur un bon pied, pourroient

") fournir à tous nos befoins, fans que nous

3) euffions davantage à craindre qu'elles nous

2) manquaffent. Il me femble que les vûes que

2) je propofe font utiles: mais j'avoue qu'el-

") les ont un grand défaut ; celui de regarder ఐ plutôt l'interêt de nos neveux que le nôtre,

3) \& nous vivons dans un fiécle philofophique ") oì l'on fait tout pour foi, \& rien pour la " poftérité.

\section{Tome I.}


(30) [ Nous votis pleurons encore, Bois charmant.] L'Auteur exprime, avec une éloquente douleur, les regrets qu'il a d'avoir vâ abbattre ce bois. La defcription qu'il en fait, ainfi que des autres agrémens de la maion de plaifance lui tient lieu d'Epifode pour terminer fon premier Livre.

(3I) [Vousavez etécouronné tant de fris.] On reçoit à l'Académie de Touloufe ceux qui ont remporté tro:s prix. Le Pere Cleric avoit déja été couronné huit fois.

(32) [Soit que digne émule de votre frere.] Campiftron a tait plufieurs Tragédies, mais très-peu de bonnes: il n'e!t refté au Théàtre François qu'une ou deux de fes piéces, encore les joue-t-on rarement. C'eft le fort qu'ont les Tragédies de prefque tous les Autenis modernes; elles tombent dans l'oubli dès leur vivant.

(33) [ Par des vers auffi touchans que les acceias d'Orplée. ] Tout le monde fait qu'Orphée defcendit aux Enfers pour chercher fa temme Euridice, \& que Pluton fut fi charmé des fons de falire, qu'il lui permit d'emmener fa femme. Qu'il y a peu d'Orphées aujourd'hui à tous égards! Voyez le bel Epifode qui eft à la fin du quatriéme Livre des Géorgiques.

(34) [Ses traits avec une fecrette vénération.] Guillaume de Lamoignon fut, en qualité de Premier Préfident du Parlement de Paris, à la tête de la Commiffion nommée par le Roi pour la rédaction des Ordomnances. 


\section{fur le premier Livre.}

(3s) [Comme wotre éloguence.] Vanobfsal Sculpteur, ayant fait des bis-reliefs pour une Dame, \& n'ayant demandé fon payement qu'un an aprés avoir livré fon ouvrage, on oppofa au Sculpteur la prefcription annale de la Coutume de Paris, qui rend la demande d'un Artifan nulle, s'il n'a fait des diligences dans l'année; le Sculpteur répondit que l'article de la Coutume éto it pour les Arts mechaniques: mais que la Peinture \& la Sculpeure font des Arts libéraux. M. de Lamoignon plaida pour Vanobftal, \& l'Académie fit imprimer fon Plaidoyer. Elle fit pius : pour reconnoitre le fervice que POrateur avoit rendu aux Arts, elle chargea M. Girardon de faire fon bufte, \& M. Champagne de faire ton portrait. M. le Brun fut engagé à folliciter M. de Lamoignon de fouffrir cette marque de diftinction; mais l'Orateur fut conftant à la refufer, \& tout ce quion put obtenir de lui fut que l'on feroit le bufte \& le portrait de M. le Premier Préfident fon pere: ce qui fut exécuté. M. Clement, connu par beaucoup de devifes \& d'infriptions eftimées, fit celle-ci qui fe lit au-deflous du bufte.

2uod Aris immunitates apud amplifjimum

Ordinem farrocinio preclare deffenderit,

Grati animi nonimentum fibi nuncspatum

Optimo parenti confecrari maluerit.

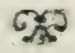

$\mathrm{Hij}$ 


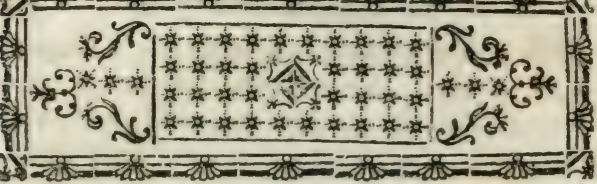

\section{ब C O N M I E \\ R U R A L E.}

\section{LIVRE SECOND.}

Choix des Domeftiques, Ef leurs différentes fonctions dans la culture des terres.

Le laboureur. $\mathrm{E}$ V AIS maintenant enfeigner à bien choifir les Domeftiques; \& puifque celui qui trace les fillons les plus droits, eft l'ouvrier qui laboure le plus utilement, ayez-en un fur-tout d'une taille avantageufe, qui, fans être cruel, ne donne de la crainte à fes bœufs que par fon extérieur ; qu'il ait les bras nerveux, l'air formidable, \& la main retenue ; 


\section{R U R A I. Liv. II.}

que content de les menacer, il n'aug- $\overline{C H O I X D E S}$ mente pas, à force de coups, la du-D OMEST Ireté de leur travail, mais qu'il les $Q 026$.

excite par des termes d'encouragement, \& qu'il fe faffe obéir par les éclats de fa voix, plus que par les coups d'aiguillon. Un grand corps, appuyé fur le manche de la charrue, fait des fillons bien plus profonds, \& remue bien plus facilement les terres qu'une année de repos a durcies : comme fa taille lui permet de voir par deffus les boufs, quoiqu'il marche derriére eux au milieu du terrein qu'on laboure, il a le coup d'œil jufte à chaque extrémité clu champ, \&r s'il $\mathrm{y}$ a quelque chofe en terre qui réfí te \& mette les boufs en danger de fe démettre le cou, ou de brifer leurs cornes, il fait faire adroitement à la charrue un petit circuit.

Qu'il connoiffe la pratique de la campagne \& les faifons propres au labourage. Il ne doit pas ouvrir la terre quand elle eft trop dure, ni quand elle eft abreuvée d'eau : car fi on la remue quand elle eft féche, fes fucs nourriciers s'évaporent, 


\section{E C O NOMIE}

* \& fi on rompt les guérêts lorf Crorx nt5 qu'elle eft imbibée d'eau, il n'eft QUEs. plus poffible de toute l'année de la difpoter à produire.

Quand une terre forte boit difficilement les eaux de pluie, on ne l'ouvre que lorfqu'elle eft féche $\& z$ vers la fin du printems, avant que les graines des mauvaifes herbes qu'elle a produites ayent quitté la gouffe \& puiffent en tombant nuire aux moiffons. Mais peu de tems après on lui donne un autre labour qui croife les premiers fillons.

On ne doit pas non plus fur les. coteaux tracer les fillons d'une façon toute uniforme, mais il faut conduire les taureaux de haut en

* Il y a dans le texte :

Veritur infractis qua zellus bumida glebis.

Ce mot infractis eft pris dans un fens afirmatif : fens que Yirgile lui a donné en différens endroits.

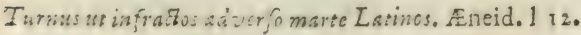

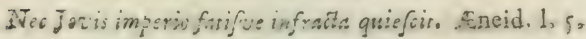




\section{R U R A E. Liv. II.}

bas \& de bas en haut, de façon que la charrue fuive une ligne diagonale en croifant les fillons.

Le laboureur \&z le berger tirent Li gallear. avantage mutueliement de leurs travaux : car quo quils tournent louvent leurs vius fur des objets différens, quoique le laboureur n'aime pas therbe dans un champ, que le palteur la cherche, \& quil fuye avec foin les lieux couverts de buiffons \& d'épines, 11 ne laifie pas d'y avoir du rapport entre leurs travaux malgré l'oppofition apparente de leurs inclinations. Lun donne fon travail à la terre, l'autre lui fournit le fumier de fes brebis. Les troupeaux rendent les champs fertiles, \& ceuxci nourriffent les troupeaux du plus tendre gazon. Les beftiaux qu manquent de pâturages, \& les campagnes qui ne font pas couvertes die troupeaux dépériffent bientôt.

( I ) Les plus grands Géréraux des Romains cultivoient eux-mêmes autrefois les champs qu'ils avoient conquis à la pointe de l'épée. Rome a fouvent tiré de la charrue, des la- 


\section{CE C ONOMIE}

CHO1X DiS boureurs pour les mettre à la tête DOMESI-de la République dans des tems Ques. orageux; \& les troubles appaifés, ces grands hommes dépofoient les faifceaux \& retournoient à leurs champs : les taureaux au labourage obéiffoient avec plus de joye à un maitre dont les nations domptées avoient fubi le joug. (2) La terre ouvroit fon fein avec plus de plaifir à un foc chargé de lauriers, \& furpaffoit les vœux de ces laboureurs * conquérans.

Si cependant j'ouvre les livres facrés \& veux m'en rapporter aux anciennes hiftoires, on croyoit (3) qu'il étoit plus noble de garder les troutpeaux de fes peres que de fatiguer la terre par des travaux pénibles pour mériter fes dons : car dans les premiers âges du monde, \& dans les ** fiécles d'or, la race augufte

* Gaudente terrâ vomere laureato ón trium. phali aratore. Plin. 1. 18. c.3.

** On pourroit dire comme Ovide :

Aurea nunc verè funt facula: plurimus auro Venit bonos: auro conciliatur amor,... 


\section{R U R A L E. Liv. II.}

des Rois ne dédaignoit pas de porter la houlette en attendant le fcep- DOM M E D I. tre : un Prince conduifoit les trou- $C \mathrm{U}$ \&s.

peaux avec douceur pour apprendre à gouverner les peuples avec humanité, \& à ne pas s'approprier leurs biens avec la cruauté de ces pafteurs qui tondent jufqu'au vif leurs brebis, mais à recevoir avec bonté le fuperflu, à traire avec modération \& non pas jufqu'au fang.

Comme en ces tems la terre en friche n'étoit qu'une vafte plaine, les pafteurs errant avec leurs troupeaux dans ces cléferts immenfes, \& vivant dans l'oifiveté fous un ciel pur \& ferein, apprirent non feulement quel étoit l'art de conferver les troupeaux, \& quelles herbes leur étoient falutaires, ou pernicieufes: mais leur efprit fut curieux de pénétrer jufqu'aux régions céleftes, (4) de connoître les phafes $\&$ les éclipfes de la lune, \&r les différentes révolutions du ciel. Ils furent les premiers à obferver le colirs infenfible des aftres, à fixer les deux poles du monde \& à lui donner un axe Tome I. 


\section{$9^{8}$

CHO1X DES

DOMESTI-

fur lequel il tourne. Ils fuivirent le foleil dans fes différentes maifons,

QUES. ils compterent les fignes du zodiaque \& leur donnerent des noms différens, voulant que le bélier qu'on voit le premier à la tête des troupeaux fût auffi la premiére conftellation, \& (5) quil ramenât chaque année comme il ramene les brebis au bercail.

De plus les bergers furent les premiers à initer le ramage des oifeaux par les chants mélodieux dont ils firent retentir les airs. Ils tirerent auffi des fons du chalumeau \& convinrent d'en joindre plufieurs enfemble avec de la cire ou de la poir, de faire des paroles pour l'air qu'ils avoient compofé \& de les affujettir à une certaine mefure: (6) c'eft encore du mode paftoral \& des pipeaux ruftiques que nous nous fervons nous autres poëtes quand nous voulons chanter les doux loifirs de la vie champêtre, ou de chaftes amours.

Mais hélas ; combien tout change avec le tems, ce font aujourd'hui 
R U R A LE. Liv. II.

de vils domeftiques $(7)$ qui font l'emploi d'Apollon \& des Rois du D о MESTIpremier âge; c'eft un homme ftu- cU Es. pide \& groffier qui conduit les troupeaux, tandis qu'autrefois ce foin n'étoit confié qu'à des enfans bien élevés \& d'une condition libre.

Choififfez parmi ces gens de néant quelqu'un qui foit honnête homme, dont l'humeur plaife davantage que la figure, qui fache conduire \& foigner les troupeaux dès fes plus tendres années, qui n'ait pas reçu la même éducation qu'on donne aux enfans de la ville, \& qui ne foir plus dans fa premiére jeuneffe; que fon âge pourtant ne touche pas à la caducité, dans la crainte. Que la difficulté de marcher ne le rende pareffeux \& ne le faffe arrêter avec fon troupeau dans les champs les plus proches, ou que couché fur l'herbe tendre, il n'obferve pas affez les mouvemens de fes brebis: elles demandent que les yeux du pafteur foient toujours en fentinelle, de peur que fi quelqu'une d'elles s'arrête, ou devance le troupeau. 
ou s'écarte dans la plaine, le loup DOMEST - qui eft en embufcade ne forte de ta cuEs. retraite, n'enleve cette brebis vagaboncle, (8) \& ne l'emmene toute tremblantedans le fortdes bois. Alors il la charge fur fon coul, où il la tient avec fes dents par l'oreille, \& de fa queue lui frappe le derriere \& $\&$ les flancs, lorfqu'elle réfifte, tandis que par fes triftes bêlemens elle appelle envain le fecours áu berger trop éloigné pour la fauver.

Le Chévrier. Que celui qui conduit un troupeaul de chévres à travers les rochers les plus ef́carpés, ait un tempérament à l'épreuve de la neige $\&$ des brouillards, \& qu'il ait le courage de fuivre ce sanimaux grimpans dans les endroits les plus rudes \& les plus dangereux. L'air fauvage de ces lieux rend farouches le caractére \& la figure du chévrier, \& lui fait perdre l'ufage de la langue; mais que ces confidérations ne yous rebutent point, pourvî que vos chévres reviennent du pâturage avec beaucoup de lait.

Un fermier doit entendre la con. 
R URA L E, Livi.II. IOI

duite des troupeaux \& la pratique du labourage : ce font là les deux Domest s pivots de l'agriculture. Il doit propor- ¿ U E s.

tionner les travaux ruftiques, dont nous reprendrons le fil dans la fuite, au génie \& à la force de ceux qui le 1ervent : car de même que les hommes différent entre eux pour la figure, \& qu'aucun ne fe reffemble pour la force du corps ou les lumiéres de l'efprit, de même à la campagne il y a différentes fortes de culture; celle-ci veut qu'on affocie l'art à la force, celle-là demande plus d'art que de vigueur: pour l'une il faut un homme de tête \& d'expérience, l'autre n'a befoin fimplement que de gens robuftes. Ne prenez point pour des ouvrages fatiguans de ces domeftiques lầches dont la force eft épuifée en un inftant, qui travaillent nonchalament à la terre, qui laiffent toujours par adreffe \& fupercherie quelques endroits en friche, qui ne creufent jamais à la profondeur néceffaire, mais qui fe contentent de remuer la fuperficie 


\section{IO2 EE ONOMIE}

CHог de la terre avec l'inftrument le plus DOMES I léger.

Le Jardinier- Les légumes demandent des jarpotagifte. diniers vigoureux \& diligens qui connoiffent les terreins propres à chaque efpéce, ils doivent fatiguer fans ceffe un potager par leur travail, donner des attentions particuliéres aux jeunes plantes, étendre leurs précautions à l'avenir, foigner le fond du maitre avec œconomie, s'attacher à faire venir du fruit plus qu'à fe faire un nom par de frivoles curiofités.

Mais furtout gardez-vous de prendre à votre fervice ces jardiniers préfomptueux qui fe vantent d'avoir une nouvelle méthode, \& (9) qui n’ont que du jargon fans talens, qui n'approuvent rien de ce que les autres ont fait, qui changent \& bouleverfent tout \& réparent moins un jardin qu'ils ne le détruifent, repaiffant leur maître d'efpérance fans jamais couvrir fa table d'un feul fruit.

Le Fermier. Ainfi qu'à la guerre l'efpoir \& la victoire ne fe rangent pas du par. 
RURALE. Liv.II. 103 ti le plus nombreux \& le plus vaillant, fi le Général fans expérience ne fait pas conduire les troupes DOMESTIau combat; de même à la campagne euffiez - vous des légions d'hommes, vous ferez peu de progrès fi le chef de la bande ne fait pas faire valoir les bras \& les forces dont il difpofe par des ordres donnés à propos. Sous un mauvais fermier vos champs deviennent mai- Fermier. gres, vos bois font dégradés, vos taillis mal gouvernés : le troupeau \& le berger lui même manquent de nourriture ; les taureaux fans conducteur défolent les moiffons \& foulent impunément l'herbe des prairies; les champs font ouverts aux rapines, \& celui qui doit veiller pour s'y oppofer eft le premier voleur, il s'approprie une partie de la cueillette des noix \& des pommes, demande à fon maître plus de grains qu'il n'en faut pour enfemencer la terre \& en garde une partie, ne porte pas toute la récolte aux greniers \& diminue les revenus par lés faux frais : la vigne eft hériffée de QUES. 


\section{IO4 E C O N O M I E}

CHorx dis chardons $\&$ de mauvailes herbes, D) OMEII-le défaut d'arrofement fait mourir CUES. les jeunes arbres, \& c ce n'eft qu'un bois fec comme un échalas qui eft fur pied au lieu d'un plane qu'on croyoit avoir, ou bien c'eft un arbre tout penché qui étend fes rameaux jufqu'à terre \& qui demeure contrefait, parce qu'on n'a pas eu le foin de le foutenir avec un appui dans fes premiéres années, ou parce qu'il a été battu par les vents du midi: le fermier parefleux voit la tête de cet arbre courbée \& fes branches balayer la terre fans dai. gner lui prêter fecours, ni le foutenir arec un pieu qui mette fa tige à l'abri des vents : fous un pareil fermier, s'il l'eft longtems, les fontaines mêmes courent rifque de perdre leurs eaux, les prairies deviennent fiériles, les eaux entrainent la terre des collines; \& lorfque ce fermier a ruiné \& mis en difcrédit une fer. me pendant quelques années, il vous laiffe un procès à vuider pour tout payement.

Il arrive même fouvent qu'un pre- 


\section{RUR A LE. Liv. II. 105}

mier créancier peli complaifant tollche l'argent qui devoit revenir au DOMESTmaitre \& dépouille le fermier de ev घs.

tout fon bien par autorité de juffice.

$\mathrm{Ce}$ fermier négligent voit mettre à l'encan la récolte qu'il avoit gardée foigneufement pour l'hiver, ainfi que fes lits, fes vins, fes uftenciles de ménage, \& tout ce qu'il avoit acheté de l'argent du créancier. On vend même jufqu'à fes voitures \& fes bœufs qu'il voit triftement obéir à un autre maître : pénétré de douleur il retourne à fa maifon auffi dégarnie de meubles qu'il eft dépourvî d'argent, mais bientôt la faim importune l'en chaffe \& l'oblige d'aller fervir après avoir été maitre : exemple frappant pour les fermiers parefleux qui devroit leur apprendre à aimer le travail $\&$ à vivre d'œconomie.

Heureux les champs qu'un fer- Le bon Fermier connoît de longue main \& mier.

qu'il cultive avec une nombreufe famille! il croit jouir de fon patrimoine lorfqu'il a eu fes ayeux pour prédéceffeurs dans la même ferme. 


\section{E C ONOMIE}

CHOIX DFS Qu'il ne foit ni trop jeune ni trop DO MESTI Vieux; la jeuneffe eft inconfidérée, QUES. \& la vieilleffe trop lente : quoique l'agriculture exige la tête d'un vieillard \& la main d'un jeune homme, cependant un maitre qui a l'un ou l'autre de ces âges fe fait obcir difficilement par fes domeftiques, parce qu'ils trouvent que l'un ne fait pas commander, \& que l'autre n'exécute pas ce qu'il commande : or l'exemple du maitre fait plus d'effet que fes ordres, car en campagne fi le domeftique fe croit plus habile que le fermier, les commandemens de celui-ci font mal exécutés.

Devoir's du

Un bon fermier fe fait à lui-mê. yermier.

me un plan de vie $\&$ de travail, il difpofe en fa tête $\&$ par ordre l'ouvrage de toute une année, $\&$ chaque foir il avertit les domeftiques avant qu'ils aillent fe repofer de ce qu'ils auront à faire le lendemain.

Il eft toujours le dernier à fe coucher, voit fi les portes font exactement fermées \& peuvent réfifter aux entreprifes des voleurs; il vifite les étables, examine s'il y a de la litiére fraîche fous les bef. 


\section{RURA L E. Liv. II. 107}

tiaux \& $\&$ fi les rateliers font affez garnis de foin pour les longues nuits d'hiver. Dès que le coq chante il CUES. fe leve \& n'entend pas que fes domeftiques aillent lentement à l'ouvrage, mais qu'ils s'y préfentent courageufement comme s'ils alloient au combat pour repouffer l'ennemi; il a l'œil à tout, excite au travail, reprend vivement les ouvriers négligens, fait l'éloge de ceux qui font habiles \& vigoureux, diminue par quelque récit agréable le poids du travail, \& ne voit qu'avec regret approcher la fin du jour $\&$ de l'ouvrage. S'il * s'apperçoit que les forces manquent aे quelqu'un de fes gens, il s'empreffe à lui donner du foulagement, \& le renvoye au logis : car il vaut mieux laiffer un do. meftique fe repofer pendant quelques jours, que de l'expofer à une longue maladie, pour avoir négligé d'abord de le foigner. Un bon fermier n'ufe point de vilaine fupercherie dans la préparation des mêts ; il. prétend que la nourriture foit pro* Voyez Columelle, liv. I. c. \&. 


\section{I08 E C O O M I}

CHOIX DES portionnée à la fatigue \& au travail; DOMESI- un intérêt fordide ne lui fait point Ques, mêler de l'eau avec le vin, nidonner du fon paitri pour du pain; il penfe avec raifon qu'il y auroit de l'inhumanité à refufer aux laboureurs les befoins de la vie, puifque la terre tient d'eux toutes fes richeffes; le fermier \& les compagnons de fes travaux prennent les mêmes alimens, \& le même vin coule indiftinctement pour tous les convives. Souvent le maitre, quoiqu'il n'ait pas befoin de confeil, fait des queftions à fes domeftiques fur la culture de la terre ou de la vigne, pour favoir lequel mérite le mieux fa confiance.

caractére \& La douceur fait fupporter le com-

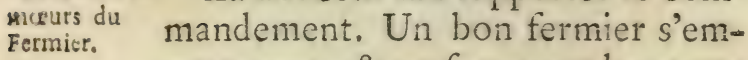
porte peu, \& ne fe permet les coups que rarement. * Il aime mieux par fa vigilance empêcher fes domeftques de tomber dans des fautes, que de les punir quand ils font coupables. Il réprime quelques défauts par la crainte, mais la pureté de fes mours corrige davantage. Les rudes

*Voyez Columelle, lir. I 2. ch. I. 
PU R A LE. Liv. II. I09 travaux aufquels il exerce fon corps confervent l'innocence de fon ame. Cron dis Les crimes féduifans, ignorés fous CU Es. les toirs ruftiques, font bien plus de progrès dans les grandes villes, où régnent plus communément le repos \& l'oifiveté : (10) le travail, ce grand maitre des mœurs, contient les gens de la campagne par d'honnêtes oçcupations; le fermier donne l'exemple; les domeftiques, témoins de fa conduite ar compagnons de fes travaux, imitent fes actions, (11) bien loin d'itre complices ou miniftres de fes paffions, comme il arrive dans le féjour des villes.

On ne refte point dans l'inaction, quoique la pluye retienne à la maifon les ouvriers. Le maitre fait laver les tonneaux, balayer partout, ¿x nétoyer les grains. On racommode les cordages, on enléve le fumier de l'étable, on pripare la charrue \& les autres uftenciles, \& l'on fend du bois pour les cheminées.

Il n'y a point en campagne de devin qui détourne du travail par fon verbiage, point de boutiques d'arti- 
fans où l'on aille rire \& ententre des contes, point de bouchon de taverne, comme en ville, qui tente les laboureurs : on ne s'occupe point à prendre des oifeaux âu lacet ou à la glu, \&c l'on ne néglige pas le foin des moiflons \& des vignes, pour aller courir un liévre à la fuite d'une meute.

Le fermier va rarement à la ville, à moins que le tems \& fes affaires ne l'exigent ; c'eft-à-dire, quand il s'agit de vendre utilement fes grains, fes brebis malades, les boufs dont il ne peut plus tirer de fervice, \& la toifon de fon troupeau; ou lorfqu'il eft queftion d'aller faire des emplettes pour garantir fes enfans des rigueurs de l'hiver, \& habiller fa femme, non pas en étoffes de goût, mais de durée : car il cft ceconome, \& craint fur tout la contagion de la ville pour le luxe, \& les exemples qui peuvent corrompre les mours.

Iuxc des vil. les.

Qu'il eft indigné quand il voit la récolta de cent arpens fufirre à peine pour la parure d'une femme mondaine! Mais fon indignation redouble, 


\section{R U R A I E. Liv. II. III}

quand il apperçoit des meres avec leurs filles, marcher dans la ville la, oms sis gorge nue, la robe flotante \& lanszuss. ceinture, avec d'énormes cercles, pour amplifier le contour de leurs juppes brillantes : ajuftement imaginé par la licence, qui fait rougir la pudeur, \& qu'il compare aux larges cerceaux dont il fe tert pour relier fes tonneaux.

(12) Une feule de ces femmes ainfi parée, occupe toute une rue, \& mếme un large carrefour. A peine peut-elle entrer dans fa mairon, quoique les deux battans de la porte foient ouverts, à caufe du circuit immenfe de fa robe tendue, qui reffemble aux voiles d'un navire enflées par les vents.

Si quelque hiftoire récente \& $\mathrm{fcan}$ daleufe court la ville, \& deshonore des gens de la premiére diftinction; fi d'illuftres maris ont à rougir de quelques infidélités de leurs femmes, ou fe plaignent qu'elles les ruinent au jeu; ce fermier eft tout étonné que ces Magiftrats qui font obferver les loix dans leur province, n'ayent 


\section{I $Q E$ CONO M I}

Сногх DEs pas la même autorité chez eux ; \& D o m Es I- que le bien \& la réputation d'un maCUES. ri dépende d'une femme coquette. En campagne les loix du mariage font bien plus en vigueur : la femme obéit à fon mari comme à fon mâ̂tre; \& fi quelqu'une, oubliant la foi conjugale, a prêté l'oreille à la féduction, aucun procès intenté à cet égard ne rend public le deshonneur du mari; ( I 3) mais il ne tolére pas plus, quoique fans éclat, les défordres de fa femme que les autres qui peuvent arriver chez lui, \& il aimeroit mieux fur le champ fe venger par le bâton, que d'aller plaider ćternellement pour faire rompre les noeuds d'un hymen infortuné. L'aultorité des maris, qu'on traite à la ville de rufticité parmi les gens polis, eft à la campagne le gardien le pltis fîr de l'amour conjugal.

An ! de quels yeux regarderoit-il les femmes \& les imbéciles maris de la ville, s'il voyoit dans des jours de réjouiffance, ces déefles affifes feules à table, les maris tête découverte, debout, autour d'elles, \& la fer. 
RURALE. Liv.II. II 3

viette fur le bras, tenir à grand honneur les plus viles fonctions de va-D CMESTES let, \& ne refufer aucun des mor- Qu $\mathrm{ks}$. ceaux qu'elles leur donnent par deffus l'épaule, \& comme par compaffion. C'eft à ces repas que fe nourrit l'orgueil des femmes; c'eft-là que les hommages rendus à leur beauté repaiffent leur gloire; \& c'eft d'après cette baffeffe indigne des hommes, ( 14 ) qu'elles les croyent nés uniquement pour les fervir.

Quoique le fermier ne foit pas dans les rues à l'affùt des nouvelles de la ville, \& qu'il ne faffe ordinairement de queftions que fur la valeur des bleds aux laboureurs que le marché a fait venir à la ville, il eft bien aife pourtant d'entendre parler des fuccès de la France dans la guerre préfente, afin de rapporter ces nouvelles aux curieux villageois de fon canton. Enfuite il achette une mefure de fel, un fer triangulaire encore informe pour battre le foc de fa charrue, \&x le rendre plus tranchant; il y joint de la poix ferme ${ }^{2}<$ en pain, des hoyaux, une faucille Tome $I$. 


\section{E C O N O MIE}

dont le dos eft courbé en forme de

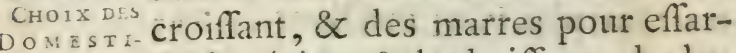
Cuns. ter les épines \& les buiffons, de haches $\&$ des ferpes pour émonder les arbres dont les branches s'étendent trop, \& pour détacher de leur tronc les rameaux fecs. Il n'achette rien de ce qui fe trouve à la campagne, ni rien de ce qu'il peutfaire; conféquemment point de corbeilles d'ofier, point de fil de lin, ni de groffe toile de chanvre, point de fabots, il les fait lui-même groffiérement, enfin point de bottines de peau de chévre pour fe garantir des ronces \& des épines. Car c'eft en vendant beaucoup qu'un fermier s'enrichit : \& s sil achette, au contraire, il eft bientôt ruiné.

Dovoirs du rernicr at the ptes, \& ne fait point écrire, il apporite. te plus fouvent à fon maître l'argent dont il eft convenu avec lui, ce qui vaut mieux que des volumes d'écriture. Aucun reproche fecret ne le rend timide \& tremblant à la vîe du mâ̂tre, qui vient voir fa campagne. Au dedans tout eft en régle, au dehors 
RUR.A I E, Liv, II. II

tout eft en bon état; fes boeufs \& fes troupeaux ne fouffrent point de la wo faim; il n'y a point de bornes dépla- CU Es. cées, nide nouveaux fentiers dans les champs; les prairies \& le jardin ne dépériffent point faute d'être arrofés, les moiffons ont la plus belle apparence, les champs font fermés par de bonnes hayes, ou de larges foffés : le fermier conduit fon maitre d'un bout de la ferme à l'autre; il eft enchanté des éloges qu'il lui donne, \& de voir que le voifin ne blâme point fa conduite ni fes travaux, \& n'accufe point les fiens de vol clandeftin. Il ne cultive pas fes champs avec moins de foin, quoique la guerre, ou quelque procès fâcheux, force le maitre d'être abfent. Ce n'eft pas fa préfence auffi qui lui donne plus d'émulation; fon devoir fait fon unique régle dans tous les tems. Mais intérieurement il eft au défefpoir quand ii voit le fils diffiper le bien du pere dans fon abfence, \& introduire dans la maifon de campagne une troupe d'amis libertins, qui font main baffé fur tout ce qui s'y préfente. Auffi le 


\section{II6 E C O NO M I E}

CHOIX DES fermier, s'il craignoit que l'ennemi

DOMEST dût venir le mettre à contribution, QUะs. ne cacheroit pas plus foigneufement fes denrées.

Ainfi jadis, lorfquaprès avoir échappé à mille dangers, Ulifie déguifé en vieillard, arriva au port d'Ithaque, \& entra dans fa Cour comme étranger, examinant fecrettement tout ce qui fe paffoit fans être connu de perfonne; ainfi, dis-je, un de fes fujets, qu'on appelloit Eumée, voyant les défordres de la Cour, \& demandant fon maître aux dieux, s'occupoit dans fes triftes regrets à labourer fes champs, gémiffoit amérement de ce que les amans de Pénélope, plus parafites que galans, vivoient des troupeaux d'Uliffe, \& fouffroit de voir les terres de ce Prince fertiles pour d'autres que pour lui.

Un bon fermier fe pourvoit de tout, fait peu de demandes à fes voifins, de peur qu'à leur tour ils ne l'importunent; il évite d'entrer dans les affaires d'autrui, ne croit à lui que ce qu'il tient de fon maitre, dé- 
R U R A E. Liv.II. II7

tefte les larcins, conferve fon bien avec tout le foin imaginable, \& n'eft D OM M E DT I-

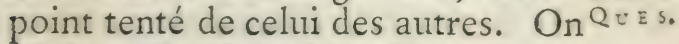
eft fi perfuadé dans le village de fon exacte probité, qu'on le choifit pour juge dans les plus grands démêlés, \& qu'il termine les procès, fans être au fait des loix.

(15)Le laboureur eft le plus heureux des hommes, \& doit chérir fon état. Retiré dans une campagne obfcure, $\&$ accoutumé à vivre de peu, il fait borner fes défirs. Il chaffe loin de lux les chagrins dévorans, ainfi que les vaines efpérances; l'ambition ne le tourmente point ; il fe met peu en peine de donner la loi ailleurs que dans fon champ $\& \varepsilon$ dans fes vergers. Il n'eft point brulé de la foif inquiéte des richeffes, pour être plus pauvre au milieu des monceaux d'or, incapables de le raffafier. Il préfére à l'étude \& au favoir faftueux, l'art de bien vivre, de gouverner fes trou. peaux, de connoitre les aftres favorables à la terre, la nature des vents, $\&$ les tems propres pour la moiffon. A l'abri des traits de l'envie, une 


\section{I8 E C O N O M I E}

Crorx jaloufie fecrette ne le confume pas:

DOMES I - On ne le voit point, porté fur le vent

Ques. de la faveur, monter au faite des honneurs pour en tomber avec éclat, \& donner un trifte exemple de la fragilité des grandeurs humaines. Il ne redoute ni les procès douteux, ni les décifions d'un Juge févére, ni les fureurs de l'implacable vengeance. Il ne craint perfonne, \& ne fe craint point lui-même. Ses joies ne font point fuivies de l'affreufe trifteffe, ni fes repas du trifte dégoût. Occupé fans relâche des travaux de la campagne, tantôt il enfemence fa terre, \& tantôt il en recueille les prérens dîs à fes peines. C'eft par là qu'il acquiert cette fanté vigonreufe, qui brave la goute, \& $\approx$ tous les autres maux que la voluptueufe indolence traine à fa fuite. (16) C'eft ainfi que fon appétit, aiguifé par le travail, trouve les mêts dont il fe nourrit plus agréables. ( I7) Sans autre lit que la terre, il goûte les douceurs du fommeil; de ce fommeil fugitif que le riche, couché fur l'or \& fur la pourpre, appelle vainement, tandis 


\section{R URALE. Liv. 1I. II9}

que les chagrins qui l'affiégent veillent toute la nuit pres de lui. Vaut-DOMEST Iil mieux, au mepris des loix de la Qu ss. nature, parcourir fur un fragile vaiffeau les mers que Dieu a féparées du continent, confier fa vie \& fa fortune à l'inconftance des vents, vivre tour à tour dans des climats divers, comme les oifeaux de paffage, \& dévouer fon ame au vil intérêt ? Celui qui habite les villes eft-il plus henreux, hii qui fe tourmente pour fe faire un nom, qui affiége fans ceffe les portes des Grands, qui flate jufqu'à leurs domeitiques, qui, par un indigne efclavage, achette un pofte avantageux, qui veut parvenir aux honneurs par la voie la plus honteufe, \& qui, toujours occupé de fervices frivoles, paffe réellement $\mathrm{fa}$ vie à ne rien faire? Eft-il plus doux de vendre fes clameurs au Barreau, \& d'y défendre d'une même voix le crime \& l'innocence, ou d'être affis à un ennuyeux Tribunal, d'y excrcer le pénible emploi de Juge, \& de négliger fes propres affaires poux 
CHOIX DIS celles des autres? * Vaudroit-il

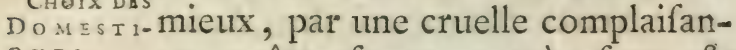
QUes. ce, prêter fon argent à ufure, \& exercer un métier odieux à ceux même qu'il foulage? Enfin eft-il plus glorieux de fuivre le parti des armes, de vivre de meurtres, de rapines, de fang \& de larmes, que des dépouilles qu'on peut enlever à la terre fans crime \& fans violence ?

(1 8) Heureux les laboureurs, s'écrie lePoëte deMantoue, s'ils connoiffoient le bonheur de leur condition! Cependant il préfére à leurs occupations l'étude du ciel, \& la connoiffance des routes myftérieufes de la nature. Eft-ce donc un fort digne d'envie, de fe tourmenter dans le défir de connoître ce qui n'eft fait que pour en jouir, d'obferver le cours de ces globes qui roulent fur nos têtes, \& de les ranger, pour ainfi dire, en bataille dans fon efprit ? Exempt de ces foins, le laboureur

* An faneratio probabilior fit etiam his invifa guibus fuccurrere videtur? Colum. 1. I. in proøm. 


\section{RU R A E. Liv. II. III}

jouit tranquillement d'une délicieufe nuit d'été, \& du magnifique fpecta- DO M ISTIcle des étoiles. Il voit dans une belle CU Es. journée fes troupeaux errer dans les prairies, \& il proméne fes regards enchantés fur des champs parés de verdure \& de fleurs; tandis que le Phyficien, aiguifant fa vîe avec le microfcope, cherche tantôt dans le fein d'une fleur, tantôt dans un cadavre infect, de petits animaux que la nature dérobe à fes yeux. Le laboureur, couché fur le bord d'un ruiffeau, ne cherche point l'origine des fontaines, ni leurs routes fecrettes dans les entrailles de la terre; il ne les fait point venir de la mer; content d'y puifer, il boit ou dans le creux de fa main, ou même il en approche fa bouche, \& il admire le courant de l'eau, foit qu'un ruiffeau coule à petit bruit fur le fable, foit qu'un torrent fe déborde avec fracas, \& renverfe tout ce qui s'oppofe à fon paffage. Que lui importe de connoître la fource des pluyes \& des fontaines, s'il ne fait l'art de dériver

Tome I. 
l'eau d'un champ voifin, \& s'il ne

CHOIX DES DOMESTI- Connoit les fignes qui lui annoncent QUES. la pluye. Il ignore comment le froid ou le chaud allume la fiévre dans le corps humain; mais ih fait par quel moyen on la guérit. Tandis que le docte Médecin ordonne favamment l'ouverture de la veine, ou des purgations, \& cent remédes femblables pour cent maladies différentes, le laboureur foulage tous fes maux par des racines \& $\boldsymbol{x}$ des herbes falutaires qu'il connoit ; il ne donne point la torture à fon palais par des potions améres, \& il ne s'empoifonne point pour recouvrer la fanté.

Ia fermiére. Heureux fermier, que la fortune vous aime! ( 19 ) fi la compagne que l'hymen vous a donnée l'eft auffi de vos travaux; fi elle remplit exactement ce qui eft de fon miniftére; fi elle n'aime pas avec paffion le fommeil, la bonne chére \& le vin, \& qu'elle montre même dans un âge peu avancé, un bon efprit, \& $x$ dudifcernement.

Le mari \& la femme bien unis 


\section{R UR A L E. Liv. II. 123}

concourent, par leurs travaux, au bien commun de la fociété. * Le mari, comme le maître \& le plus CUEs. fort, doit cultiver la terre, \& fupporter la rigueur de l'hiver, \& l'ardeur du foleil. Sa chére moitié porte le fardeau du ménage ; mais fes occupations font moins fatiguantes : l'un gouverne dans les plaines de Cérès, l'autre préfide dans l'intérieur de la maifon. Le fermier ordonne \& dirige les ouvrages des domeftiques, la fermiére apprête lour repas; lé mari veille aux productions de la terre, \& dépofe la récolte dans fes greniers, après bien des fueurs. Quand elle y eft tranfportée, l'ouvrage de la femme eft de la conferver; \& comme l'effet de la crainte eft de multiplicr les précautions, la nature a créé la femme timide \& défiante, \&x a donné le courage \& la force à lhomme pour le rendre propre aux plus rudes travaux. C'eft ainfi qu'ils ont befoin mutuellement l'un de l'autre : leur fortune s'accroît par leur * Ces defcriptions font toutes tirées de Co. lumelle. L. I2. in praf.

$$
\mathrm{L} \text { ij }
$$




\section{CE C O NOM IE}

CHO:X D union, \& par leur amour récipro.

DOMESTI-qUe.

CUES

La femme a foin de bien ranger fa la Fer petite chaumiére. Les murs n'y font point ornés de tapifferie; mais une élégante fimplicité y reléve l'indigence. Au lieu d'or \& d'ivoire, ce font des grappes de raifin fufpendues qui parent le plancher ; un riche buffet n'y étale point la vanité du maître; on n'y voit ni tableaux curieux, ni ftatues rares; toute la vaiffelle confifte en écuelles, en verres, quelques plats d'étain, \& des affiettes de fayance; encore celles-ci fontelles réfervées pour les perfonnes de diftinction, pour le jour de la fête du village, ou pour le maître lorfqu'il vient feul à fa maifon de campagne, \& qu'il veut bien fans cérémonial prendre un repas champêtre à la table de fon fermier. Le plancher noirci par la fumée, eft garni de porc falé, de paquets d'ail qu'on fent au loin, de bottes d'oignon, \& de grappes de raifins un peu ridés: c'eft un préfent de la terre dont la fermiére aime mieux régaler fes enfans, 
R UR A L E. Liv. II. $\mathrm{r} 25$

que de repaitre leursyeux d'eftampes ou de tableaux. Le foir elle couvre la CHOIX Dis table d'une nappe, \& $a$ la range auprès Q u $\mathrm{s}$. du foyer quand il fait froid; mais dans les grandes chaleurs, elle la met près de la porte, ou même en plein air, quelquefois fous un feuillage épais, afin qu'on refpire la fraicheur.

Dirai-je toutes les peines qu'elle provifions fe donne pour avoir des provifions des virres. à peu de frais, du lard, des châtaignes, \& des raifins fecs ? Elle fonge Façon dapdès l'automne à fe munir pour l'hi- precter les fecs.

ver, \& plonge des grappes attachées enfemble par deux ou partrois dans des chaudiéres expofées au feu; elle laiffe ainfi le raifin jufqu'à ce qu'il fe forme des rides fur les grains, \& que la leffive, dont les chaudiéres font pleines, ait par fa chaleur fait perdre au raifin fa crudité. Alors elle prend de fa petite cruche un peu d'huile d'olive, qu'elle verfe dans la chaudiére, afin que le raifin ait meilleur goût, \& plaife davantage à la vîe. Enfuite elle l'étend fur une longue claye, dans un endroit expofé au foleil, mais à l'abri de la pluye \& 


\section{I26 EE C O NO M IE}

CHo1X dFs de la rofée. Après quoi, quand il eft Domes r - bien fec, elle le ferre dans des cor¿ U в. beilles d'ofier.

Duconfifage Outre cela, elle fait cuire des descoins, \& coins dans du vin doux, ou les connement des fit au miel; ou bien elle incife artiolives. ftement des olives encore vertes, pour leur faire prendre le goût du fel, du fenouil, de la menthe \& $\mathrm{du}$ laurier.

salaion de Quand les pourceaux reviennent ioic.

de la glandée chargés de graiffe, la fermiére les enferme dans leur toit, ne leur permet plus ni buvée, ni nourriture liquide avant de les tuer, $\&$ les écarte des bourbiers, afin que la chair en foit plus ferme. Lorfqu'un porc eft fuffifamment engraiffé, \& qu'on eft au moment de le tuer, on lui bouche la refpiration, dans la crainte qu'il ne morde ou ne fatigue les oreilles par des cris fans fin, $8 x$ auffitôt on l'égorge. La petite famille du fermier fe range en haye tout à l'entour pour voir couller fon fang, \&z s'étonne qu'il ne poufie aucuns cris, quoiqu'il batte des flancs avec violence. Enfuite la 
RU R A E. Liv. I1. I I27 fermiére a la patience de l'épiler à l'aide d'une chaudiére bouillante, OU DOMESI de lui arracher les foyes jufqu'à la Qu Es. racine, en allumant de la paille. Après quoi elle lui détache les entrailles avec un fer chaud; elle fale abondamment pendant dix jours, les morceaux qu'elle a coupés, \& les couvre dans le faloir avec quelque chofe de pefant. Elle fufpendenfuite à une poutre le lard \& les jambons, dans un endroit expofé à la chaleur \& à la fumée.

C'eft ainfi que la fermiére voit Travaux de couler tranquillement fes jours ; \& 2 , la Fermiére à moins que la Religion ne lui or-champs. donne d'aller vifiter quelques faints lieux éloignés du village, elle ne quitte point la maifon pour aller ailleurs s'amufer à la bagatelle : elle obferve toujours la réfidence. Mais s'il eft d'une néceffité indifpenfable qu'elle quitte la quenouille pour manier le rateau, ni chaud ni froid ne la détournent. Il en eft de même s'il faut aller cueillir des olives dans un terrein raboteux, ou couper les blondes moiffons pendant les plus

L iiij 


\section{8 \\ (E) C O OMIE}

CHo1x D.s apres chaleurs. Sur le point même

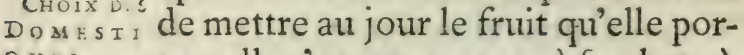
QUES. te, elle s'occupe encore à farcler, à ôter d'un champ les herbes qui nuifent au bled, ou à botteler le farment. Elle aime tant les travaux champêtres, \& elle eft fi infatigable, qu'en pleine campagne elle fe délivre ellemême, \& vient préfenter à fon mari le fruit de leurs amours. A la voir, on ne diroit jamais qu'elle en fuit la mere; mais on jureroit que c'eft un enfant trouvé dans les champs. Ah! qu'heureux fera fon deftin fous le chaume \& dans l'indigence!

Education Cette mere ne fouffre point qu'udetenfans de ne autre qu'elle donne le fein à fes la carmpagne. enfans; elle eft charmée de leur tranfmettre fes mœurs avec fon lait, \& de les avoir auprès d'elle, afin qu'ils lui faffent d'innocentes careffes, \& qu' 'ils reçoivent les fiennes; que par un fouris ils reconnoiffent leur pere quand il rentre le foir, \& lui marquent, en étendant leurs bras, le défir qu'ils ont de l'embraffer. Mais, au contraire, un enfant né fous des lambris dorés, eft exilé de la maifon 
R U R I E. Liv. II. 129

paternelle dès qu'il voit le jour, \& fa mere femble, auffitôt qu'elle en eft délivrée, n'avoir plus d'entrailles DOMESTIF pour lui. Elle l'envoye nourrir loin de la capitale, dans quelque vile chaumiére, parmi les animaux; (20) \& ce fera à un chien qu'elle préfentera la mamelle qu'elle refure à fon fruit. Quelques années après elle retire fon enfant de la nourrice, les cuiffes \& le corps tout contrefaits : mais, en le voyant, le cri de la nature ne le lui fait point reconnoitre ni fentir tout ce qu'il a fouffert.

La fermiére plus tendre garde auprès d'elle fes enfans; fon lait ne leur eft point épargné, \& la nature l'en a pourvûe avec abondance. Quelque part qu'elle aille, fon enfant fur fon fein la tient embraffée : cet agréable fardeau abrége fon chemin. Si elle eft obligée d'agir, elle le pofe à terre, \& l'enfant y refte fans pleurer : ainfi dès le berceau on l'ha. bitue à l'ardeur du foleil. Cette bonne mere eft attentive aux leçons de la nature, elle obferve les cris des oifeaux quand ils ont perdu leurs pe- 


\section{CE C NOMIE}

tits; (2I) elle voit l'inquiétude d'ü

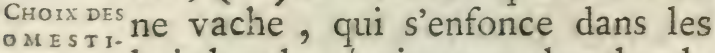
QUES. bois les plus épais pour chercher le veau qu'on lui a ravi, qui le demande par les mugiffemens dont elle remplit les airs, \& qui lorfqu'elle retourne à l'étable au coucher du foleil, n'eft tentée ni de l'herbe la plus délicate, ni de l'eau la plus claire : uniquement occupée de fon veau, elle ne fe repait que de larmes. Tantôt elle entend les triftes bêlemens d'une brebis qui appelle fon agneau : elle voit avec quel plaifir elle l'alaite; elle admire la nature qui fait à cette mere reconnoître fon agneau entre mille autres, \& dont également elle eft reconnue, quoiqu'il n'y ait entr'eux aucune différence pour la couleur, la figure \& le cri. Et d'après ces exemples, elle croiroit manquer à l'amour maternel, fi elle avoit moins de tendreffe que les animaux.

A peine un enfant de la campagne peut-il marcher, qu'on le forme aux exercices champêtres, qu'il commence à manier le hoyau, \& à mon 


\section{RUR ALE, Liv.II. I3I}

trer une certaine vigueur qui ne dé-

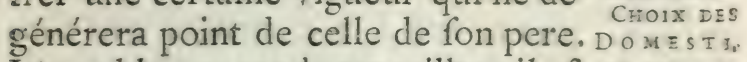
Incapable encore de travailler, il eft QU E s.

témoin de ce que font les autres; il aime l'agriculture, \& l'apprend en voyant ce qui fe pratique, quelque difficile qu'elle foit. Deja prenant le ton de fon pere, il fe préfente en for: abfence, \& fait avancer l'ouvrage par fon commandement, s'il ne peut encore y prêter la main.

Cependant le pere donne des leçons à fon fils relatives aux différentes faifons \& aux différens terreins. (22) Il lui enfeigne fur-tout à invoquer Dieu par la priére, à lui préfenter fes vœux comme au fouverain arbitre des pluyes $\&$ des moiffons, \& à n’apporter au pied des aultels qu'un coeur pur \& fans tache. Il l'avertit que fi la terre lui obéit dans fes travaux, il doit auffi obéir au Maître fuprême de la terre, le prier de donner aux moiffons des tems propices, \& d'en écarter les. orages. Il faut, ajoute-t-il, fanctifier. les jours de fête, fufpendre d'effet $\$ x$ fans fraude tous les ouvrages que 


\section{I32 E CONOMIE}

CHO1X DES défend la Loi pendant ces faints DOMEST 1-jours, tant à la campagne que dans Q $\mathrm{E}$ E. la maifon; exempter les bœufs mêmes du travail, \& les laiffer libres du joug errer dans les prairies, jouir du repos, \& réparer leurs forces. Il lui recommande d'aimer fes voifins, de ne toucher nide nuire à leurs troulpeaux $\&$ à leurs moiffons, afin qu'ils lui rendent le même fervice, \& le garantiffent des voleurs. Ne portez, dit-il, envie à perfonne; mais tâchez, quand vous voyez aux autres de belles moiffons, d'en avoir encore de plus riches par votre travail. Evitez les procès douteux : ce font des guerres intertines, ordinairement ruineufes pour les deux partis. Rendez à chacun tous les bons offices que vous pourrez. Ayez quelques amis, mais n'en faites pas un grand nombre. Enfin ne vous repofez pas tant fur les reffources de l'a. mitié que fur celles de la terre; c'eft elle qui fonde vos efpérances les plus certaines. Il faut, pourfuit-il, vanter les vaftes domaines, mais s'en tenir aux petits par prédilection. Un fond 
R O R A E. Liv. II. I 33 médiocre bien cultivé eft d'un meilleur rapport qu'un terrein de mille arpens, quand le laboureur indigent QU E $s$. manque de fumier pour l'engraiffer, d'uftenciles \& d'ouvriers, pour le faire valoir par des foins perpétuels : car la terre lutte contre nous; \& lorfqu'elle a le deffus, mille herbes ftériles qu'elle fe hâte de produire, fatiguent \& défefpérent le maître, s'il ne la contraint par fa fermeté \& fa conftance, de céder à fes travaux.

Gardez-vous d'effayer une façon de cultiver qui vous foit étrangére, \& d'adopter une nouvelle méthode; fuivez celle qui eft approuvée par l'ufage. Bornez vos voux ; ne vous laiffez point vaincre par la foif des richeffes, elles font un obftacle aux vertus. Ne fuivez point auffiles confeils de l'indigence, elle méne au crime ; \& d'ailleurs, quand on eft dans le befoin, notre état eft à charge à nos amis, oul pour nous-mêmes eft un fardeau. Ainfi tracez-vous une route entre ces deux extrémités, de façon que vous ne vous attiriez point 


\section{3,4 CE O NO M I E}

l'envie du village par votre opulenDOMESI. ce, ni fa commifération par votre Q $U$ S. mifére.

Faites couper vos moiffons \&z cueillir vos olives par des gens de journée, \& ne nourriffez pas plus d'ouvriers que votre ferme n'en exige. De peur qu'il ne fe forme des partis, \& 2 qu'il ne fe fomente des haines \& des querelles entre vos domeftiques, choifffez-les d'une humeur douce \& tranquille. Il s'en trouve quin'aiment que leur patrie, qui ne peuvent s'accorder qu'avec des gens de leur pays, \& qui, ennemis de tous les autres, brouillent $\&$ divifent la maifon du maitre, par leur miférable efprit de difcorde \&z de fédition. N'en ayez jamais plufieurs de cette efpéce.

Adoucifiez, par votre exemple, la condition de ceux qui vous fervent; faites-vous craindre plus par votre filence que par les éclats d'une voix tonnante. Que votre dureté ne vous faffe pas détefter de votre maifon; qu'on refpecte en vous un juge févére; mais qu'en vous on aime 


\section{RUR A I E. Liv.II. 135}

encore davantage un maître jufte \& raiionnable.

Pour vous faire aimer de vos do- $\mathrm{Qu}$ \&s. meftiques, aimez-les comme vos enfans, ne leur retenez point leur falaire, ayez de la confiance en eux pour les rendre fidéles. Qui prend trop de précaution invite à le voler. Le maitre doit avoir connoiffance de tout, \& difimuler bien des cho. fes. Qu'il occupe les domertiques en état de travailler; mais que fes foins compatiffans aillent jufqu'à l'inquiétude pour ceux qui font infirmes : il oblige tous les autres en fecourant celui qui eft malade. L'aiguillon qui excite le plus un domeftique au travail, eft fon attachement pour le maître, \& l'envie qu'il a de Iui plaire.

C'eft ainfi que le pere inftruit fon fils ; \& lorfqu'il fent la vieilleffe approcher, quoiqu'il foit toujours prompt \& vigoureux, \& qu'il ait encore la tête pour le commandement, $\&$ le bras pour l'exécution, il lui remet les rênes du gouvernement ruf. tique; afin que ce fils né pour avoir 


\section{I36 CE C O N O M I E}

CHOIX DES

feul un jour la régie de la ferme, acDO M E S 1-quierre, parles confeils de fon pere, QUEs. les connoiffances de l'agriculture, auxquelles les autres ne parviennent qu'après bien des méprifes. Par ce moyen le pere, fans être amateur du repos, peut fe livrer à un genre de vie plus tranquille. Le fils, enrichi des talens de fon pere, \& doté de fes exemples, lui fuccéde dans le gouvernement; \& la terre, également féconde, ne s'apperçoit pas qu'elle ait changé de maître.

¿a jeune vil- La fille déja grande \& nubile pariageoife. tage les pénibles travaux de fa mere, \& ne rougit point de manier la houe \& le rateau. Elle ne brille point par l'éclat de fes vêtemens, n'a point de chevelure empruntée, point de pierres précieufes de l'Arabie, ni de riche parure; \& quoique, par une inclination commune à toutes les femmes, elle veuille paroitre belle, aucun árt ne reléve fa figure. C'eft dans les prés fleuris qu'elle va chercher fes pierreries les jours de fête, \& c'eft le criftal d'un ruiffeau qui lui fert de glace pour l'arrangement de 


\section{R U R A L E, Liv. III. I37}

cheveux; fa tête n'eft point chargée d'une énorme coëffure, la fimplicité en eft l'ornement ; une pudeur ingéDOMESTI\% nue pare fes joules au lieu de rouge, \& c'eft par la force \& non par la beauté qu'elle tâche de l'emporter fur fes compagnes. C'eft avec cette dot qu'elle trouve un riche parti.

Lorfque le tendre Hymen la folliSes nôses. cite pour la premiére fois d'aimer \& de fe ranger fous fes loix, lorfque fon amant lui plaît, \& que tous deux d'un âge égal, fe conviennent réciproquement, ils tâchent de faire la vendange dans la même vigne, \& de couper dans le même champ les blonds épis de Cérès, pour avoir la commodité de fe parler. La jeune fille fe metà la tête des moiffonneurs \& entreprend le premier fillon; mais pour plaire à fon amant, elle devance les autres ouvriers déja fatigués. Le galant épris d'un charme fecret, la regarde moiffonner, \& eft enchanté que, par fon activité, elle le devance lui-même. Souvent à deffein il retarde fa maitreffe, \& lui fait de doux reproches d'ayoir paffé par def-

$$
\text { Tome } I \text {, }
$$




\section{I38 CEONOMIE}

fus quelques épis fans les couper, CHOIX DES afin qu'elle le flatte un moment de
DOMESII QUES. fes regards en fe retournant. Lesalltres moiffonneurs fe livrent au fommeil après le dîner, pour réparer leurs forces; mais nos deux amans en reprennent dans leurs tendres entretiens. Déja ils délibérent entre eux fur les moyens de rendre leurs champs de bon rapport, \& de gouverner en paix leur ménage.

Des que les parens des deux côtés font informés de l'amour de leurs enfans, \& qu'ils les jugent dignes l'un de l'autre, auffitôt pour affurer les conventions matrimoniales, ils en paffent contrat. Alors viennent les parens \& les amis de tous les environs du village, chargés de préfens champêtres, \&z difpofés à célébrer la fête nuptiale.

Quand eft venu ce jour défiré, \& que le Prêtre, déja dans fes habits de cérémonie, commence à murmurer de ce qu'on n'arrive pas, les époux futurs fe mettent à genoux devant la maifon, fur le feuil même de la porte. Les deux peres s'avancent vers eux, 


\section{RURAIE. Liv.II. I39}

leurs yeux mouillés de larmes; enfuite levant la main \& hauffant la voix, ils leur donnent leur bénédi- $C$ U Es.

Etion; \& la tendreffe dicte à ces peres mille vœux pour la profpérité des enfans. Après quoi ils vont au temple, l'amant avec un chapeau orné de rubans de deux couleurs, \& fa maîtreffe les yeux modeftement baiffés, \& excédée de fueur fous fes habits de nôces. Enfin ils fedonnent tous deux la main un peu noircie par le foleil, malgré la quantité de fon çu’ils ont employée pour la blanchir ; \& prennent la Divinité même pour têmoir deleur inviolable union. Les garçons font la conduite du mari, \& les filles celle de l'époufe, avec des cris d'allégreffe, \& au fon des tambours \& des inftrumens. Alors, fuivant l'ufage antique, ils ordonnent aux nouveaux époux de s'affeoir fous un ormeau touffu, qui placé au milieu des hameaux, eft commun à tous les habitans. (23) Une jeune fille répand devant tout le cercle des fpectateurs, des grains de froment fur la tête dư couple affis; enfuite, une fecrette rou- 
CHOAX DES geur lui couvrant le vifage, elle pro DOMEST- nonce des vœux pour l'honneur \&z Ques. la fécondité du lit nuptiale, \& préfente des gâteaux dans une corbeille. Auffitôt la folâtre jeunefle s'avife de railler fur les maris, \& de tirer quelque malin horofcope; à moins que le nouvel époux ne paye une rancon, \& ne faffe couler à grands flots le vin de la nôce, pour fermer la bouche aux mauvais plaifans.

Cependant les viandes fument fur les tables dreffées. Mais, quoiqu'elles foient abondamment couvertes, aucun mêts ne vient du marché ; car c'eft à leurs troupeaux qu'ils doivent le mouton \& le chevreau dont la premiére faim eft raffafiée, \& la volaille eft le fruit de l'œconomie de la fermiére, qui a confervé depuis longtems des poules \& des canards pour faire honneur à la fête. Les pommes, les châtaignes \& le fromage ne manquent point au deffert. Le vin ne fait pas feul la joie du feftin; le fon d'un violon qui jure fous l'archet, les verres caffés, les ris éclatans, \& les différentes chan- 


\section{R U R A L E. Liv, II. I $4 \mathrm{I}^{\circ}$}

fons en l'honneur de la nouvelle $\overline{C H O 1 X \text { DES }}$ époufe, contribuent à la gayeté duD O M E ST I. repas; les danfes \& les jeux vien- $Q$ U E s. nent enfuite, \& c'eft jour de fête dans tout le village. Cette affemblée fait la nouvelle du jour dans les campagnes voifines ; les oreilles n'entendent qu'à cette nôce, il n'eft bruit d'autre chofe. Tout le voifinage loin de porter envie au bonheur des nouveaux époux, leur fouhaite une heureufe poftérité, \& des enfans qui reffemblent à leur pere \& à leurs aieux.

Fin du fecond Livre: 


\section{REMARQUES}

\section{Sur le fecond Livre.}

TL s'agit dans ce fecond Livre du choix des 1 domeftiques du fermier, de leurs qualités $\&$ de leurs fonctions. Le jardinier, le chérrier, le laboureur \& le berger font paffés en revîe. Ce qui améne une digreffion fur la dignité de la vie paftorale dans les premiers tems. Les devoirs \& les mœurs d'un bon fermier font auffi détaillés. L'Auteur oppofe la fimplicité \&: l'œeconomie rurale au luxe de la ville; d'où il paffe, ainfi que Virgile, à l'éloge de la vie champêtre. Il n'oublie point de parler des foins de la fermiere, de l'édu- cation de fes enfans, \& des nôces de fa fille, dont il fait une agréable defcription.

(1) [Les plus grands Généraux des Romains. ] Les Curius Dentatus, les Catons, \& tant d'autres, cultivoient eux-mêmes leurs champs. L'agriculture étoit alors aufi honorée qu'elle elt aujourd'hui méprifée.

(2) [ La terre ouvroit fon fein avec plas de plaifir. ] Le Pere Vanniere donne en Poëte la raifon qui faifoit répondre la terre aux vœux de ces refpectables laboureurs. Mais fi elle étoit plus docile, comme le remarque Pline, s'eft que ces illuftres perfonnages avoient plus 


\section{Remarques fur le fecond Livre. 143}

de lumiére \& de génie que des gens du peuple, qui s'en tiennent à une fimple routine.

(3) [Qu'il étoit plus nuble de garder les troupeaux. ] Si l'on confulte Héfiode, Homere \& l'hiftoire des Hébreux, tous les Princes é:oient pafteurs de leurs troupeaux, mais ne labouroient que rarement leurs terres.

(4) [De connoitre les phafes ér les éclipses de la lune.] C'eft aux anciens bergers de la Chaldée, de l'Arabie \& de l'Egypte que nous fommes redevables des premiers principes de l'aftronomie.

(s) [ Et qu'il ramienátchaque année. ] Le Belier eft le premier figne du Zodiaque, \& celui du mois de Mars, par lequel commençoit antrefois l'année. C'eft ce qui fait dire au Pere Vanniere qu'il ramene chaque année, comme il ramene les brebis au bercail. Mais on s'apperçoit fans doute que cette penfée tient de concetti Italien, \& a plus de brillant que de jufteffe. Le premier figne du Zodiaque ne reffemble pas plus à un belier qu'à un moulin à vent ; \& d'ailleurs ce ne font point des conftellations qui ramenent les aunées, c'eft le cours du foleil, ou plutôt le mouvement de la terre.

(6) [C'eft encore du mode paftoral. ] M. de Fontenelle dans fes Eglogues, ne s'en eft guéres fervi. Le Diapazon de l'Opera lui a donné le ton.

(7) [Qui font l'emploi d'Apollon.] Ce Dieu garda pendant neuf ans les troupeaur d'Admerte, Roi de Theffalie. Yoyez le Di- 
ctionnaire de la Fable, par M. de Chompré.

(8) [Et ne l'emmene toute tremblarte. ] 'Rouffeau, dans des vers adreflés à M. Duché, fait la même defcription.

Ia fiévre eft comme un loup cruel \&r raviffant, Qui vers les antres fourds, traîne un agneau timide, Et des coups de $f_{2}$ queue hâtant fes pas rétifs, Devance le berger \& le dogue intrépide, Qu'appellent au fecouss fes bêlemens plaintifs. Bientôt le raviffeur, tout palpitant de joye, $\mathrm{Au}$ fond d'un bois obfcur dévorera fa proye.

(9) [Et qui n'ont que du jargon fans tx. lent. ] Il y a des charlatans dans toutes fortes d'états. Pour percer il faut fe vanter foi-même; la plupart des gens aiment mieux sen rapporter à votre parole, que de prendre la peine d'examiner votre favoir. Mais fi cette méthode réuffit de particulier à particulier, elle ne prend pas vis-à-vis du public : les Auteurs dramatiques en ont fait pour la plupart la mortifiante épreuve, malgré leur ton avantageux, \& le manége des vils courtiers du Parnaffe: Que de pieces au néant depuis quelques années.

(10) [ Le travail ce grand maitre des mours. ] M. de Voltaire a dit quelque part,

Inftruit pa: le malheur, ce grand maitre de l'homme.

Ce vers paroît dérivé de la penfée du Pere Vanniere. 
(II) [ Bien loin d'etre complices ou miniftres de fes pajfions.] Comme les fubalternes en général ne font point dans le cas d'être utiles aux Grands, plufieurs, pour mériter leur protection, ont la baffeffe de fervir leurs plaifirs. C'eft la clé des faveurs pour bien des gens.

Ie plaiîr eft le noeud des plus grandes affaires; Tout $y$ va, tout $y$ tient

Boifl. Dehors trompeurs.

\section{( 12 ) [Une seule de ces fermmes.] Il y a dans le texte:}

Occupat una vias laxofque canephora vicos.

On appelloit autrefois $C$ anephores les femmes qui portoient fur la tête des corbeilles remplies de plufieurs chofes néceffaires aus facrifices. Je n'ai point confervé le mot $C$ anepliore dans la traduction, parce que ce terme n'étane point ufité dans notre langue, n'auroit point Ia grace qu'il a dans le latin, \& ne feroit entendu que de fort peu de gens.

(13) [ Mars il ne tolere pas plus, quoique Sans éclat, les défordres de fa femme, que les autres qui peuvent arriver chez lui.] Il y a dans le texte:

Cafigat pueros, meritas à conjuge panas

\section{2 uo peitore fontes}

Clam reperit Sponfus.

Tome I. 


\section{$I_{4} 6$ Remarques}

Jai crû devoư ici détourner le fens du latin; On ne conçoit pas comment le Pere Vanniere a eu la fimplicité de penfer qu'un fermier corrigeoit fa femme de la même façon que fes enfans.

( I4) [Qu'elles les croyent nés uniquement pour les fervir.] Le Poëte, fous le nom du fermier, condamne d'une maniére incirecte, mais fort dure, les ajuftemens \& les panniers des femmes; \& quoique fes comparaifons foient ingénieufes, elles ont quelque chofe de cynique qui les dépare. Que fignifie également cette longue tirade contre les égards, les foins \& les attentions des hommes pour les femmes? L'Auteur voudroit-il engager la Nation Françoife, qui paffe pour la plus gas lante \& la plus polie de l'univers, à prendre les mœurs des fauvages ou des villageois? Déroge-t-on à fon état, \& devient-on valet, parce qu'on eft poli, \& qu'on fert une fem$m e$ ? S'il en eft quelqu'une qui prenne droit de nos complaifances pour nous traiter avec hauteur, on la méprife. En un mot, il n'y a point de ridicule à fuivre un ufage généralement reçû̀; \& je ferois prefque tenté, en qua. lité de Traducteur, de faire réparation au fexe pour mon Original.

(Is) [Le laboureur eft le plus boureux.] L'Auteur, à l'imitation de Virgile \& de Columelle, décrit avec élégance les avantages \& le bonheur de la vie champêtre; il fuit le plan du Pcète Romain ; \&, après avoir montré les défagrémens des autres états, il donne 


$$
\text { f:l- le fecond Livre. }
$$

Is préférence à celui de laboureur. Ce morceau, quoique bien écrit, paroît trop long, \& d'ailleurs n'eft pas concluant.

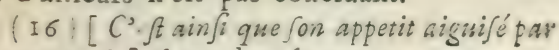
for travail. ] Il y a dans le texte :

\section{Labore diurnum}

Obfonante famem.

Ce mot obfonante eft bien énergique. C'eft ainfi que Cicéron a dit, famem ambulando obfonatur.

( I 7 ) [Sans autrelit que la terre.] Lucrece peint à neu près de la mềme façon le bonheur de la vie champêtre.

Non citharis reboant laqueata aurataque templa,

Atramen inter fe proftrati in gramine molli

Propter aqua rivum, Jub ramis arberis alita,

Non magnis opibus jucundé corpora curant,

Prefertim cùm tempeftas arridet, of anni

Tempora confpergunt viridames floribus herbas,

Nec calida citivis decedunt corpore fibres

Textilibus si in piaturis, of rogue rubeni

Jacteris, quàm fi plebeia in vefte cubandum eft.

(I 8 ) [Heureux les laboureurs, s'écriele Poëte de Mantoue.]

O fortunatos nimiim, fua fi bona norint Agricolas!

Me verò primuim dulces ante omnia mufa -1ccipinnt calique vias o fodera monffrent.

Virg Georg.Lib.2.

$\mathrm{N}$ ij 
J'avertis que l'Abbé Desfontaines a traduit la digreffion du Pere Vanniere depuis le vers Ille fuos bominurn, \&c. jufqu'au vers $O$ tibi quam vultu, \&c. \& que j’ai fuivi fa traduction à quelques mots près, perfuadé qu'elle vaur bien celle que j'aurois faite, \& que le public $n^{\prime} y$ perd point.

(Ig) [ Si la comparne que l'Hymen vous a donnée.] Horace décrit élégamment les foins d'une fermiére.

2uod si pudica mulier in partem juvę

Domum atque dulces liberos:

(Sabina qualis, aut perufta folibus

Pernicis uxor Appuli)

Sacrum vetuftis exrruat lignis focum,

Lafs fub adventum viri :

Chaudenjque textis craibus latum pecus

Didienta ficcet ubera

$E_{t}$ horna dulci vina promens dolio

Dapes inempias apparet. Epod, 2.

(20) [Et ce Sera à un chien.] Il y a des Dames qui fe font têter quelques jours par un petit chien, afin que leur lait ne fe répande pas intérieurement, \& ne s’altére pas, aprè\& qu'on a abandonné lenfant à la nourrice.

(2I) [Elle voit l'inquiétude d'une vache.] Ce morceau eft copié de Lucrece Liv. 2. \& n'eft différent que par l'expreffion. Afin que le Lecteur foit en état de faire la comparaifon, je vais rapporter ici les vers de Lucrece, 
At mater viriles fal-us orbata peragrans

Linquit humi pedibus veftsgia pređa bifulcis

Omnia convifens oculis loca, is queat u/quam

Confpicere ami, um ferum, complesque quere! is

Frondiferum nemus adjbtens, ou crebra revifu Ad ftabulum defiderio perfixa juvenci :

Nec tenera falices atgue herbe rore vigentes,

Fluminaque ulla queunt Jummis labentia ripis,

Olledare animum, fubitamque avertere curam :

Nec vitulorum aliz species per pabula lata

Dcrivare queunt alio, curâque levare;

USque adeo quiddam proprium, notumque requirit.

Praterea teneri tremulis cum vocibus hadi

Cornigeras norunt matres, agnique petulci

Balantes pecudcs, ita guod natura repofcit;

Ad Jua quifque ferè decurrunt ubera lactis.

(22) [Il lui enfeigne fur tout à invoquer Dieu.] M. Rollin rapporte une formule de priéres pour les gens de la campagne. C'elt dans les ouvrages de Caton qu'il l's prife.

\Pere Mars, dit le Suppliant, je vous prie

§ \& vous conjure de nous être propice \&

) favorable, à moi, à ma maifón, à tous

» mes domeftiques, pour ce qui fait le fu-

» jet de la préfente proceffion dans mon

"champ, dans ma terre, \& dans mon

* fonds : d'empêcher, de détourner, \& d'é, loigner de nous les maladies commues \& in» comnues, les défolations, les orages, les ca" lamités, les intemperies de l'air; de faire' " crôirle \& parvenir à bien nos légumes, 
»nos blés, nos vignes, nos arbres; de con$\leadsto$ ferver les pafteurs \& les troupeaux; de 2) nous accorder la confervation de la vie \& 2) de la fanté, à moi, à ma maifon, \& à tous 2) mes domeftiques.

Après cette formule, M. Rollin fait cette réflexion : "Q Quelle honte que des Chrétiens, $\leadsto$ \& fouvent ceux qui ont le plus de part aur „) biens de la terre, foient maintenant fi peu 》) foigneux de les demander à Dieu, \& qu'ils 2) rougiffent de l'en remercier! Chez les $\leadsto$ payens tous les repas commenço:ent \&.finif3) foient par des priéres : elles font mainte2) nant bannies de prefque toutes nos tables. (23) [Une jeune fille répand.] Apparemment que c'eft un ufage dans les villages du Languedoc, \& que le Pere Vanniere, qui étoit de Beziers, avoit affifté à pareille cérémonie. Je ne crois pas qu'il y ait bealicoup de pays où cela fe pratique.

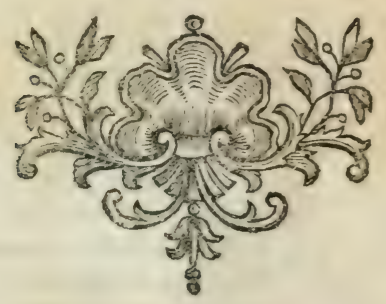




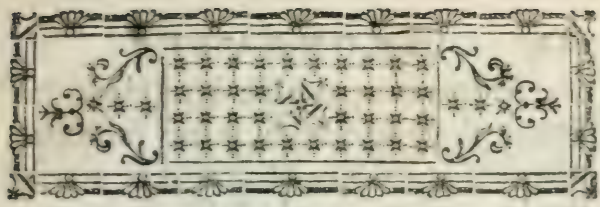

\section{बe C O OMIE \\ R U R A L E。}

\section{LIVRE TROISIÉME。}

\section{Le gros Bétail.}

Es Laboureurs ne fuffifent pas L pour la culture des terres, il faut encore des beftiaux qui enfoncent le foc de la charrue dans les champs, \& qui engraiffent de leur fumier ceux qui font maigres.

Que celui qui a du goût pour les Iecheral; longs voyages, ou qui aime à fuivre les drapeaux fanglans du dieu Mars, fe plaife à former un cheval qui ait la bouche tendre; (I) qu'il lui apprenne à faire de fatiguantes courbettes; qu'affujettiffant au frein fa bou.

$\mathrm{N}$ iiij 


\section{E C ONOMIE}

$I_{E G R O S}$ che écumante, tantôt il lui pique les BEIAI. flancs dans la plaine pour lui faire prendre le galop, \& tantôt le manie fur les voltes, ou le faffe avec gravité marcher au pas.

Ie Bour. C'eft pour d'autres ufages qu'on doit dreffer le bœuf. * Il faut qu'avec le foc il ouvre la terre la plus dure, \& que fon cou vigoureux traîne des charrettes dont l'effieu gémiffe fous la charge. Parmi les boufs, choififfez ceux qui ont une grande corpulence, les cornes hautes, la tête hideufe, les nazeaux larges \& relevés, le cou ramaffé \& charnu, le front hériffé, les oreilles velues, le fanon pendant fous la gorge, le corps large \& nerveux, l'humeur douce $\&$ paifible, avec un extérieur farouche.

Ia vache. La vache doit avoir l'air moins rnde ${ }^{* *}$, le cuir doux, la jambe mé-

* Voyez Columelle. Bos laboriofifsimus bominis focius in agricultura : cujus tanta fuit apud antiquos veneratio ut tam capitale effet bovem necafse quam civem. Colum, in praf. 1. 6.

** Voyez Virg. Georg. 1. 2. \& Varron, de re ruffic. 
R'UR A L E: Liv. III. 153

diocrement grande, \& la corne du pied plus petite que celle dubœuf; BEFARO qu'elle refiemble au taureau d'ailleurs; qu'elle ait les membres grands, la poitrine large, des mufcles faillans, l'encolure haute, $\&$ de larges flancs; le fanon lui pendra jufqu'aux genoux; fa queue tombera jufqu'à l'extrémité du pied, \& la hauteur de fes cornes relevera encore fa belle tête.

Qu'il n'y ait que l'aiguillon \& la voix du bouvier capables de faire trembler le bouf ; qu'aucun bruit ne l'épouvante, qu'aucun chemin ne l'arrête, \&z qu'il ait affez de confiance dans fa force pour entrer dans une ville, paffer fur un pont tremblant, ou traverfer une riviére, quelque bruit qu'il entende, quelque objet qu'il voye.

Autrefois avant que l'homme eût, par fon induftrie, tiré les animaux des bois, pour les apprivoifer, \& les rendre, après bien des foins, dociles à fon commandement, les. taureaux libres du joug erroient aे leur gré dans les forêts; l'hommx

Le Boruf. 


\section{$154 \quad$ E CONOMIE}

LEGROS alors n'avoit que fes bras pour rea BÉTAIL, muer la terre. Il ne favoit point encore atteler des boufs, fe faire porter par un cheval, retenir chez lai des chiens \& les dreffer, ni conferver des veaux dans une étable pour fa nourriture. Mais ainfi qu'actuellement nous allons, avec un meute, à la chaffe du cerf, du liévre \& du fanglier, quand nous voulons donner un repas, de même nos premiers parens étoient obligés d'aller chaffer dans les bois le bœuf \& le mouton, s'ils vouloient en avoir à leur table, $\&$ ils s'habilloient groffiérement de la peau de ces animaux, fans qu'elle fût apprétée.

(2) Quand des extrémités de l'A. fie feptentrionale, ils fe frayérent un chemin à travers les bois pour pénétrer au nouveau Monde, ils confervérent les mœurs des premiers âges auxquels ils touchoient encore, la chaffe étoit leur paffion, \& leur nourriture dépendoit de leur adreffe à manier l'arc. Auffi lorfqu'ils virent pour la premiére fois les vaiffeaux de l'Efpagne, fes cavaliers fous les 


\section{R U R A I E. Liv.III. 155}

armes, \& des taureaux attelés trầnant des voitures, ces habitans faul- BEE ERAO vages ne prirent pas les Efpagnols pour des hommes, mais pour des dieux defcendus du ciel, \& fe foumirent volontairement à des gens qui difpofoient à leur gré des bêtes les plus féroces. C'eft ainfi que cette autre partie du monde reçut le joug d'une poignée de foldats.

Tous les autres animaux fe dé- La maniórs pouillent dans l'étable de leur natu- de domprer rel fauvage; il n'y a que les bœufs qui en confervent toujours quelques reftes. S'ils ne font pas domptés dans leurs premiéres années, leur con rébelle au joug ne s'y foumet qqu'avec bien de la peine.

Il faut qu'un jeune taureau foit habitué de bonne heure à fouffrir la main de fon maitre quand ille careffe, \& à fe laiffer entrelaçer les cornes de feuilles \& de branches d'arbre. C'eft le trifte effai du joug auquel il fera un jour affujetti. Vous le lui ferez porter ( 3 ) après qu'i? aura vû trois récoltes, \& 8 avant qu'il aille paître l'herbe nouvelle au com- 


\section{CEONOMIE}

LE GROS BÉTAII.

mencement de fa quatriéme année : car lorfque les bœufs ont acquis toute leur vigueur, \& qu'ils font parvenus à la vieilleffe, âge indocile \& qui rend pareffeux, ils n'obéiffent au commandement qu'avec beaucoup de répugnance. Vous adouci-* rez leur humeur farouche, \& vous calmerez la violence de leurs emportemiens avec du fain-doux $\&$ du vin ; \& cette liqueur, dont l'excès rend les hommes intraitables, appaife les fureurs d'un taureau quand on lui en fait boire.

Si le vin ni les gâteaux préparés ne peuvent le réduire, fi vous n'obtenez rien de lui en adoucirfant la voix pour le flater, il faut enchainer le rebelle dans l'étable, fans qu'il puiffe toucher au foin dont il voit le ratelier garni, \& dompter à force de jeûnes fon naturel fougueux.

Vous n'approcherez de lui qu'avec précaution quand il eft dans l'accès de fa colére, qu'il agite fa tête pour détacher fes cornes, \& qu'il porte vers le ciel fes regards effroyables : car s'il vous éloigne après vous avoir 
RUR A L E. Liv. III. I57

donné un coup de pied, ce fuccès ne fait qu'augmenter fa mauvaife hu-BẼTAIL. meur. Devenu préfomptueux, il ofe refufer le joug, menace de la corne, \& fait des ruades de tout côté. Quand une fois il s'eft laiffé atteler à la charrue, il fe foumet enfuite avec douceur à toute forte de travaux; $\&$ la voix d'un enfant ou fon aiguillon fait trembler cet animal, qui feroit terrible s'il connoiffoit fa force. Auffitôt que deux bœufs (4) fe font rangés fous le joug, qu'il y ait quelqu'un qui tienne les cordeaux par derriére, \& que celui qui veut les dompter marche devant, \& les pique alternativement de l'aiguillon pour les faire avancer d'un pas égal; qu'il les effaye d'abord avec un fardeau léger, \& qu'il ne leur faffe ouvrir des fillons que dans une terre déja préparée, ou dans un endroit fabloneux où le foc puiffe entrer fa. cilement ; de peur qu'un travail trop rude ne rebute ces jeunes taureaux, qui ne font pas faits aux exercices fatiguans, ou ne leur démette les mnembres qui font encore délicatș. 


\section{I58 C C O NOMIE}

Lorfqu'un taureau mal dreffé déLE GROS figure un champ, \& confond les fillons, parles détours qu’il fait à droite \& à gauche, il faut joindre cet animal indocile à un taureau vigoureux \& bien dompté, quil le retienne lorfqu'il veut courir de côté \& d'autre, l'entraîne quand il n'avance pas, $\&$ le force d'affujettir fa marche à la volonté du bouvier, quoiqu'il exhale le feu de fa colére par fes nazeaux fumans, \& qu'il effaye par des fecouffes violentes de rompre le joug.

Mais s'il tente de fe fouftraire au travail par la rufe, après avoir effayé inutilement la force, \& que rétifil fe couche avec obftination au milieu des champs, il ne faut point le charger de coups, ni lui mettre du feu fous le ventre pour le faire lever; mais on doit l'enchainer, \& l'attacher de façon qu'il refte couché fans pouvoir manger, ni fe tenir debout, devenu fage à fes dépens, il ne fe couchera plus dans le fort de l'ouvrage; fon eftomac dompté par la faim, lui confeillera la docilité.

Le bouvier fe fert encore d'un au- 
R U R A I E. Liv.III. I 59 tre moyen pour dompter les boufs qui n'ont point encore travaillé. Il en BE T $A$ I I joint trois pour tirer la même charrue; le novice au milieu des deux vétérans, eft obligé de faire le même ouvrage qu'eux, \& de marcher à leur gré. Quelques coups de fouet l'endoctrinent ; après quoi il fait fa befogne de lui-même.

N'attelez enfemble que des taureaux d'égale force \& de même âge, afin qu'en labourant ils fatiguent autant l'un que l'autre : le fort ruine le foible, ou (comme les animaux ont du penchant à devenir vicieux) celui qui a de bonnes qualités contracte infenfiblement les défauts de celui qui eft pareffeux.

Afin que les boufs marchent tête levée, \& ne faffent pas tant d'efforts en labourant, qu'on les joigne enfem. ble avec une forte courroie, \& qu'on leur attache le joug au cou, \& non pas aux cornes : car les taureaux tirent plus du cou \& du poitrail que de la tête $\&$ des cornes. De cette façon ils employent toute leur force, font pénétrer le foc bien plus 


\section{ECONOMIE}

L. $620 \mathrm{~s}$

BEIAIX. pas toujours tendue, \& ne fatigue pas tant. Mais il faut que la main officieufe du bouvier dérange de tems en tems le joug pour foulager leurs épaules froiffées, dans la crainte qu'il ne fe forme à leur cou des playes dangereufes.

Quand le laboureur a découplé les bœufs au coucher du foleil, qu'il ne leur permette pas d'aller au ratelier ou à l'abreuvoir, tandis qu'ils font mouillés de fueur; mais qu'il leur frotte foigneufement le cou $\&$ les flancs avec du foin.

I'amitié des

L'affociation des travaux établit boeufs. une forte d'intimitéentredeuxbœufs, \& la douce amitié qui unit les animaux par la longue habitude qu'ils ont de vivre enfemble, ne laiffe pas d'avoir fa force. Voyez comime ils vont paître \& boire de compagnie, comme ils fe repofent enfemble au milieu des champs, \& ruminent l'un à côté de l'autre.

Quoique le bœuf foit courageux, \& que la nature ait armé fon front pour le combat; quoique les animaux 


\section{RUR A L E. Liv. III. 6 I}

maux qui habitent les forêts ou l'étable vivent rarement en paix fOUS BÉTAILO.

le même toit, \& que le bélier même ait du penchant à fe battre malgré la foibleffe de fes cornes : cependant les bœufs, accoutumés à vivre enfemble, ne font point en guerre pour leur nourriture. Ils paffent leur vie fans débats, \& de bon accord, fe donnent même des baifers d'amitié ; \& lorfque fatigués du travail, ils fe repofent fur un tendre gazon, ils fe font de douces careffes, \& fe rendent mutuellement le fervice de fe frotter avec leurs dents, quand ils ont la peau tourmentée par quelque demangeaifon. A voir deux bœufs accouplés tendre également le cou, \& faire ufage de toute leur force pour tirer une charrette chargée, on diroit qu'ils difputent entre eux d'honnêteté, \& que chacun d'eux veut foulager fon compagnon dans fa peine.

Si par hafard un loup preffé par la faim, attaque l'un de ces bceufs, \& a l'adreffe de le mordre, auffitôt l'autre excité par les mugiffemens de

Tome $I$.

$\mathrm{O}$ 


\section{I62 E CONOMIE}

IEGROS fon compagnon, (5) vient à fon fe:

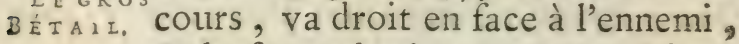
$\&$ le force de s'en retourner à jeun comme il étoit venu.

Dès qu'une mort prématurée enłporte l'un des deux, celui qui refte, défefpéré d'avoir perdu fon compagnon, le pleure amérement. Les gémiffemens dont il remplit les airs, ne font qu'irriter le chagrin du laboureur; il craint de faire une nouvelle perte, \& que la douleur n'enléve auffi le furvivant, tant il le voit obitiné dans fa trifteffe à refufer toute nourriture.

Ie Bouf dans fa vicil leffe,

(6) Retirez du travail un bouf quand il eft vieux; que libre du joug, il aille s'engraiffer dans d'agréables pâturages : afin qu'après vous avoir aidé pendant fa vie à labourer la terre, vous tiriez encore avantage de fa mort, en le vendant au marché. C'eit une fin, à la vérité, injufte : car cet animal que vous avez affocié à vos travaux de campagne, \& qui vous a été utile dans le tems de fa jeuneffe \& de fa force, mériteroit dans fa vieilleffe un fort plus heureux. 
RURA I. E. Liv. III. I ${ }_{6} 3$

Le bœuf qu'on a licencié foule les prairies, \& s'engraiffe dans les verds B É E G R O 0 , pâturages, furpris qu'on lui permette d'auffi doux loifirs. Mais, hélas! il ne fait pas qu'une mort funefte l'attend, \& qu'une pefante maffue menace fa tête.

C'eft à peu près ainfi qu'un homme enflé de fes heureux fuccès, fe livre à des tranfports de joie au milieu des richeffes; \& que fur la foi de la fortune, il conçoit les plus halites efpérances; tandis qu'à fa porte la mort, armée d'une faulx cruelle, a déja le bras levé pour trancher d'un même coup le fil de fes jours fortunés, \& de fes projets ambitieux.

L'âne \& le mulet labourent auffi L'Afne: la terre; mais ils vont à la charrue de bon gré, ils reçoivent le joug, ouvrent la terre avec le foc, \& traî. nent des charrettes chargées, fans. fe refufer au travail.

L'âne fe nourrit facilement, \& aे peu de frais; il fupporte patiemment le travail \& la faim. Des feuilles: de mauvaifes herbes de marais, de

$\mathrm{O}$ ij 


\section{EE ONOMIE}

C. GR OS petites branches d'arbre, des buif-

BETAIL. fons, de la paille, tout cela eft aliment pour lui, tout cela l'engraiffe. II ne connoît point les maladies (7) auxquelles en général le gros bétail eft fujet : cependant il n'a point de relâche dans fon travail; car s'il y a quelque chofe à porter à la ville ou à la maifon, c'eft toujours à ce pauvre animal qu'on s'adreffe : il prête fon dos \& fes flancs endurcis par les coups à toute forte d'ufages. Quoiqu'il foit né pour porter les domeftiques, bien des Dames en font leur monture, fans rougir de la fimplicité des premiers tems, \& ne fe fervent que de baguettes pour le conduire, au lieu d'un mors. L'âne tout fier de fon fardeau \& de fes caparaçons dorés, achéve le voyage fans remuer indécemment fes grandes oreilles.

Quelquefois cependant il s'oublie, \& a l'incivilité de cacher fa tête entre fes genoux, \& tout d'un coup fe remuant avec foupleffe, il hauffe le dos, \& précipite fon cavalier dans une orniére; après quoi il fe met à braire pour faire rire le peuple. Sou- 


\section{RURALE, Liv, III. I65}

vent il s'arrête au milieu de la ville, \& s'amufe à ronger de mauvais BETAIL, choux, ou des feuilles de faule, fans fe mettre en peine des exhortations réitérées de fon maître, ni des coups de bâton qu'il lui donne pour le faire avancer.

(8) La mule eft engendrée de deux animaux d'efpece différente, \& $\&$ tient de tous les deux pour les qualités : car elle eft dure au travail, \& vit de peu; elle a le pied agile, \& fe prête au tirage comme à porter la charge. Deux grandes mules bien choifies laboureront plus d'arpens que trois couples de boufs ; à moins que ce ne foit dans une terre graffe \& forte, qui demande toute la vigueur des taureaux les plus robuftes. Car fi la mule ne peut rompre les guérêts, elle fe fait plutôt quelque fracture à force de tirer, que de céder à la réfiftance qu'elle trouve.

Elle porte le voyageur en route fans le fatiguer ; \& toujours ardente, elle marche d'un pied fûr dans les endroits les plus difficiles \& les plus efcarpés. (9) L'Efpagne préfé- 


\section{$\$ 66$ E CONOMIE}

E rant l'utile à l'agréable, \& fidele के

BЕTAIL. fes anciens ufages, ne monte encore aujourd'hui que des mules; elle réferve pour les champs de Belloneles chevaux courageux qu'elle nourrit en fon fein. On n'y eft point choqué des longues oreilles d'une mule, ni de fa vilaine tête ; mais on confidére qu'elle a le pas doux, qu'elle eft d'une merveilleufe agilité, \& qu'un per de chaume ou de paille fuffit pour l'engraiffer.

Ah ! que font devenus les anciens François, fi refpectables par la fimplicité de leurs mours! Quand ils étoient vieux, (10) ils ne fe faifoient porter au Sénat que par des mules prefque aufí vieilles qu'eux, \& chemin faifant accordoient aux plaideurs des momens d'audience qu'ils ne faifoient point acheter. Ainf qu'on faifoit tervir à tout le même domeftique, \& qu'il ( I I ) étoit à la fois portier, palfrenier \& cuifinier; de même une mule alternativement fellée \& bâtée, portoit le bois \& la récolte, après avoir fervi de monture au mâtre; \& témoignoit ou de la 
RURAIE, Liv. III. I69

patience quand on l'employoit à de vils ouvrages, oule la gaieté quand th GROS

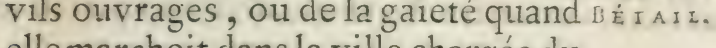
elle marchoit dans la ville chargée du mari $\&$ de fa femme en croupe.

C'eft par un vain fafte que nous furpaffons nos aieux, \& non par les richeffes : notre luxe les épuife. On a par oftentation, \& non pour s'en fervir, une troupe de domeftiques. Il feroit bien plus à propos de les employer au métier de la guerre, ou dans leur village aux fatiguans travaux de Cérès, que de les laiffer dans une coupable oifiveté, trainer une vie honteufe. Tous ces fainéans caufent plus d'embarras à leurs maîn. tres, qu'ils ne leur épargnent de foins.

Ce n'eft pas affez que la dépenfe des écuries \& des chevaux excéde les frais de la table, qu'un maître foit mené comme en triomphe dans un char doré, \& que des deux côtés de l'équipage il ait des pages vêtus auffi proprement que fes en. fans, on a encore à fon fervice des gens qui remplacent les chevaux, par la baffeffe de leur emploi, Un 


\section{C O NOMIE}

LEGROS homme, oubliant ce qu'il eft, porte BÉTAIL. Un autre homme; \& l'on ne rougit pas de fe faire voiturer dans une ville par fon femblable, \& de couvrir de cette infamie la race humaine que créérent les dieux à leur image.

Mais pourquoi entreprendrois-je ici de guérir les hommes de cette maladie? J'enfeignerai avec plus de fuccès à connoître celles des beftiaux, \& la maniére d'y remédier. Que le fermier faffe ufage pour le refte du gros bétail des traitemens que je vais indiquer pour le bœuf; car il feroit trop long de détailler les différens accidens qui peuvent arriver aux divers troupeaux.

Il arrive fouvent qu'un bouf en langueur a du dégoût pour les plus gras pâturages, \& qu'il ne peut ni manger ni ruminer. Il ne fe frotte pas même avec la langue; mais fe couchant nonchalamment à terre, il tourne triftement la tête de côté \& d'autre, agite fa queue, \& remplit l'air de fes mugiffemens; il a de fréquens rapports, \& fon gofier fatigue à rendre ces vents; fes yeux font pefans, 


\section{RU R A L E. Liv. III. 169}

pefans, \& répandent des larmes; enfin le bruiffement de fes entrailles LE GR OS demande pour lui le fecours d'une main habile.

Cette maladie provient du foin trop verd qu'il a mangé, ou d'une fiente recuite qui lui tourmente les inteftins. Le fermier, chagrin de voir fes champs fans culture, \& fon bouf malade, doit effayer de le faire vomir avec quelque forte médecine, $\&$ de foulager fes entrailles avec des plantes émollientes qui diminuent. fes tranchées. Du fromage vieux délayé dans le vin le plus rude, avec des noix de galle \&de ciprès broyées, diffipe les vents, \& calme fouvent les grandes douleurs.

La fiévre fait auffi de terribles rava. ges dans le corps des bœufs; ils en font attaqués quand vous leur voyez. les yeux enfoncés \& mouillés de larmes, \& qu'avec un dégoût général, ils ont la tête panchée, \& la refpiration généc. Si, après les avoir faignés, la fiévre ne ciminue pas, coupez des choux, faites-les cuire avec de l'huile ( I2) \& du garum, Tome $I$. 


\section{0 \\ (E) CONOM I E}

\& \& donnez-leur cette potion; rendezBEIAI. 'leur enfuite l'appétit, en leur faifant manger des feuilles de vigne.

Afin qu'un bœuf malade fe laiffe approcher quand on veut lui faire prendre des remédes, \& qu'il n'écarte pas à coups de pied les mains fecourables, on conftruit avec des folives \& des traverfes de bois, une machine commode, dans laquelle on l'enferme comme dans une cage, la tête en l'air \& attachée avec de bons licols. De cette façon on lui fait avaler malgré lui les fucs utiles à fa guérifon.

Le Bœufboi- Quelquefois un bœuf eft boiteux seus. fans avoir de bleffure apparente : mais fi vous lui touchez les jambes, il indique lui-même l'endroit où le fang extravafé s'eft corrompu par la fenfibilité qu'il témoigne. Ne craignez pas alors d'employer un fer falutaire, \& de percer la tumeur cachée. Si l'ulcére eft à l'extrémité du pied, il faut le déchauffer jufqu'au vif, \& nétoyer la playe avec le fcalpel \& $\&$ de l'étoupe. On panfe enfuite le pied avec différens remédes, afin 
R U R A I E. Liv.IIT. I7I que le fabot repouffe; \& l'on ferre les bandes avec des liens de jonc L. GRos pour préferver la playe de toute humidité, qui feroit alors pernicieufe.

Les eaux falées de l'Océan em- Lagalle. portent la galle : mais fi l'on demeure au milieu des terres loin de la mer, il faut en contrefaire les eaux, \& faire fondre du fel, ou fe fervir d'ail dont on aura enlevé la premiére peau, ou de fouffre délayé dans de l'écume d'huile.

Il furvient au cuir du bouf une maladie plus dangereufe, lorfqu'échauffé \& mouillé de fueur, il s'eft réfroidi à l'air. La peau fe defféche, $\&$ femble attachée à fes côtes. Pour ce mal, faites bouillir du laurier rofe avec du mare d'olives, \& de la lie de vin, \& frottez-lui-en le dos à l'ardeur du foleil.

Il faut lui ouvrir la veine toutes Les tumeurs. les fois qu'il s'eft fait des contufions au cou \& aux épaules, pour avoir trop fatigué dans un champ difficile à labourer. S'il a la tête enflée, \& fi les faignées qu'on lui a faites aux deux oreilles, n'ont apporté aucun

$P$ ij 
172 E C ONOMIE

foulagement, il faut le frotter avec IE gros de la graiffe de bouc, de la poix liquide, \& $x$ de la moële de bouf.

sangfue dans Lorfqu'une fangfue eft entrée dans le golier d'un le gofier d'un taureau, \& qu'on ne
Bœuf. peut arracher avec la main cet infecte acharné, inférez le tuyau d'un entonnoir dans la machoire du bœuf, brulez enfuite des punaifes de façon que l'entonnoir en reçoive la vapeur \& la porte dans le gofier du patient. Cette odeur infecte détache la fangfue; \& comme on tient la tête du bouf panchée, il eft bientôt délivré de cet infecte qui fort de lui-même, quoiqu'il ne foit pas encore raffafié de fang.

Morfure de Il arrive fouvent qu'un bœuf eft ro pent. couché, fans le favoir, furr un ferpent qu'il n'a point vî dans un pâturage épais; le reptile incommodé de ce fardeau, pique le pefant quadrupéde, \& bientôt fon venin circule avec le fang dans tout le corps du bœuf. Si, par bonheur, cette blef. fure mortelie vient à votre connoiffance, faites-lui prendre de la rhue, clle pouffe au-dehors tout le venin; 


\section{R U R A L E. Liv. III. I 73}

\& ne croyez pas qu'aucun Médecin, (I3) aucun Machaon ait indiqué ce $8 E G R$ reméde : ces gens-là ne connoiffent que le nom des plantes, leurs efpéces \& leurs claffes. Mais la nature, plus utile aux animaux, leur enfeigne la propriété des fimples, \& la façon d'en ufer.

C'eft de la belette qu'un laboureur apprit autrefois à fe fervir de la Vertus de la Rhue, \&: de rhue pour les piquures de ferpent. plantes.

Une belette étant un jour aux prifes avec une couleuvre, qui lui faifoit réfiftance, elle alloit toutes les fois qu'elle en avoit été piquée, chercher de la rhue, fur laquelle s'étant roulée fecrettement pour fe panfer, elle retournoit au combat avec la même ardeur. Un payfan qui, d'un champ élevé, examinoit ce manége, fut arracher jufqu'aux racines cette plante de rhue, qui fe trouva être l'unique du canton. La belette revint, \& cherchant, hélas! inutilement dans tout le champ fon reméde ordinaire, le venin gagna infenfiblement jufqu'au cœur; elle enfla, \& mourut incontinent.

$P$ iij 


\section{E C ONOMIE}

IEGROS Si la vertu des fimples étoit conBETAILO nue, quelle maladie les hommes auroient-ils à craindre? C'eft à nous d'ufer de la raifon \& $z$ de l'expérience pour préparer \& mettre en pratique les fecrets que la nature indique aux animaux : ce font-là les guides que la Médecine a fuivis pour atteindre aux connoiffances dont elle fe glorifie tant. La cigogne s'eft la premiére rafraîchi les entrailles avec des fucs bienfaifans que lui adminiftroit fon long bec; le cheval marin avec un brin de jonc aigu, s'eft ouvert la veine le premier, quand il a eu trop će fang; \& le chien, en fe purgeant avec certaines herbes, nous a appris leur propriété, \& la façon de s'en fervir.

Il y a une pierre noirâtre \& fort ferpentine. légére, qu'on a apportée depuis peu du Levant, (I 4 ) qu'on appelle Pierre ferpentine, \&r qui a une vertu finguliére. Quand on la porte avec foi, on peut manier des ferpens, fans craindre l'effet de leur piquure. Cette pierre appliquée fur la playe, attire à elle tout le venin, \& le rend aufitotot, fi on la plonge dans de l'eau 
R U R A E. Liv. III. $x>5$ ou du lait chaud. De plus, cette même pierre s'imbibe du fang cor-bit rompu d'un ulcére, \& y refte attachée juiqu'à ce qu'enivrée de pus, pour ainfi dire, elle tombe d'ellemême.

Que dirai-je de la pefte, cette La Pefte mortelle contagion qui défole la campagne, \& lui enléve fubitement les taureaux qui la cultivoient ? Ils meurent de toute part au milieu des champs \& des bois, \& l'air au loin eft infecté de leur corruption; le matin le fermier voit les bœufs qu'il avoit enfermés le foir dans l'étable, y rendre les derniers foupirs. Plus d'une fois, en labourant la terre, l'un des bœufs de la charrue eft tombé mort au milieu de l'ouvrage, \& l'autre en pleurant le fort funefte du compagnon de fes travaux, \& traînant fon cadavre à l'extrémité du champ, devient encore compagnon de fa mort en tombant fur lui, \& $\&$ ferme pour jamais à la lumiére fes yeux mouillés de larmes.

Le trifte fermier retire fa charrue, $\&$ la trainant à contre cœur, porte à

$\mathrm{P}$ iii] 


\section{I76 C C O N O M I E}

i E GRos fa maifon, qu'il allarme, la nouvelle *isais. de cette double mort, \& va femer un jufte effroi dans tous les hameaux voifins.

C'eft pourquoi, dès que cette maladie contagieufe s'eft déclarée par fes ravages, ne fongez à conferver de vos troupeaux que les beftiaux qui font en fanté; reléguez-les au loin fur des montagnes, ou dans des bois, \& a abandonnez à leur deftin ceux qui font malades, fans chercher a les guérir. Cependant les Chrétiens ont tout à efpérer de la puiffante interceffion du Bienheureux Roch, qui, tandis qu'il vivoit, chaffa la pefte de fon pays par fes ferventes priéres, \& qui, toujours notre patron, \& puiffant auprès de Dieu, arrêtera du haut du ciel cette contagion dans fon cours.

Depuis peu déja Touloufe \& Montpellier ont élevé des autels fous fon invocation, après avoir éprouvé la protection de ce Saint, qui fut leur citoyen.

Il a récemment détourné de notre province ( I s) la perte qui défoloit 
R U R A L E. Liv. III. I I7 Marfeille, \& qui, dans tous les environs, exerçant fes fureurs, nous $C_{B E T A I L S}$ retenus dans l'enceinte de nos murs, par la crainte de la mort. Hélas! que de milliers d'hommes elle a fait périr! Mais, parmi tant de fujets de regrets \& d'allarmes, il en eft un bien grand de confolation, quand on fe fouvient que ces tems de calamité ont rendu à la Religion toute la fplendeur qu'elle avoit dans les premiers fiécles; \& lorfqu'on fe rappelle les illuftres exemples de zéle \& de charité que ce fléau a provoqués $\left({ }^{16}\right)$ chez les Fidéles. On les vit arriver par différentes bandes à Marfeille, où les appelloit le défrir de mourir glorieufement pour honorer la Religion \& l'humanité. Aucune confidération perfonnelle neles retient; ils s'ouvrent à travers les riviéres un paffage qu'un coupable en fuite, après s'être échappé de la prifon, n'auroit pas ofé tenter; ils ne craignent point, pour abréger leur chemin, de paffer un fleuve à la nage, malgré la largeur de fon lit, (épreuve que perfonne encore n'a- 


\section{$178 \quad \mathbb{E}$ C O N O M I E}

$L_{E G R O S}$ voit ofé faire ) \& s'expofent ainfi à ВЕ́тAIL, deux genres de mort différens.

La ville de Montpellier, fi utile à l'humanité, envoya des lecours à Marfeille. Il n'y vint ( I 7 ) que trois Médecins, mais qui valoient eux feuls toute la faculté. Ils fe livrent avec ardeur aux travaux de leur pro. feffion, oublient jufqu'à leur confervation propre, \& , difputant de coutrage entre eux, s'empreffent de prêter aux peftiférés les lecours que des concitoyens n'ofoient fe donner, \& qu'un pere même refufoit à fon fils. Non feulement ils vifitent \& foignent les malades, mais ils difféquent encore les morts, pour examiner la caufe de cette contagion, \& trouver dans la mort même des fecours utiles aux vivans. Ayant reconnu combien le peuple avoit de frayeur de ce mal, ( I 8 ) ils prouvent, moins par leur éloquence que par leur zéle, qu'on s'effraye mal-à-propos de la pefte, comme d'un mal contagieux. Cette terreur une fois bannie des efprits, ils prennent des précautions pour empêcher quue la faim 
RURA LE. Liv. III. I79

ne précipite plus de malades au tombeau que la pefte, qui n'eft pas UחBẼAII. mal incurable.

Des Militaires mêmes, qu'on ne foupçonne pas de bruler ordinairement du feu de la charité, (I g) abandonnérent leur pofte, \& vinrent à Marfeille. Miniftres de la mort au champ de Mars, ils employérent ici leurs bras à conferver la vie, \& ne craignirent pas plus la mort fous l'appareil de la pefte, \& à la vîe de fes victimes, qu'ils ne l'avoient redoutée au milieu du carnage \& des horreurs de la guerre.

Plufieurs femmes auffi, oubliant leur foibleffe naturelle, \& animées par la Religion qui les fortifoit, fecoururent, non-feulement leurs époux \& leurs enfans, mais encore tous les autres malades. Elles eurent la tendre générofité, dans le fort de la contagion, d'employer leurs mains délicates aux fonctions les plus ferviles, \& $r$ de panfer fans crainte les ulcéres les plus capables de révolter les fens.

(20) Ce fut vous, Illuftre Prélat , 


\section{0 (E C O NOMIE}

LEGROS qui, prodiguant vos jours, ranimâBÉTAIL. tes le courage de tous les habitans. On vous vit, bravant la mort \& $\mathrm{c}$ la crainte, marcher d'un pas intrépide au milieu des cadavres, \& voler au fecours des mourans, pour foulager leur corps, \& fauver leur ame.

Le bruit de ces exemples fe répandit avec la contagion dans les villes circonvoifines, \& la France (2i) fut toute furprife de voir les Evêques de nos jours, dignes émules des premiers pafteurs de l'Eglife, s'expofer à la mort pour le peuple, \& furpaffer autant les Miniftres fubalternes par leurs foins \& leur courage, qu'ils leur étoient fupérieurs par le mérite \& la dignité.

Parmi le nombre de ces Pafteurs, il y en eut un qui, après avoir appris l'extrémité \& la défolation de fon troupeau, accourut pour le foulager avec l'empreffement de quelqu'un qui viendroit recueillir une fucceffion. Peu inquiet de fes jours qu'il facrifioit pour le falut public, il quitta la Capitale que tous les aum tres alloient chercher. 


\section{R UR A L E. Liv. III. I8I}

$O$ vous! qui embouchez la trompette héroïque pour tranfmettre à la poitérité les actions des grands hommes, immortalifez les illuitres noms de ces $P$ afteurs généreux. Pour nous, continuons notre ouvrage, \& reprenons le foin des troupeaux.

Quand les gras pâturages manqlient dans un endroit, c'eft affez qu'un laboureur entende le gouvernement des boufs qui fervent à la charrue. L'Auvergne féconde en troupeaux éléve des vaches, \& s'attache à faire provifion de lait. Les vaches reftent dans les étables pendant l'hiver, tandis que la neige cout vre \& blanchit les champs de toute part, \& le foin qu'on donne alors aux troupeaux leur fait fupporter l'ennui de leur longue prifon. Mais auffitôt que l'haleine des zéphirs fait fondre la neige des montagnes, $\&$ que la terre, après un long froid, commence à fe parer d'un gazon renaiffant, alors, comme on voit les bandes guerriéres quitter les villes, \& fe raffembler au champ de Mars, dis que la trompetto en a donné le 
182

E C O NO M IE

LEGROS fignal, les vaches fortent avec preBE IAIL. cipitation des étables, fe rendent à l'envifur les plus hautes montagnes, \& prennent fans aucun guide la route qu'elles font dans l'habitude de Suivre.

Dès que ces troupeaux ont atteint les hauteurs, ils entrent dans les pâturages, s'en raffafient avec délices, 2 y paffent tout le jour. Mais le foir, quand la nuit approche, ils ont la précaution de former une forte de bataillon, \& d'affeoir une efpéce de camp, en fe couchant en rond fur l'herbe. C'eft ainfi qu'ils épouvantent ou qu'ils repouffent par la force les loups qui, fur ces montagnes, dreffent des embûches aux jeunes veaux. Ceux-ci font placés au milieu, \&z les bœufs fe couchent autour d'eux rangés côte à côte. Leurs corps pefans lont les fortifications qui défendent le camp, \& leurs cornes, prêtes au choc dans le cas de quelque alerte, font les palifiades dont les retranchemens font revêtus. Ainfi les meres tranquilles pour leurs petits, \& les petits en fureté près de 


\section{R U R A L E. Liv. III. I 83}

leurs meres, dont ils approchent le plus qu'ils peuvent, dorment touS SET ARL. fur un tendre gazon, fans craindre aucun danger.

Si une vache a remarqué au lever du foleil quelque loup rodant aux environs, elle remplit l'air de fes mugiffemens pour appeller du fecours : auffitôt les autres vaches accourant de toute part, lui répondent par leurs cris, \& ne touchent pas au moindre brin d'herbe jufqu'à ce que l'inquiétude foit bannie du troupeau par la fuite de l'ennemi.

Mais quoique les vaches errent à leur gré dans ces pâturages, elles ne manquent point tous les matins de fe rendre des l'aube du jour à la cabanne dui pafteur, pour fe faire traire. Le berger les récompenfe par un peu de fel, \& ce petit préfent les invite à venir d'elles-mêmes offrir des flots de lait à leur bienfaiteur. Le matin quand elles arrivent, le * ber-

* C'eft le devoir du bon palteur de connoître \& de conduire fon troupeau. Paftor pro. prias oves vacat nominatim, é educet eas io ante eas vadet. Evang. S. Jean, 


\section{4 (E C O NOM I E}

IEGROS ger appelle chaque vache par fon BETAIL. nOm, pour la faire approcher plus près qu'elle ne voudroit ; elle obéit, $\&$ il la trait, après lui avoir fait tourner le derriére du côté des vafes qui font dans fa cabanne. Mais de peur que les meres, fe fouvenant de leurs veaux, ne retiennent leur lait en refferrant leurs mamelles, chaque veau a la premiére libation de celui de fa mere.

Enfuite quand les vaches font retournées au pâturage, les bergers jettent de la préfure liquide dans le lait, le preffent bien avec leurs mains, \& mettent deffus une groffe pierre pour lui faire rendre toutes les parties fereufes.

Si quelquefois pour éviter les grandes chaleurs, \& 2 refpirer un air plus pur, les maîtres viennent de la ville voir leurs troupeaux fur la montagne : quel plaifir n'ont-ils pas de fe promener dans un pâturage délicieux, de compter les fromages, d'examiner les bergers, \& de voir le troupeau en bon état, foit queles beftiaux errent à leur gré dans les prairies, 
R U R A L E. Liv.IIT. I 85 prairies, qu'ils fe repofent, \& ru- $\overline{\text { LEGROS }_{\text {G }}}$ minent fur l'herbe, que les veauxBETAIL. jouent autour de leurs meres, \& qu'ils tondent quelquefois l'herbe d'un coup de dent mal affuré, foit que le pafteur s'occupe à traire les vaches, \&, les bras nuds, preffe le lait dans des vafes, foit que les bergers des montagnes voifines $f e$ réuniffent un jour de fête, \& boivent largement pour égayer leurs repas !

Souvent même les maîtres, renonçant au vin pour quelque tems, prennent le lait pour fe rafraîchir; \& lorfqu'ils ont befoin d'une médecine, ils n'ont point recours à ces eaux minérales, que la terre, par fes fels, rend falutaires; mais le matin (22) ils rempliffent de grands verres d'urine de vache, avec laquelle ils fe purgent. Potion qui fait beaucoup rire le berger, \& qui n'eft point enviće par le veau qui téte encore.

Mais lorfque les aquilons com-. mencent à foufler, \& $z$ que les premić-

Tome $I$. 


\section{Q C O NOM I E}

$\overline{L_{I C R O}}$ res neiges annoncent l'hiver \& la BETAIL. pluye, les troupeaux fongent à quitter les montagnes, paiffent jour \& nuit, font avec avidité provifion de nourriture pour la route; \& quoiqu'ils ne hâtent pas leur marche, ils defcendent pourtant d'eux-mêmes de ces froides montagnes pour aller paffer l'hiver dans les étables, à l'abri du vent.

(23) C'eft ainfi que Progné fugitive, quand les premiers frimats fe font fentir, \& lorfque le foleil s'eft éloigné de nos climats, abandonne fon habitation paffagére qu'elle récréoit par fon chant, \& va chercher des régions plus tempérées.

C'eft ainfi que Philoméle, qui le matin falue le Dieu du jour par fes tendres accens, (24) garde le filence pendant la nuit ; tandis qu'au milieu des ténébres, le hibou, par fa voix lugubre, annonce aux mortels de funeftes préfages.

(25) C'eft ainfi encore que la maifon d'un maître, dans le tems de fa profpérité, eft fréquentée par un troupeau d'amis, qui s'enfuient dès 
R U'R A I E. Liv.III. I87 qu'il furvient un tems fâcheux; \& $\overline{\overline{L_{E G R O S}}}$ que la fortune, qui fe plait à loger $B \equiv \mathrm{I}_{\mathrm{A}} \mathrm{R}$. fous différens toits, emméne avec elle ces amis inconftans chez tous les hôtes où elle va camper.

Fin du Livre troifiéme. 


\section{REMARQUES}

Sur le troifiéme Livre.

E gros Bétail fait la matiére de ce Livre. 1 L'Auteur ne dit qu'un mot du cheval, qu'il regarde ici comme un animal plus utile aur voyageurs \& aux guerriers, que propre au labourage : mais il parle amplement des boufs, de leur ta:lle, de leurs qualités, de la maniére de les dompter, de l'amitié qu'ont entr'eux ces animaux, \& de leurs différentes maladies. Il fait auffi mention des vaches, de l'àne, du mulet; \& à l'occafion des remédes qu'il indique pour leurs maladies, il fait l'éloge de quelques plantes, \& principalement de la rhue; il exalte auffi les vertus de la pierre ferpentine. Enfin la pefte, dont le gros bétail fent trop fouvent les funertes effets, lui donne lieu de décrire celle de Marfeille : d'où il paffe pour terminer ce Livre, à l'ufage des habitans d'Auvergne, qui envoyent au printems les troupeaux fur les montagnes.

(I) [Qu'il lui apprenne à faire de fatiguanses courbettes.] Virgile dit également, Georg. L. 3 .

Uli quarta accefférit alas Carpere max garum iucipiat, gradibufque fonare 


\section{Renarq. Surle troifiéme Livre. I 89}

Compofrtis : finueigue alterna volumina crurum:

Sitque laborantifimilis: tum curfibus auras

Provocet, ac per aperta volans, ceu liber habenis, Equora, vix fummâ veftigia ponat arenâ.

(2) [Quand des extrémités de l'A $A$ be fopo tertrionale. ] L'opinion la plus commune eft que la Tartarie eft jointe à l'A mérique ; con.. féquemment fi certe quatriéme partie du monde n'eft qu'une prefqu'ife, il n'elt point étonnant que Criftophe Colomb l'ait trouvée fi peuplée. Il eft vrai que ce chemin qui conduit de l'Afie feptentrionale en Amérique n'eft point encore connu, mais feulement confidéré comme poffible.

(3) [Après qu'il aura vî̀ trois récoltes.] C'eft un tour poëtique pour dire qu'il faut accoutumer le bøuf à porter le joug quand il a trois ans paffés.

(4) [Se font rangés fous le joug. ] Il y a dans le texte pellite jugo. L'auteur donne au joug cette épithéte, parce qu’on le garnit d'une peau, de peur qu'il ne bleffe le cou des jeunes bœufs.

(5) [Vient promptement à fon secours.] I! $y$ a dans le texte :

Auxilio jam non piger advolat.

Je n'ai pas crû devoir rendre le mot ad colat p.ir le terme françois vole; parce que l'agilité n'ctant pas à beaucoup près la qualité ulu bơuf il m’a femblé que l'oreille françoife feroit te- 
volrée fi l'on difoit d'un bouf qu'il vole au fecours de fon compagnon. Cetre figure eft un peu trop forte pour un animal aufi pefant : cependant elle choque moins dans le texte, parce que c'eft un Poëme.

(6) [Retirez du travail un bouf quand il eft vieux.] Cet endroit eft imité d'Horace :

Solve fenefcentem mature fanus equum, ne Peccet in extremum ridendus o ilia ducat.

(7) [Auxquelles le gros bétail eft fujet.] L'Abbé Desfontaines, dans fa traduction de Virgile, a rendu pecora majora er minora, par grands \& petits troupeaux. Il eft fingulier que ce Littérateur ait confondu les grands \& les petits troupeaux avec le gros \& le menu bétail : les grands \& les petits troupeaux défignent feulement la quantité, mais non pas l'efpéce. C'eft pour la diftinguer qu'on dit gros \& menu bétail. Par la premiére dénomination, on entend les bøufs, les vaches, les chevaux, les ânes, les mulets; voilà ce que fignifient pecora majora for armenta: \& par la feconde, on entend les moutons, les béliers, les brebis, les chévres, les pourceaux ; qu'on appelle en latin fecora minora aut greges. On peut dire qu'on a un grand troupeau de moutons, \& un petit troupeau de bœufs : ce qui ne fe pourroit pas, fi le fens que donne l'Abbé Desfontaines à pecora majora, étoit jufte.

(8) [ La mule eft engendrée.] Il y a dans 


\section{Sur le troifléme Livre.}

le texte, mula Rhutenenfis. L'Aliteur l'appelle mule de Rouergue, parce qu’on en éléve beaucoup dans ce petit pays du Lyonnois. Mais dans une traduction, de pareilles épithéfont toujours de trop.

(9) [ ['Espagne préférant. ] Les équipages du Roi même nont que des mules, \& ces animaux fervent de monture à la plupart des habitans.

(10) [Ne Se faifoient porter.] Je ne fai fis ces tems font aufí à regretter que le penfe l'Auteur. Les Magiftrats d'aujourd'hui peuvent dire pour leur juftification, autre tems autres inxurs. Dès quion a du bien pour fe procurer fes commodités, pourquoi ne pas s'en fervir ? D'ailleurs les Juges qui alloient autrefois au Palais fur des mules, pouvoient, eû égard à leur fiécle, être taxés d’autant de fafte que les Magiftrats de nos jours ; parce que, dans des tems plus reculés, les Juges fe rendoient peut-être à pied où les appelloit leur miniftére. Ainfi l'on pollvoit dire, en comparaifon de l'ufage précédent, que ceux qui fe faifoient porter par des mules, montroient trop de fafte, \& avoient trop de vanité : tout eft relatif.

(II) [Etoit à la fois portier, palfrenier \& cuifinier. ] Moliere, dans fa Comédie de l'Avare, a trop jetté de ridicule fur les gens qui, avec du bien, portent l'œconomie à ce point$1 \mathrm{i}$, pour que cet ancien ufage reprenne $f_{2}-$ veur.

( I2) [Et du Garum.] C'eft une fauffe 
que les anciens faifoient avec la faumure du poiffon nommé Garus, que Voflius prétend être le maquereau.

( I 3) [Aucun Machaon.] Il étoit fils d'E. culape, \& l'un des célébres Médecins de la Gréce. Il partit pour le fiége de Troye, \& y fut tué par Eurypile. Virgile dit qu’il fut le premier à fortir du cheval de bois pour s'emparer de la ville.

\section{Illos patefaltus ad auras}

Reddit equis, latigue cavo fe robore promunt Tifandrus Stbenelufque duces, \& dirus Ulyfes , Demijfum lapfa per funem, Atbama que Throajgue Pelidefque Neopelemus, primufque Machaon.

Fneid. 1. 2:

(I4) [Q $u^{\prime}$ on appelle pierre serpertine.] On a attribué à cette pierre, ainfi qu'au bézoard, quantité d'effets merveilleux. Mais leurs vertus, fi prônées par les charlatans, s'évanouiffent quand ce font des naturaliftes éclairés qui en font l'épreuve. Au refte, l'éloge qu'en fait le Pere Vanniere ne doit pas feduire le Lecteur : les Poëtes adoptent les opinions communes, quand elles leur fourniffent des images : c'eft au Phyficien à les examiner. Voyez le Traité univerfel des Drogues fimples, par Nicolas Lemery, article Lapis Serpentis. Voyez auffi Tavernier. Les charlatans font accroire que c'eft une pierre qu'on trouve dans un ferpent que les Portugais appellent, Ebra de Capelos, \& les François, Serpent aus chateron, 
chaperon; quoique ce ne foit qu'un morceau de corne de cerf brulé fur les charbons.

( Is) [La pefte qui défoloit Marfeille.] L'auteur fait ici la defcription de la pefte de Marfeille, à l'imitation de Virgile, qui, à la fin du troifiéme Livre des Géorgiques, décrit celie qui délola le Frioul \& la Carniole dans les Alpes Italiennes; \& de Lucrece, qui peint celle de l'Aitique, qu'a aufil rapportée Thucydide. Mais il s'en faut bien que la defcription du Pere Vanniere égale celles des deux Poetes \& de l'Hiftorien dont je viens de parler. La fienne eft une gazette, un récit froid, plutôt qu'un tableav. Lucrece, au contraire, fait une peinture fi vive de cette affreufe maladie, qu'on croit en être attaqué, \& qu'on eft prefque tenté de prendre un prefervatif. Si Lucrece \& Virgile n'étoient pas dans les mains de tout le monde, j’aurois inféré ici leurs defcriptions.

( I6) [Chezles Fidéles. III y a dans cet endroit une tirade de vingt vers qu’on a jugé à propos de fupprimer, comme un hors-d'cuvre. Cette fortie déplacée fur les Janféniftes ma $^{2}$ parue peu convenir au caractére du Pere Vanniere, qui, par fon efprit, fa douceur \& fa politefle, a mérité l'amitie de tant d'hommes illuftres. D ailleurs dans un Poëme où il s’agit des délices \& des travaux de la campagne, peut-on prendre avec grace le ton d'Archiloque ?

(I7) [Que trois Médecins.] Ce furent Tome $I$.

$\mathrm{R}$ 
MM. Chycoineau, Chancelier de l'Univerfité de Montpellier, Didier, Profeffeur de la même Univerfité, \& Vergizy', Médecin de cette ville.

(I 8) [Ils prouvent moins par leur éloquence. ] M. Chycoineau fit imprimer un Livre où il foutient que la pefte n'eft point con tagieufe. Peut-être fut-ce par politique que ce Médecin ofa réfuter l'opinion commune; parce que plufieurs perfonnes, dans la crainte de gagner cette maladie, refufoient leur fecours aux peftiférés. M. Aftruc, Médecin alors à Montpellier, fit une Differtation pour prouver que la pefte eft contagieufe, \& $\mathrm{fe}$ communique par les corpufcules peftiférés, dont l'air eft chargé. M. Didier, dans un Difcours, a réfuté ces deux opinions, \& dit : $\mathrm{Si}$ la terreur feule eft capable de produire la pefte, comment des enfans de huit jours ont1ls pu mourir de cette maladie ? Si elle fe prend par l'atmofphere des atômes peftilentiels, comment quelqu'tun a-t-il pu entres dans une infirmerie de peftiférés, fans être frappé de la pefte. Le fentiment de M. Didier eit que la pefte fe gagne par un contact immédiat \& durable.

(ig) [ Abandonnérent leur pofte.] Ce furent MM. de Langeron, de Montaud, \& de soiffons.

(20) [ Ce fut vous, Illuftre Prélat. ] L'Aureur entend parler de Henri de Belfunce, Evêque de Marfeille, dont le zéle entendu, 
les foins \& les aumônes, fauverrent plufieurs perfonnes, \& reveillérent les fentimens d'ht. manité parni bien des gens que la crainie écartoit du danger.

(2I) [ Fut toute furprifo de voir les Ez $6-$ ques de nos jours. ] Voici les noms de ces Ereques charitables, qui ont fait homneur a l'humanité en fe dérouant pour le falut du penple. MM. de Ventimille du Luc, Archeve. que d'Aix, Forbin de Janfon, Archevềque d'Arles, Louis de la Tour-du-Pin. Montanban, Evêque de Toulon, de Forefta de Colongue, Evêque d'Apt, \& Davejan, Eveque d'Ales.

(22) [Ils rempliffent de grainds verres.] L'urine de vache, qu'on appelle Eau de mille-fleurs, cit un bon reméde quand on a l'eftomac chargé.

(23) [C'eft ainji que Pronné. ] Elle étoit fille de Fandion, Roi d'Athenes. Eile fut changée en hirondelle. Voyez les Métan morphofes d'Ovide, \& le Dictionnaire de la Fable.

(24) [Garde le filence pendant la nuit.] Ceci n'eit pas exact: quand le rofignol eit: dans la faifon de chanter, on entend fon ramage auff fouvent la nuit que le jour.

(25) [C'eft ainfi.] Cette penfée eft imitée d'Ovide.

Donec eris felix mulcos numerabis amicos,

Tempora fo fuerint nubila, folus eris.

$R$ ij 
196 Remarques, Ecc.

Pétrone fait dire à un des convives du repas de Trimalcion : Scito autem cùm olla malè ferret ón ubi fimul res inclinata eft amici de medio. Horace dit auffi:

\section{Diffugiunt cadis}

Cum foec ficcatis a mici.

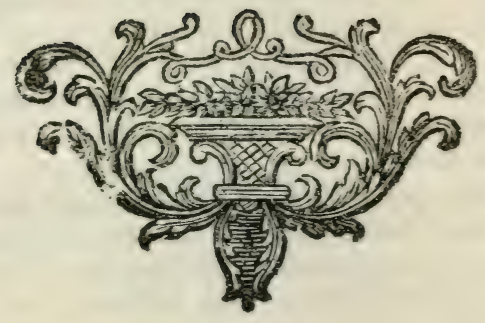




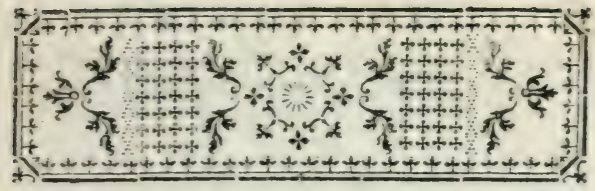

\section{E C O N O M IE}

R U R A L E.

\section{LIVRE QUATRIÉME.}

\section{Le petit Bétail.}

DARLONS maintenant du foin Les Brebis.

1 qu'on doit prendre des troupeaux de brebis. (I) Elles font le préfent de la nature le plus utile à la terre \& aux hommes : car le fumier de ces beftiaux rend la terre meilleure pour les bleds, leur toifon couvre les hommes, leur chair les nourrit, \& je ferois tenté de croire, agréable argent, (2) que vous prîtes votre nom de celui de troupeau, après que la vie paftorale eut élevé Rémus \& Romulus, \& enrichi ces 


\section{C C ONOMIE}

LE PET 12 fameux bergers au point qu'ils furent

Q ESALL. en état de bâtir Rome, de l'entourer de murailles, \& de faire adopter leurs ufages \& leurs loix aux peuples qu'ils avoient fubjugués.

Les fermiers n'auront pas moins de foin du menu bétail que du gros: car la brebis imbécille ne veille fur elle d'aucune façon. Dieu lui a donné une riche toifon, au lieu de la force $\& r$ des armes qu'il a départies aul refte des animaux. (3) Le bouf attaque courageufement fon ennemi avec fes cornes, le cheval fe défend avec le pied, le lion déchire avec les griffes, le tigre mord, le renard employe la rufe, le chien montre les dents \& s'en fert dans l'action, \& le cerf timide pourvoit à fa fureté par Yagilité de fes pieds.

Mais la brebis n'a ni rufe, ni force, ni aucune efpéce d'armes; point de courage, point de reffource dans fes dents pour repouffer les attaques du loup, ni d'agilité pour éviter fes embuches. A peine doubleroit-elle le pas pendant un orage, fi le pafteur avec fa houlette ne la preffoit 


\section{RURALE. Liv.IV. I 99}

de marcher, \& ne l'avertiffoit par fes cris de fe mettre à couvert de la BEIAIL. pluye.

Mais, quoique la nature l'ait vétue plus qu'aucun autre animal, cependant elle eft $\mathrm{fi}$ délicate que les grands froids la font mourir, fi la bergerie n'eft pas expofée au midi, \& fi le berger n'a pas foin de faire au troupeau une litiére (4) de paille \& de fougére bien féche, fur laqnelle les agneaux avec leurs meres foient coulchés mollement \& proprement pour fe repofer. Car les brebis qui, dans des tems bien reculés, vivoient en plein air au milieu des forêts , \& bravoient l'hiver \& fes frimats, font devenues délicates comme nous depuis que nous en avons fait des animaux domeftiques. Plus on prend de précaution pour fe conferver, plus les corps devenus fenfibles don. nent de prife aux maladies.

C'eft pourquoi examinons les foins Les Agnaaux. qu'il faut prendre d'un agneau dès fon âge le plus tendre. Auffitôt qu'il eft né on le léve \& on le tient droit fur fes jambes; on prefle les mamel- 
LE PEIII BEIAII.

les de la brebis, \& l'on fait gouter fon lait à l'agneau, afin de l'habituer à téter lui-même fa mere. Mais lorfque le berger la trait pour la premiére fois, il doit jetter le lait; car il eft pernicieux, \& cauferoit des maladies aux agneaux dès leur naiffance.

On enferme enfuite l'agneau avec fa mere, afin que celle-ci le foigne davantage, \& que l'agneau apprenne à la connoître. Après deux jours on permet aux brebis, qui ont mis bas, d'aller paitre de (5) l'orge en herbe : mais on retient les agneaux dans la bergerie, quoiqu'ils appellent leur. mere par des bêlemens fans fin qui font retentir le bercail.

Lorfque l'âge aura fortifiè l'agneau, \& qu'il commencera à être grand, on le laiffera aller au pâturage , pour exercer fes dents fur les herbes tendres; \& quand fa mere \& lui fe feront raffafiés de leur premiére tendreffe, \& qu'ils pourront l'un \& l'autre fupporter leur abfence fans inquiétude, la mere retournera au pâturage à l'ordinaire, \& les tendres 


\section{R U R A L E. Liv. IV. 201}

agneaux iront paitre, fous la condui-

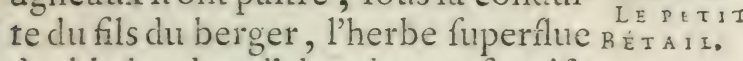
des bleds, dont l'abondance eft nuifible quand ils commencent à pouffer ; ou bien que le berger éléve fon fils aux travaux champêtres, $\&$ s'il a chez lui une jeune fille, qu'elle faffe paître les agneaux, \& qu'elle ne les enferme pas dans l'étable après qu'ils font raffafiés, mais qu'elle les laiffe bondir fur le gazon, tandis qu'elle s'amufera à rouler fur un fufeau le fil de fa quenouille.

Cependant, jeunes filles, ne vous accoutumez pas à ce genre de vie. Il étoit permis autrefois dans les fiécles d'or; mais aujourd'hui vous ne cievez connoitre (6) ni les fatyres qui fe cachent dans les bois, ni d'autres larcins que ceux qu'on fait des brebis.

Lorfque les meres reviennent le foir du pâturage, on les enferme avec leurs petits, à qui elles donnent leurs mainelles à preffer pour fupplément de la nourriture du jour. Quand ils font févrés on les laiffe pầtre à la campagne avec le refte du troupeau, \& on les met dans la mệ. 


\section{C C O O M I E}

I E PEIIT me bergerie; ou bien, on les fait par-

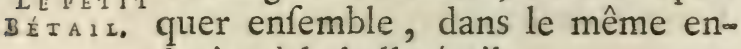
droit, à la belle étoile.

Mais la concorde n'habite pas longtems parmi eux, (7) \& le cruel Amour, qui, prefque toujours dans les villes, fait le tourment \& la perte des hommes, régne avec le même empire parmi les troupeaux. A peine un agneau fent-il fon front armé de cornes, qu'il clécéle par mille em. portemens le feu brulant qui le dévore, \& que tous les béliers devenus rivaux fe livrent des combats; à moins que le pafteur, avec le fer, ne tranche la caufe de leurs amours effrénés.

Le Bélicr.

Il faut que le bélier auquel on deftine l'emploi \& le titre de pere, ait le corps large \& élevé, qu'il foit chargé de laine, \& qu'elle foit plus blanche que la neige. Sa langue ni fa toifon ne doivent point être bigarrées de différentes couleurs, de peur que la laine des agneaux ne reffemble à la fienne. Il faut qu'il ait beaucoup de laine au cou, à la tête, au ventre, \& même autour des yeux; 
RURALE. Liv.1V. 203 que fes cornes foient courbées fur le mufeau. Ses rivaux en font bleffés LE REт1 quand il les a droites. Dès qu'il les fent pouffer, fier de fes armes, \& piqué de jaloufie, il eft continuellement en guerre ayec les autres. Mais voici la façon de le corriger : on prend un petit ais de bois, qu'on arme de pointes de fer; on le lie aux cornes du bélier qui eft jaloux \& hargneux, les pointes tournées vers le front. Avec cette efpéce de cafque, il fond fur fon ennemi, \& élevé fur fes pieds, il lui heurte la tête de la fienne : mais, bleffé de fes propres coups, il fe garde bien dans la fuite d'ufer d'une arme qui lui eft funefte à lui-même.

Pour chef de votre troupeau, prenez un bélier qui ait les cornes mutilées. Ainfi défarmé, il aimera la paix, \& ne cherchera point à lutter contre les autres. Ne luidonnez point à faillir des brebis trop vieilles ou trop jeunes; les unes font expofées à une mort prochaine, $\&$ les autres trompent fouvent vos efpérances.

Que le pafteur ne méne pas paitro 


\section{$204 \quad E$ C O N O M I E}

LEPEI fon troupeau loin de la bergerie, BÉTAIL lorfque $(8)$ les grues \& la finitre préfages de corneille appellent la pluye par leurs pluye. cris aigus, ou que les boufs lévent la tête \& ouvrent les nazeaux pour refpirer, ni lorfque l'air eft pefant, ou que les mouches fe font plus fentir qu'à l'ordinaire, ni quand le héron s'éléve au-deflus des nues pour éviter les vapeurs qu'exhale la terre lorique le tems menace de pluye. Craignez encore qu'il n'en tombe lorfque le vent fait voltiger des feuilles légéres, \& les entraîne dans les tourbillons qu'il excite; ou quand vous voyez des traits de flamme briller dans les airs; (9) ou quand Iris fe difpofe à verfer dans les campagnes l'eau qu'elle pompe avec les deux pointes de fon arc; mais furtout lorfque pendant l'été le tonnerre gronde dans les airs, \& qu'un nuage épais fe réfout en pluye chargée de petits animaux venimeux. Enfermez votre troupeau dans la bergerie; car il ne pourroit prendre de poifon plus mortel : \& cependant l'mprudente brebis l'avale avec plaifir. 


\section{R URALE, Liv.IV. 205}

Dans le printems, vous n'ouvrirez le bercail que lorfque le foleil au- $B$ E ra diffipé la gelée blanche qui couvre l'herbe. Des que la canicule fera Les pàturzfentir fa brulante haleine, menez paître votre troupeau deux fois par jour; une fois le matin, lorfque la rofée rend l'herbe plus délicate, \& une autre fois lorfqu'elle eft humectée par la fraîcheur du foir, qui en rend les fucs plus agréables. Car lorfque l'aftre du jour au milieu de fa courfe, darde fes rayons avec le plus de force, \& que l'herbe flétrie $\&$ defféchée fe foutient à peine fur fa tige, le berger doit conduire le troupeau dans quelque vallée; afin de le mettre fous des arbres touffus ( I0) à l'abri de la chaleur.

Pour accompagner \& venger le troupeau, le pafteur doit avoir un chien, qui, dans les pâturages, lui ferve de garde, \& qui, pendant la nuit, fentinelle infatigable, foit la fureté de la bergerie, \& dont les cris menaçans fuffifent pour épouvanter les loups \& les voleurs.

Que le berger conduife lentement ges. 


\section{6}

fes brebis dans les champs; qu'il IE ETIT excite les pareffeufes, \& qu'il arrête celles qui fe hâtent trop : enfin qu'il rappelle par des fiflemens aigus, ou en prenant la voix menaçante d'un homme en colére, celles qui s'écartent du troupeau. Si quelque brebis nouvellement mere fe couche de foibleffe, le tendre berger doit mettre fa tête fous elle pour la foutenir, lui montrer l'agneau qui vient de naître, $\&$ le rechauffer dans fon fein.

Il doit connoître la caufe des maladies du troupeau, \& la façon de les guérir ; les différentes faifons, \& les endroits propres aux pâturages ; quelle couleur de laine fe vend le mieux, \& annonce en même tems la meilleure chair. Il doit favoir dans quelle faifon fe tondent les brebis, $\&$ à quelle heure il faut les ramener du pâturage, \& les abreuver à quelque agréable fontaine.

Le berger qui ne veut pas négliger pour fon troupeau les plus petits foins, le méne paître le matin du côté du couchant, \& le foir du côté du levant : car la grande chaleur eft 


\section{R U R A L E. Liv. IV. 207}

pernicieufe aux brebis, lorfque panchées pour paitre, elles ont encore LE ĖTIT la tête expofée à toute l'ardeur du foleil.

Qu'on ne choiffife pas fur-tout de gras pâturages, qui raffafient le troupeau. On doit donner la préférence aux collines \& aux terreins fecs, dont l'herbe courte contribue beaucoup à rendre la laine des brebis plus belle \& plus fine. Le meilleur mouton pour le goût \& la délicateffe de la chair, eft celui ( I I) du Gange, qui fe nourrit de thim.

Le berger fenfible aux premiers froids, ne doit pas être affez lâche pour refufer de paffer à la belle étoile quelques nuits fraîches de l'automne, fous le prétexte que fes brebis font foibles \& malades : car la menue fiente des brebis parquées, \& leur chaleur modérée, engraiffent bien mieux une terre, que fi on la chargeoit de grands tas de fumier.

Si cependant l'hiver, par un froid prématuré, rend la faifon trop rude, vous ne laifferez pas coucher yos brebis fur la terre, ni aller les 


\section{CE C O N O M I E}

LE PETAT pieds tout gelés chercher triftement BÉTAIL. fous la neige quelques brins d'herbe féche $\&$ aride : mais vous leur donnerez dans la bergerie, de la vefce, des pois cornus, des feuilles d'arbres \& du foin; de peur que la faim cruelle ne les gagne, \& que la gale fa compagne ne s'empare de tous leurs membres. Dès que ce mal infecte le troupeau, la demangeaifon excite les brebis à fe froter contre les arbres; elles fe gratent avec leurs cornes recourbées, ou fe déchirent avec les dents : après quoi bientôt cette pefte fe communique à touıe la peau.

Après l'hiver, quand le foleil a fait fondre les neiges, les troupeaux retourneront aux pâturages. Le bélier marche à la tête; fous un tel guide les brebis errent fans crainte dans la campagne, elles aiment à l'avoir pour chef, foit que le berger les raméne le foir, foit que pendant la chaleur il les conduife dans les vallées ou dans les bois, foit qu'il faille paffer un ruiffeau, entrer dans une barque pour traverfer un fleuve, ou

fauter 


\section{RURA L E. Liv. IV. 209}

fauter un foffé. Ce font des animaux qui aiment tant à fuivre l'exemple BETAII, de leur chef, que s'il prend envie au bélier de fauter, toutes les brebis ( I 2) fautent à fon imitation, quoique ce foit dans un terrein plat.

Les moutons qui ne font qu'à moi- Les Moutons. tié mâles, fe laiffent auffi conduire au pâturage par le méme chef. On ne choifit point pour marcher à la tête du troupeau le bélier qui a la plus belle apparence, la plus riche toifon, le plus d'âge ou d'expérience : mais, de même que parmi les Grands la faveur capricieufe éléve aux honneurs ceux qu'il lui plaît, ainfi le goût de préférence qu'un pafteur a pour un bélier, fuffit pour en faire le général du troupeau. II marche toujours le premier, fonde le terrein : \& , de même qüil conduit les brebis à l'abreuvoir \& au pâturage, il eft leur perfide conducteur quand elles vont à la boucherie. Ainfi, parmicette efpéce d'animaux, il y en a qui trahiffent leurs femblables, \& qui fe foumettent d'cuxmêmes à ce trifte miniftére pour une

Tome $I$. 
210

QE C O N O I E

vile récompenfe : car le pafteur paye

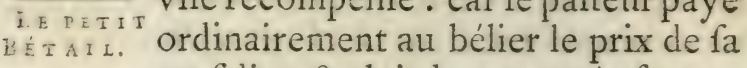
perfidie, \& lui donne après fon retour un peu de bled, ou quelques autres graines de fon goût.

Is Eor:c, C'eft le devoir du bouc de devancer les chévres, lorfqu'elles graviffent fur le haut des montagnes. Mais ( I 3) la goutte lui permet à peine de faire un pas avecelles. Ce mal eft le trifte falaire des plaifirs auxquels le bouc fe livre dès fes premiéres années. A peine la barbe lui croitelle au menton, à peine fes cornes ont-elles commencé à percer, que les feux cachés de l'amour font déja des progrès dans fes veines. Aufi une vieillefie prématurée le rend bientôt infirme; il devient lent, pareffeux, malade, inutile à tous égards : fon odeur infupportable infecte les troupeaux \& l'air des environs, \& bientôt la mort met fin à fes triftes jours.

ies Cinéries. Les chévres agiles \& les bêtes à laine ne paiffent pas dans les mêmes lieux. La chévre marche en fureté au milieu des rochers les plus efcar- 
R U R A L E. Liv.IV. $2 I I$

pés, \& recherche avec avidité le citife \& les petits arbriffeaux qui DETETII font fur le penchant des montagnes. Les brebis aiment à paître dans les champs, \& non pas fur de ftériles rochers, qui ne font couverts que de ronces \& de buiffons ; les épines leur déchirent la peau, \& leur arrachent des floccons de laine, que les oifeaux enlévent avec foin pour en tapiffer leur nid.

L'Efpagne, qui a foin de charger fes brebis de peaux de boucs, les garantit avec cette couverture épaiffe, des ronces $\&$ des épines, \& en retire de très-fines laines; $\&$ de même qu'elle fait deux récoltes de foin tous les ans, elle tond deux fois l'année fes lucratives brebis.

Ces animaux font fantafques, \& Ia varíté des rebutent les pâturages qu'ils ont paturages. long-tems fréquentés. Ainfi que nous aimons à voir fur nos tables des mêts variés \& apprêtés par une habile main, de même les troupeaux aiment à faire un'échange des plus. gras pâturages avec ceux qui ont le moins de fuc, \& les feuilles renaif- 


\section{$2 I_{2}$ E C NO MIE}

fantes des arbiffeaux leur ôtent le

LETEIIT dégoût que la fatiété leur avoit caufé. Mais fur-tout après l'hiver \& les pluyes, lorfque la faifon approche de mener les brebis fur les montagnes, les plus vertes prairies ne les arrêteroient pas davantage que ne feroient retenus des jeunes gens par les délices de la ville, \&z la fociété de leurs amis, quand l'automne raméne les fruits $\&$ les vacances.

Ia tonte des Les brebis font charmées au comMoutons. mencement de l'été qu'on les dépouille de leur toifon : c'eft une courverture d'hiver qui les échauffe trop. Le pafteur couche par terre la brebis qu'il veut tondre, l'attache par les pieds avec une corde, \& lui coupe enfuite fa toifon. La bergerie, pendant cette opération, ne retentit pas du moindre bêlement, on n'entend. que le bruit des cifeaux, à peine la brebis pouffe-t-elle un gémiffement, quoique le cruel pafteur, en la tondant jufqu'au vif, lui faffe de larges bleffures, qu'il ne daigne panier qu'avec de la pouffiére de charbon, au lieu de frotter les playes avec de 
R U R A E. Liv.IV. 213

I'huile d'olive, ou de la poix liquide. Autrefois, quand on devoit tondre fes brebis, on donnoit une fète à fes amis, \& on les invitoit à manger. Ces agréables feftins revenoient au tems de la moirfon; on les répétoit encore pendant les vendanges, lorfque la vigne foutenue de lormeau avoit prodigué fes fruits, \& que Bacchus par fa préfence ranimoit la joie du village. La gayeté n'habite plus la terre à préfent, depuis que Bellonne la délole par fes fureurs. Mais la paix au vifage ferein, \& fource des richeffes, va bientót rappeller les ris \& la félicité. D: haut des Donceurs de cieux je la vois defcendre; la Piété la fuit, \& l'heureufe Abondance.

Déja cette puiffante Déeffe, qui fait terminer les difcordes des Rois, volant de Royaume en Royaume, parcourt leurs fuperbes palais, \& nous efpérons qu'elle ne leur confeillera pas en vain d'épargner le fang de leurs fujets, \& de vivre helireux dans leurs Etats pacifiés.

Ainfi nos oreilles fatiguées n'entendront plus le fon bruyant de la fatale 


\section{Q $C$ C N O M IE}

IEPEIIT trompette; mais de tout côté les DẼAII. bergers chanteront fur le chalumeau leurs tendres amours; les vaiffeaux étendront librement leurs voiles, \& vogueront fans crainte; il n'y aura plus pour les nautonniers d'ennemis à combattre que les vents en fureur ; les épées déformais feront rouillées dans le fourreau, on ne verra briller que les armes champêtres, \& le laboureur trouvant fes greniers trop étroits pour fes riches moiffons, admirera combien les tems font changés. Les fiences \& les arts rendront les villes floriffantes, \& les Mufes recevront encore nos hommages \& nos éloges. Quoique pourtant elles ne gardent pas le filence, malgré la Mention de longueur de la guerre, ( 14 ) le refM.de Bignon. pectable Bignon les protége. Il tient le fceptre du Parnaffe; \&, Prêtre à la fois de Thémis \& d'Apollon, illuftré par fes aieux, mais plus encore par lui-même, il honore \& chérit les Poëtes, \& favorife par fes foins le progrès des beaux Arts. La nature par fon fecours fe montre \& fe dévoile dans l'étude des plantes, 
RUR A LE. Liv. IV. 2 I 5

\& nos yeux pénétrent jufqu'aux aftres, \& en mefurent l'étendue; nous recherchons l'origine cachée des fources \& des vents; il n'eft point d'image que notre cizeau ne rende fur le marbre; notre fiécle n'envie plus à la Gréce l'Apelle qu'el. le a tant vanté, \& qui, à l'antiquité près, n'a rien de plus que nos artiftes. Notre langue, favant Bignon, s'ett parée par vos lumiéres d'une grace nouvelle, fa richeffe \& fes agrémens font connus dans l'univers auffi loin que nos armes.

Mais reprenons notre fujet, \& con- L'art d'aptinuons de parler des troupeaux \& $x$ de prêter la lajla campagne. J'aimerois affez à dire comment il faut nétoyer une toifon, la peigner \& la carder; je montrerois comment il faut tirer la laine d'une quenouille, la devider en plufieurs pelotons, \& de quelle maniére le fil attaché à une navette, \& abandonné d'une main légére, paffe \& repaffe dans les ouvertures de la chaine, pour en faire un tiffu ferré : peut-être même enfeignerois-je à teindre la laine dans des vafes d'ai- 


\section{$216 \quad$ E C ONOMIE}

$\widetilde{L_{E P E T I T}}$ rain remplis de fucs préparés, à lui

BETAIL, donner l'éclatante couleur de la pourpre, ou celle du fafran, à lui faire prendre une teinture noire ou violette. Mais, fans doute, il fe trouvera un jour quelque Poëte qui choifira pour fijet l'art d'apprêter les laines, \& celui de manier le peigne, ou l'aiguille à broder, qui repréfente les délicieufes occupations de la campagne, ou les combats des Rois, dans des tapifferies délicatement travaillées. Pour nous il nous refte encore plufieurs chofes à dire des brebis \& du chien qui les garde.

Difperfion Divifez votre troupeau en différendu troupeau. tes bandes, afin que, paiffant dans plufieurs endroits éloignés les uns des autres, il confomme les pâturages qui font au loin, \& que vos brebis ne s'épuifent pas à faire trop de chemin, ou ne périffent pas toutes, fi la pefte infecte un canton, \& ne s'étend pas encore de toute part. Mais cette contagion eft bien plus à craindre encore pour les chévres; à moins que vous n'enfermiez dans un enclos celles qui en font attaquées, 


\section{RUR A L E, Liv. IV. 217}

$\&$ que vous ne leur faffiez prendre pourantidote des racines de rofeaUX DEFEIL, \& d'épine blanche bien broyées \& délayées dans de l'eau.

Il y a des pays où les bergers mê- Différentes lent enfemble toutes les efpéces de affections du troupeaux, \& conduifent indiftinc-bresise tement dans les mêmes pâturages les porcs \& les brebis, quoiqu'on fache que leurs goûts foient très-différens. Les porcs aiment les forêts \& les lieux ombragés; la brebis hait tous les bois, fe plaît dans de verds pâturages, \& détefte les rivages où le porc aime à fouir $\&$ à faire de larges foffes. De plus, il fe veautre avec volupté dans l'ordure \& dans la boue, \& la brebis ofe à peine toucher de l'extrémité clu pied un endroit fangeux.

Les porcs font toujours prêts à fe déchirer à coups de dents, \& il n'y a point d'animaux auffi doux que les brebis ; elles paiffent enfemble au milieu des champs, elles s'affemblent en rond ferrées dans un tas; \& lorfque, pendant les grandes chaleurs, l'ombrage leur manque, elles Tome $I$. 
LE fe cachent la tête fous le ventre les BÉTAI. unes des autres. Si quelqu'une fur fa route rencontre un coin de champ où l'herbe foit plus agréable au goût, elle ne veut pas feule en profiter, $\&$ n'eit point jaloufe que les autres partagent avec elle fa bonne fortune; elle les appelle au contraire de toute fa force, par des bêlemens réitérés, pour les inviter à venir faire avec elle un meilleur repas.

Leur guerre \& leurs débats ne font pas dangereux; \& $\mathrm{fl}$ dans le fond des vallées il leur prend envie de fe livrer quelque affaut, le berger fur une hauteur fe fait un jeu de leurs fréquens combats; parce qu'il voit qu'ils fe terminent toujours fans effufion de fang, quoiqu'elles fe heurtent réciproquement, \& que courbant la tête pour de nouvelles attaques, elles s'élancent avec fureur fur leur adverfaire. $\mathrm{Si}$ par hafard leur animofité va trop loin, il n'eft pas néceflaire d'employer le bâton pour mettre la paix ; un des moutons s'expofe à leurs coups en fe préfentant au milieu d'elles, \& finit leur difpute en les féparant. 


\section{R URALE. Liv. IV. 219}

Le penchant dominant du porc eft une gourmandife infatiable : car une truie, fi la faim la tourmente, dévore jufqu’à fes petits. La brebis, au contraire, eft de toutes les meres la plus tendre; elle prodigue fes foins \& ies carefles à fon agneau pour l'élever. Si elle eft obligée de le quitter, lorfqu'il refte à la bergerie, elle s'ennuie au pâturage, \& le demande par fes cris ; tandis que de fes bêlemens il fait auffi retentir le bercail. La patiente brebis ne fait point fe venger par la force, quand il s'agit d'elle feule; mais elle oublie fa timidité naturelle, \& ofe avec coura. ge fe préfenter au combat contre les plus gros chiens, s'il en eft quelqu'un au pâturage qui feigne en jouant de fe précipiter fur un agneau, pour lui donner une faufle allarme.

Quoique le berger ne puiffe pas connoître quelle eft la mere de chaque agneau en particulier, puifqu'ils ont tous la même couleur, \& qu'il ne paroît entre eux aucune différence fenfible ; cependant toutes les me res reconnoiffent leurs petits, \& 
LE PEIIT BET A I L. tous les petits pareillement reconnoiffent leur mere par l'effet d'une merveilleufe tendreffe. Car le foir, dès que les brebis à leur retour du pâturage, rentrent dans le bercail, les agneaux s'applaudiffent de l'arrivée de leurs meres, chacun témoigne fa joie à la fienne, en remuant la queue, \& s'épuife en careffes que fa mere lui rend à fon tour ; après quoi, fans tarder ils vont tous preffer la mammelle de leurs meres pour éteindre leur foif, \& fatisfaire l'envie qu'ils avoient d'être avec elles.

La truie, au contraire, fi l'on n'a pas foin de marquer fes petits, de donner une autre couleur à ceux d'une autre truie, \& de mettre chaque portée fous chaque mere; la truie, dis-je,étendra fes mammelles à terre, ( I 5 ) \& alaitera les petits des autres $\&$ les fiens indiftinctement, fans remarquer entr'eux aucune différence.

Les bienfaits ne la touchent point: fi le porcher du haut d'un chêne lui abbat du gland bien mûr, elle ne donne pas le moindre foupçon de reconnoiffance à la main bienfaifante 
R URA LE. Liv. IV. 221

de qui elle le tient. Mais fi un berger fait des careffes à quelque brebis, $B$ B $D E T 2$ elle s'attache à lui, \& devient fa fidéle compagne, ou fe repofe fur l'herbe près de fon cher pafteur, en dépit du chien jaloux. On ne devroit donc pas conduire au même pâturage ces troupeaux différens, afin de ne pas fouiller les brebis par la fociété des porcs.

Menez paître les pourceaux, ou dans les terres en jachére, ou au Pàturages des porss. milieu des bois, \& fonnez fouvent du cornet pour les appeller \& les raffembler, quand ils fe difperfent. Lorfque vous verrez un porc attiré par l'odeur des truffes, qu'il recherche avec avidité, grater la terre $\&$ fouir avec le grouin, courez, volez vîte à lui, de peur que fa voracité ne fe repaiffe d'un mêts digne de la table de votre maître.

Si l'on voit une truie baiffer la tête, la porter de travers, \& fubitement attaquée d'un vertige, tomber au milieu des champs, il faut la faigner auffitôt fous la queue, \& quand on a tiré affez de fang, faire une liga-

$$
\mathrm{T} \text { iij }
$$




\section{2 \\ EE C O O M I E}

IE PETII ture à la plaie avec quelque légére BETAII. écorce; on enferme enfuite la truie dans fon toit, on lui fait avaler trois * Sorte de verres de Garum*, \& on lui prépare faumure. fa nourriture dans de l'eau tiéde.

N'enfermez pas les truies par bandes comme les brebis, mais que chacune ait fon toit, \& une litiére propre : car quoique cet animal immonde fe plaife dans l'ordure, \& fe veautre même en mangeant, cependant une étable fale \& fangeufe l'inquiéte \& le chagrine.

Les porcs font fujets aux écrouelles \& aux inflammations de gofier; la lépre leur couvre tous les membres d'écaille; la toux leur ôte la refpiration, \& leur fait battre des flancs ; \& quand ils font au pâturage, le lait des herbes tendres leur caufe des flux de ventre. Vous ap. porterez à toutes ces maladies les re. médes que vous jugerez à propos : car ma Mufe ( 16 ) dédaigne de prêter des fecours à ces fales animaux, \& défire de parler des qualités du chien, recommandable par fon exa cte garde, \& par fon vif attache. ment. 
R U R I E. Liv. IV. 223

Il y a des chiens de plus d'une efpéce; les uns font la garde dans les LE DETIT maifons, fuivent le maitre, \& vivent de ce qu'on fert à fa table; d'autres B É I A I L. nés avec un fort penchant pour la chaffe, femblent voler dans leur courfe en pourfuivant les hôtes des bois, ou guidés par la fubtilité de leur odorat, découvrent la voie du gibier; ceux-ci dociles \& prompts au commandement, obéiffent à tous les ordres du maître, fe tiennent droits fur les pieds, danfent en mefure, font agilement les fauts qu'on leur commande, \& amufent les paffans dans les carrefours des villes; ceux-là font légers à la courfe, \& ceux-ci trop pefans pour courir; les uns enfermés dans une large roue, font tourner la broche, \& cuire les liévres qu'un autre a chaffés dans la plaine. Il y a auffi de jeunes chiennes qui, dès qu'elles font nées, font les délices de leurs maîtreffes, en fautant fans ceffe autour d'elles pour leur donner \& prendre quelques bair fers, ou qui, fe repofant fur elles, jappent avec audace, \& marquent

$T$ iiij

Differentes efpéces de chiens. (n) 


\section{E C O N O I E}

IE PEIIT plus d'emportement que la Dame BЕ́т A I L. même du logis.

Ieschiens de Parmi les chiens propres aux exerchaffe. cices fatiguans de la chaffe, il y en a qui fuivent la voie des bêtes fur les montagnes, \& d'autres qui ne courent le gibier que dans la plaine; les uns font excellens pour la caille, d'autres pour la perdrix; ceux-ci forcent les cerfs à entrer dans les toiles, \& fe repofant fur leur courage \& leur habileté à attaquer un taureau par fon endroit le plus foible, ofent le provoquer au combat au milieu d'une arêne.

Un autre, défagréable à la vîe par le poil \& la barbe, traverfe aifément à la nage les étangs les plus larges ; \& fi le plomb mortel du chaffeur abbat une poule d'eau, qui flote fur un marais après fa chûte, \& le teigne de fon fang, ce chien va la chercher à la nage, \& la rapportant aux pieds de fon maitre, fe réjouit de l'applaudiffement qu'il lui donne, \& fait en fe fecouant pleuvoir une rofée dont l'air au loin eft inondé.

Il y a des chiens qui rafent la terre 


\section{RURALE. Liv.IV. 225}

avec leur ventre, tant ils font bas; ils ont les oreilles pendantes, chaf LE PETIT fent le nez haut, \& ont l'odorat d'une fineffe admirable pour fuivre la trace des bêtes fauvages \& des oifeaux, \& quêter fans appeller. Pleins d’ardeur, ils battent les champs de côté \& d'autre ; dès qu'ils ont fenti l'odeur du gibier, ils s'arrêtent \& le tiennent en refpect, en reftant euxmêmes immobiles, jufqu'à ce qu'on ait achevé de tendre les filets; alors ils s'élancent fur leur proie, \& l'épouvantent par leurs cris menaçans. Le gibier bat l'air inutilement de fes aîles, il eft trop tard, les rêts lui ferment toute iffue; la main du chaffeur ou la dent cruelle du chien lui donne la mort ; \& l'on eft touché de pitié en voyant la perdrix, qu'on prend à la main, demander la vie par fes larmes. Souvent un liévre endormi dans un champ, s'éveillant par la frayeur que lui donne l'attaque inopinée des chiens, fe trouve enveloppé dans les lacs, il faute en l'air, fe tourne \& retourne pour en fortir : mais plus il fe donne de 


\section{CE C NO MIE}

mouvement, plus fon corps enlacé LE PEIIT
BẼAIL. S'y embarraffe.

Il y a encore d'autres chiens qui, dans les bois \& dans les champs, crient fur la voie en courant le liévre, le raménent dans le même endroit d'où ils l'ont fait partir, \& $\&$ fous la main du chaffeur, qui attend fa proie pour tirer. Ces chiens ont les jambes menues \& déliées, de longues jointures aux cuiffes, le mufeau pointu, le pied fec \& nerveux, l'eftomac avalé, \& fort peu de ventre.

Que le laboureur occupé de foins campagne ou plus intéreffans laiffe aux maîtres màtin. defouvrés la paffion de la chaffe $\&$ des chiens de meute, \& qu'il cherche à fe procurer quelque mâtin vigoureux, dont la garde faffe la fureté de la maifon. Le jour un chien de cette efpéce défend le troupeau des loups, \& la nuit en fentinelle il veille autour de la bergerie ; \& fi quelque voleur étoit tenté d'y entrer, il aboye pour l'écarter, ou le déchire à belles dents. Il doit avoir la queue courtę ainfi que le mufeau, la tête énorme $\&$ hideufe pour la groffeur, 
R URA L E. Liv. IV. 227

Ies oreilles pendantes, le poil rude fous le ventre, les pieds, l'épaule IE $P E T 13$ le cou \& les flancs larges, de même que les autres parties du corps. Un mâtin fait beaucoup de bruit en aboyant, \& fe fait entendre auloin. D'abord il épouvante par fes cris, \& fa vîe fait enfuite trembler lorfqu'affis il entr'ouvre une gueule frémiffante, \& gronde entre fes dents qu'il montre fans les defferrer.

Il tient d'abord de la nature fon humeur farouche; mais la façon dure de l'élever l'augmentera beaucoup fi on le tient près de la porte enchaîné par le cou : là il aboye en pure perte, jufqu’à ce qu'au foleil couchant il rode en liberté autour de la maifon \& de la bergerie, \& répande au loin l'ćpouvante par fes cris. Comme il ne convient pas qu'il foit d'un naturel fi doux qu'il épargne jufqu'aux voleurs mêmes, il ne doit pas auffi être méchant au point d'attaquer fans fujet les perfonies qui ne font pas fur leurs gardes, \& de mordre indifféremment les amis com. me les ennemis. 


\section{CE C N O M I}

Les plaifirs de l'amour doivent LEPEIIT être interdits aux jeunes chiennes; chiens.

Les jeunes \& $\mathrm{fi}$ quelque femelle de belle race s'eft laiffee careffer à votre iniçz, il faut lui enlever fecrétement fa premiére portée : car une mere fijeune $\&$ fi novice n'éléve pas bien fes petits; \& quand une chienne alaite dans un âge fi tendre, elle ne peut plus croître ni fe fortifier.

Quoiqu'elle vous demande par fes cris les petits qu'elle a perdus, n'en foyez point touché : ( 17 ) les regrets de la jeunefle ne font pas longs; elle oubliera bientôt la perte qu'elle a faite, pourvî qu'on lui permette de jouer avec d'autres chiens, de courir en liberté, \& de fe livrer dans peu à la tendreffe folâtre de fes amoureux, qui renouvelleront en peu fa maternité.

Dans le nombre des chiens qu'elle aura à fa feconde portée, choififfezen deux feulement ; ou, fi vous voulez lui confier ce choix à elle-même, vous étendrez circulairement des fagots, $2 \alpha$ vous les allumerez, après avoir mis fes petits au milieu; en- 


\section{RURAIE. Liv.IV. 229}

iuite vous appellerez la mere, qui, bien plus excitée par leurs cris, quO-BETAIL. béiffante au commandement, vole à leur fecours. Dès qu'elle les apperçoit entourrés de feu, effrayée de leur danger, elle s'élance auffitôt au milieu des flammes; \& d'abord, ouvrant une large gueule, elle prend entre fes dents, tantôt celui-ci, tantôt celui-là, jufqu'à ce qu'elle les ait tous délivrés du péril évident où ils étoient. Remarquez ceux qu'elle a enlevés les premiers, \& 2 mettez-les à part pour les garder; faites mourir les autres au loin, cu enterrezles, de peur que leur mere, par un mouvement de tendreffe, ne les rapporte, \& ne veuille les réchauffer fous elle pour les rappeller à la vie. Quand les jeunes chiens feront fevrés, donnez-leur d'autres alimens dont les fucs plus fubftantiels puiffent augmenter leur force.

Sivous voulez préferver les chiens de la rage, vous aurez la précaution deleur arracher doucement avec les dents un nerf qui a fon principe aux premiéres articulations de l'épine dus 
$\widetilde{\sum_{\text {E }} \text { ITIT }}$ dos, \& qui s'étend jufqu'à l'extré-

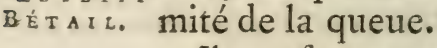

Il ne faut permettre aux jeunes chiens de jouter \& de faire ufage de leurs dents qu'avec leur mere, \& bien prendre garde que, lorfqu'ils font encore foibles, ils n'aillent attaquer les hommes ou les animaux; de peur que, punis de leur témérité parle bâton ou la dent du loup, ils ne reçoivent une impreffion de frayeur difficile à détruire dans un âge plus avancé : mais fouffrez qu'ils aboyent pour annoncer, par leur vigilance, tous ceux qui entrent, en attendant qu'ils puiffent s'exercer aux combats.

Que le chien qu'on deftine à la garde du troupeau, foit ardent; qu'il ait la taille longue, le poil blanchâtre \& d'une feule couleur, de crainte que le berger ne frappe fon chien, lorfque fur le foir il pourfuit un loup avec le bâton. Il faut qu'un mâtin foit également propre à la courfe \& au combat, qu'il ait du courage \& de l'agilité, \& qu'après avoir pourfuivi le loup raviffant à 


\section{RURAIE. Liv, IV. 23 I}

travers les bois \& fur les montagnes, il lui faffe lâcher prife, \& $\operatorname{le}_{\operatorname{LE}_{\text {E }} \mathrm{TI}=}$ chaffe au loin tout chargé de blefflres, \& hurlant de douleur dans le fond des bois. Mais de peur que le chien lui-même ne revienne bleffé du combat, on lui attache au cou un collier garni de pointes de fer : car c'eft par cet endroit que les loups attaquent les chiens, \& s'en rendent maitres. Ils fe jettent avec une aveugle fureur fur leur ennemi; mais ils fe déchirent eux-mêmes la machoire, qu'ils teignent de leur propre fang, par la précaution du berger.

Quelque part qu'un pafteur méne paitre fes brebis \& fes chévres, le chien comme un fidéle compagnon eft toujours à fes côtés prêt à le défendre ou le fervir; ils partagent tous deux le gouvernement du troupeau; le chien fait des careffes au pafteur, $\&$ fe plait à en recevoir de lui, fon maître eft l'arbitre de fa joie ou de fa trifteffe : deux hommes ne s'aiment pas davantage ; \& le fort qui fait par fes revers déferter les amis, se peut par aucune adverfité dimi- 
LETETTT B É T A T L.

Anitié des nuer l'amitié qu'un chien a pour fon maître. Amitié des ( 18 ) Sabinus étant aux fers, Ro-
chiens pour me autrefois admira fon chien qu'on
ieur maitre. ne put jamais, quelques coups qu'on lui donnât, faire fortir de prifon. Sabinus fut précipité dans le Tibre de deffus un pont, les mains liées derriére le dos; fon chien fidéle fe jetta auffitôt dans ce fleuve, \& foutenant avec le dos, autant qu'il le pouvoit, le corps de fon maître déja mort, il aima mieux fe noyer avec lui que de lui furvivre. Le peuple avec douleur, examinoit ce prodige, \& paroiffoit furpris de voir uniquement dans un chien l'exemple d'un amour conftant \& d'une fidélité inviolable.

Les François n'admirérent pas moins autrefois ( 19 ) un chien qui fut le vengeur de fon maitre. Les murs du palais, où l'hiftoire de cette action mémorable eft peinte, font un monument éternel de cette merveille. Le chien dans ce tableau montre les dents, \& tient fous lui le meurtrier qu'il a déchiré. Son maître attaqué lâchement, étoit tombé 


\section{RUR A L E. Liv. IV. 233}

mort devant lui, après avoir perdu beaucoup de fang; quelque temS LEDETI. après le chien apperçoit l'affaffin au milieu d'une cour; cette rencontre l'excite à la vengeance, \& réveille fa colere; il aboye fans relâche après cet homme, \& par cet acharnement le défigne pour le meurtrier de fon maitre. Auffitôt il s'élance fur lui pour le punir de fon crime ; \&, quoique l'affaffin fùt armé, \& que le chien n'eût d'autre reffource que l'ardeur de fa fidélité, il s'attacha aux flancs du meurtrier, \& lui déchira les entrailles.

Les chiens fe repentent auffi d'avoir offenfé leur maitre. Un jour un homme étant entré mafqué dans fa maifon, fon chien fe précipita fur lui avec fureur, \& le mordit, ignorant que ce füt fon maître. Celui-ci fe découvrit le vifage, malheureufement trop tard, \& montra fes bleffures, (20) pardonnables fans doute, fi l'amour pouvoit fe pardonner quand il a offenfé ce qu'il aime. Auffitôt le chien, déteftant la vie \& la lumiére, fe dévoue à la mort, $\&$ va fe caTome $I$. 


\section{4 \\ CE C O O MIE}

cher dans une cave fous un tonneau,

BETA I. Où il demeure gémiffant \& accablé de trifteffe. Son maître lui pardonnant, l'appelle avec douceur, \& d'un ton d'ami; mais fa voix reconnue par le chien, ne fait qu'irriter fa douleur, il ne lui répond que par de triftes hurlemens, \& refufant de prendre la moindre nourriture pour conferver fa vie, il meurt victime de fon abftinence \& de fes regrets.

Qu'on croye maintenant les opinions abfurdes de ces Philofophes, qui vous difent que ces mouvemens $f i$ vifs \& fi tendres ne font point caufés dans les animaux par la fenfibilité, qu'ils n'ont point d'ame qui les faffe mouvoir \& fentir, \& qu'ils reffemblent à une machine que font remuer des refforts, ou à une aiguille aimantée, qui, d'une façon merveilleufe, parcourt fans relâche toutes les parties d'une bouffole, jufqu'à ce qu'elle fe foit arrêtée fur le point qui regarde directement le nord.

Quoi! un chien dreffera des embuches, \& après avoir pourfuivi fa 
R U R A L E. Liv. IV. 235 proie dans la plaine, quittera brufquement la grande route pour l'aller B I I A I. furprendre par un fentier détourné : un liévre fe jouera des chiens qui le fuivent, \& brouillera la voie par des circuits qui fe croifent les uns les autres, fans que ces rufes foient le fruit de la réflexion? Quoi! un finge fera mille tours d'adreffe, fans deffein, fans induftrie; la crainte des coups le forcera à fe cacher, fans qu'il fache qu'il a commis une faute; le caftor, dans les fleuves les plus profonds, fe conftruira pour prendre le poiffon des cabanes, qui font des chef-d'œuvres de génie ; les oifeaux fe logeront dans des nids bâtis avec tout l'art poffible; (2 I ) l'abeille \& la fourmi auront la prudence en été de faire des provifions pour l'hiver, fans qu'aucune efpéce de difcernement \& de connoiffance préfide à des actions \& à des travaux auffi admirables ? Si quelqu'un peut parvenir à vous perfuader que les bêtes ne font que des machines, il vous prouvera par les mêmes raifonnemens que les hommes font des $\mathrm{V}$ ij 


\section{6 (E) C NOMIE}

$\overline{L_{E} D E T I T}$ corps fans ame. Mais, pour ne pas ВЕТAIL. en dire davantage, un feul chien va me fournir des exemples de fenfibilité qu'on ne pourra révoquer en doute. Cet animal veille $\&$ fait la garde à la porte de fon maitre, il obferve le moindre de fes mouvemens pour voler où fes ordres l'appellent; quand fon maître eft gai, il fe réjouit avec lui ; s'il a du chagrin, il eft trifte; il époufe fa querelle, \& fe déclare fon vengeur; compagnon fidéle, il fuit fes pas ; fes regrets enfin le font mourir fur fon tombeau ; \& ce chien n'auroit ni tendreffe, ni reconnoiffance ?

(22) De pareils délires ne peuvent être enfantés que par des cerveaux creux, \& par ces gens qui ont vî dans leur imagination, la terre, la mer, les cieux, \& tout ce que l'univers enferre, fe former par un feul \& fimple mouvement (23) de la matiére divifée en petits cubes. Ils ont même décidé que ce n'étoit qu'une légére pouffiére qui avoit donne l'être au foleil; que les étoiles fe livroient des combats, \& étoient 
R U R A LE. Liv. IV. 237 affujetties aux mêmes paffions que

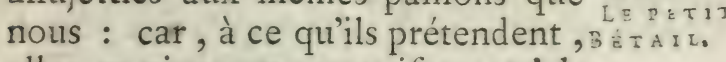
elles en viennent aux prifes entr'elles, ont de terribles guerres à foutenir, étendent les limites de leur empire, ou font fubjuguées \& forcées de fubir la loi du vainqueur. Ainfi elles errent fans place fixe dans l'immenfité des cieux, comme les cométes dont le défaftre préfage des événemens fâcheux, \& qui ne font errantes, que parce qu'elles ont été vaincues par le tourbillon qui étoit leur plus proche voifin. * Oubien, comme notre planéte qui eft déchue du rang qu'elle avoit parmi les aftres, enveloppée dans le tourbillon du foleil plus puiffant qu'elle, \& privée de la lumiére, elle eft obligée de tenir la route que lui prefcrivent les chevaux triomphans du dieu du jour, quoiqu'elle faffe tous fes efforts pour rentrer dans fes premiers droits. Car, s'il faut en croire les prophéties de ces Philofophes, la terre dont la lumiére eft obfcurcie par les matiéres opaques qui la couvrent, peut * Voyez Defcartes, P. 4. Principes. 


\section{CE C O N O M I E}

$\overline{L_{E S E T I T}}$ reprendre fa premiére forme d'aftre BETTAL. quand fes feux fe feront fait jour à travers les croutes fatales qui l'enveloppent, \& nous confumer tout à coup par fes flammes dévorantes. Ils craignent, au contraire, que les taches du foleil fe multipliant, il ne fe couvre quelque jour d'un voile auffi noir que de la poix, \& que perdant fa lumiére \& fes rayons, d'épaiffes ténébres ne dérobent la terre aux yeux.

(24) Laiffons Defcartes, ce nourveau créateur d'aftres, ce fublime architecte de l'univers, donner carriére à fon imagination fur la nature des animaux, comme il l'a exercé fur la ftructure des cieux. Pour vous, ô Laboureur! méprifez les rêveries des Philofophes; \& , prenant des leçons des animaux mêmes, ne faites cas que de l'efprit induftrieux \& prudent. Ne rougiffez point de rappeller aux ferviteurs ingrats les chiens fidéles \& reconnoiffans, \& à votre fils rébelle le naturel du bœuf, qui, pouvant combattre les lions \& les ours, obéit au commandement d'un 
R U R A E. Liv. IV. 239 enfant. Rappellez fouvent la trifte deftinée de la cigale qui chante aprèS LE DEI I T s'être enivrée de la rofée du matin, \& s'amufe pendant les beaux jours \& le tems de la moiffon, à battre l'air d'un vain bruit, (25) tandis que la fourmi plus fage fait fa récolte pour la ftérile faifon de l'hiver. Vous reprendrez vivement des mêmes défauts les laboureurs qui, ne fongeant qu'aux plaifirs de la vie, ne favent pas étendre leurs foins aux befoins de toute l'année ; \& qui, au retour dụ froid \& des frimats, font dévorés par la faim.

L'hiver auprès du feu, repaffez fouvent dans votre efprit la trifteffe (26) \& les gémiffemens d'un tourtereau qui a perdu fa compagne, (27) la fidélité d'une colombe pour le mâle qu'elle a choifi, ( 28 ) la tendreffe de la cigogne qui nourrit ceux de qui elle tient le jour, l'attention d'une poule, qui, après avoir béqueté long-tems la terre, s'abftient des grains qu'elle a trouvés, afin que fes petits en profitent. Sur-tout fongez fouvent aux laborieufes \& infa- 


\section{CE C O N O M IE, \&C.}

IE BËTAL. inclinations pareilles les font vivre agréablement fous le même toit. Elles ne gardent point pour elles feules le miel qu'elles préparent, \& dont elles ont été cueillir la matiére fur différentes fleurs; mais elles le portent dans un réfervoir public pour la fubfiftance commune. Les autres exemples que fournit la campagne à divers égards, feront auffi la matiére de vos entretiens, ainfi que les foins que prennent généralement tous les animaux pour leurs befoins. Vos enfans autour de vous, attentifs à vos hiftoires, les écouteront avec plaifir, \& l'amour de la vertu (29) s'imprimera infenfiblement dans leur cour.

Fin du quatriéme Livre. 


\section{REMARQUES}

\section{Sur le quatriéme Livre.}

T'Auteur décrit dans ce Livre les foins 1 qu’on doit prendre du menu Bétail, des brebis, des agneaux, des montons, des béliers, ainfi que leurs mœurs \& leurs inclinations, qu'il compare avec celles des pourceaux. Les chévres, les maladies des différens troupeaux, les qualités des chiens quiles gardent, la maniére de les élever, \& leur attachement pour leur maître, font peints avec beaucoup d'expreffion. Une differtation fur l'ame des bêtes, \& une réfutation du fyltême de Defcartes fervent d’épilogue à ce Livre.

( I) [Elles font le préfent. ] Virgile, Georg. liv. 3 .

Hic labor, hinc ba udem forres perate coloni.

(2) [Que vous prites votre nom. ] Le mot latin Pecunia, qui fignifie argent, vient du mot Pecus, qui fignifie troupeau.

Satire I.

(3) [ Le bouff attaque.] Horace, liv. 2,

Dente lupas, cornu testrus pesit : unde, nift intus Monfratum?

Tome $I$. 
(4) [De paille és de fourére. ] C'eft aufí le confeil que donne Virgile, Georg. 1. 3.

Et multâ duram fipulî flicumque maniplis Sternerc fubter humum : glacies ne frigida lad :t Molle pecus, foabiemque ferat, turpefque podagras.

(s) [ L'orge en herbe.] Cet ufage étoit pratiqué du tems de Virgile.

Luxuriem fegetis primâ depafcat in herbâ.

Pline dit : Luxuria Segetum caftigatur dente pecoris.

(6) [Ni les fatyres.] Quoiqu'il n'y ait plus de fatyres dans les bois, une jeune bergére n'y court pas moins de rifque aujourd'hui. Les bergers font quelquefois de vrais fatyres.

(7) [ Et le cruel Amour. ] Rouffeau peint ainfi les regrets des amans malheureux.

A fa voix * les amans renouvellent leurs plaintes, Ils fentent ranimer leurs défirs \& leurs craintes. I'un, outré du mépris qu'on fait de fes amours, Appelle vainement la mort à fon fecours;

I'autre, témoin des feux d'une infidéle amante, Exhale en vains fermens fa colére impuilfante. Qui pourroir épuifer les fonges déréglés, Ies fantômes trompeurs dont leurs fens font troublés, Quand le fang alluméd'un feu qui l'empoifonne, Au tetour du printems, dans leurs veines bouillonase

* De l'Amour. 


\section{fur le quatriéme Livre.}

Jadis nos fens plus vifs dans la taifon des fleurs,

Se fentoient excités par les mêmes chaleurs:

Mrais de trente printems la fageife efcortée,

De jour en jour s'oppofe à leur fougue indomptie.

Pour ceux de qui l'été fait mûrir la raifon,

Le printems \& l'hiver font la même faifon.

Je ne puis me refufer le plaifir de copier ici un bel enciroit du Difcours de M. deBuffon fur la nature des animaux, qui eft en tête du quatriéme volume.

2) Amour! s'écrie ce favant Naturalifte, » défir inné ! ame de la nature ! principe iné-

》) puifable d'exiftence! puiffance fouveraine

D qui peut tout, \& contre laquelle rien ne

"peut, par qui tout agit, tout refpire, \&

\ tout fe renouvelle! divine flamme! germe

„) de perpétuité que l'Eternel a répandu dans

D) tout arec le foufle de vie! précieux ferti-

»ment qui peut feul amollir les cœurs féro-

D) ces \& glacés, en les pénétrant d'une douce

" chaleur! caufe premiere de tout bien, de

w toute fociété, qui réunis fans contrainte, \&

D par tes feuls actraits, les natures faurages \&

$\rightarrow$ difperfées! fource unique \& féconde de

") tout plaifir, de toute volupté ! Amour, D pourquoi fais-tu l'état heureux de cous les

») êtres, \& le malheur de l'honme? C'eft

" qu'il n'y a que le fhylique de cette paffion $\forall$ qui loit bon ; c'eft que, malgre ce que peuD vent dire les gens épris, le moral n en vaut

w rien. Qu'ert-ce en effet que le moral de " l’Amour a la vansté. Vanite dans le plaitir 
") de la conquête : erreur qui vient de ce ") qu'on en fait trop de cas. Vanité dans le ») défir de la conferver exclufivement : état

ग) malheureux qu'accompagne toujours la ja") loufie, petite paffion fi baffe qu'on voudroit » la cacher. Vanité dans la maniére d'en ") jouir, qui fait qu'on ne multiplie que fes s) geftes \& fes efforts, fans multiplier fes plai》) firs. Vanité daris la façon même de la per2) dre : on veut romprele premier; carfil'on $n$ eft quitté, quelle humiliation! Et cette hu》) miliation fe tourne en défefpoir, loifqu'on » vient à reconnoître qu'on a éré long-tems i) dupe \& trompé.

Cependant eft-il bien vrai que l'Amour foit la caufe premiére de tout bien, la fource unique de tout plaifir; qu'il faffe le malheur de l'homme; que le moral en foit mauvais; que la vanité foit ce moral de l'Amour ? Il faut convenir que ces propofitions paroiffent un peu trop générales.

(8) [Les grues ér la jiniftre corneille.] Le Pere Vanniere a tiré tous ces ridicules pronoftics de Virgile, qui les avoít pris lui-même dans Aratus, Poëte Grec fort ancien, de qui dit Ovide :

Cum fole đơ lunâ femper Araus erit.

Voici quelques vers de Virgile à ce fujet : Aist illum furgentem vallibus imis 


\section{fur le quatriéme Livre.}

Aeris fugere grues: aut bucula calum

Sufpiciens patulis captavit naribus auras;

Tim cornix plenâ pluviam vocat improba voce, êc.

Lucain, Horace \& Catulle adoptent aufi ces différens pronoftics. Au refte, ce font des Poëtes; \& ces idées leur offrant des images, ils font peut-être excufables de s'ĉtre conformés aux préjugés du peuple. Virgile paroît perfuadé de l'infaillibilité de ces fignes; car il ca explique phyfiquement la caufe.Je vais me fervir de la traduction de l'Abbé Desfontaine. "Cen'eft pas que je croye que ces divers " animaux foient doués d'un efprit prophéti》 que, ni que leur prévoyance puiffe rien chan" ger au cours de la nature : mais lorfque la ") température de l'air a varié, \& que le foufie " des vents l'a condenfé ou rarefié, il fe fait 2) alors une différente impreffion fur les or" ganes de ces animaux caufée par les divers 2) mouvemens de l'air. Voila ce qui occafion») ne le chant des oifeaux dans les campagnes, "l'agitation des corbeaux fous les feuilla" ges, \& la joie de tous les troupeaux dans ») les prairies. a Ce qui furprend davantage, c'eft que Pline qui étoit Philofophe \& Naturalifte, ait donné dans ces puérilités, \& ait employé un long chapitre dans fon dix-huitiéme Livre, à décrire ces préfages. le texte:

(9) [Ou quand Iris se dispose. ] Il y a dans 
Et aquioreas gemino Thaumantias ore

Ducit aquas.

Ins étoit fille de Thaumante ; c'eft pour cela qu'on l'appelle Thaumantias. Claud. de rapэн Prof.

Juppiter interea cinctam Thaumantida nimbis

Ire jubet totoque Deos accerfere mundo, Illa colorato zephiros tranggreffa volatu, of 6 .

Les Poëtes ont feint qu’elle avoit été changée en arc en-ciel, \& qu'elle étoit la meffagére de Junon; parce que fous le nom de cette Déeffe, ils entendoient l'air ou la pluye, \& qu'ils croyoient que l'arc-en-ciel l'annoncoit. Ils ont tous fuivi cette opinion commuse, foit que leur mauvaife phyfique leur fit confidérer l'arc-en-ciel comme un fiphonqui pompoit l'eau de la mer, ou parce que cetre opinion prête à la poëfie, \& forme une image. Ovide L. I. Métamor. f. 7. dit :

Nuntia Junonis vario induta colores

Concipit Iris equas, alimontaque nubibus affers.

Virg. Geor. 3. donne dans la méme crreur. Et bilit ingens

Propert L. I.

Purpuress pluvias cur bibit arcus aquas?

Plaute, Curcul. L. 3 .

Ecce aurem bibit arcus! pluet,

Credo bercle bodie, 
L'arc-en-ciel n'eft qu'un affemblage de plufieurs couleurs difpofées en arc, que l'on apperçoit, lorfqu'un nuage commence à fe réloudre en pluye, que le foleil lui eft oppofé, \& qu'il êt peu élevé fur l'horifon : ainf l'arc-en-ciel ne pompe point l'eau \& ne régle point la pluye; il en eft une fuite, mais n’agit point fur elle. Voyez Poliniere dans fes expériences phyfiques.

le texte :

(10) [à l'abri de la chaleur.] Il y a dans

Icarium vitent paut is fub quercubus affum.

Je n'ai point rendu dans ma traduction le nor Icarium, parce que ne le pouvant faire que par une périphrafe, l'expreffion auroit été làche \& prolixe; d'ailleurs, quand on diroit la chaleur qui fut funefte à lcare, quel autre effet cela feroit-il que de rappeller une fable connue de tout le monde ? Un traducteur ne doit pas toujours tout traduire.

(I I) [Du Gange. ] C'eit un canton du Languedoc renommé pour les bons moutons.

(12) [ Sautent à Son imitation.]

O imitatores fervum pecus.! Hor. 1. 1. Epift 19.

( I 3) [ La groute lui permet, Éc. ] L'Abbé de Chaulieu l'appelle fille des plaifirs. Mais la caufe en varie fouvent; tous les gouteux ne l'ont pas méritée, \& tous les débauchés ne l'ont pas. D'ailleurs, ce pauvre bouc ne fait pas pis que le bélier qui n’y eft point fujet.

$\mathrm{X}$ iiij 
( 44 ) [ Le respectable Bignon.] Jean-Paul Bignon naquit à Paris le I 9 Septembre 1662 . de Jérôme Bignon, alors Avocat Général de Paris, Confeiller d'Etat, fils du célébre Jérôme Bignon, \& de Suzane-Phelypeaux de Pont-Chartrain. Il choifit l'état Eccléfiaftique, comme le feul dans lequel il Jui feroit permis de fe livrer fans réferve \& fans diftraction à fon goût pour l'étude. En 1683 , il entra à l'Inftitution de l'Oratoire, il fe lia avec le P. de Sainte Marthe, \& entreprit avec lui un cours d'étude de l'antiquité facrée \& profane : il quitta la congrégation de l'Oratoire en $369 \mathrm{I}$; il fut nommé Confeiller d'Etat en ₹70I, \& l'attention qu'il donnoit aux Lettres ne l'avoit point empêché de remplir avec exactitude, \& même avec éclat, les plus importantes fonctions de cet emploi ; il n'avoit point abandonné la prédication, les fermons qu'il prononça en diverfes occafions étoient reçûs avec applaudiffement. La variété de fes talens, fon application, l'érendue \& l'exactitude de fes connoiffances le mettoient en état de fuffire à tout ; il étoit de trois Académies. Il mourut en 1743 , âgé de 80 ans fix mois. $V$ oyez fon éloge par M. Freret, dans l'hiftoire de l'Académie des Infcriptions.

(Is) [ Et alaitera les petits des autres. ] Il y a dans le texte :

\section{Carulis dabit ubera notis.}

Les mots catuli \& vituli font fouvent em- 


\section{fur le quatriéme Livre. 249}

ployés génériquement \& par tranflation pour exprimer les petits de toute efpéce d’animaux quadrupedes.

( 16 ) [ Dédaigre de príter du fecours, Éc. ] Cetre plaifanterie eft affez froide, elle ne feroit fupportable que dans la bouche des Juifs qui ne mangent point de porc: quand cet animal ne donneroit que le jambon, il mérite bien-qu'on en prenne foin.

(I7) [ Les regrets de la jeunesje ne lont pas longs. ] C'eft une des raifons pour lefqueiles la jeuneffe eft appellée le bel age.

(i 8 ) [Sabinus étrnt aux fers, erc.] Cette hiftoire eft tirée de Pline, L. 8. ch. 40 . où il rapporte plufieurs autres exemples de la fidélité \& de l'attachement des chiens.

(I9) [ Un chien qui fut le vengeur de fon maitrc.] Ce fait eft arrivé à Montargis fous le régne de Charles V. Voyez les monumens de la monarchie franç. de Dom Bernard de Monfaucon, tom 3. Voyez auffi les effais de M. Saint Foix, hift. fur Paris, tom. I. à lart. Ine Notre-Dame ou Saint Louis.

(20) [Pardonnable, fans doute, fi l'amour, éc. ] Ceci paroît imité de Virgile Georg. L. 4 .

Ignofcenda quidem, foirent fi ignofoert Manes.

(2I) [ L'Abeille of la fourmi auront $l a$ prudence. ] Il eft à préfent décidé que ce n'eft' point la prudence qui fait agir la fourmi lorfqu'elle fait des amas de bled.

Voici ce que dit M. de Buffon, tom. 4. de 
l'hiftoire naturelle dans le difcours prélininaire fur la nature des animaux.

"La prévoyance des fourmis n'étoit qư un "préjugé ; on la leur avoit accordée en les ob"fervant, on la leur a ôtée en les obfervant »mieux : elles font engourdies tout l'hiver, ") leurs provifions ne font donc que des amas w fuperflus, amas accumulés fans vûes, fans nconnoiffance de l'avenir, puifque par cette " connoiffance même, elles en auroient pré》) vû toute l'inutilité. N'eft-il pas très-natun) rel que des animaux qui ont une demeure » fixe où ils font accoutumés à tranfporter les ") nourritures dont ils ont actuellement befoin, " \& qui flatent leur appétit, en tranfportent "beaucoup plus qu'il ne leur en faut, déter„ minés par le fentiment feul, \& par le plaiD) fir de l'odorat ou de quelques autres de leurs » fens, \& guidés par l'habitude qu'ils ont prife nd'emporter leurs vivres pour les manger en ") repos : Cela même ne démontre-t-il pas "qu'ils n'ont que du fentiment \& point de w) raifonnement?

(22) [ De pareils délires, érc.] Le pere Vanniere attaque ici le fameux Defcartes, il combat fon opinion fur l'ame des bêtes, \& fon fyftême fur la formation de l'univers ; mais il traite ce grand homme avec des termes pett mefurés. Defcartes, malgré fes erreurs, eft roujours le premier philofophe françois. Sa grande imagination l'a détourné quelquefois des fentiers de la vérité, mais il y eft entré le premier : les principes qu'il a établis ont fait 


\section{fur le quatriéme Livre. 251}

éclore la faine philofophie, en détruifant les qualités occultes \& toutes les quiddités des Péripatéticiens, \& c'eft encore de fon flambeau que fe fervent fes antagoniftes quand ils veulent montrer qu'il s'eft égaré.

M. de Reaumur, hiftoire des infectes, rend dece grand homme un témoignage plus avantageux. " Nous devons, dit il, nous trouver " heureux d'avoir été précédés par un maître w) tel que Defcartes, qui nous a appris à difcuఐ) ter les idées les plus reçûes, \& à n'adopter "que celles qui n'ont rien que d'évident : nquels fervices un feul homme n'a-t-il pas ") rendu à tout le genre humain ? " La Fontaine jufte appréciateur di mérite, ayoit auffi meilleure opinion de Defcartes :que le Pere Vanniere : avec quelle vénération il en parle dans fa belle fable, ou plutôt dans fon bear difcours à Madame de la Sabliere a

Voici de la façon que Defcartes l'expofe, Defcartes ce mottel dont on eût fait un Dieu

Chez les païens; \& qui tient le milieu

Entre l'homme \& l'efprit, comme entre l'huitre \&: l'homme,

Le tient tel de nos gens, franche bête de fomme.

Ce difcours eft un précis du fentiment: de Def= cartes fur l'ame des bêtes : il contient de grandes beautés. J'invite les jeunes gens à le lire fouvent, à le retenir, \& à en faire leur profit, sinfi que de toutes les fables de cet Auteur.

(23)[Do la matiére diviféc en petits cubes.] v. le monde de Defcartes. 


\section{Remarques}

Defcartes dans fon monde rejette le vuide; \& veut que tout foit plein. Voici comme il v. le traitéen conçoit la formation. "Dieu forme d'ade la lumiere $)$ bord une maffe immenfe de matiére homo\& les princi- » géne, \& dont toutes les parcelles font dures, pes.

„) cubiques ou du moins anguleufes; enfuite il ग) imprime à ces parcelles un mouvement dou»ble, il les fait toumer la plupart fur ieur wcentre, \& divers pelotons d'entr'elles attw) tour d'un centre commun, ce qu'il nomme s) tourbillon. Cela fait, felon lui, tout eft fait, ») \& du frotement de ces parcelles écornées par w) leurs angles, il s'en formera une pouffiére i) très-fine qu'il nomme le premier élément ou »la matiére fubtile; en fecond lieu une ma» tiére globuleufe qu'il nomme le fecond élé") ment ou la lumiére; \& enfin une pouffiére s) maftive, ftriée, branchue qu'il nomme le ») troifiéme élément dont fe formeront toutes n) fortes de maffes. Ce cahos forti de la main »de Dieu s'arrange, felon Defcartes, en vertu э) de la continuation des deux mouvemens que эDieu y a imprimés, \& devient de lui-même ») un monde femblable au nôtre, dans lequel, "quorque Dieu n'y mette aucun ordre ni $v$. le monde " proportion, on pourra voir toutes les chooule traitéde » fes tant générales que particuliéres, qui pala lumiére. i) roiffent dans le vrai monde.

Ce n'eft point un cerveau creux qui enfante d'auffi fublimes erreurs.

Il eft beau qu'un morrel jufques au ciel s'éléve, Il êt beâ mêtme d'en tomber.

Pheëton, Opira. 


\section{fur le quatriéme Livre. 25 ह}

(4) [LaijJons Defcuries, éc.] Ce philofophe étoit Gentilhomme françois, de la Haie en Touraine, d'une maifon qui eft encore à préfent illuftre en Breragne \& en Poitou; il eft mort à Stokolm en 1650 , àgé de 54 ans, fon corps a été apporté en France, \& on voit fon tombeau avec un éloge funébre dars l' $E$ glife de Sainte Geneviéze du Mont. On a plufieurs volumes de lui. Voyez fa vie par Adrien Baillet Pérault dans les hommes illuftres du dix-feptiéme fiécle; Moreri, Bayle.

(26) [ Tandis que la fourmi plus sage.] Voyez la remarque vingt-uniéme.

(2s) [ Et les gomifjemens d'un tourtereau.] Cet endroit paroît imité du vers fuivant.

Turturis inftar ego non gemebsuda forens.

(27) [ La fidélité d'une colombe. ] C'eft Pline qui en eft le garant L. IO. ch. 34. Pudicitia illis prima, í neutri nots adulteria, conjugii fidem zon violant, communemque servant domum, nifi cslebs aut vidua nidum non relinquit. Et imperiojos mares fubinde etiam iniquos ferunt quippe fufpicio eft adulterii quamvis nsiura noin $2 t$. Ces derniers mois fur-tout font remarquables.

(28) [ La tendreffe de la Cicorne.] Genitricum fenectam invicem educant. Plin. Liv. I0. ch. 23 .

(29) [S'imprimera infenjiblement, ésc.] Il y a dans le texte: 
$254:$ Remarques, Ec.

Tacitumque bibent virtutis amorem.

C'eft ainfi qu'Horace dit :

Pugnas of exactos tirannos

D:nfum humeris bibit aute vulgus,

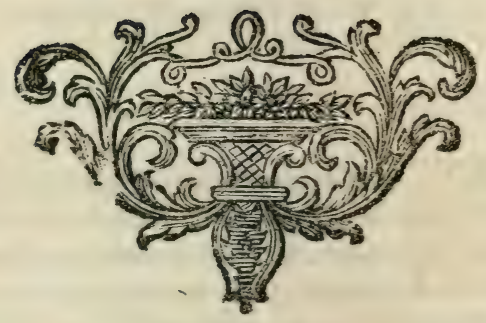




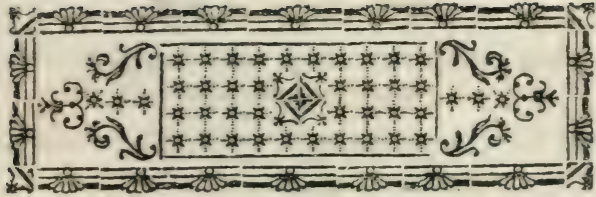

\section{ब C O NOM I E \\ R U R A L E。}

LIVRE CINQUIÉME.

Les Arbres.

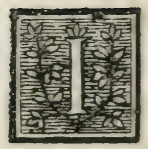

$L$ en eft tems : parlons des foins qu'on doit donner à la LESARBRSSo culture des arbres, employons les fruitiers de toutes les efpéces à décorer les champs, couvrons de chênes les montagnes, $\&$ d'oliviers le penchant des collines. On peut fe procurer les commodités de la vie avec beaucoup d'argent $\&$ de travail ; mais ce n'eft qu'après une longue fuite d'années que les vergers \& les jardins rapportent de beau fruit, \& que la terre 


\section{6 - E C ONOMIE}

IES ARBRES.

pareffeufe produit les hautes futaies.

C'eft pourquoi fi vous voulez avoir de l'ombrage fur votre terre, \& cueillir un jour abondamment du fruit qui, provenant des arbres que vous aurez plantés, vous paroiffe meilleur ; mettez la main à l'œuvre \& confiez de bons plants au fein de la terre. Faites porter de beaux fruits à un fujet de mauvaife nature, en lui faifant adopter par la greffe une branche de bonne efpéce.

Daignez, ( I ) illuftre Lamoignon, diffiper avec moi l'ignorance des Agriculteurs, \& mettre au jour pour l'utilité publique, les écrits qu'a

M. de La- laiffés votre pere fur les plantes, \&

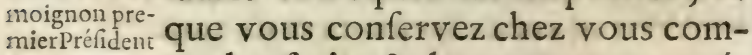
du Parlement me les fruits \& les monumens préde Paris. cieux de fes travaux : car tandis que ce refpectable Magiftrat dictoit les oracles de Thémis à la tête du premier Tribunal du Royaume, l'étude de l'agriculture lui fervoit de délaffement ; femblable à Salomon, il étendit fes connoiffances depuis le Cédre jufqu'à l'Hiffope, donna tout à la 


\section{R U R A I E. Liv. V. 257}

fois des régles pour le gouvernement des peuples \& des arbres, \& fit des unes fon occupation, \& fon amufement des autres. Ce grand homme ne fe délaffoit jamais de fes travaux qu'en les variant, \& il employoit le tems que lui donnoient pendant l'autonne les vacances du barreau, à écrire fur les occupations champêtres, afin qu'après avoir fervi fon fiécle par la fageffe de fes arrêts; fes momens de récréation fuffent encore utiles à la poftérité. Puiffent à jamais les Sénateurs fuivre fes décifions comme une régle invariable, \& pefer à la balance de cet homme refpectable les droits douteux des plaideurs. Pour nous, fuivons les préceptes qu'il donnoit pour la diftribution des arbres fur fa terre de Baville.

Je vais cependant parler d'abord L'olivier, de l'olivier dont il n'a pas fait mention. Soit que les fleurs de cet arbre femblables pour la forme à une grappe de raifin, annonçent d'avance une heureufe cueillette, fort que fes rameaux courbés fous le fruit en Tome. 


\section{C C ONOMIE}

LES ARBRES. de tous les arbres celui que l'avide fermier contemple avec le plus de complaifance, malgré la trifte couleur de fes feuilles.

Les oliviers viennent à merveille dans les champs expofés au midi, \& dont la terre n'eft ni fabloneufe ni trop graffe: mais il faut avant l'hiver labourer ces champs, \& y faire de larges foffes; enfuite vous prendrez fur un coteau voifin quelques-uns de ces jeunes rejettons qui pouffent au pied des oliviers à la faveur de leur ombrage, vous les enleverez à leur meretige pour les tranfplanter, \& $\mathrm{ils}$ emporteront même avec eux ( 3 ) quelque sracines comme une efpéce de dot, fans qu'elle en fouffre.

Gardez-vous d'arracher les rejettons aux vieilles fouches; vous rifqueriez de faire mourir ces vieux troncs. Faites - en brouter les drageons par les troupeaux de brebis; à moins que pour multiplier vos plants, vous ne vouliez facrifier le vieux tronc, le couper, \& élever en fa place ces rejettons qui font 


\section{RU R A L E. Liv. V. 259}

pleins de vie \& bien enracinés. Le laboureur doit tranfplanter à LES ARBRES. l'approche de l'hiver les jeunes plants qui ont pris racine, après en avoir coupé les branches; mais il faut leur couvrir la tête de terre glaife \& de mouffe verte que l'on affujettit avec un lien, de peur que les grands froids ne les pénétrent \& ne les gelent entiérement. Les oliviers aiment le penchant des collines bien aërées; il faut les y planter de loin à loin, afin qu'ils aient de l'efpace pour étendre leurs rameaux de tout côté, $\&$ qu'ils puiffent en croiffant prendre une large circonférence; car ceux dont la tête fe termine en pointe, donnent peu de fruit \& n'abondent qu'en feuilles.

Que le tronc ait la tête haute de peur que les troupeaux ne mangent les feuilles des branches courbées fous le poids du fruit. Car on voit fouvent des chevres s'élever fur l'extrémité du pied pour atteindre aux bas oliviers, fous lefquels il arrive quelquefois qu'on les laiffe coucher dans les beaux jours de l'été : mais il 


\section{0 (E) C N O M IE}

faut frotter les branches d'oliviers

LEDARBRES. avec de la fiente de bouf délayée dans de la boue, pour mettre en fureté les feuilles que leur amertume naturelle ne garantit pas affez.

Si un jeune olivier eft trop battu parles vents, \& que la pente du terrein le faffe courber facilement, on enfonce à côté un pieu de chêne qui lui fert d'appui, le redreffe \& le met en état de réfifter à tous les vents. S'il tombe de la pluye dans un tems convenable, il faut bécher la terre autour des oliviers, ou labourer tout le champ; ces foins ne font pas croître ces arbres plus vîte, mais les font durer plus long - tems. Car de même que les productions d'efprit dont on veut étendre la durée atı-delà de plufieurs fiécles ne font pas l'ouvraze d'un moment ni d'un fimple eftort de génie, mais qu'elles s'achevent peu-à-peu \& n'atteignent le point de perfection qu'apres plufieurs années; de même la terre qui fait croître en peu de tems le figuier \& le poirier, retarde les progrès de fa féve pour les tilleuls, les 


\section{R U R A LE. Liv. V. 26I}

chênes \& ( 4 ) les oliviers qui vivent plus d'un fiécle, \& ne les garnit de branches qu'après bien du tems; \& lorfque leur tronc s'eft muni de fortes racines.

Quand un olivier eft dans fes premiéres années, \& que fes olives mûriffent pour la premiére fois, ce feroit une cruauté de les abbattre avec la perche, elle romproit les branches. Il faut cueillir à la main tout le fruit auquel on peut atteindre; mais lorique les branches de l'arbre feront plus fortes \& pourront fupporter les coups de perche, il faut les battre obliquement \& ne pas frapper les olives en face, de peur de les meurtrir ; on les reçoit dans des draps à mefure qu'elles tombent, \& le foir on les vanne dans in endroit fpacieux de la même maniére à peu pres qu'onvanneles bleds

Mais je ne fongè pas que je parle varióré des trop d'un feul arbre, $\propto$ que j'oul-arbress. blie les autres: fécuit par un amour national pour l'olivier, je ne vois. pas quelle vafte forêt $j$ 'ai à décrire dans mes vers, \& combien il eft d'ar- 


\section{CE C O NOM IE}

$\overline{\text { LES ARBRES }}$ bres de différentes efpéces que je dois montrer à tailler, à élaguer, ou à rendre fertiles par l'infertion d'un germe étranger. Il y a des arbres qui portent des fleurs odoriférantes; d'autres étendent leurs rameaux pour donner un délicieux ombrage ; enfin les autres courbés fous un noble faix, rapportent des fruits. J'ai deffein de les décrire tous malgré leur nombreufe variété, puifque notre pays fitué fous une zone tempérée nous en produit de toute efpéce.

żes bois. Je parlerai d'abord des bois, j'enfeignerai la forme qu'on doit leur donner, \& la maniére de les planter; car un bois épais, qui comme un nuage fert de voile contre le foleil, eft le plus agréable ornement d'une maifon de cam pagne.

Quoiqu'autrefois la France pût à peine nourrir fes citoyens, ils eurent tant d'attachement pour leurs forêts, qu'ils aimérent mieux aller s'établirdans des pays étrangers que de pourvoir à leur fubfiftance en abbattant leurs bois. 


\section{R U R A L E. Liv. V. 263}

Que n'avons nous encore pour les forêts ce même attachement, afin de LES ARERES. nous oppofer aux coups de la hache cruelle! Dans quelle campagne voiton maintenant de beaux chênes refpectés par la coignée parvenir à une extrême vieilleffe, à moins qu'ifolés fur des montagnes inacceffibles, ils ne fe défendent eux-mêmes par l'avantage de leur fituation? Si nos ayeux ont laiffé quelques bois à leur poftérité, ils ne donnent point d'ombrage impénétrable aux rayons du foleil, \& ne cachent point dans les cieux leur tête altiére, tels que ces arbres prodigieux \& refpectables que le peuple adoroit autrefois; ce ne font que des rejettons de vieilles fouches condamnés après quatre luftres à devenir la proie de nos foyers. A peine un liévre trouvet-il un refuge dans les forêts qui fervoient anciennement de retraite aux ours \& aux daims timides. Eh! quel peut - être l'agrément d'une campagne fans celui des bois? Pendant les âpres chaleurs de la canicule, on eft forcé de refter chez foi comme fi l'on 


\section{E C O O MIE}

$\overline{\text { IESARBRIS }}$ étoit affiégé ; on ne peut dans l'été, ni fe repoier, ni gouter la fraicheur à l'ombre d'un chêne, ni compofer des vers, qui dans le filence des bois interrompu feulement par le coricert des oifeaux, fe préfentent d'euxmêmes à l'efprit \& de la mefure qu'on défire.

Etendez donc vos foins à l'avenir, \& plantez des bois. Si vous êtes d'un âge avancé, \& que vous n'efpériez pas d'affez longs jours pour les voir dans leur beauté \& jouir de leur ombrage, vous aurez du moins le plaifir de voir ces jeunes plants s'embellir, croître infenfiblement, parer leur tête de feuilles fans nombre, \& inviter le roffignol paffager à ravir les oreilles par fes chants. Quand même l'agréable vûe d'un jeune bois ne vous toucheroit point, ne devez-vous pas rous fouvenir de vos chers enfans, \& planter pour votre poftérité fi ce n'eft pas pour vous?

O vous, jeunes difciples de Loyola, qui êtes nouvellement entrés dans notre fociété, s'il m'étoit per- 
RURALE. Liv. V. 265 mis de replanter (6) l'ancien bois qu'on a fait abbattre, \& dont ciLESAR3RES devant j’ai amérement pleuré la perte; ma main feroit la premiére au travail, quelque fatiguant qu'il füt ; ce feroit un foulagement pour moi dans mes regrets, de favoir qu'un jour, mes chers confreres, (7) vous prendriezdes plaifirs aufquels $j^{\prime}$ 'aurois contribué.Je labourerois troisou qua. tre champs contigus à notre maifondu côté que Borée fuivi des tempêtes, fe déchaîne avec fureur, \& je femerois du gland dans tout ce terrein : dès que les jeunes tiges commence. roient à fortir du fein de la terre, $\&$ à fe couvrir de feuilles, j'en écarterois les troupeaux, \& je laifferois ces nouveaux plants pouffer confufément \& fans ordre.

Lorfqu'enfuite ces jeunes éléves commenceroient à étendre leurs rameaux, \& à être agités par les vents, je les élaguerois avant l'hiver, j'en laifferois peu en terre, j'arracherois ceux qui ne feroient pas de belle venue, \& planterois de jeunes chênes de

Tome $I$.

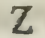




\section{$266 \quad$ E C ONOM IE}

même âge les endroits dégarnis, avant que les autres arbres des environs fuffent plus touffus \& plus hauts : car ainfi que dans une ville ceux qui la gouvernent \& qui font à la tête des affaires, contiennent le peuple dans fon état obfcur, \& l'empêchent de s'élever; de même dans les bois épais les jeunes arbres ne croiffent jamais parmi les grands qui portent jufqu'aux cieux leur tête fuperbe, \& dont le nuifible ombrage offufque les petits. Enfin j'arracherois toutes les épines qui pouffent au pié des jeunes arbres, \&r je tâcherois de donner à mes éléves la plus belle forme en les taillant à propos : mais ce travail n'eft utile que dans les premiéres années, car le chêne dans les bois fe délivre lui-même de fes branches les plus baffes quand il eft un peu grand; au lieu que dans les champs fe trouvant plus au large, fes rameaux s'étendent de toute part \& fourniffent beaucoup d'ombre. Le chêne des bois s'éléve au - deffus des arbres qui croiffent autour de lui, \& femble vouloir atteindre aux 
R U R A.L E. Liv. V. 267 cieux \& s'unir avec le foleil ; peu inquiet de l'accroiffement de fes raLES ARBRES. meaux, il ne s'embarraffe guéres de leur diftribuer les fucs qu'il reçoit de la terre, \& fe les approprie uniquement pour l'élévation de fa tige.

Si vous êtes carieux de belles avenues au-devant de vos maifons, plantez trois ranos d'arbres, \& pro- cyprès \& 80 plantez trois rangs d'arbres, \& pro-charme. curez-vous de l'ombrage avec l'ormeau touffu, le tilleul uni, \& le cyprès taillé en éventail, ou avec le charme qui fe prête à toutes les formes qu'on lui donne : il eft d'un grand ornement dans les jardins; 1oit que les cizeaux du jardinier le courbent en arcade, foit qu'il ferve à brouiller les voies d'un labyrinthe oì parcourant toujours les mêmes routes, \& retournant toujours fur fes pas, on a peine à trouver l'iffue de ces agréables détours quand une fois on y eft entré.

Les (8) mûriers dans le voifinage Le Mürice. d'une maifon, lui fourniffent auffi un ombrage qui plaît; mais ils ne confer. vent pas long - tems l'ornement de leurs rameaux; car dès qu'ils fe cou.

$$
Z \text { ij }
$$


268 CE C O N M IE

vrent de feuilles renaiffantes une LES ARBRES. troupe de jeunes filles s'empreffent impitoyablement de les en dépouiller pour en nourrir les vers à foie : dommage cependant qui ne feroit pas irréparable, fi ces arbres reprenoient leur premier agrément au retour des feuilles; mais leurs rameaux defféchés tiennent fans grace à leur tige maltraitée, parce qu'ils n'ont pas été ménagés dans le tems de la féve où ils font encore tendres. $\mathrm{O}$ jeunefle fans pitié, épargnez du moins les feuilles les plus élevées des mûriers; écartez de la main gauche les branches d'en haut fans les dépouiller, \& de la droite, prenez vos provifions fur les plus baffes, de peur que ces arbres ne montrent une tête nue, hideufe à voir, \& que leurs branches couvertes de nouds ne donnent de l'ombre qu'à leurs troncs.

les yrands Le Prince, en ordonnant que les shemins doi- grands chemins fuffent plantés d'arvent être plantés d'Ar bres des deux côtés, a voulu procurer bres.

à tout fon royaume les mêmes ornemens que je demande dans les ter- 


\section{R U R A L E. Liv. $V .269$}

res des particuliers : cette précalition feroit un jour d'un grand fou- LESA RBR:S lagement au voyageur pendant l'été, \& d'une utilité confidérable pour le public dans la difette où I'on eft de bois de chauffage : mais à quoi fervent des loix fans exécution ? Si l'on a planté quelques arbres, celui qui les a mis les arrache, ou les fait mourir par avarice, dans la crainte que leur ombre un jour ne faffe tort à fes moiffons. Pourvoyez, grand Prince, à l'exécution de vos loix, en diminuant la taille des villages, \& condamnant à une légére amende ceux qui contreviendront à vos ordonnances; vous changerez par ce moyen la deftinée de ces arbres, \& vous les verrez croître en peu d'années, pour l'embelliffement des chemins. Si vous ne dédaignez pas de porter vos regards fur l'avenir, prévenez par vos foins la deftruction générale des bois, l'entreprife n'eft pas difficile; exemptez d'impôts les particuliers qui planteront leurs champs de pins ou de chênes, \& vous verrez avec admiration 


\section{E C ONOMIE}

LES ARBRES. fortir de terre de nouvelles forêts dans différens cantons.

Les Arbres Les faules \& le peuplier blanc aiaquatiques. ment les riviéres : la furface des eaux en paroit plus riante lorfqu'elles coulent fous leur ombrage; ces arbres fourniffent des feuilles aux troupeaux, des planchers aux maifons \& du bois aux foyers; de plus leurs racines ferviront de rempart à vos champs contre l'effort de l'eau qui poumrô̂t $s^{\prime} y$ infinuer peu à peu \& gagner du terrain à leurs dépens.

I'Aulne. Souvent un fleuve déracinera vos faules \& vos aulnes récemment plantés, \& devenu plus rapide, les entraînera dans fon cours; mais ne vous rebutez pas, recommencez le même ouvrage au printems fuivant, $\&$ remettez de nouveaux plants fur la rive: fi une fois leurs racines font bien adhérentes à la terre, \& fi les caux tranquilles ne quittent point de long-tems leur lit ordinaire, le faule foible, \& l'aulne tout méprifable qu'il eft, réfifteront par la fuite à la fureur des flots, braveront impunément ce fleuve impétueux, qui 
R U R A L E. Liv. $V . \quad 27$ I

bruyant au loin ravage les campagnes, rompt les digues qu'on lui oppofe, \& roule des pierres énormes; envain viendra-t-il battre ces arbres fur le rivage, ils fe défendront par leur nombre : frémiffant \& furieux il reprendra fon cours, \& couvrira tout au plus leurs branches d'écume \& de limon qui attefteront fa rage \& fon débordement.

Les faules donnent auffi de l'a. grément aux prairies qu'ils bordent; plus l'humidité les pénétre, \& plutôt croiffent leurs rameaux : d'ailleurs, ils fourniffent des liens pour réprimer la fougue de Bacchus.

Il faut que la branche de faule que I'on plante de bouture foit taillée par le bout en forme de coin, afin qu'elle n'ait pas de peine à prendre racine, \& qu'elle donne promptement des feuilles; il arrive fouvent qu'une (9) branche féche tirée d'un fagot de faule reprend de bouture après avoir été piquée en terre pour fervir de gardien \& d'appui à de jeunes plants : elle fe couvre de feuilles, \& nuit méchamment par fon ombre

$\mathrm{Z}$ iiij 


\section{CE C ONOMIE}

$\overline{\text { LESARBREs, }}$ aux progrès des éléves qu'on lui a confiés. Et comme l'aveugle mort fait fa proie des meilleures chofes; on voit périr pour toujours le tilleul \& l'ormeau à côté du faule que le voifinage de la mort n'empêche pas de reverdir \& de s'étendre.

Ie Euis. Le buis qui conferve en tout tems fes feuilles, autrefois fans culture, n'habitoit que les montagnes : maintenant il (10) alligne les fentiers d'un jardin par des bordures ferrées \& précifes; il tranche d'un beauverd l'émail des fleurs dans les différens com. partimens; quand on veut, il s'éléve en forme de muraille, il entoure un jardin \& tient lieu de haie, fert de fiége \& offre un lit de fes feuilles, ou bien fes tendres rameaux courbés, préfentent de petites grotes qui font un abri fûr contre l'ardeur du foleil. Le cizeau du jardinier lui fait prendre la figure, tantôt d'un lion furieux, tantôt de Diane l'arc en main \& lançant des traits, \& tantôt d'une tour, d'un ferpent, ou d'un oifeau qui déploye fes aîles, $\&$ qui femblant vouloir s'élever 


\section{R U R A I E. Liv. V. 273}

dans les airs, tient à la terre par les pieds.

(I I) L'iffe plaît dans les jardins L'If, les mieux cultivés, \& prend toutes les figures qu'on veut lui donner, foit qu'arrondi par le fer, il s'appuye fur la terre en forme de globe ; foit que fes rameaux courbés \& conduits avec art, imitent un ciel, une voute, un foleil, un croiffant de lune; foit que taillé par la cime, il fe termine en pyramide, ou qu'un jardinier habile le métamorphofe en homme ou en différentes fortes d'animaux.

Que dirai-je du myrte, du laurier qu'on a confacré aux mufes ( 12 ) Peuplier, is $\&$ dont on couronne les Poëtes, de la branche urfine, du pin aux feuilles hériffées, du trifte cyprès, du plane, \& de l'aulne qui fe plaît fur la rive des fleuves, de l'acacia ( I 3 )qui depuis peu nous a été apporté de l'Amérique, arbre fi propre à tapiffer les murs de fa verdure, \& à orner au printems le devant d'une mai-. fon. Que dirai-je encore du peu= plier dont ( I 4) les feuilles touipours 


\section{4 \\ E C O NOM I E}

LES ARBRES. agitées font fenfibles à la plus douce haleine des zéphirs, \& du fapin qui, après avoir ćté fur les montagnes battu des vents les plus terribles, fe voit fur la mer expofé aux fureurs d'Eole $2 x$ de Neptune.

Arbres frui- Les doux fruits de Pomone m'intiers. vitent à me tranfporter dans les jardins : s'il y a d'une part beaucoup de travail pour le fermier; d'un autre côtéla cueillette des fruits le récompenfe de fes peines. Il doit donc commencer par ouvrir des foffes au commencement du printems, afin que les chaleurs qui fuccéderont, corrigent les mauvaifes qualités que la terre peut avoir, \& qu'elle fe pénétre ( 15 ) des nitres de l'air néceflaires à toutes les productions; lesfoffes doivent être creufées en forme de cône, qui s'élargit par le bas afin que les racines des arbres s'étendent en liberté dans la partie inférieure de la foffe, \& que la partie fupérieure plus étroite ne donne que peu d'entrée aux grandes pluies.

Choir des Vous choifrez pour plants ceux plants. qui auront la tige droite fans nouds 
R U R A E. Liv. V. 275

$\&$ fans plaie, \& qui feront garnis de trois racines $\&$ de trois bonnes LES ARBRES: branches, afin que celle du milieu fe foutienne plus droite, \& qu'elle forme de fes rameaux une tête plus vafte \& plus arrondie : défiez-vous des plants quion expofe en vente dans les villes, ils font fouvent à demi morts quand on les replante, parce qu'il y a trop de tems qu'ils font privés de la fubitance de la terre. Souvent auffi ils trompent vos efpérances, \& ne vous rapportent que des fruits impofteurs, parce qu'ils ne font pas de la qualité pour laquelle on vous les a vendus.

Vous enfemencerez vous-même la Pépinićs votre champ, \& prendrez les pre-re. miers foins que demande une pépi. niére pour donner de beaux éléves. Si vous manquez de jeunes plants, détachez d'un bon arbre une petite branche que vous nourrirez d'eau de pluie dans une bouteille expofée au foleil. Si cette branche s'imbibe toujours de l'eat nouvelle que vous. remettrez, elle pouffera une petite 


\section{EE C O OMIE}

$\widetilde{\text { LESARERES }}$ racine après un mois : alors on lui donne une nourriture plus folide, on broye dans la main un peu de terre, que l'on mêle avec l'eau. Enfuite, lorfqu'on voit que les boutons de feuilles commencent à percer l'écorce, on met cette branche en terre, \& on l'éléve avec foin dans la crainte que le froid ne la géle, que l'ardeur du foleil ne la defféche, ou que noyée par trop d'humidité, elle ne jauniffe.

Mais les plants d'arbres ne viennent pas également bien dans tous les champs; car les fucs nourriciers ne font pas par tout les mêmes, les racines n'ont pas toutes les mêmes tiffures ni les mêmes canaux propres à donner paffage aux différens fels de la terre : c'eft pourquoi le laboureur varie les femences felon les lieux, \& feme du millet \& $z$ de l'avoine dans les champs où le froment ne vient pas bien, parce que cette terre eft plus analogue à ces grains qu'à d'autres femences.

Remplace- Quand un vieil arbre eft mort, ment des ar- c'eft avec bien de la peine qu'on en
bres qui man वृuent. 
RUR A L E. Liv. V. 277

eléve un autre dans fa place; foit parce que les racines qui reftent du précédent, interceptent la nourriture, ou parce que le vice du fol fe communique au jeune plant, $8 x$ lui eft funefte.

Quoi qu'il en foit, afin d'avoir une belle avenue d'arbres plantés à égale diftance, il faut, dès qu'on en veut remplacer quelqu'un, creufer une large foffe que vous laifferez longtems ouverte; vous brulerez les vieilles fouches, vous nétoyerez bien le fond de la foffe, \& vous irez prendre dans quelque vallée de la terre fraîche bien engraiffée par le fuc des feuilles tombées \& corrompues, que vous fubftituerez à celle que vous aurez tirée. C'eft ainfi que dans les maifons où il eft mort quelqu'un de la pefte, on jette par les fenêtres, crainte de la contagion, les meubles \& les autres chofes que le peftiféré a pu toucher, \& l'on brule des plantes aromatiques dans les appartemens pour les parfumer \& chaffer le mauvais air.

Il faut obferver quelle partie 


\section{CE C NOM I E}

$\overline{\text { ES ARBRES. }}$ du ciel regardent les arbres quion veut tranfplanter, \& les remettre dans la même expofition, de peur qu'ils ne reçoivent difficilement leur nourriture, fila partie des arbres qui regardoit le midi dans leur état précédent, regarde le nord dans leur nouvelle fituation. Car les veines d'un arbre font moins grofles fous l'écorce qui eft tournée vers le feptentrion, \& le foleil fait monter la feve dans cette partie en plus petite quantité. Examinez ces cercles (16) qui fe forment dans le tronc du chêne, \& qui fe terminent un peu en ovale, ils font plus épais du côté du midi, \& plus minces du côté du nord: d'après cela vous fçaurez vous orienter \& reconnoître la route qu'il faut tenir quand vous vous ferez égaré dans un bois, fi vous coupez horifontalement une branche d'arbre; car du côté que l'écorce fe trouvera moins nourrie, \& plus proche de la moëlle, ce fera le feptentrion, conféquemment le midi du côté oppofé : fi vous tournez le dos au pole arctique, vous aurez à 
RURAIE. Liv. $V .279$ votre droite le couchant $\&$ à votre gauche le levant.

LES ARBRES.

Si un jeune arbre, au lieu de pouffer de longues racines en terre, jet- lagues.

te trop de branches, élaguez-le avec la ferpe, afin que la féve defcende à la fouche $\&$ la fortifie dans fes promiéres années. C'eft ainfi qu'au printems on méne paitre les troupeaux dans les champs enfemencés, afin que les moiffons délivrées des herbes furabondantes deviennent plus belles, \& que la tige du bled ne s'affaiffe pas fous l'épi trop chargé.

Lorfqu'une branche du milieu d'un arbre tire à elle tous les fucs nourriciers, \& que les autres meurent faute de fubftance, il faut l'abbattre pour forcer la féve à prendre une autre route \& à diftribuer également fes faveurs aux autres rameaux, fans prédilection pour le même.

Eh ! plût à Dieu que le Prince confultant l'intérêt public lorfqu'un nouveau parvenu s'eft élevé de la lie du peuple au faite de la fortune, abaiffât cette tête fuperbe qui fe 
$\overline{\text { LES ARERISS }}$ dreffe vers le ciel avec une hauteur infoutenable, \& que les richeffes de tout le royaume poffédées par un feul, fuffent reparties à tous les citoyens! plît à Dieu que le Prince ne fouffrit pas que ce vil mortel s'engraiffât aux dépens du public, \& infultât à notre mifére par la magnificence de fes bâtimens \& la fomptuofité de fa table!

L'urage de Quoique la greffe réponde mieux la greffe.

à nos vœux quand les arbres font jeunes; fi cependant vous avez envie de corriger quelque fruit, ou d'en raffembler de plufieurs efpéces fur un même tronc, il y a différentes façons de le faire.

On greffe en fente, non pas cependant fur un endroit oì fe trouve un oil, comme ( I7) l'enfeignoit le Prince des poëtes, mais plutôt dans la partie du fujet la plus unie où il ne fe trouve ni noud ni cicatrice: l'on fait entrer fous cette écorce une petite branche d'un autre arbre : ou bien le jardinier greffe en levant de deffus un arbre de bonne efpéce un œil accompagné de l'écorce qu'il a 
RU R A L E. Liv. $V \cdot 28 \mathrm{r}$ taillée en forme d'écuffon. Il détache du fujet qui recevra cet œil, un écufLES ARBRES. fon d'écorce précifément de la même taille \& de la même grandeur que le précédent. La place vuide eft remplie à l'inftant par l'écuffon de bonne efpéce qui fait corps avec l'arbre oì il eft adopté. On couvre de terre les trois fentes de l'écorce; on y fait une ligature avec de l'ofier, \& cet héritier étranger s'éléve \& s'impatronife dans fa nouvelle habitation.

On greffe en poupée, lorfque les arbres ont beaucoup de féve; on choifit une greffe bien unie, bien faine \& chargée de boutons ; on l'applanit à deux faces en forme de coin ; on abbat enfuite les branches du fujet qui deviennent inutiles ; on l'étête, \& avant que d'enfoncer le coin dans l'épaiffeur du tronc qu'or veut fendre, on le lie bien dans la crainte qu'il ne fe faffe une trop grande ouverture ; on lui fait enfuite une poupée avec de l'argile \& de la mouffe, $\& z$ on la lie tout à l'entour afin qu'immobile elle puiffe réfifter aux injilres de l'air, \& aux coups de vent.

\section{Tome $I$.}




\section{E C O NOMIE}

LES ARBRES. On eft dans l'ufage de lier les greffes avec de l'ofier, mais nous préférons le jonc \& toutes les ligatures douces $\&$ fouples; car lorfque la chaleur a defféché l'ofier, il ferre trop la greffe.

On greffe en couronne, lorfqu'au printems les arbres abondent en féve ; on étronçonne une tige fous l'écorce de laquelle on infére plufieurs greffes, de maniére qu'elles forment une efpéce de couronne fur ce tronc.

On greffe auffi en flute, lorfqu'on léve en forme de chalumeau l'écorce d'une branche avec tous fes yeux fains \& entiers pour revêtir une autre branche dépouillée pareillement de fon écorce, \& corriger le goût du fruit.

Quand ( 18 ) on greffe en approche un citronier dont les fleurs \&z les fruits relévent la beauté d'un vafe de marbre blanc, la greffe fe marie fi étroitement au fujet, qu'elle $s^{5} \mathrm{y}$ attache comme à fon tronc natiurel, \& qu'elle tire un double fuc des deux tiges. On la févre de la 


\section{R U RALE. Liv. V. 283}

nourriture de fon tronc, \& on la coupe lorfqu'elle eft habituée aux IES ARBRES. nouveaux fucs de celui qui l'a adoptée.

L'ufage de la greffe eft ce qu'il y a de plus agréable $\&$ de plus utile dans le vafte champ de l'agriculture; on a trouvé par-là le fecret de changer les fauvageons de nature. Un arbre bien greffé profite en toute forte de terre; les pêchers qui en aiment une bien féche, profitent dans les champs les plus gras, ainfi que le cérifier, pourvû que le tronc quiles a adoptés, fe plaife dans ces terreins. Un poirier greffé fe défarme de fes pointes, femble étonné de donner de nouveaux fruits, \& une ombre différente de la fienne. Ainfi, le châtaigner fur lequel on greffe un noyer, produit des fruits unis qui n'ont plus d'enveloppe hériffée ; le prunier donne des pommes $\&$ fe greffe auffi fur le frêne, auquel il fait prendre fon nom; le pommier enté fur le faule lui fait porter for fruit ; \& le buiffon né pour produire uniquement des épines $\&$ des

$$
A \text { a ij }
$$

I'utilité de lá grette. 


\section{E CONOMIE}

ronces, fe pare de fleurs \& charge LES ARBRES, de fruit fes rameaux : ainfi l'ormeau plus feuillu, rapporte du gland ; ainfi (19) les bayes du laurier fe chan. gent en cérifes; ainfi le mûrier tout glorieux de fes nouvelles branches, \& de fon nouveau feuillage, fe pare avec fafte des belles fleurs du citronier, \& les jeunes filles vont cueillir des citrons au même arbre qui nourriffoit leurs vers à foie, \& prendre des fleurs pour s'en orner la tête fur des branches d'où elles ne rapportoient auparavant que des feuilles dans des corbeilles.

Des fucs . C'eft ainfi que des fruits différens

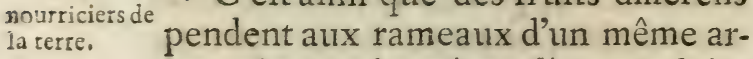
bre, \& que la même féve conduite par les mêmes racines, fe durcit pour donner le fruit de l'amandier, s'amollit pour former la prune, fe revêt d'une blancheur admirable dans les fleurs, donne une tunique de pourpre aux cérifes, \& teint en noir les mûres. Les fruits d'une faveur donce ou acide, font également fes productions, (20) elle prend comme Protée toulte forte de forme \& de couleur; 
R URA L E: Liv. $V . \quad 285$

fes qualités varient dans les différentes plantes qu'elle vivifie, elle pro- LES ARER Es. duit à côté de l'ail infupportable par fon odeur, l'oillet \& la rofe qui exhalent un parfum raviffant ; \& falutaire \& mortelle tout à la fois, elle fait naître les (2I) mauves émollientes, \& la ciguë poifon dangereux.

C'eft ainfí que la même eau fortant par des tubes différemment percés, prend mille figures variées; tantôt elle paroît concave en coulant dans des verres, tantôt hériffée de pointes lorfqu'elle repréfente une gerbe, tantôt applanie quand elle forme phufieurs nappes; tantôt auffi elle s'élance dans l'air par un jet rapide, s'arrondit comme une voile de vaiffeau, repréfente les rayons du foleil, toutes les couleurs de l'arc-enciel, fe répand en pluie, \& prenant la forme d'un dragon, ou d'un trait qu'on décoche, inonde l'air d'une humide rofée.

L'arbre fur lequel on veut enter, saiton ca doit être fain \& dans fa premiéregreier. jeuneffe ; car de même que les bleffures dans un âge tendre, fe ferment 


\section{E C O N O M I E}

$\overline{\text { IES ARBRES }}$ \& fe guériffent bientôt : ainfi les plaies que fait la greffe à un jeune arbre font légéres, \& quelques jours après l'opération le rameau introduit chez fon nouvel hôte, ne fait qu'un corps avec lui.

Tout arbre cependant n'adopte pas toute efpéce de fruit au gré de vos defirs; car il eft impoffible de vaincre certaines antipathies invétérées, \& de réconcilier le chêne \& le poirier, l'olivier \& la vigne, Bacchus \& Minerve.

Quand vos plants auront trois ans, vous les ôterez de leur terre natale, \& vous les tranfplanterez dans un terrein convenable, \& qui leur plaîe; s'il y en a quelqu'un qui ne pouffe pas, ou qui après avoir pouffé, ne continue pas de profiter, tranfplantez-le ailleurs, \& vous embarraffez plutôt de lui choifir une terre qui lui foit propre par fa qualité \& fon expofition, que de le placer dans un quartier diftingué par un charmant ombrage 20 de teaux fruits. Dans les champs dont la terre eft légére, $\&$ qui ont une pente douce vers $]$ 
R'U R A L E. Liv. V. 287 midi, les fruits font d'un meilleur $\overline{\text { LES ARBRESa }}$ goût, \& dans les terres graffes \& humides, ils font plus gros \& mieux nourris, tels qu'il en faut pour faire des pyramides qui ne doivent repaître que les yeux, \& qu'on donne en fpectacle aux convives comme des tableaux amufans.

Choifffez pour élever des pommiers, un champ qui foit plus fertile par lui-même que par le fecours d'un ruiffeau qui l'arrofe. Ces arbres ne haiffent pas les montagnes, ni même les terreins fabloneux quand ils ont de l'eau fuffifamment pour tempérer leur ardeur. (ependant, com. me les pommes dégénérent ordinairement dans les champs trop gras, $\&$ n'ont plus le goût auffi piquant ; de même dans les terreins trop fecs, elles tombent de l'arbre avant d'être mûres, \& fe rempliffent de vers. Le pommier vient auffi fort bien dans les prairies : dès que cet arbre y a pris une fois racine, il n'a plus befoin des foins du fermier? \& fans le fecours de la chamme, il rapporte des fruits à qui l'herbe ten- 


\section{E C ONOMIE}

Lis Are fauve le dommage de la chute en les recevant dans fon fein lorfque le vent les abbat.

Ie Figuier. Le figuier aime le foleil, \& on ne le plante point en plein vent dans les pays froids, mais on le tient dans une grande caiffe, \& chaque année au retour de l'hiver on le met à l'abri dans une ferre, \& on le rapporte au grand air lorfque les doux zéphirs ont fait fuir au loin Borée du côté de l'Ourfe. * Pour nous, nous plantons le figuier, ou dans nos jardins ou dans nos vignes, \& nous lui faifons fupporter en plein air les vents rigoureux du Nord : quoique depuis peu nous ayons effuyé un hiver quiauroit dî allarmer notre fécurité, \& que tous les figuiers aient péri dans nos champs au grand étonnement des fermiers qui ne pouvoient concevoir un accident aufif extraordinaire. Mais heureufement les germes \& les rejettons qui s'étoient confervés en terre, ont pouffé

* Il faut obferver que le Pere Ianiaiore étoit du Languedoc.

prompte- 


\section{RURA I E. Liv. $V_{0} \quad 289$}

promtement, que nous ne nous appercevons plus de nos pertes. Le fi- Las Argres. guier étend fes rameaux en peu de tems, mais auffi fa carriére eft bien courte. La mort(22)vole à la deftruction de tous les êtres dont la nature a hâté la perfection.

La fortune fe comporte à peu près de la même maniére; elle comble de richeffes les mortels \& les éléve au haut de fa roue : mais du faite des honneurs, elle les précipite dans le néant par un prompt retour; elle adopte enfuite un nouveau favori, qu'elle ne montre auff qu'un inftant pour l'enfevelir aufitôt dans l'obfcurité où vivoient fes ancêtres. Plus une maifon eft élevée, plus fa chute fait de fracas ; c'eft comme un cédre qu'un voyageur avec admiration avoit vû dans une forêt élever fes rameaux jufqu'aux cieux, peu de tems après cet homme à fon retour porte fes regards où cet arbre fuperbe couvroit tout un bois de fon ombrage, $(23)$ il cherche envain la tê. te altiére du cédre, il ne voit que les traces de fa chute dans les arbres

Tome I.

$\mathrm{Bb}$ 
voifins dont il a rompu les branches.

$\mathrm{Ne}$ négligez pas de faire venir des figuiers de bouture en les piquant dans un terrein pierreux, c'eft-là qu'ils fe plaifent ; mais malgré la bonne expofition, prenez-en beaucoup de foin dans les commencemens: ainfi fendez un rofeau entre fes nouds, \& couvrez-en comme d'un chapeau la tête de votre jeune plant pour le garantir du froid.

Afin que le figuier hâtif donne des fruits avant la faifon, faites bouillir de l'huile, des oignons $\&$ du poivre, $\&$ arrofez-en fes racines, c'eft un moyen fûr pour exciter la féve \& avoir des figues précoces : vous en aurez au contraire de tardives, $f$ vous arrachez les fruits dès qu'ils commencent à paroître ; car cet arbre fécond en repouffe d'autres incontinent, mais les vents imprévîs du nord les gélent quelquefois, \& les empêchent de venir à maturité.

Ie Cirro- Le citronier eft encore plus délinier. cat, \& demande de plus grands foins: s'il n'eft pas enfermé dans une ferre, s'il n'eft pas couvert de paille qui 
R URA L E. Liv. $\nu .29 I$ le garantiffe des grands froids, à $\overline{\text { LES ARBRES. }}$ peine peut-il les fupporter, quoiqu'il foit dans un terrein expofé au foleil \& à l'abri du vent. Il veut être mis dans une caiffe, \& cet arbre ambulant jouit tantôt pendant l'été des rayons bienfaifans du foleil au milieu des jardins, \& tantôt logé dans une longue ferre, écoute impunément foufler les vents du midi; $\&$ tandis que le chêne pénétré de froid \& dépouillé de feuilles montre une tête chauve, le citronier fans être endommagé conferve fon même agrément, \& fon fruit \& fes fleurs parent en même tems fes rameaux.

$S i$ vous voulez orner de citroniers un long portique, rangez-y vos caiffes de file \& à égale diftance, vous jouirez ainfi d'un printems perpétuel; car fi le mauvais tems ou la difficulté des chemins vous oblige de garder la maifon, vous pourrez au milieu de l'hiver jouir fous ce por-. tique des parfums du printems $\&$ des préfens de l'automne, $\&$ cueillir à la fois des fruits \& des fleurs au mê. me arbre.

$\mathrm{Bb}$ ij 


\section{2 \\ CE C O NOMI E}

Le noyer né pour être grand \&

IISARBRES. braver un jour la fureur des vents, le Noyer. doit être expofé au grand air : c'eft en pleine terre, qu'il faut planter les noix humectées \& la pointe en bas, afin que l'arbre en naiflant étende plus loin fes racines, \& puiffe réfifter aux fecouffes des vents.

Il faut faire changer de terre au noyer trois ou quatre fois pendant les premiéres années : car de même que les jeunes gens qui voyagent au loin \& s'expatrient de bonne heure, multiplient leurs connoiffances ( 24 ) $\&$ acquiérent des perfections, de même le noyer quand on l'ôte jeune de fa terre natale devient plus grand $\&$ plus fertile.

On doit mettre une large diftance entre les noyers qu'on plante, de peur qu'ils ne fe nuifent par leur ombrage, que leurs branches ne fe frappent les unes les autres, \& que les noix tendres encore ne foient les victimes de leurs coups réciproques. Mais comme ces arbres étendent au loin leurs rameaux, \& que leur ombrage eft mortel aux moiffons, il 
RURALE. Liv. $V_{0} \quad 293$

faut les planter fur la lifiére des champs, de façon cependant qu'ils ne foient pas fur le bord du chemin ni trop près de la ville; car les paffans les attaquent pour avoir leurs fruits, \& font pleuvoir fur leurs branches une grêle de pierres qui les fracaffe \& deshonore les arbres. Les noix quand on les cueille ne doivent pas encore avoir leur premiére écor ce ouverte, elles s'en dépouillent d'elles-mêmes après qu'on les a mifes fur de la paille.

Il n'eft pas befoin de tranfplanter Le Châtai le châtaignier, ou $f i$ on le fait, $i l^{\text {gnier. }}$ faut garnir fes racines d'une terre bien humectée, afin qu'il ne fe reffente point du changement de place lorfqu'il fera établi dans fa nouvelle demeure.

Placez l'amandier dans les champs où l'on feme du froment, pourvû L'Aman qu'il n'y foit point expofé au foufle impétueux des aquilons, car le vent brule les fleurs trop précoces que cet arbre imprudent tous les printem's fait éclore.

C'eft la fleur del'arbre qui fonde De la fleur $\mathrm{B} b$ iij des arbres. 


\section{CE C O N O M I E}

$x$ ES ARBRFS toutes nos efpérances, auffi la natu; re induftrieufe en prend un foin particulier; elle la fait naître parmi le feuillage des rameaux, \& revêtue d'une affez ferme tunique en forme de calice; elle lui permet enfuite de s'épanouir médiocrement, \& $\&$ de développer fes pétales, \& non de s'ouvrir d'abord en entier : mais elle l'habitue infenfiblement à fupporter la fraîcheur de la nuit \& l'ardeur du foleil; cette fleur délica. te nourritle fruit en fon fein parfumé, $\&$ garantit des vents fon tendre éléve ; car les fleurs font comme le berceau des fruits, elles leur fervent d'ornement \& d'appui, \& connoiffent, pour ainfi dire, ce qu'elles font venues faire; elles ne quittent les rameaux que lorfque le fruit fortifié par le tems peut impunément voir le grand air, mais les feuilles reftent plus long-tems pour tempérer par leur agitation \& leur ombrage l'ardeur du foleil.

ie Cerifier. Quoique la vigne fe plaife dans la compagnie du cerifier $\&$ du figuier. \& vive en bonne union avec le poi: 
R U R A E. Liv. V. 295 rier \& le pêcher, il convient quie vous réferviez pour ces arbres fruitiers les champs les plus proches de votre maifon, afin de les garantir du ravage des troupeaux \& du pillage du petit peuple.

On laiffe le poirier croître en li- Le Foirier. berté fans toucher à fes branches, ou bien on le taille, \& on le réduit par la force au rang des arbres de baffe tige, ou bien étendu fur un treillage, il garnit un mur de fes feuilles, jouit de la chaleur réfléchie du foleil, \& décore un jardin d'un tapis de verdure.

Soit que le poirier taillé en efpa- Taille du lier s'étende fur un mur en forme Poirier. d'éventail, foit que libre d'entraves il prenne par la taille la figure d'un vafe, fouvenez-vous de réprimer fon penchant à s'étendre, vous en ferez récompenfé par la grace que la taille lui donnera : mais il faut qu'il la reçoive dès les premiéres années; car un ( 25 ) arbre mal taillé, ainfi qu'un jeune homme mal élevé, ne va qu'en empirant: l'âge ne corrige prefque jamais ce qui n'a pû être redreffé àla premiére culture. $\mathrm{B} \mathrm{b}$ iiij 


\section{E C ONOMIE}

IES ARBRES.

Quand les boutons s'enflent \&

La taille des commencent à s'ouvrir, le jardinier aristes.

connoît aifément quelle eft la branche à fruit qu'il faudra conferver : fes boutons font ferrés \& nombreux, elle fleurit fur la branche qui a été taillée l'année précédente, elle eft courte, épaiffe, propre à porter beaucoup de fruit $\&$ à le bien nourrir.

Si un poirier nain jette trop de bois, il faut empêcher fes rameaux d'excéder la rondeur qu'on livi a prefcrite, $\&$ la hauteur du mur près duquel on l'affujettit à un treillage; mais furtout confervez les branches fécondes $\&$ les bons yeux qui font le plus cher objet de vos efpérances, \& coupez fans miféricorde les bran. ches gourmandes \& inutiles: telles ront toutes celles qui pouffent droit, qui ont l'écorce nette \& unie, la tige dure, \& qui font d'une moitié plus hautes que l'arbre. Cependant ne coupez pas entiérement celles à qui les racines prodiguent leur féve, mais n'en retranchez que la moitié; caraprès avoir été taillée, elle pour fera d'autres branches à fruit qui perceront de toute part. 
R U R A E. Liv. V. 297

On n'aime pas à voir dans un arbre taillé une branche qui croife les LES ARBRES; autres à moins qu'elle ne foit char. gée de boutons quil promettent beau= coup de fruit; car c'eft ce qu'on defre \& ce qui plaît davantage ; mais qu'un agriculteur ne conçoive pas de hautes efpérances fur l'abondance des fleurs, elles foifonnent toujours beaucoup lorfqu'un arbre approche de fa fin; refufez par compaffion les derniers préfens d'un pareil arbre, $\&$ faites tomber fes fleurs avec la main, peut-être que fa féve ayant moins de parties à nourrir fera re. verdir fon tronc. C'eft ainfi que dans les familles, une maifon ruinée fe reléve \&r recouvre par la fuppreffion du luxe fon ancien éclat \& toute la dignité de fes auteurs.

Quand les arbres font foibles, il faut les tailler avant la neige $\&$ les gelées, couper court les branches, \& ne pas leur laiffer plus de boutons que l'âge \& la force du tronc n'en peuvent porter. On peut au contraire différer jufqu'au printems de tailler les arbres trop vigoureux, On 


\section{CEONOMIE}

IESARBRES. arrête ainfi le progrès de leur féve, \& on les affoiblit fagement de peur qu'ils ne fleuriffent avant que la belle faifon foit tout à fait décidée.

Lorfque le foleil conduit fon char dans la conftellation de la Vierge, il faut retailler les arbres, afin qu'ils confervent toute leur féve pour le fruit, \& qu'ils ne pouffent pas des jets ftériles. Quand on taille, il faut tenir d'une main la branche, \& la couper de l'autre, de façon que l'amputation faite entre deux yeux, regarde obliquement le foleil ; car lorfqu'elle eft horifontale, la féve qui fort fait enfler l'extrémité de la branche, \& détruit les yeux voifins.

Ne laiffez point tailler vos arbres par vos domeftiques, ce font des bourreaux qui les mettroient en piéces. Apprenez vous-même à manier adroitement la ferpette, \& les arbres reconnoiffans vous dédommageront devos peines par leurs riches préfens.

Aux environs de Beziers, ma chere patrie, où l'Orb ( 26 ) après avoir roulé fes eaux à travers les précipices, les rochers \& les montagnes, 


\section{RURA LE. Liv. $V .299$}

femble fufpendre le cours rapide de fon onde comme s'il étoit encore faifi LES ARBREs, dela crainte \& de l'horreur qu'infpirent ces lieux : près de Beziers, disje , où par fon calme agréable l'Orb invite à jouir de la beauté du ciel, $\&$ des délices d'un féjour enchanté, il y avoit, je m'en fouviens, un amateur du jardinage, fi jamais il en fût un, qui donnoit tous fes foins à la culture des arbres : je me rappelle encore combien il avoit la main heureufe pour greffer, \& avec quelle adreffe il tailloit fes citroniers devant moi : encore enfant alors, je me faifois un plaifir de ramaffer à terre les rameaux odoriférans qui tomboient fous fa ferpette, $2 x$ de les porter à pleins bras au logis ; je n'ai point oublié combien de beaux fruits lui donnoient fucceffivement fes arbres, quelle hauteur avoient fes citroniers, qui l'auroient difputé aux oliviers pour la grandeur, ni quelles fleurs éclatantes par leur blancheur contraftoient les fruits couleur d'or qui. pendoient aux mêmes rameaux.

Cet homme, hélas! eft mon pere, 


\section{0 \\ CE CONOMIE}

LES ARBRES.

que la mort cruelle vient de m'en. lever, mais dont les coups impuiffans n'ont pû ine ravir ma tendreffe pour lui.

Quand je me rappelle fa conduite \& fes vertueux exemples qui devroient être plutôt dans la mé. moire que dans la bouche d'un fils, je (27) ne voudrois pas être forti d'un autre pere, fût-il du fang royal, tant je prifois en lui fes fentimens de religion, une fimplicité digne de l'âge d'or, une candeur ingénue, un cœur fermé à tout intérêt fordide, une probité incorruptible \& des mœurs irréprochables.

Quej'ai de plaifir à paffer en revîe dans mon efprit cette troupe innombrable de pauvres, qui tous les jours affiégeoient fa porte : fa charité \& $\&$ fon zéle pour leur foulagement, la douceur de fon caractére \& $x$ fon penchant à faire des largeffes étoient fi bien connus dans tout le village, que dès qu'on voyoit des pauvres ou des étrangers, qui la nuit demandoient l'hof pitalité, on leur indiquoit la maşfon de mon pere, comme fi elle êt 
RU R.A LE. Liv. $Y .30$ I été un hofpice fondé pour tous les paffans malheureux qui fe trouvoient ${ }^{\text {LES ARBR ES, }}$ dans l'indigence.

Pere refpectable,dont la mémoire m'eft fi chére, recevez mes hommages; vous qui enfeigniez que l'amour de l'Agriculture contribuoit à la perfection des mourrs : réjouiffez-vous, $f_{1}$ le fort de votre fils vous touche encore: les occupations \& les plaifirs champêtres font mon unique ambition; plein des fages confeils que vo. tre amitié me donnoit, je ne de. mande d'autre fruit de mes travaux que les innocens plaifirs que procute la campagne. Si jai eu pendant votre vivant quelque célébrité, elle ne me flattoit, que parce qu'elle faifoit la confolation de votre vieilleffe; mais je ne fuis plus: fenfible à cette gloire, que je ne puis déformais partager avec vous, \& le beau ciel de mon pays n'a plus à préfent d'attraits pour moi. Si ma patrie peut encore me plaire en votre abfence, c'eft parce que votre nom y eft toujours révéré; c'eft qu'à mon arrivée tout le village vient me faire l'éloge de vos 


\section{C C O NOM I E, \&C.}

IES ARBRES. vertus qui lui font toujours préfentes; c'eft qu'il regrette en vous un protecteur, \& pleure avec moi mon pere $\&$ le fien.

Fin du cinquiéme Liyre. 


\section{REMARQUES}

\section{Sur le cinquiéme Livre.}

L eft queftion des arbres dans ce livre: 1 l'Auteur, après avoir parlé de l'olivier \& des bois, décrit plufieurs arbres en particulier; il enfeigne la maniére de femer \& de planter, les foins qu'on doit prendre des jeunes plants; dans quel tems on doit les tranfplanter de la pépiniére, \& les différentes façons de greffer. Il n'y a, dans ce livre, ni defcriptions ni épifodes: nuls poëtiques écarts ne relévent la féchereffe des préceptes; tout y eft purementdidactique, à quelques fatyres près, fur des nouveaux parvenus \& des fangfuës publiques pour délaffer le lęteur. Le Poëre termine ce livre par l'éloge de fon pere, \& par des regrets fur fa mort. Ces fentimens font très-louables de la part d'un fils, mais une fable out quelque autre digreffion auroit fait plus de plaifir.

(1) [ Daignez, illuftre Lamoignon.] Il paroît par ce qui fuit, que M. de Lamoignon, premier Prélident au Parlement de Paris, avoit écrit fur les plantes : le public gagneroit beaucoup, fans doute, fi cet ouvrage étoit imprimé.

(2) [ En paroifant tout noirs, éc. ] 
Quand les olives font mûres, elles fone noires, \& à une certaine diftance les branches de l'arbre paroiffent l'être auffi.

(3) [ Quelques racines pour leur dot, Ecc.] Cette penfée eit très-poëtique, \& offre une image agréable; il femble que ces rejettons foient des enfans qui fortent de la maifon paternelle pour aller s'établir ailleurs, \& qu'ils emportent leurs racines comme un troufleau.

(4) [ Et les oliviers qui vivent plus d'un fiécle, éc. ] Virgile dit auff G. 2.

Palladiâ gaudent falvâ vivacis oliva.

Pline les fait vivre deux cens ans: fortiffime ad vivendum olea ut quas durare annis ducentis inter authores conveniat.

Les anciens Auteurs rapportent que fur le tombeau de Corébus, il y avoit un vieux olivier fous l'écorce duquel il y avoit des armes cachées \& fufpendues, \& qu'ayant incifé cette écorce, on y trouva des chauffures \& des cafques dont les guerriers fe fervoient autrefois. Les orangers vivent encore davantage : celui de Verfailles appellé le grand Bourbon, a près de trois cens ans.

Pline, livre 2 I. ch. I. fait obferver, dit M. Rollin, la différence que la nature a mife pour la durée entre les arbres \& les fleurs. Aux plantes \& aux arbres deftinés à nourrir l'homme par leurs fruits \& à entrer dans la conftruction des édifices \& des navires, elle a accordé des années \& même des fiécles entiers: aux fleurs \& aux odeurs qui ne fervent qu'au 


\section{Sur le cinquiéme Livre. $\quad 305$}

plaifir, elle n’a donné que quelques momens \& quelques journées.

(5) [Séduitt par un amour national pour ['olivier. ] Le Pere Vanniere aimoit les oliviers parce que le Languedoc fa parrie en éléve ainfi que la Provence; ce font les feules Provinces de France où on les cultive; l'amour national n'eft peut-être pas une expreffion bien exacte dans le fens oil je l'employe, mais j’ai mieux aimé la hazarder que de me fervir d'une périphrafe pour rendre le mos patrie.

(6) [ L'ancien bois, éc. ] L'Auteur parle du bois qui fervoit de décoration à la maifon de plaifance dés Jéfuites de Touloufe. Voyez la fin du premier Livre.

(7) [Vous preidriez des plaigrars auxquels j'aurois contribué, érc. ] La Fontaine parle de l'utilité de planter dans la Fable du Vieillard $\&$ des trois jeunes Hommes.

Un octogénaire plantoit.

Faffe eacor de bùtir ; mais planter à cet âge !

Difoient trois jouvenceaux, enfans du voifinage,

Affurement il radotoit.

Car au nom des Dieux, je yous prie,

Quel fruit de ce labeur pouvez - vous recueillir?

Autant qu'un Partiarche il vous faudroit vieillit.

A quoi bon charger vorre vie

Des foins d'un avenir qui n'elt pas fair pour "ous?

Ne fongez déformais qu'à vos erreurs paffées:

Quittez le long efpoir \& les valtes penfées.

Tour cela ne convient qu'à nous.

\section{Tome $I$.}


Il ne corivient pas à vous-mêmes,

Repartit le Vieillard : tout établiffement

Vient tard \& dure peu : la main des parques blêmes

De vos jours \& des miens fe joue également.

Nos termes font pareils par leur courte durée.

Qui de nous des clartés de la voute azurée

Doit jour le dernier? eft-il aucun moment

Qui vous puiffe affurer d'un fecond feulement?

Mes arriére-neveux me devront cet ombrage :

Hébien! défendez-vous au fage

De fe donner des foins pour le plaifir d'autrui ?

Cela même eft un fruit que je goûte aujourd'hui

J'en puis jouir demain \& quelques jours encore:

Je puis enfin conter l'aurore

Plus d'une fois fur vos tombeaux.

Ie Vieillard eut raifon: l'un des trois jouvenceaux

Se noya dès le port allant à $P^{\circ}$ A mérique, \&c.

(8) [ [es mûriers, éc. ] Ce font les plus. fages de tous les arbres, parce qu'ils ne pouffent jamais de boutons que les froids ne foient paffés de façon, que lorfqu'ils bourgeonnent, on peut dire qu'il n'y a plus de gelée à craindre; ceux qui voudront favoir quels arbres reçoivent avec fuccès la greffe du mûrier n'ont qu'à lire Palladius. On rapporte dans la Fable que le fruit de cet arbre n'eft devenu rouge que depuis l'avanture de Pirame \& de Thisbé, \& qu’autrefois il étoit blanc:

Qui du fang de Pirame a reçu la teinture ;

dit M. Roi dans fa Cantate de Siléne.

(9) [ Q u'une branche féche tirée d'un fagot de saule, $\delta$ c. . ] Virgile dit pareillement de l'O. 


\section{Sur le cinquiéme Livre.}

livier qu'un tronc fec de cet arbre dépouillé de toures fes branches, étant mis dans la terre, reprend une nouvelle vie \& pouffe des racines.

2uin sơ caudicibus fectis, mirabile dich,

Truditur ê ficco radi: oleagina ligno.

Georg. L. 2.

Feftus penfe que le faule a été appellé en latin : Salix: quòd faliat citò, à caufe qu'il crồt vîte, \& comme s'il fautoit en croiffant.

( Io) [Il alligne les fentiers d'un jardin: erc. ] On ne fe fert prefque plus de buis pour la bordure des parterres : il donne refuge aux limaçons \& à plufieurs infectes qui rongen les fleurs: il y en a de deux fortes, le buis nain, autrement appellé buis d'Artois, dont les feuilles reffemblent beaucoup aux feuilles de myrte ; c'eft celui qu'on employoit dans les bordures : la feconde efpéce eft le buis de bois qui s'éléve bien plus haut, \& a fes feuilles plus grandes que l'autre, ce qui le rend propre à former des paliffades, de petites grotes \& des haies, mais il lui faut beaucoup de tems pour acquérir un peu de hauteur.

(II) [ L'i, fe plait dans les jardins, erc. ] Pline prétend que l'ombre de l'if eft morrelle lorfqu'on dort ou qu'on mange deffous; il ajoute que fes bayes caufent la mort $f i$ on en mange, fur-tout en Efpagne, \& que chez les Gaulois le vin devenoit poifón dans des tonneaux faits du bois de cet arbre: Rouffeau a embelli cette opinion dans fon Ode fur les détracteurs de l'antiquité;

\section{C.cii}


Cieux ! gardez vos eaux fécondes, Pour le myrte aimé des Dieux,

Ne prodiguez plus vos ondes,

A cet if contagieux :

Et vous enfans des nuages,

Vents, miniftres des orages,

Venez, fiers tyrans du nord,

De vos brulantes froidures

Sécher ces feuilles impures

Dont l'ombre donne la mort.

(I2) [ Et dont on couranize les Pö̈tes, Éc.] Pline dit, que le laurier a été confacré à Apollon \& aux Mufes, parce qu'il y en avoit un bois fur le Mont Parnaffe. Le laurier eft la couronne des Poëtes, ainfi que des Héros; la gloire eft également leur partage, mais ceux-ci vivent avant \& après leur mort, au lieu que les Poètes pour la plûpart, même les bons, ne vivent que dans l'hiftoire.

(13) [ Del’acacia, óc.] Il a été en vogue dans le dernier fiécle, parce que c'eft l’arbre qui croît le plus vîte, qui pouffe le plus de bois, \& qui fleurit le premier : on liai préfére le maronier d'Inde, la tête de l'acacia étant fujette à fe dégarnir.

( I4) [Dont les feuilles tonjours agitées, goc.] Elles tremblent toujours fans vent, parse qu'elles font attachées à une longue queuie mince \& fort tendre. Pline cite une particuIarité du peuplier \& de quelques autres arbres: Mirum in primis id quod ulmo, tiliaque, 
ón populo albs, ós Salici evenit. Circumazuntur enim folia earum poft fo!ffitiam, nec alio argumento certius intelligitur fidus confectum: Si cela eft, c'eft une remarque curieufe dont il ne feroit pas aifé de donner la raifon.

( Is i [ Et qu'elle e pénétre des nitres de l'air nécefjaires à toutes les productionis, ofc. ] M. Lemery, dans un mémoire inféré parmiceux de l'Academie des Sciences année I 7 I 7 , pag. 43. regarde le fyftême du nitre á́rien comme un ancien préjugé qu'on a foutenu fans preuve: car, fe demante M. Lemery, fous quelle forme le nitre de l'air peut-il y être contenu? Sera-ce fous la forme de falpètre? mais fa péfanteur l'empécheroit d'y être fo:ltenu. Si c'eft fous la forme d'efprit de nitre, l'air ne feroit pas bon à refpirer, \& la quant:ré d’acides qui entreroient perpétueliement dans les poumons, cauferoit une toux continuelle. Quo:qu'on ne puiffe nier, ajoute $t-11$, qu'il n'y ait quelquefois dans l'air des exhalaifons nitreufes, toujours eft-il certain, que fi ces exhalaifons portent du nitre dans toute la la mafle de l'air, c'eft infiniment au-deffus de la quantité qu'on eftobligé d'y en fuppofer, pour les effets qu'il a plû̀ de mettre fur le compte du nitre aérien. M. Lemery cite l'expérience de M. Mariotte, qui ayant choifi l'étage le plus élevé d'une nuaifon pour y laifer à l'air pendant deux ans une portion de terre qui auparavant avoit éré exactement dénitrée, n'en put retirer enfuite aucun grain de nitre, mais il en retira beaucoup d'une portion de 
la même terre qui avoit été portée à la cave.

Autre expérience. M. Lemery mit dans trois plats de terre, trois fortes de matiéres alkalines; favoir, de la chaulx, du fel de tartre, \& de la terre qui avoit été exactement dépouillée de fon nitre, il plaça ces trois plats fur trois efcabelles dans une efpéce de rez - de chauffée où le foleil ne donnoit point, \& où l'air entroit librement de plufieurs côtés; endroit tel qu'il le falloit pour faire une bonne récolte de nitre, puifque les murailles \& $l_{1}$ terre du lieu étoient garnies d'une grande quantité de falpêtre. Ces trois matiéres font demeurées pendant deux ans \& plus, expofées à l'air fans donner aucune marque de nitre, mais elles en ont donné beaucoup lorfqu'elles ont été pénétrées des fucs ou des fels des matiéres animales, dans lefquelles M. Lemery a découvert qu'il y avoit beaucoup de nitre, comme on le peut voir dans les mémoires cidevant cités, pag. 44. \& fuiv. \& pag. I 22. Ainfi, felon M. Lemery, ce n'eft point l'air qui fournit aux terres le nitre qu'on en retire, mais bien les matiéres animales. Par ce terme, on entend le fumier \& les parties quelconques de toute efpéce d'animaux. Ce n'elt point effectivement par fon nitre, que l'air difpofe les terres à produire : $s^{\prime}$ il en a, il eft en trop petite quantité pour faire cet effet ; les influences de l'air ne font falutaires aux végétaux qu'à caufe des portions huileufes \& balzamiques dont cet élément eft chargé.

(16) [Ces cercles qui fe forment, esc.] 


\section{fur le cinquiéme Livre. $\quad 318$}

11 fe forme chaque année un nouveau cercle au bois de l'arbre entre l'écorce \& le tronc: \& en coupant le tronc horifontalement, on voit fouvent tous ces cercles très-bien figurés, \& on les compte aifément principalement dans les chênes; mais ces cercles ne font pas également nourris, cela dépend de la fertilité de l'année ; car lorfqu'elle a été favorable à la végétation, le cercle a plus de volume. On remarque même que ces cercles ne font pas tout à fait ronds, \& qu'ils dégénérent un peu en ovale; enforte que la moëlle n'eft jamais exactement au milieu: l'arbre eft mieux nourri \& les cercles font plus épais du côté du midi, au contraire du côté du fepzentrion le tronc a moins profité \& le rayou du centre à la circonférence y eft le plus court de tous.

La raifon de ces différences eft que l'afpect du midi eft bien plus favorable à la végétation que le nord : c'eft pourquoi dans la Zone Torride où le foleil donne également de tous côtés les cercles du bois des arbres font tous parfaitement ronds \& exactement concentriques, comme on le remarque dans l'ébéne qui y croît.

Au moyen de ces obfervations, il eft aifé quand on fe perd dans un bois de fe retrozver en s'orientant : l'on peut auffi par le nombre des cercles du tronc favoir l'àge del'arbre puifqu'il s'y forme un cercle chaque année tant que l'arbre augmente. Voyez la mai. fon ruftique.

(I7) [Comme l'enseignoit le Prinse des 


\section{3 i2 Remarques}

Poütes, ér. ] Virgile dit qu'il faut faire l'ino. culation dans le nœud même ou l'œil de l'arbre : il a fuivi l'ufage de fon tems.

Nam quà fe medio erudunt de cürtice gemma, Et tenues rumpunt sunicas, anguftus in ipfo

Fit nodo finus.

L'ufage moderne eft d'élever l'écorce au-dếfus ou au-deffous de l'œil dans l'endroit le plus uni, parce que ce neft point le nœud du Sauvageon, mais celui de la greffe qui travaille \& fait un nouvel arbre. Voyez $M$. Pluche furlagreffe.

( I I) [Quand on greffe en approcbe, ivc.] 3) Cette manićre de greffer, dit M. Pluche, ə) ne peut s'exécuter que fur deux arbres vo:3) fins l'un de l'autre. On fend une branche ou $\Rightarrow$ un tronc d'arbre dont on eft mécontent pour ") y faire entrer le bout d'une bonne branche 2) qui tienne encore à fa tige en couvrant la 2) plaie avec de la cire \& du linge. On attend 2) un tems raifonnable pour être fûr que les 3) deux perites écorces font incorporées \& n'en 2) font plus qu'une : alors, on févre la bonne 2) branche, c'eft-à-dire, qu'on la coupe \& 3) qu'on la prive de la féve qu'elle tiroit de fa $\gg$ tige naturelle pour la laiffer vivre de ce s qu’elle tire du fujet, fur lequel elle eft 》) entrée : on retranche tout le bois de ces lui-ci pour tirer une nouvelle tête de la bran») che greffée. Cette méthode n'eft guéres en v) ufage que pour les arbres encaiflés, qu'on 


\section{fur le cinquiéme Livre. 3 I 3}

s) eft maître de rapprocher les uns des autres v à volonté. cs

(I9) [ Ainfile laurier, ór.] M. Pluche dit que ce font des monftres, plutôt que des merveilles, parce que n'y ayant dans ces lujets aucun fuc convenable aux fruits qu'on en veut tirer, tout ce qu'on fait venir de la forte eft forcé \& de mauvais fuc.

Le même Auteur parle d'une nouvelle méthode de greffer, dont les Allemans \& les Anglois ont commencé à faire ufage, mais qui na pas encore pris faveur parmi nous : elle confifte à enter une belle branche de bon fruit fur un tronçon de racines : on choifit une des groffes racines d'un arbre qui ait de la conformité avec la nature de ce qu'on y veut greffer, on coupe cette racine en plufieurs morceaux, fur chacun defquels on met une greffe felon quelques-unes des opérations précédentes: quand un arbre eft vigoureus, rien n'empèche de lui ôter une grolle racine qui peut fournir tout d'un coup vingt ou trente iujets : \& fi la pratique de greffer fur racine éroit fuffirmment éprouvee, \& d'un fucces certain, on pourroit, en la fuivant, planter tout d'abord la racine \& 12 greffe dans l'endroit même où l'arbre doitchemeurer : au lieu. que dans les opérations précédentes; enter \& tranfplanier font prefque toujours deux chofes léparées par de longs iniervalles.

(20) [ Elle preisd comme Protée, Éc.] Dieu marin, fils de l'Océan \& de Thétis, qui conduifoit les troupeaus de Neptune, \&

Tome $I$.

$\mathrm{Dd}$ 
qui avoit le pouvoir de prendre toutes les formes qu'il vouloit.

Tum varie illudent species atgue ora ferarum

Fiet enim fubito, fus horrilus atraque tigris

Squamojufque Draco ơ fuluâ cervice leana

Aut acrem flamme fonitum dibit, oc.

Virg. Georg. L. 4.

(2I) [ Les maures émollientes, Éc.] Roufleau dans une de fes Odes exprime la mé. me penfée.

De la célefte tofée

La tcrre fertilifée,

Quand les frimats ont ceffe

Fait égalementéclore

Er les doux parfums de Flore

Et les poifons de Circé.

(12) [ La mort voléala deftruction de tous les étres, dont la noture a bâté la perfection, éc.] Si cette obfervation eft jufte, que je tremble pour tes jours, charmante Eglé ! toi fur qui la nature a verfé de fi boune heurefes dons les plus rares $a$ les plus fiateurs : toi qui joins à tous les agrémens défirables, le mérite de penfer, de t'exprimer avec juftefle \& de t'occuper utilement, dans un âge où ton fexe ne connoît que l'art de la coquetterie, \& se veut lire que dans un miroir.

(23) [Il cherche envain la téte altiére: 


\section{fur le cinquiéme Livre. $\quad 315$}

éc. ] Cela reffemble à certain paffage de la Bible : tranfivi ón ecce non crat.

(24) [ Etacquerent des perfections: óc.] Les voyages ne perfectionnent pas tout le monde, on revient fouvent chaz foi avec des qualités de moins \& des vices de plus. C'eft ainfi que penfe l'augréable Auteur de Ver-vert.

Dans maint auteur de fcience profonde J'ai lû qu'on perd à trop courir le monde; Très-rarement en devient-on meilleur.

Un fort errant ne conduit qu'à l'erreur, Il nous vaut mieux vivre au fein de nos lares

It conferver paifibles calaniers

Notre vertu dans nos propres foyers, Que parcourir bords lointains \& harbares:

Sans quoi le cœur victime des dangers

Revient chargé de vices étrangers.

(25) [ Un arbre mal taillé, ónc.] C'et i peu près la penfée d'Horace.

Doctrina fed vim promovet inform

Rectique culius pectora roborant

Uccumque defeccre mores

Dedecorant bene nata culpa.

Hor. Od. 3. L. 3 .

(26) [Ou l'Orb aprèsazoir roulé, éc.] C'elt une riviére qui prend fol fource fur de hautes montagnes, \& qui baigne les murs de Beziers.

$\mathrm{Dd}$ ij 
(27) [ Je ne voudrois, forc.] Horace difoit précifément la même chofe de fon pere.

....... Longe mea difcrepat iffis

Et vox \& ratio: nam fi natura juberet

$A$ certis annis avum remeare peractum,

Atque alios legere ad faftun quofcumque parentes

Optater fabi quifque; meiscontentus, honeftos

Fafcibus er fellis nolim mihi fumere. . . . . :

Sat. 6. L. I.

Cette tendreffe filiale fait honneur à la mémoire du Pere Vanniere.

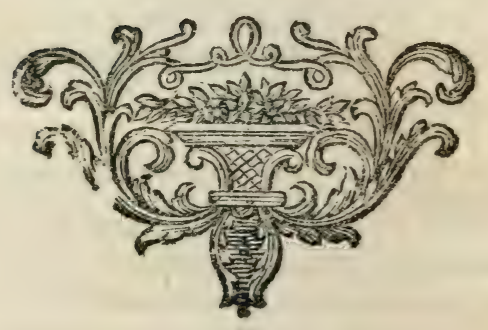




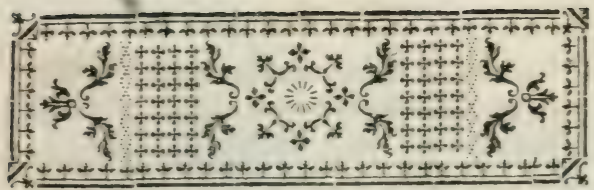

匢CONOMIE

R U R A E.

\section{LIVRE SIXIÉME.}

Caufes des maladies des Arbres \& moyens d’y remédier.

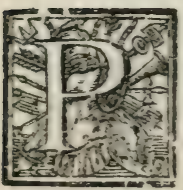

ARLONS maintenant des maladies des arbres \& dé ARBREs, de la façon de les guérir : MOYEs: D'y comme les hommes \& REMEDIER.

les arbres, par le rapport qu'ils ont entr'eux, font fujets aux mêmes accidens, jindiquerai les caufes de leurs maladies communes, $\&$ les remédes qu'il convient d'y apporter d'après ce que j'ai obfervé chezles hommes. Leur forme eft à

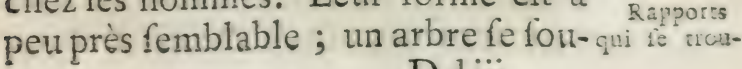

D diij 


\section{$318 \quad$ E C O NOMIE}

tient fur fes racines comme fur des Mararryt pieds, fon tronc lui tient lieu de MOYFS D'Y corps, \& fes rameaux étendus Frmédier. font fes bras, le fuc de la terre cir-

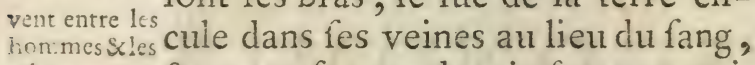
arbres. $\&$ cette fource de vie fe communique à toutes fes feuilles.

Lorfque de jeunes plants commencent à fe parer de fleurs, \& qu'ils peuvent à peine réfifter aux vents \& aux intempéries de l'air ; leur âge tendre \& brillant donne tout à la fois de la crainte $\&$ de l'efpérance.

Quoique le jardinier cultive un arbre dès fes premiéres années, il a cependant quelques égards pour la foibleffe de fon âge, \& ne lui fait pas effuyer des traitemens durs, à moins que fon tronc ne foit fort, bien enraciné, \& que les efforts de la féve n'avertiffent de réprimer fa fougue avec la ferpette, \& d'affervir à des loix fes rameaux vagabonds; alors il les contient dans la plus exacte difcipline, les force de fe plier à fa volonté, de fe courber en forme d'arcade, ou de couvrir un mur d'un beau tapis verd, felon la figu- 


\section{R U R A L E. Liv. VI. 3 I9}

re qu'il veut leur donner par la taille.

MIATADIES

Après que l'ardeur de leur jeunef- MOYENS D'Y

fe indocile eft ralentie, vient l'âge REMEDIER. mur où les arbres rapportent du fruit ; ils fe reffentent auffi de l'importune vieilleffe qui les dépouille de leurs feuilles \& rideleur écorce ; ainfi qu'une longue maladie décolore les hommes, les rend maigres \&r les affoiblit, de même une trifte M êmes

fimptômes \& mêmes caufes maigreur s'empare du tronc des arbres quand ils font malades, \& leurs branches languiffantes prennent bientôt une couleur pâle : ces maladies qui affectent les hommes \& les arbres ont une même caufe, $\&$ provien. nent, ou d'un fuc qui n'eft pas affez fubitantiel, ou d'une nourriture trop abondante.

De même que parmi les hommes lorfque le fang bout dans les veines \& s'extravale dans l'ardeur d'une fiévre brîlante, les maladies déchainnées font des ravages $\&$ des progrès rapides: ainfi dans les arbres leur févé impétueufe s'épanche hors des conduits par une

Dd iiil 


\section{$320 \quad \mathbb{E}$ CONOMIE}

MALADIES éruption fubite, fe putréfie \& gâte les troncs où féjourne fa corruption: MOYERS D'Y la tête de l'arbre fe defféche, fes REMEDIER.

bras s'affoiblifient, fa chevelure tombe, \& tous les conduits de la féve étant bouchés, fes racines bienfaifantes ne lui portent plus de fucs Circulation nourriciers. Car c'eft par les racines
de la feve égase à celle du que s'infinue le fuc de la terre dans tasg.

les plus petits canaux, \& qu'il parvient jufqu'aux feuillages, après quoi retournant du haut de la cime i. circule \& fe répand dans tous les rameaux : ainfi que le fang arrofe \& vivifie toutes les parties de l'homme.

Preuves de Ne voit-on pas lorfqu'on a lié quel. extre circula - que branche avec de l'ofier, comme
rion. la féve qui reflue, fait gonfler l'écorce; ne voit-on pas qu'un arbre reverdit \& reprend auffitôt vigueur, pour peu que fes rameaux foient humectés par la pluie ; \& ne fait-on pas que certains reptiles le font mourrir par la communication de leur venin, quoique la piquure n'ait été faite qu'à une de fes branches.

Si vous voulez vous convaincre 
R U R A L E. Liv, VI. 32 I

de la circulation de la féve par une expérience très-facile; arrachez de l'herbe avec fes racines, faites-En DOSAENS I'Y tremper une partie dans un vafe REMEDIER. rempli d'eau d'où elle tirera fa fubftance ; laiffez l'autre partie hors du vafe, vous verrez que tous les brins d'herbe recevront cgalement de la nourriture par la circulation de la féve : de plus, s'il arrive qu'une riviére dans fon cours découvre quelques racines d'arbres; taillez-en une, $\&$ vous remarquerez avec furprife qu'elle pouffera des feuilles \& reverdira, quoiqu'elle ne reçoive de la terre d'autre nourriture que celle qui lui eft tranfmife par les canaux où la féve defcend des rameaux les plus élevés.

Des que l'hiver commence à fufpendre la circulation de la féve dans un arbre, fes feuilles tombent faute de nourriture, \& fes rameaux engourdis par le froid, n'ont plus daction ni de vigueur, jufqu'à ce que le printems rouvre leurs racines ref. ferrées, \& que les fucs dont la terre a fait provifion après la fonte des 


\section{CE C N O M IE}

MaLAD neiges, puiffent fe communiquer avec DES ARBRES, plus d'abondance \& de liberté à rous MOYENS D'y les végétaux. C'efit cette circulation qui fait reverdir la terre; l'herbe des bleds monte plus fenfiblement, les arbres reprennent vie, les fucs abondans qu'ils reçoivent les dédommagent de la faim qu'ils ont foufferte pendant l'hiver, un verd tendre peint leur feuillage renaiffant, \& ils pouffent de jeunes rameaux qui domnent Preuves de bientôt un épais ombrage. Je vais la même cir- révéler les fecrets de la nature, \& zéesdela thy-enfeigner comment la féve sintro-
figue.

duit dans les racines, pénétre juf qu'aux feuilles les plus élevées \& rc. flue enfuite de la cime d'un arbre jufqu'à fa fouche.

L'air embraffe, non-feulement toutes les régions fupérieures à notre planéte, mais s'étend encore dans les entrailles de la terre; il comprime par fa pefanteur tous les fluides \& les force de s'élever par des conduits imperceptibles dès qu'ils trouvent un paffa. ge libre : ainfi qu'on voit jaillir le vin entre les doigts des pieds du vigneion, lorfqu'il foule le raifin, ou comma 


\section{R U R A I E. Liv. VI. 323}

la liqueur monte au haut d'un linge quoiqu'il n'y trempe que par une ex. trémité, ou de même que l'eau s'éléve au fommet des plus hautes montagnes, \& s'ouvre un paffage à travers les rochers fur la cime defquels elle forme une fource, ou de même encore qu'on voit l'eau monter dans un tube fans autre effort que la preffion de l'air ; de même la pefanteur de l'atmofiphére contraint les fucs d'entrer dans les veines des arbres: les feux concentrés que recéle la terre ouvrent fes pores, \& fes fucs trouvant une iffue dans les racines s'y gliffent en obéiffant à l'impulfion. Ces fucs cependant ne parviendroient pas jufqu'à la tête de l'arbre, s'il n'y avoit un ferment très - actif mélé avec la féve qui la fit monter $\&$ s'étendre au loin, \& fi les veines où elle circule (I) n'étoient munies de petites valvules faciles aे fe fermer, qui l'empêchent de fortir ; c'eft par ce moyen qu'elle fe communique ate tronc, aux rameaux \& 8 aux feuilles, \& qu'elle prend une nouvelle route pour defcendre à la fouche d'où clle

MALADIES dEsARBREs, MOYENS D'Y REMÉDIER. 


\section{E C O N O M IE}

MALADIES JES ARBRES, o par les memes voies après avoir MOYFNS D'Y réparé fes pertes en recevant de la terre une nouvelle provifion de fucs.

Cette circulation divine, \& ces fucs nourriciers qui renouvellent merveilleufement la vie, fe manifeftent aux yeux dans les veines du corps humain, \& le fortifient de la même façon qu'ils fervent à l'accroiffement des arbres; car la nature toujours femblable à ellemême fuit les voies les plus fimples \& obferve la même marche pour la confervation des hommes, des plantes \& des animaux.

Urilité de Qui eft-ce qui ne faura pas main-

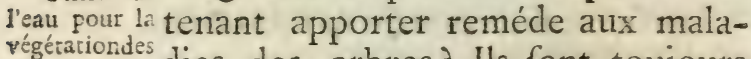
végétationdes dies des arbres? Ils font toujours
plantes, fains, lorfque le terrein qu'ils occupent leur fournit la fubstance néceffaire, \& que celle-ci ne trouve point d'obftacle à fon paffage; mais la féve ne fauroit fe filtrer, à moins qu'une pluie féconde ne détrempe les fels de la terre; auffi les feuilles d'un jeune arbre fe defféchent, \& il meurt bientôt s'il n'eft defalteré par 


\section{R U R A L E, Liv. VI. 325}

la pluie: les grands arbres au contraire qui ont pouffé de profondes Maladies racines trouvent les réfervoirs d'eau MO YENS $D^{\prime}$, qui font cachés dans les entrailles de REMEDIEE. la terre \& s'en abreuvent.

Il y a à l'extrémité de l'Amérique $\&$ près de la mer une (2) Ville qu'on appelle Lima \& qui eft fituée fous l'équateur. Lorfque le foleil l'éclaire perpendiculairement, il y régne des vents qui viennent tous les matins du côté de l'Océan, \& qui rafraîchiffent l'air: quand ces vents fe font calmés, les Aquilons fuccedent le foir, ils foufflent d'un autre côté par une agréable alternative \& portentarbres donavec eux le froid des fleuves \& des nent du fruir montagnes couvertes de neige au-quiarrofent. deffus defquelles ils roulent.

Les habitans y jouiffent d'un printems éternel; tous les jours de l'année s'y reffemblent. Le même arbre qui eft ftérile quand aucun ruiffeau ne lui porte fes eaux bienfaifantes, produit des fleurs \& des fruits au gré du laboureur qui l'arrofe ; \& quoique le ciel y foit toujours pur, \& qu'il n'y tombe jamais de pluie, 


\section{$326 \quad$ E C O N O M I E}

les champs cependant toujours verds

MALADIEs ne s'y reffentent point de la féche24OYENS DY reffe; mais au lieu que nous nous REMÉdER, fatiguons à puifer de l'eau dans nos puits pour arrofer nos jardins, les habitans de Lima conduifent de l'eau dans leurs champs par différens canaux, \& font mûrir leurs fruits dans le mois qu'ils veulent, ou ne les font venir qu'à la fin de l'année en différant d'humecter la terre.

Ainfi l'on voit en même-tems dans leurs jardins des poiriers en fleur, \& d'autres poiriers courbés fous le poids du fruit; les pommes ne leur manquent en aucune faifon; \& tandis que le vigneron laboure un côté de fa vigne, ou en coupe les farmens trop allongés, il y cueille aufi du raifin d'un autre côté, \& d'autre part la voit en fleur \& en refpire le parfum.

O trop heureux habitans à qui la terre difpenfe fes largeffes felon la mefure de leurs defirs ! ils jouiffent du printems pendant l'été, ils ont un hiver fans froid, un air 
R U R A LE. Liv.VI. 327

toujours pur, \& des terres fécondes fans pluie.

MALADIES

Ce climat fRARARES, \& en fruits, \& 11 riche en métaux, REMÉdER. eft encore plus abondant en génies rares \& en caractéres aimables : fi tous les habitans refiemblent (3) à cet homme admirable qui a vî̀ depuis peu, fans aucun interpréte, les différens peuples de l'Europe dont il connoiffoit $\&$ la langue $\&$ les mœurs, \& qui, quoique voyageur en tant de contrées différentes, n'a été nul part étranger.

La féve trop abondante, que la pluie fait regorger, eft très nuifible aux arbres: fa corruption pourrit les troncs, ou les défigure par diffé。 rentes tumeurs.

Souvent un arbre qui a trop de La féve tro féve s'en délivre lui-mème. Son aboadanterso écorce fe fend \& ouvre un paffagorge. ge à fes fucs pernicieux, fur-tout au printems; parce qualors la terre échauffée fait prendre aux racines plus de fubftance. C'eft de la féve furabondante des arbres que proviennent la myrrhe, l'encens

Lamyrtic. L'encens. 


\section{E C O N O M I E}

Mazu'on brule dans les temples des D.ESARBRES Dieux, \& ces précieux baumes qui DOYERS D'Y découlent des forêts d'Arabie \& Res baumes. qui enrichifient fes habitans; c'eft Les baumes. par ce moyen que l'ifle de Scio (4)

Lemaftic. tire le maftic en larmes, \& que les bois de la Calabre donnent une rofée qui s'épaiffit à l'air. Le petiple crédule affure qu'elle tombe du ciel ıa manne. \& l'appelle manne célefte par reminifcence de celle dont Dieu nourrit fi lontems les Ifraëlites errans dans les déferts.

Le Laboureur dépouille le Pin, Ea poix. afin que la poix coule plus abondamment de fes veines : l'hiver épaiffit cette liqueur, qu'aucune écorce ne met plus à l'abridu froid; il ferme les iffues par lefquelles l'air fe communique aux arbres, \& ôte au Pin la vie avec la refpiration; De la teip - car on n'ignore plus que les arbres, sation des ainfi que les bêtes fauvages, les oi-
plantes. feaux \& les poiffons tiennent la vie de l'air, \& la perdent en ceffant de refpirer.

Térébration La (5) térébration la plus fûre jos arbres pour tirer le furc des arbres fe fait is fuc. 


\section{R U R A L E. Liv. VI. 329}

en perçant le côté qui eft expofé au midi. De même que le corps hul- Maradits main recouvre fouvent la fanté après MOY YENS $D^{\prime} Y$, la faignée, ainfi l'arbre fe porte REMEDIER。 mieux quand on le délivre d'une féve furabondante qui lui étoit nuifible; bientôt après cette opération il ne fe borne plus à donner un ombrage ftérile, fon fruit fait courber fes rameaux, \& acquiert pour le goût un degré fupérieur.

Servez-vous donc fans répugnance de la tariére pour percer vos arbres; faites une ouverture profonde au tronc, \& de façon qu'elle aille toujours en montant, pour faciliter l'écoulement de la féve par le tuyau qu'on infere, \& vous obferverez de percer du côté qui regarde le midi, afin que la féve coule plus abondamment.

Vous tirerez par ce moyen des vfage des fucs utiles à la Médecine; celui d'or- fucs darbres me eft un fpécifique contre les fié- dans.

vres, celui de fureau guérit l'hydropifie; le fuc de frêne diminue les. douleurs de tête \& des reins, il éclaircit \& fortifie la vûe, guérit Tome $I$. 


\section{$330 \cdot \mathbb{E}$ C ONOMIE}

la furdité \& fert d'antidote contre MALADIF le poifon le plus mortel.

DESARBRES, Le bois de frêne a auffi de granREAIZDiER, des propriétés contre lesflux de fang ou les cours de ventre; fes feuilles. guériffent les plaies, arrêtent les progrès du cancer, \& empêchent le venin de la vipére de fe répandre dans la maffe du fang.

Il y a une telle antipathie entre le frêne \& les ferpens qu'ils fuyent jufqu'à fon ombrage, \& l'on a remarqué que fi l'on en plaçoit un au milieu d'un cercle garni d'un côté de feuilles de frêne, \&r d'autre part de charbons ardens, il aimeroit mieux paffer à travers le feu \& s'enfuir à demi brulé.

La féve du chêne eft un aftringent qui arrête les pertes de fang; celle de tilleul dégage les eftomacs trop chargés. La gomme de prunier fauvage eft excellente contre les démangeaifons de la peau. Le fuc de bouleau n'eft pas moins utile pour bien des maladies, il guérit les chaleurs de foie \& d'eftomac, (6) \& eft fouverain contre la pierre qui vient aux reins. 
R U R A IE. Liv.VI. 33 I

Les Anglois meilleurs phyficiens que nous ont pouffé leurs expériences jufqu'à faire des (7) punctions DES ARBRES, aux fleurs, \& ils en recueillent des li- REMÉTER,

queurs bien plus efficaces que celles qui fe diffillent à l'alembic pour l'ufage de la Médecine. Par ce moyen l'on fait à préfent tirer des têtes du pavot, un fuc plus propre que tous les autres à procurer un prompt fommeil.

Toutes les fois que la féve trop abondante nuit aux arbres, on la fait couler par le moyen des coins qu'on enfonce dans le tronc; mais de même qu'il eft plus prudent à un malade de s'abftenir des mêts qui pourroient l'incommoder, que d'être oblige de prendre des vomitifs pour s'en délivrer: ainfi il eft plus à propos de retrancher aux arbres quelques racines, \& de les contenir dans une forte d'abftinence, que de les percer pour faire couler la féve qui les endommage.

Quand un arbre donne pelu II faut coutde fruit, \& que cette modicité $\begin{gathered}\text { per les perites } \\ \text { racines d'un }\end{gathered}$ n'eft compenfée que par beau- arbire trop for coup de feuilles inutiles \& par 


\section{CE ONOMIE}

de belles branches qu'il étend avec

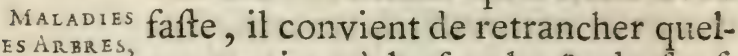
DES ARBRES
MOYENS D
M Y ques racines à la fouche $\&$ de foufr.EMÉDER traire au tronc les fucs nourriciers. Ainfi lorfque le luxe, l'oifiveté \& l'opulence ont corrompu la pureté des moeurs, \& $z$ que Dieu daigne rappeller à lui les pécheurs du fein de la licence: l'on commence par fupprimer les richeffes comme l'aliment des vices \& comme la racine d'où dérivent tous les maux, après quoi l'on conduit les ames dans la voie du falut, pour leur faire produire des fruits dignes d'éloge \& d'admiration.

Si au contraire un arbre languit, \& que fes rameaux fe defféchent; ấ fa tête devient chauve, \& que fes feuilles tombent avant la faifon, par le peu de nourriture qui leur parvient; c'eft dans les racines qu'eft le frége du mal, c'eft un fuc trop épais qui les gonfle, qui remplit les veines \& qui empêche la com-

Ies atbres munication de la féve : répandez aul-

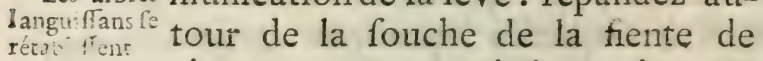
revectelafen- pigeon pour rouvrir les voies aux
ave de pigeon, 
R U R A L. Liv. VI. 333

fucs nourriciers, \& rendre aux rameaux leurs feuillages \& leur verdure.

MALADIES

Mais il n'y a point de meilleur re REMÉDILR. méde que le vin. Comme l'eau fait l'arrofement ordinaire des arbres, on leur rend la vie, fuffent-ils à l'extrémité, fi au lieu de cette liqueur froide on fubftitue le jus de la treille; le plane fur-tout, dès-qu'il eft malade de langueur, rétablit en peu de tems fes forces \& $\&$ reprend les agrémens de fon ombrage, auffitôt que Bacchus vient le fortifier.

Si quelque œconome penfe que tameilleure le vin eft une liqueur trop précieufe médecine pour les arbres, il peut quand ils ione a puiffont malades les humeeter avec fiand les at l'écume des olivès preffées; mais bres font ma s'il veut employer le plus fouverain. des remédes, qu'à la ville comme à la campagne il fafie amaffer toutes les ordures \& les chofes de re. but qui peuvent receler quelques fels utiles, comme les vieilles femelles, les rognures de corne qu'enle vent les maréchaux en ferrant les chevaux, des os concafiés, des plu- 


\section{E C ONOMIE}

mes, des peaux de bêtes écorchées, $\underset{\text { MALADiES }}{\text { MARBRES }}$ de la fiente de pigeon \& de la cenMOYENS D' ${ }^{\prime}$ dre de romarin, qu'on mette enfemremebier. ble ces différentes chofes dans de grandes cuves avec de l'eau de pluie \& qu'on les y tienne lontems en macération. Ces ordures ainfi infufées compofent un breuvage falutaire pour les arbres malades, qui fait même pouffer l'herbe \& donne plus d'éclat aux fleurs. A peine le jardinier pourra-t'il reconnoitre fes oignons qui auparavant avoient la tête enflée \& difforme, ainfi que fon ail \& fes autres légumes, après qu'il les aura arrofés avec cette liqueur chargée de nitre; c'eft ce fel qui fait toute la vertu de la terre; elle ne peut en avoir trop, la quantité n'en eft jamais nuifible; l'on. doit lui reftituer par les amendemens, celui qu'elle a perdu par fes productions, \& felon moi l'art d'améliorer une terre eft l'effentiel de l'agriculture. Quelquefois la nature prend plaifrr à fe jouter dans les arbres par les différens coloris, \& par le mélange du rouge $2 x$ du blanc 
R URA L E. Liv. VI. 335

dont elle peint les fruits. Il vous fera facile d'imiter ces jeux, (8)

MALADIES fi vous melez au printems des fuCS MOYENS D'Y di vous melez au printems des fucs REMEDIER, de différente couleur avec les eaux qui arroferont vos arbres, \& vos pommes prendront la douceur du miel, fi vous en infufez dans le tronc de l'arbre; fendez donc fans crainte un pommier, ôtez la moële qui fe trouve dans le coeur de l'arbre; fubftituez-y des fucs préparés \& du miel, frottez \& couvrez l'ouverture avec de la fiente de vache, \&. liez l'arbre avec un licn bien doux, de peur que la rigueur du froid, ou que l'ardeur du foleil n'empire la plaie; ces jeux n'incommodent point les jeunes plants, ils les fouffrent vow lontiers, mais un vieux tronc ne s'y préteroit pas, il s'en trouveroit offenfé.

Ces jeux de l'art réuffiflent fur le tilleul, car cet arbre dans fa jeus neffe eft d'une merveilleufe docili. té; fi vous lui donriez la forme d'une arcade \&z que vous abbaiffes jufqu'à terre fa tête courbée, vous admirerez fes rameaux pouffer en 


\section{EE ONOMIE}

MAIADIFS

terre \& faire les fonctions de fes DESARBRES, racines: quand les nouvelles ont MOYFNS D'Y pris pied, on arrache les vieilles; ainfi la tige de cet arbre renverfée fens - deffus-deffous, eft forcée de pouffer en l'air par les pieds qui font élevés au lieu de la tête, fes rameaux dont le fort eft changé rampent fous la terre $\& z$ envoyent à la fouche \& au corps de l'arbre la nourriture qu'ils en recevoient dans leurs premiéres années. La fouche au contraire par un miracle de l'art produit des feuilles $\&$ des fleurs, \& après avoir fervi dans la terre de pâture aux vers, fe voit careffée par l'abeille qui bourdonne agréablement autour de fes rameaux fleuris.

Ainfi les hommes éprouvent fouvent les (9) jeux cruels de la fortune, qui tranfportant fes honneurs aे d'autres favoris, terraffe les têtes les plus fuperbes, \& par contrafte éléve du fein de la poufićre au faite de la gloire les plis vils mortels; mais quoiqu'ils fermblent toncher les aftres par leur ćlévation, \& que leur éclat 
R URA L E. Liv. VI. 337 éclat faftueux efface celui de tout le monde; les taches qui leur ref- Malaures tent de leur premiére origine four- MOFEAS D'y niffent matiere à la raillerie: ce font des acteurs comiques, (10) qui pour avoir chauffé le cothurne, font rire à leurs dépens : cependant on fe couvre de leur protection \& l'on porte le culte jufqu'à l'idolâtrie pour une fouche ignoble, parée des dépouilles du peuple.

Détaillerai-je tous les accidens Différensacauxquels un arbre eft expofé! tan- cideas qui er. tôt il eft battu par la grêle, tantôt dommagent la gelée le fait mourir, \& tantôt la mouffe le confume; la grêle par fes coups fait couler la féve \& caufe à l'arbre des tumeurs quile deshonorent \& l'empêchent de porter ausun fruit, à moins que le jardinier ne coupe tous les rameaux offenfés, afin que le tronc reverdiffe \& poufle de nouvelles branches.

La grêle caufe moins de domunage à l'arbre, s'il eft tombé récemment de la pluie, parce qu'alors l'écorce mouillée \& gliffante pare \& amortit les coups; (II) Tome $I$. 


\section{CE C ONO MIE}

tant il eft important de favoir en

MAZADIES tout céder à la fureur, \& de ne MOYEAs D'r pas oppofer la force aux tranfREMEDIER. ports.

Mais un arbre eft menacé du plus funefte accident lorfqu'un froid exceffif vient à fuccéder à la pluie; l'eau fe gele fous l'écorce \& rompt par fa dureté les tendres fibres des arbres, de la même maniére que le froid fait fendre un vafe d'argile en mille endroits.

La rigueur de l'hiver peut aller au point que le froid pénétre jufqu'au cour d'un arbre, en épaiffiffe la féve \& empêche la circulation; c'eft un hiver * femblable qui a porté la défolation dans nos champs \& qui a fait périr tous les noyers \& les oliviers. A peine le chêne a-t'il pû réfifter à fa violence.

Si l'hiver eft moderé, les feuilles tombent à la vérité, mais la terre bienfaifante préferve les racines de la gelée \& 2 abandonne vo-

* Le grand hiver de l'année 1709. 
R UR A LE. Liv. VI. 339

Iontiers aux aquilons furieux les feuilles \& leur ombrage, ornemens inutiles en hiver \& que les zéphirs rameneront avec le printems.

Lorfque de trop grandes chaleurs Les grandes durciffent \& defféchent la terre, fes fucs diminués ne font pas une nourriture fuffifante pour les arbres; la maigreur s'empare de leurs ra. meaux exténués, \& à voir leurs feuilles couvrir la terre, on jureroit que le mois de Décembre eft déja paffé, \& qu’il a dépouillé les forêts.

Heureux les peuples qui habitent fous l'équateur, à qui le foleil donne conftamment des jours égaux aux nuits pour la durée, \& qui penćant toute l'année voyent leurs arbres parés d'un verd feuillage! Peutêtre auffil l'habitude diminue-t'elle le plaifir de ce beau ipectacle; on aimeroit peut-être mieux l'alternative de nos arbres qui, apres s'être dépouillés de leur parure, reprennent au printems leur feuillage, pour donner de l'ombre dans une faifon qui fait trouver la fraîcheur agréable.

$F$ fi 


\section{CE C O N M I E}

Si la pourriture attaque un arbre

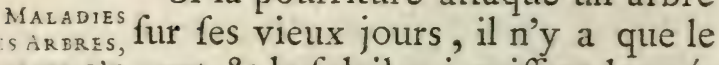
2.:YYRS $D^{\prime} Y$ vent $\&$ le foleil qui puiffent le gué-

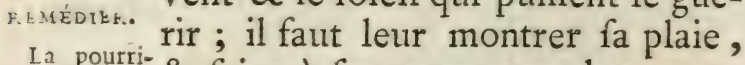
Lare. pourri- \& faire à fon tronc une large ouverture, afin que le foleil \& le grand air pénétrant plus avant confolident les parties gâtées \& empêchent la contagion de fe communiquer au loin \& de gagner les rameaux les plus élevés.

Divers acci- Les jeunes plants font auffi en dens aufquels naiffant fujets à des maladies fort jeunesplants, dangereufes, foit qu'ils ayent effuyé un été trop fec, un froid trop vif, ou des pluies trop abondantes. Souvent la main cruelle du voyageur fecoue violemment leur tige délicate, ou bien le foffoyeur \& même la taupe déchauffent leurs racines, \& fi leur tige n'eft garnie d'un fagot d'épine, la chévre broute leur écorce, \& les fait mourir.

Une fertilité prématurée dans les jeunes poiriers leur caufe plus de dommage que tout autre accident; car autant qu'on voit de fleurs fur les branches, autant font-ce de 


\section{R URALE, Liv. VI. $34^{\mathrm{I}}$}

fymptomes de maladies, \& autant de préfages d'une mort affurée.

Quand

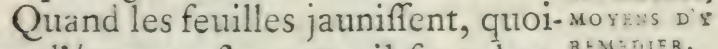
que l'écorce refte verte, il faut chercher dans la terre la caufe du mal, découvrir les racines \& les nétoyer; mais lorfque l'écorce eft féche \& commence à noircir, il n'y a prefque plus de reméde.

Si le microfcope n'eft point trom- Caures dipeur, la moinffure n'eft autre cho- verfesdes ma. fé qu'une forte de champignon qui bres. s'infinue dans les veines des arbres, te. $\& z$ dont la corruption ronge les branches, \& les fait mourir ; mais pour la mouffe elle intercepte leur ta mourt. féve, à moins qu'on ne la ratiffe avec le fer lorfque leur écorce a été amollie \& humectée par la pluie.

Le lierre, comme une chaîne, en- Le lisre, tourre le tronc des arbres \& ofe méler à leurs fruits les plus élevés fes graines défagréables. Dès qu'il commence à s'étendre \& à monter fur l'écorce du tronc, il faut l'arracher avant qu'il attache fes crochets au haut des arbres, \& qu'engraifé F f iij 


\section{E CONOMIE}

de leur fubftance, il (1 2 ) les étouffe MALADIFS par fes embraffemens.

MOYENS D Les chenilles filent une bourre REMEDIER les.

Les chenil tenace, qui fert de berceau \& d'enveloppe à leurs œufs, \& répandent fur les feuilles une liqueur mortelle qui les brule : défaites-vous de ces infectes après qu'il eft tombé de la pluie; cette opération n'eft pas alors difficile, car la fraîcheur les raffemble en un peloton. Vous nris.

Ies four - écarterez les fourmis, fi vous frotez l'écorce de l'arbre qui en eft maltraité, avec de la lie de vin, ou de fort vinaigre.

Les vers. Souvent les vers naifient dans un arbre, ou bien y pratiquent un chemin peu - à - peu jufqu'à fa moële, \& y font un dégât confidérable, fi l'on n'a foin de retrancher les branches qui en font infectées avant que les autres rameaux s'en refo - fentent.

te Pivert Tous les autres oifeaux fufpencreurefon nid dent leur nid au haut des arbres; dans le tronc
des arbres. le chêne le plus dur, le creufe 
R U R A LE. Liv. NI. 343

\& s'y loge; dreffez-lui des embu- Marad: ches lorfqu'il conftruit fa maifon, DESARBR 's, \& que l'arbre gémit de fes coups MOYESS DY de bec qu'il fait entendre au loin. Un voleur étant un jour caché dans une forêt, examina la manœuvre de cet oifeau, \& quand le nid fut fait, cet homme méchant par état \& capable de tout, ferma l'entrée étroite de ce nid avec un fer qu'il y enfonça, \& fe fit un plaifir de voir le pivert revenu s'attacher contre l'arbre, fe défoler des murmures de fes petits enfermés, auxquels il répond par fes cris perçans.

O puiffante nature! ô providence admirable! l'oifeau vole de tout côté dans la forêt, \& apporte une plante merveilleufe pour fes effets, au moyen de laquelle il fait fortir le fer, \& rentre dans fon nid: le voleur étonné de la propriété de cette plante avec laquelle le pivert avoit fauvé la vie à fes petits, fe rappella fon métier, \& fe propofa bien d'en faire ufage (I 3 ) pour taire fauter fans bruit les clous \&

Ff iiij 


\section{C C ONOMIE}

les ferrures qui font la fureté des MALADIES portes contre les attaques de fes MOYENS D'Y femblables.

T. EMEEDIER.

Souvent on voit par un caprice de la nature, non par un effet de l'art, un arbre parafite s'élever fur in autre arbre, foit qu'un oifeau perché fur une branche ait parmi fes ordures laiffé tomber quelque graine fur l'écorce tendre d'un arbre, \& que celui-ci ait permis à cette graine de prendre racine fur fa tige, \& une partie de la féve pour fa nourriture, à peu près comme l'on voit des giroflées jaunes pouffer fur les murs, \& des plantes communes croître fur le haut d'une vieille tour, où le vent a porté leurs graines; foit que par une qualité vicieufe des fibres de l'arbre, la féve produife quelques branches qui dégénérent $\&$ font d'un verd différent, production monftrueufe qui pourtant nous a été utile, puifqu'elle a enfeigné aux jardiniers l'opération de la greffe.

( I4) C'eft ainfi que le chêne porte le gui, dont les feuilles font 
RURA I E. Liv.VI. 343

fort differentes des fiennes. Les Gaulois n'avoient rien autrefois de Gaulois n'avoient rien autrefois de DDS BRERES,
plus facré que l'arbre qui le por- MOAEES D'Y toit; \& quoique ceux qui en avoient coupé dans les bois \& qui en superfition avoient apporté dans leur maifon, Gailois, ne craigniffent plus pour eux, ni pour leurs troupeaux, l'effet d'aulcun poifon, ni la fureur des vents pour leurs moiffons; cependant après avoir coupé ces rameaux facrés, fuivant la coutume de leurs ancêtres, ils les faifoient placer par les Druides dans leurs temples pour le fervice du public; c'eft pourquoi au jour confacré, lorfque la lune avoit montré fix fois fon croiffant, la nobleffe \& le peuple, les hommes \& les femmes alloient dans les bois \& fur les montagnes, où leur religion les appelloit, \& l'on coupoit le gui facre avec une ferpe d'or, car il n'étoit pas permis de toucher à ce bois refpectable avec le fer; le Prêtre après avoir reçû dans la robe blanche dont il étoit revêtu, le précieux rameau au grand applaudiffement du peuple, 


\section{6 (Е) C ONOM IE}

MALADIES immoloit des boufs fous le chêne

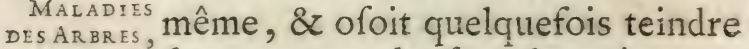
MOYENS DY fon couteau du fang humain.
REMEDER.

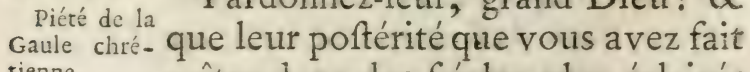
Pardonnez-leur, grand Dieu! \& tienne. naître dans des fiécles plus éclairés \& plus fages n'expie pas leur crime. Si la Gaule autrefois livrée au culte des faux dieux a pû, au mépris de vos faintes loix, commettre d'auffi grandes impiétés, il n'eft point de nation maintenant qui ait plus en horreur les cérémonies payennes \& qui vous ferve mieux; car les François n'ont jamais combattu avec plus de courage pour la défenfe de leur pays \& de la couronne, que pour la confervation de vos autels.

(I;) C'eft de nous que les PontifesRomains tiennent aujourd'hui en fouveraineté l'étendue de leur domination, \& le droit de donner des loix à plufieurs villes d'Italie, où ils n'étoient autrefois obéis qu'en matiére de religion. Nous avons changé leur houlette en un fceptre d'or, afin que le pafteur à qui le 
R U R A L E. Liv. VT. 347

foin du troupeau de Dieu a été confié, fùt décoré des marques de la fouveraineté.

Que dirai-je de nos anciens triomDESARBRLS, MOYENS D'Y RLYEDIER. phes \& des mers que nous avons traverfées, lorfqu'autrcfois les François alloient avec leurs Rois prodigues de leur augufte fang, porter leurs armes \& (16) leurs croix victorieufes dans les villes de la $\mathrm{Pa}$ leftine.

Nous avons encore pour la religion le même zéle qu'avoient au- Louis le trefois nos ancêtres. Louis le Grand la propagaporte fes vîes pour la propagation tion de la rede la foi, julqu'à l'extrémité de tienne, \& lexl'oris d'une fois déj tinction de l'Orient ; \& plus d'une fois déja thertine. nos vaiffeaux ont parcouru le vafte océan \& fait le tour du monde avec les pieures milices de Jefus-Chrift, non pour y foumettre les peuples aux fleurs de lis, mais pour leur préfenter la Croix, gage précieux du falut : pour élever des temples à Dieu, \& non des fortifications au nom de Louis, pour faire part des tréfors céleftes aux nouveaux fujets de Jefus-Chrift, \& non pour 


\section{$348 \quad \mathbb{E}$ C O N O M I E}

rapporter des richeffes qui font al-

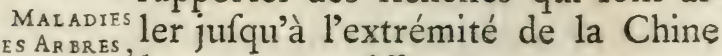
MOYENS D'Y les autres vaiffeaux.

C'eft vous, grand Prince, qui avez extirpé l'héréfie, qui avez banni de la France les dogmes des novateurs, \& qui par vos coups avez forcé les furies de replonger leurs têtes impies dans les enfers d'où elles avoient ofé fortir pour infecter nos climats. Nos ayeux s'étoient imaginé qu'il falloit une longue fuite de Rois \& plufieurs frécles pour abolir ce culte criminel, \& croioient s'être affez coilverts de gloire, quand ils avoient pu regagner à Dieu les habitans d'une feule ville, \& y relever fes autels. Louis parle, à fa voix tombent tous les temples confacrés à d'abominables myftéres, \& l'on ne met pas plus de jours à les rafer, que l'artificieufe \& rebelle héréfie n'avoit employé d'années pour détacher les citoiens de la religion de leurs peres.

Aujourd'hui réunis, nous n'avons qu'une même foi \& qu'un même cul- 
R'U R A Le. Liv. 1 I. 349

te ; la France n'a plus les mêmes furjets de crainte qu'elle eut autrefois lorqque fes fujets armés les uns con- Mo Yexs D'Y tre les autres touchérent au moment de leur deftruction; l'héréfie expirante exhale fes derniéres fureurs, $\&$ montrant avec plaifir du haut des Cevenes les toits encore fumans, les temples en proie à des flammes facriléges, des cadavres horriblement déchirés, des genres de mort qui tuent mille fois pour une, des fupplices recherchés, inconnus même aux Tyrans de l'antiquité; elle fe confole elle-même de fa douleur, \& par ce cruel fpectacle rappelle aux François qu'elle a enfin abandonné un fouvenir utile mais lamentable des maux qu'ils ont foufferts.

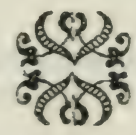




\section{REMARQUES}

\section{Sur le fixiéme Livre.}

N a vû dans ce livre les maladies des arbres, les caufes \& les remédes de ces maladies, \& les rapports qu'il y a entre les hommes \& les arbres ; l'Aureur effaye de prouver que la circulation de la féve fe fait chezles uns comme la circulation du fang chez les autres; il renouvelle la méthode de tirer par la térébration des arbres, des fucs qui feroient très-utiles à la Médecine; viennent enfuite les moyens de corriger le goût \& de changer la couleur des fruits, après quoi le Poëte dém taille les différens accidens qui furviennent aux arbres \& les remédes qu'il convient ployer. Le Guy qui vient par excroiffance fur le chène, fournit au Pere Vanniere l'occafion de décrire le refpect des Gaulois pour cet arbufte, leur maniére de le cueillir \&leur fuperftition à cet égard; il paffe delà à l'éloge des François, qui au lieu de ce culte fuperftisieux de leurs ancêtres, reconnoiffent le vrai Dieu \& vivent dans le Chriftianifme : cet éloge améne celui de Louis XIV. au fujet de la propagation de la foi \& de l'extinction de l'héréfie.

( I) [N'étoicnt munies de peitites valvules, 


\section{fur le flxiéme Livre. $\quad 358$}

Grc. J Ces valvules font imaginaires, on ne les trouve point, \& la féve va librement de haut en bas, comme de bas en haut.

(2) [Une ville qu'on appelle Lima, orc.] C'eft la Capirale du Pérou dans l'Amérique méridionale : il y régne un printems perpétuel, \& tout ce qu'en dit le Pere Vanniere, eft exactement vaai; mais il ne parle point des tremblemens de terre qui y font fréquens \& terribles, \& qui ont enfin renverfé cette ville de fond en comble: la nouvelle ville eft bâtie auprès des ruines de l'ancienne : ces tremblemens n'en font point un féjour agréable, quelque beall qu'y foir le ciel.

(3) [ A cet bomme admirable, érc. ] L'Auteur parle de Dom Jofeph Pardo de Figueroa, Gentilhomme de Lima, verfé dans toutes les fciences, \& Commandant des troupes du Mexique.

(4) [ Tire le maftic en larmes, ér.] C'eft une forte de gomme qui coule d'un arbre qu'on appelle lentifquie.

( 5 ) [ La téréuration la plus furre, éc.] C'eft la maniére de tirer les fucs des arbres. La térébration fe fait en perçant le tronc d'un arbre avec une tariére à l'approche du printems quand la fére commence à monter; elle a été inconnue aux anciens, \& nous la tenons des Anglois. La térébration, dit le Chancelier Bacon, eft une efpéce de faignée qui délivre les arbres d'une réplétion de fiics qui nuit à leur fécondité. On a bien enchéri fu: les víes de M. Bacon. On a trouvé que les 
fucs tirés par la térébration étoient d'une Maradies grande utilité dans la Médecine. Voici l'orDES ARBRES, dre qu'il faut garder felon le Docteur Torge. MOYENS D'Y "Il y a, dit-il, différentes maniéres de tirer Dle fuc d'un arbre pour en avoir beaucoup : D) il ne fuffit pas d'entamer l'arbre légérement v) avec un couteau, il faut percer le tronc du ") côté du midi, paffer au-delà de la moelle, ") \& ne s'arrêter qu'à un pouce près de l'écorग) ce qui eft du côté du feptentrion; on doit n) conduire la tariére de façon que le trou n aille toujours en montant afin de donner " lieu à l'écoulement de la féve : le trou 》) doit être fait proche de la terre; $I^{\circ}$. pour " ne point gater le trone de larbre; 2 . afin ") qu'il ne foit point befoin d'un long tuyau ") pour conduire la féve dans le vaiffeau qui ») doit la recevoir. " $\mathrm{La}$ térébration fe fait avec plus de fuccès à midi dans la chaleur du jour, parce que les fucs font plus en motivement. La chaleur fait monter la féve, c'eft un alambic fait des mains de la nature, les alambics artificiels n'en font que des copies.

(6) [Et eft fouverain contre la pierre, éc.] Il y a bien à rabattre de toutes ces prétendues propriétés : ces fucs onc des vertus, fans doute, mais on les a exagerées. D'ailleurs, quelque dépuration que l'on en faffe, ils ne peuvent fe garder auff long-tems à beaucoup près que les eaux des plantes qu'on tire au feu par la diftillation: aufi a-t-on abandonné l'ufage de ces fucs, quoique plus naturels \& plus efficaces. 


\section{fur le fexiéme Livre.}

(7) i Jufqu'a faire des punctions aux fleurs, ór.] Le Docteur Harvejus eft defcendu de la térébration des arbres à la punction des plantes, il a trouvé le fecret de tirer des têtes de pavot l'Opium le plus pur qui fut jamais. On commence par expofer au foleil durant quelques heures les plantes entiéres, enfuite on en pique les têtes, \& en peu de tems on en tire plein une taffe de fuc de pavot qui eft l'Opium véritable \& qu'on ne fauroit affez payer. Ceux qui favent en quel état l'Opium vient de la Gréce ou de l'E.gypte, eftimeroient infiniment celui du Docteur Hervejus. Il eft certain que le bon Opiam ne vient point jufqu'à nous, que les étrangers qui le titent des têtes de pavot le gardent pour leur ufage, \& qu'ils ne nous envoyent que le meconium qui n'eft qu'un fuc tiré par expreffion, \& qu'ils font épaiffir pour en faciliter le tranfport. Le meconium eft beaucoup inférieur en activité à l'Opium, mais d'ailleurs, il eft mêlé de beaucoup de parties hétérogénes \& impures. C'eftpour cela que les Chymiftes en font un extrait qu'ils appellen: laudanum: Voyez M. Charras dans fa pharmacopée. Ce que je viens de dire de la térébration \& de la punction eft tiré en partie des curiofités de la nature par l'Abbéde V allemont. Le mot térébration vient de terebra qui fignifie tariére.

(8) [Si vous mélez au printems des fucs, óc. ] Ce font des contes de jardiniers aufquęls I Abbé de Vallemont dans le livre que je viens de citer, a donné mal à propos un air de véTome $I$.

Gg 


\section{$354 \quad$ Remarquies}

rité. Les nouveaux fleuriftes y donnent à plein collier, ils font des épreuves réitérées; \& lorfqu'ils fe font convaincus à leurs dépens, que c'ett une duperie, ils enfeignent aux autres ces prétendus fecrets pour perpétuer les dupes.

(9) [Les jeux cruels de la fortune, ofc.] Cette penfée eft imitée d'Horace, elle fe troulve dans deux Odes différentes.

\section{Valet ima fummis}

Mutare, or infignem attenuat Deus, Obfcura promens : hinc apicem rapax

Fortuna cum ftridore acuis Suftulit; bic pofuile gauder.

1. 1. Od. 34 .

\section{Et dans l'Ode 29. Livre 3.}

Fortuna Savo lata negotio, o

Iudum infolentem ludere pertinax,

Tranfmutat incertos honores,

Nunc mibi nunc aliis bengna.

(10) [ Qui pour avoir chanfféle cotburne, óc. ] Cette chauffure eft affectée à la Tragédie : auffi un acteur qui joue ordinairemene dans le bas comique, eft-il ridicule quand it s'avife de chauffer le cothurne. Feu Poiffon, Comédien, \& le dernier mort, jounit quel quefois au carnaval le rôle de Mithridate dans la Tragédie qui porte ce nom, \& l'on y riois plus gu'à la Comédie la plus divertiffante. 


\section{Sur le fixiéme Livre. \\ (ii) [ Tant il eft important, ơc.] Salo- mon difoit auffi:}

$\operatorname{Refponfio~mollis~frangit~iram.~}$

\section{Prov.}

(I2) [ Il les étouffe par es embrafjemens, ơc. ] Néron dit dans Britannicus.

J'embraffe mon rival, mais c'eft pour l'étouffer.

(I 3) [ Pour faire fauter fans bruitles clous; éc.] Ce font des contes de ma mere l'oye \& de peau d'ane. Mais les Poëtes ont droit d'adopter toutes les Fables qui leur fourniffent des defcriptions \& des images agréables. Je ne crois pas que la nature produife pareille plante : s'il en eft une, nous fommes fort heureux qu'elle ne foit point connue : il y a déja affez de voleurs $\&$ de plantes ruineufes, comme le tabac, le caffé, \&rc.

( I 4 ) [ C'efs ainfi que le chéne porte le guy. ónc. C'eft une excroifcence d'arbre ou plan. te qui ne fe trouve jamais fur la terre \& qui naît fur le chene \& quelques autres arbres. Ses fruits naiffent trois à trois difpofés en trefle dans l'extrémité des rameaux, ce font des bayes ovalesfemblables à une perite perle remplies d'une femence plate, de la figure d'un cœur, converte d'une membrane argentée, très-délicate, enveloppée de glu. Ces fruits naiffent fur des branches differentes de celles qui portent les fleurs. Les grives font fort friandes des bayes du guy, elles les avalent \& les vuident enfuite fur les branches des arbres oil elles fe perchent, par ce moyen ellss

$$
G \text { fil }
$$


doanent lieu à une nouvelle production du guy; mais en écrafant ces bayes avec leurs pattes ou avec leur bec, elles en font fortir la glu avec laquelle elles s'attachent aux branches; ce qui a fait dire à Plaute : ip $\int a$ fibi avis mortem cacat. Virgile ne croyoit pas que le guy vînt de fa propre graine.

2uale folet falvis brumali frigore vifcum, Fronde virere nová quuam non fua Jeminat arbos.

Aneid. L. 6.

M. Rai eft de la même opinion dans fon hiftoire des plantes, mais l'expérience l'emporte fur l'autorité.

Chez les Gaulois, les Druides alloient anciennement au mois de Décembre qu'ils appelloient facré, cueillir le guy du chêne en grande cérémonie : cela fe faifoit avec beaucoup de folemnité. Les devins marchoient les premiers entonnant des cantiques \& des bymnes en l'honneur de leurs divinités. Enfuite venoit un héraut le caducée en main; après lui fuivoient trois Druides de front portant les chofes néceffaires pour le facrifice. Enfin paroiffoir le Chef ou le Prince des Druides accompagné de tout le peuple : le chef des Druides montoit fur le chêne \& coupoit le guy avec une ferpe d'or, les autres Druides le scevoient, \& au premier jour de l'an on le diftrubuoit au peuple, comme une chofe fainte apiès l'avoir béni \& confacré.

(Is) [ C eft de nous que les Pontifes Remains 


\section{fur le fixieme Livre. $\quad 357$}

tiennont aujourd'bui en rouveraineté, Ér. ] L'Exarcat de Navenne fut donné à l'Eglife Romaine, par Pepin \& par Charlemagne. Mais en donnant le Domaine utile, ils fe réfer. vérent la fouveraineté, \& la laifférent perdre par la fuite. On trouvera à ce fujet beaucoup de lumiére dans l'Hiftoire Civile de Naples, par Giannone, quelque peu dans l'origine de la grandeur Romaine par l'Abbé de Vertot. (16) [Et leurs croix victorioufes, éc. ] Dans le tems des croifades tous les croifés portoient vne croin fur leur habit ou fur leurs armes.

\section{Fin du Tome premier.}




\section{$A P P R O B A T I O N$.}

T'A lû par orire de Monfeigneur le Chancelier, un Manuicrit qui a pour titre : $\mathcal{L}$ a Metairie, on CEconomie Rurale; Pö̈me traduit du Latin du Pere Vamiere, avec des remarqucs; \& il m'a paru que cetre traduction répondoit au mérite de l'original. Fait à Paris le io Novembre 1755 .

\section{PHILIPPE DE PRETOT.}

\section{$P R I V I L E G E$.}

1 Ouis par la grace de Dieu, Roi de 1 France $\&$ de Navarre; $A$ nos amés $\&$ féaux Confeillers, les Gens tenans nos Cours de Parlement, Maitres des Requêtes ordinaires de notre Hôtel, Grand-Confeil , Prévôt de Paris, Baillifs, Sénéchaux, leurs Lieutenans Civils, \& autres nos Jufticiers qu'il appartiendra : Salut. Notre amé le fieur Fstienne, Libraire, Nous a fait expofer qu'il défireroit faire imprimer \& donner au Public un Ouvrage gui a pour ticre : La Metairie, Poëme traduit du Latin du Pere Vanniere : s'il Nous plaifcit lui accorder nos Lettres de Privilége pour ce nécelfaires: A CES CAUSES, voulant favorablement traiter l't xpofant, Nous lui avons permis \& permettons par ces Préfentes de faire imprimer ledit Ouvrage autant de fois que bun lui femblera, \& de le faire vendre \&i débiser par tout notre Royaume, pendant le tems 
de fix années confécutives, à compter da jotrs de la date des Préfentes; Faifons défenfes à tous Imprimeurs, Libraires \& autres perfonnes de quelque qualité \& condition qu'elles foient, d'en introduire d'impreffion étrangére dans aucun lieu de notre obéiflance ; comme auffi d'imprimer ou faire imprimer, vendre, faire vendre, débiter ni contrefaire ledit Ouvrage ni d'en faire aucun extrait, fous quel. que prérexte que ce puilfe ćrre, fans la permifîn expreffe \& par écrit dudit Expofant ou de ceux qui auront droit delui, à peine de confifation des Exemplaires contrefaits, de trois mille livres d'amende contre chacun des contrevenans, dont un tiers à Nous, un tiers a l'Hôtel-Dieu de Paris \& l'autre tiers audit Expofant ou à celui qui auradroir de lui, \& de tous dépens, donmages \& intérêts: A la charge que ces Préfentes feront enregiftrées tout au long fur le Regifte de la Conmunauté des Imprimeurs \&: Libraires de Paris, dans trois mois de la date d'icelle; que l'impreftion dudit Ouvrage fera faite dans notre Royaume \& non ailleurs, en bon papier \& beaux caracteres, conformément à la feuille imprimće, attachée pour modele fous le contrefcel des Préfentes; que l'impétrant fe conformera en tout aux réglemens de la Librairie, \& notamment a celui du 10 Avril 1725 ; qu'avane de l'expofer en vente, le Manufcrit qui aura fero vi de copie a l'impreffion dudit Ouvrage fera remis dans le nuême état où l'Approbation y aura été donnée ès mains de notre très - che? \& féal Chevalier, Chancelier de France, le fieun DE LAMOIG NON; \& qu'il en fera enfuite remis deux Exemplaires dans notre Biblio- 
shéque publique, un dans celle de notre Château du Louvre, un dans celle de notre très-cher \& féal Chevalier Chancelier de France le fieur DE LAMOIGNON, \& un dans celle de notre très-cher \& féal Chevalier, Gardedes-Sceaux de France le fieur DE MACHAULT, Commandeur de nos Ordres; le tout à peine de nullitédes Préfentes: du contenu defquelles vous mandons \& enjoignons de faire jouir ledit Expofant \& fes ayans caufe pleinement \& paifiblement, fans fouffrir qu'il leur foit fait aucun trouble ou empêchement. Voulons que la copie des Préfentes qui fera imprimée tout au long zu commencement ou à la fin dudit Ouvrage, foit tenue pour dûement fignifiée, \& qu'aux copies collationnées par l'un de nos amés \& feaux Confeillers Sécretaires, foi foit ajoutée comme à l'Original ; Commandons au premier notre Huiffier ou Sergent fur ce requis, de faire pour l'exécution d'icelles tous Actes requis \& nécelfaires, fans demanderautre permitfion, \& nonobftant clameur de Haro, Charte Normande \& Lettres à ce contraires: $C_{A R}$ tel eft notre plarfir. Donne' à Paris le crente - uniéme jour du mois de Janvier, l'an de grace mil fept cens cinquante fix, \& de notre Regne le quarante-re-uniéme. Par le Roi en fon Confeil.

\section{LE BEGUE.}

Regiflé fur le Regiftre 14, de la Chambre Royale des Libraires es Imprimeurs de Paris $N^{\circ}$. 22. fol. 21. conformément aux snciens Réglemens confirmés par celui du 28 Féurier I723. A Pxisle 19 Mars 1756.

$$
\text { C. A. JOM B ER T, Adjoint. }
$$


FAUTES A CORRIGER

dans le premier Volume.

\section{P R E F A C E.}

$P$

Age 27. ligne 4. Poetiques. lifez Poëtique. P. 34.l. s. EEuvres d'Honére, lif. d'Horace.

\section{बC CONOMIE RURALE.}

P. 38. l. 27. ou faites-le amener, lif. ou le faites amener.

$P$ 48.l. 21. un peu plus élevé, ôtez plus.

P. 49. l. 17. graines mauvaifes, lif. mauvaifes graines.

P. $53 \cdot 1.23$. s'occupent, lif. s'occuper.

P. $\{9.1$. 27. donc un ingrat, ôtez donc.

P. 99. l. I8. dans la crainte. Que la; lifez dans la crainte que la.

P. I 10. l. 3. comme en ville, lif. comme à la ville.

$P$. II 2. $l$. 3 . dépende, lif. dépendent.

P. I13.l. Is. Supprimez de la Ville.

P. I14.l. 22. Supprimez plus fouvent.

P. I16.l. I. s'il craignoit, lif. s'il croyoit.

P. 139.l. 4. Supprimez \&.

Ibid. l. 6. Enfans. Après quoi, lif. Enfans, après quoi.

Ibid.l. I s. Supprimez car.

P. I43.l. 20. de concetti, lif. du concetti.

P. I 56.l. 24. quand il, lif. lorfqu'il.

P. 162.l. 24. Jupprimez car.

P. I65.l. II. Supprimez car.

P. $167 . l$. 26. on a encore, lif, il a encore. 
P. 189. 2.20. Pellite, lif. pellito.

P. 193. l. 8. Alpes Italiennes, lif. Alpes Juliennęs.

Itid. l. 2 g. m'a parue, lif. m'a paru.

P. I96.l. 3. ferret, lif. fervet.

P. 203.l. 2. mufeau. Ses rivaux, lif. mufeau, fes rivaux.

P. $205.1 .25 . \&$ dont les cris menaçans fuffi. fent pour épouvanter, lif.par les cris menaçans dont il épouvantera.

P. $213 \cdot$. . 20. difcores, lif. difcords.

P. 214. l. 24. Illuftré, lif. Illuftre.

P. 225. l. 26. les lacs, lif. le lac.

P. 238.1 . 17. exercé, lif. exercée.

P. 296.l. 24. celles, lif. celle.

9. 309. l. 24. au-defius, lif. ant-defíous.

P. 3 12. l. 28. entrée, lif. entée.

P. 327.l. 14. nulpart, lif. nulle part.

P. 329.l. 1.5. \& de façon, ôtez \&.

Ibid. l. 18. \& vous oblerverez, lif, \& oblere vez.

Ibid. 1.24 . les fievres, lif. la fievie. Ibid. l. 27. \& de des reins, lif. \& de reiths, p. 349. l. 17. abandanné, Wf, abandonnés. 5. $357, l, 3$, de Aavenne, llf. de Ravenne, 





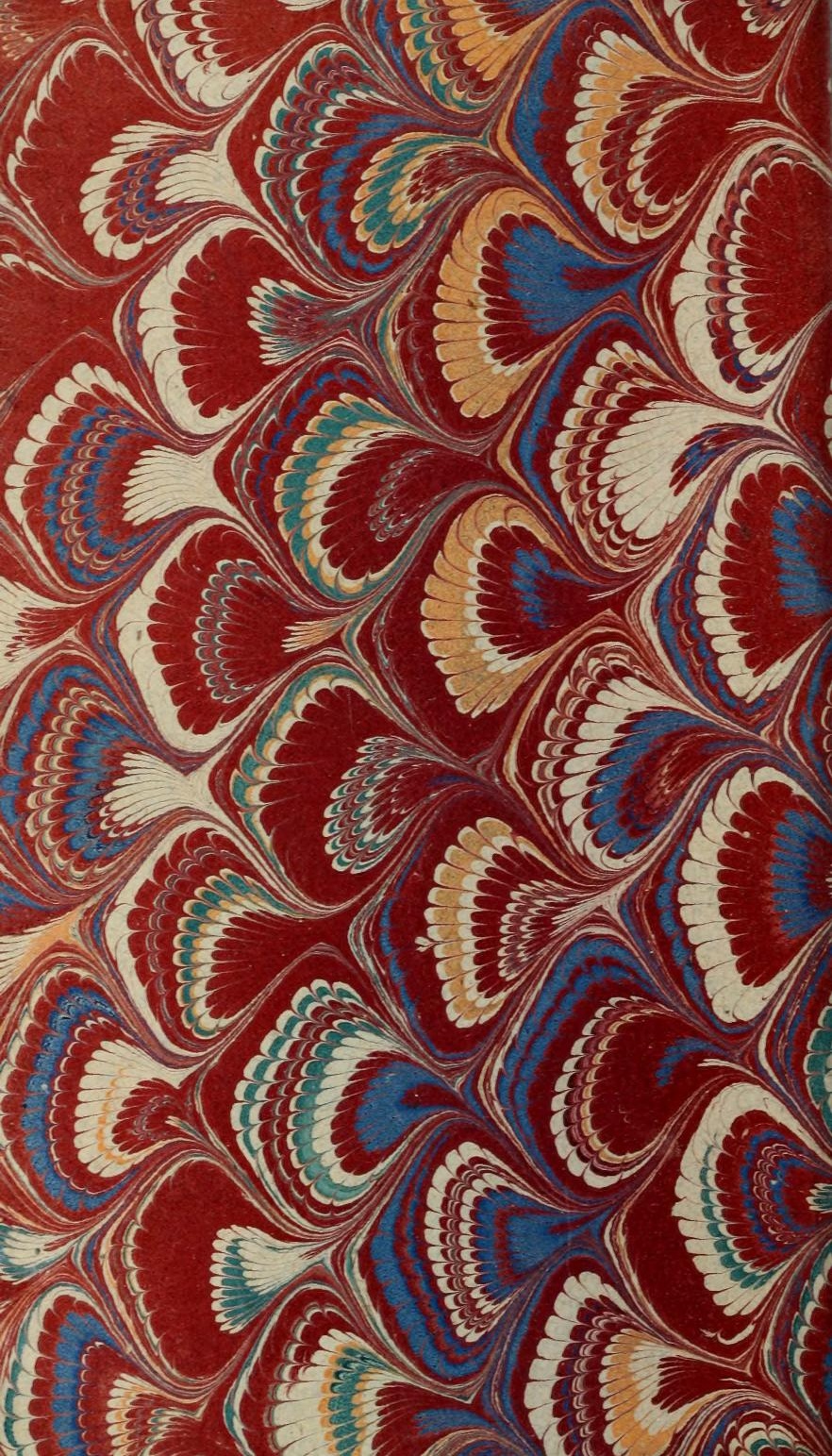


